YASMIN TEIXEIRA TRINDADE

Numerical modeling of the post-cracking behavior of SFRC and its application on design of beams according to fib Model Code 2010 
YASMIN TEIXEIRA TRINDADE

Numerical modeling of the post-cracking behavior of SFRC and its application on design of beams according to fib Model Code 2010

Dissertation presented to the Polytechnic School at the University of São Paulo as a requirement for obtaining the Master's Degree in Science. 
YASMIN TEIXEIRA TRINDADE

\section{Numerical modeling of the post-cracking behavior of SFRC and its application on design of beams according to fib Model Code 2010}

Dissertation presented to the Polytechnic School at the University of São Paulo as a requirement for obtaining the Master's Degree in Science.

Area of Concentration: Structural Engineering

Advisor: Prof. Dr. Luís A. G. Bitencourt Jr. 
Autorizo a reprodução e divulgação total ou parcial deste trabalho, por qualquer meio convencional ou eletrônico, para fins de estudo e pesquisa, desde que citada a fonte.

Este exemplar foi revisado e corrigido em relação à versão original, sob responsabilidade única do autor e com a anuência de seu orientador.

São Paulo, de de

Assinatura do autor:

Assinatura do orientador:

\section{Catalogação-na-publicação}

Trindade, Yasmin Teixeira

Numerical modeling of the post-cracking behavior of SFRC and its application on design of beams according to fib Model Code 2010 / Y. T. Trindade -- versão corr. -- São Paulo, 2018.

$171 \mathrm{p}$.

Dissertação (Mestrado) - Escola Politécnica da Universidade de São Paulo. Departamento de Engenharia de Estruturas e Geotécnica.

1.Steel fiber reinforced concrete 2.RC-SFRC beams 3.Numerical modeling 4.Post-cracking behavior 5.fib Model Code I.Universidade de São Paulo. Escola Politécnica. Departamento de Engenharia de Estruturas e Geotécnica II.t. 


\section{Acknowledgments - Agradecimentos}

Eu gostaria de expressar meus sinceros agradecimentos ao meu orientador Prof. Luís Bitencourt Jr. pelo conhecimento transmitido, disponibilidade, paciência e especialmente pelo incentivo à pesquisa. Ao Prof. Antonio Figueredo por sua disposição em ajudar e pelos conselhos e ao Prof. Osvaldo Manzoli pela colaboração e expertise.

À Coordenação de Aperfeiçoamento de Pessoal de Nível Superior (CAPES) (Código de Financiamento 001) pelo apoio financeiro, ao Programa de Pós-Graduação em Engenharia Civil da Escola Politécnica da Universidade de São Paulo (USP) pela estrutura, aos funcionários e também aos professores os quais tive o privilégio de ter aulas e adquirir conhecimento.

Aos meus colegas do Laboratório de Estruturas e Materiais Estruturais (LEM) André, Marcos, Paulo Vitor, Fernanda, Tarcísio, Felipe e especialmente ao Gusta, pela amizade e a Bel pelo apoio constante, amizade e companheirismo.

Finalmente, eu gostaria de dedicar essa dissertação à minha família, aos meus irmãos Carol e Marquinhos e em especial aos meus pais Marcos e Dagmar pelo apoio incondicional e por sempre incentivar e acreditar que a educação é sempre o melhor caminho. A vocês o meu eterno agradecimento. 


\section{Abstract}

A finite element model with discrete and explicit representation of steel fibers is applied for modeling the post-cracking behavior of Steel Fiber Reinforced Concrete (SFRC) in order to contribute on the design of beams with combined reinforcement of steel fibers and rebars (RC-SFRC beams). In this numerical approach, concrete and fibers are initially discretized in finite elements in an independent way, avoiding high computational costs due to conforming meshes. Then, coupling finite elements are introduced to describe the concrete-fiber interaction. The steel fibers are discretized using truss finite elements and their behavior described by an elastoplastic constitutive model. The position of each fiber is defined into the specimen by an uniform isotropic random distribution using as reference the concrete finite element mesh. Concrete and concrete-fiber interface are represented using three and fournoded triangular finite elements, respectively, and their behavior represented by appropriate continuum damage models integrated using an implicit-explicit scheme to enhance the robustness and to reduce the expense of computation. Firstly, the numerical tool is applied in the simulation of three-point bending tests according to EN 14651 to verify its ability to obtain the performance parameters of SFRC and for calibrating the material parameters that describe the concrete-fiber interface. Secondly, both numerical and experimental performance parameters of SFRC are used on the design of RC-SFRC beams according to fib Model Code 2010 to study their influence on the amount of bending and shear reinforcements required. Thirdly, the RC-SFRC beams designed are numerically simulated and the results are compared to the designed ones in terms of crack width, mean crack spacing, deflection and ultimate and service loads. Finally, the numerical results of small scale beams are compared to the experimental and the fib Model Code 2010 predictions to study the capability of the numerical tool to simulate the behavior of structural members. The results demonstrated that computational simulations with an appropriated approach to represent the composite may be an important tool to contribute to better understanding its behavior, extrapolating the conditions considered in laboratory 
and contributing on the design of SFRC structural members.

Keywords: Steel fiber reinforced concrete; RC-SFRC beams; numerical modeling; post-cracking behavior; fib Model Code. 


\section{Resumo}

Um modelo em elementos finitos com representação discreta e explícita de fibras de aço é utilizado para modelar o comportamento pós-fissuração do Concreto Reforçado com Fibras de Aço (CRFA) com objetivo de contribuir para o dimensionamento de vigas com reforço combinado de fibras e armadura convencional (vigas de CACRFA). Na abordagem numérica utilizada para modelagem de CRFA o concreto e as fibras são inicialmente discretizados em elementos finitos de forma independente, evitando altos custos computacionais devido às malhas conformes. Então, elementos finitos de acoplamento são introduzidos para descrever a interação concreto-fibra. As fibras de aço são discretizadas utilizando elementos finitos de treliça e seu comportamento é descrito por um modelo constitutivo elastoplástico unidimensional. Um algoritmo para distribuição isotrópica randômica é utilizado para gerar e distribuir fibras de aço com base na malha de elementos finitos do concreto. O concreto e a interface concreto-fibra são representados utilizando elementos finitos triangulares de três e quatro nós, respectivamente, e seus comportamentos representados por uma modelos apropriados de dano contínuo integrados utilizando um esquema implícito-explícito com objetivo de aumentar a robustez a reduzir o custo computacional. Primeiramente, a ferramenta numérica é aplicada na simulação de ensaios de flexão de três pontos de acordo com EN 14651 para verificar sua capacidade de obter os parâmetros de desempenho do CRFA e para calibrar os parâmetros do material que descrevem a interface concreto-fibra. Em segundo lugar, os parâmetros de desempenho numéricos e experimentais do CRFA são usados no projeto das vigas de CA-CRFA de acordo com o fib Model Code 2010, a fim de estudar sua influência na quantidade de armadura de flexão e cisalhamento necessárias. Em terceiro lugar, as vigas de CA-CRFA são numericamente simuladas e os resultados são comparados com os dimensionados em termos de largura de fissura, espaçamento médio entre fissuras, flecha e cargas últimas e de serviço. Finalmente, os resultados numéricos de vigas de pequena escala são comparados com aqueles obtidos experimentalmente e pelo fib Model Code 2010 para estudar a capacidade da ferramenta 
numérica em simular o comportamento de elementos estruturais. Os resultados demonstraram que a utilização de simulações computacionais com uma abordagem apropriada para representar o compósito podem ser uma importante ferramenta para contribuir para um melhor entendimento do seu comportamento, extrapolando as condições consideradas em laboratório e contribuindo para o dimensionamento de elementos estruturais de CRFA.

Palavras-chave: Concreto reforçado com fibras de aço; vigas de CA-CRFA; modelagem numérica; comportamento pós-fissuração; fib Model Code. 


\section{List of Figures}

1.1. Effect of the addition of steel fibers in concrete: stress $(\sigma)$ vs. crack width $(w)$ curve for concrete and SFRC (adapted from Maya et al. $(2012)) \ldots \ldots \ldots \ldots \ldots \ldots \ldots \ldots$

1.2. Examples of SFRC applications: (a) CCTV (China Central Television Building) Headquarters, Beijin, China (Brochure Dramix $\left.{ }^{\circledR}\right)$; (b) Barcelona metro line 9 tunnel lining, Spain (Maccaferri, 2010); (c) Oceanographic Park in Valencia, Spain (<www.cac.es $>$ ); (d) Centro Ovale Chiasso, Switzerland (Photo: Simone Mengani); (e) Maison de l'Écriture at Montricher, Switzerland (Muttoni et al., 2013) and (f) São Paulo metro line 4 tunnel lining, Brazil (<www.metrocptm.com.br $>$ ).

1.3. Evolution timeline of the principal design standards, suggested methods and guidelines for SFRC. . . . . . . . . . . . . . . . 9

1.4. Procedures to design SFRC structural members. . . . . . . . . . . 10

2.1. Coupling procedure for non-matching finite element meshes: (a) discretization of the concrete in FEs; (b) generation and discretization of a cloud of steel fibers; (c) creation and discretization of rebar; (d) creation and insertion of the CFEs and (e) detail of the coupling in overlapping meshes. . . . . . . . . . . . . . . . . . 18

2.2. $2 \mathrm{D}$ coupling finite elements with linear interpolation functions of displacements: 3 -noded triangle $+C_{\text {node }} \ldots \ldots$. . . . . . . . 19

2.3. Influence length of the coupling node for steel fiber or rebar. . . . . . 22

2.4. Interface stress bond-slip relationship (monotonic loading) proposed by fib Model Code 2010 (2013). . . . . . . . . . . . . . . 25

2.5. Interface stress bond-slip relationship (monotonic loading). . . . . . 26

2.6. Truss finite element in 2D. . . . . . . . . . . . . . 27

2.7. One-dimensional elastoplastic material model (adapted from Bitencourt Jr. (2015)) . . . . . . . . . . . . . . . . . . . . 27 
2.8. Pseudo code of the algorithm developed for generating steel fibers in a random geometry. . . . . . . . . . . . . . . . . . . . 30

2.9. Generation of fibers: (a) 3D distribution and (b) projection of the fibers onto a plane. . . . . . . . . . . . . . . 31

2.10. Numerical analysis using the computational platform. . . . . . . . . 36

3.1. Main steps in the design of beams reinforced with fibers according to MC2010. . . . . . . . . . . . . . . . . . . 38

3.2. Typical arrangement of the three-point bending test according to EN $14651 \ldots \ldots \ldots \ldots \ldots$

3.3. Typical load vs. CMOD curve for SFRC according to EN 14651. . . 39

3.4. Linear stress distribution in the mid-span section of the beam.. . . . . 40

3.5. Definition of $F_{L}$ from $\mathrm{F}$ vs. CMOD curve (adapted from EN 14651 $(2005)) \ldots \ldots \ldots \ldots \ldots$. . . . . . . . . . . . . . . . . . . . . . . .

3.6. Definition of the first parameter defined by the strength interval based

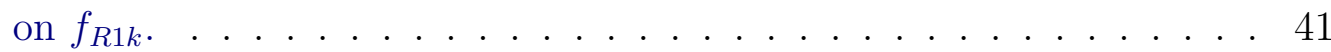

3.7. Definition of the second parameter based on residual strength ratio

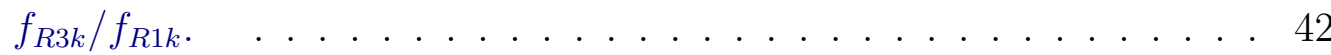

3.8. Simplified constitutive laws (stress vs. crack opening): (a) rigidplastic model and (b) linear model. . . . . . . . . . . . . . . . . . 42

3.9. Stress-crack opening graph for linear post-cracking constitutive model (adapted from fib Model Code 2010 (2013)). . . . . . . . . . . . . . . 43

3.10. Definition of the parameter $y$ for SFRC sections (a) with traditional reinforcement and (b) without traditional reinforcement. . . . . . . . 45

3.11. Typical curve of load $P$ vs. displacement $\delta$ for FRC structure (MC2010).

3.12. ULS for bending moment: (a) cross-section; (b) strain diagram; (c) stress distribution and $(\mathrm{d})$ simplified stress distribution. . . . . . . . 49

3.13. Definition of effective area $A_{c, \text { ef }}$ for beams. . . . . . . . . . 53

3.14. Strains and stresses of RC-SFRC cross-section in bending: (a) crosssection (b) strain diagram at crack (c) stresses and forces at crack. . . 54

4.1. Setup of the three-point bending beams tested according to EN 14651 (2005) at the Laboratory of Structures and Structural Materials at the University of São Paulo. . . . . . . . . . . . . . . . . . . 57 
4.2. Geometrical properties, boundary conditions and FE discretization (Mesh 2 - medium) of the three-point bending tests performed for plain concrete. . . . . . . . . . . . . . . . . . . . 58

4.3. Crack patterns obtained for: (a) Mesh 1 (coarse); (b) Mesh 2 (medium) and (c) Mesh 3 (fine) . . . . . . . . . . . . . . . . . . . . . 59

4.4. Force vs. CMOD (Crack Mouth Opening Displacement) curves for the three mesh refinements adopted. . . . . . . . . . . . 60

4.5. Three-point bending beam for steel fiber content of $30 \mathrm{~kg} / \mathrm{m}^{3}$ simulated using: (a) mesoscale model and (b) concurrent multiscale model (dimensions in $\mathrm{mm}) . \ldots \ldots$. . . . . . . . . . . . . 61

4.6. Force vs. CMOD curves. Comparison between numerical (mesoscale and multiscale) and experimental responses for fiber content of $30 \mathrm{~kg} / \mathrm{m}^{3}$.

4.7. Force vs. CMOD curves for the different number of load steps: (a) plain concrete and (b) concurrent multiscale model with a $30 \mathrm{~kg} / \mathrm{m}^{3}$ fiber content. . . . . . . . . . . . . . . . . . 63

4.8. Fiber distributions for the three fiber contents considered:

(a) $15 \mathrm{~kg} / \mathrm{m}^{3}$; (b) $30 \mathrm{~kg} / \mathrm{m}^{3}$ and (c) $45 \mathrm{~kg} / \mathrm{m}^{3}$.

4.9. Force vs. CMOD curves. Comparison between numerical and experimental responses for fiber content of $30 \mathrm{~kg} / \mathrm{m}^{3}$.

4.10. Number of steel fibers crossing the crack plane for fiber distributions 1 and 2.

4.11. Concrete-fiber interaction laws for analyses with fiber contents of $15 \mathrm{~kg} / \mathrm{m}^{3}$ and $45 \mathrm{~kg} / \mathrm{m}^{3}$.

4.12. Force vs. CMOD curves obtained for fiber distributions 1 and 2 by adopting the interface laws defined in Figure $4.11 . \ldots 66$

4.13. Force vs. CMOD curves for fiber content of $15 \mathrm{~kg} / \mathrm{m}^{3}$. . . . . . . . . 67

4.14. Force vs. CMOD curves for fiber content of $45 \mathrm{~kg} / \mathrm{m}^{3}$. . . . . . . . . 67

4.15. Force vs. CMOD curves. Numerical responses for the three different fiber contents $\left(15 \mathrm{~kg} / \mathrm{m}^{3}, 30 \mathrm{~kg} / \mathrm{m}^{3}\right.$ and $\left.45 \mathrm{~kg} / \mathrm{m}^{3}\right)$ by adopting two interface laws and for plain concrete. . . . . . . . . . . . . . . 68

4.16. Typical crack propagation in mode-I obtained in three-point bending tests for important CMOD (scale factor of 5). . . . . . . . . . 68

4.17. Setup of the four-point bending tests: geometry, boundary conditions and loads. 
4.18. Force vs. CMOD average curves of the experimental and numerical responses for $15 \mathrm{~kg} / \mathrm{m}^{3}, 30 \mathrm{~kg} / \mathrm{m}^{3}$ and $45 \mathrm{~kg} / \mathrm{m}^{3}$. . . . . . . . . 70

4.19. Post-cracking behavior of SFRC described by rigid-plastic and linear constitutive models defined by parameters obtained from: (a) experimental tests; (b) numerical analyses 1 and (c) numerical analyses 2.

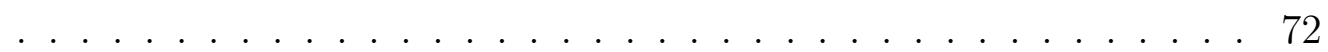

4.20. Stirrups distribution along the $\mathrm{RC}$ beam. . . . . . . . . . . . 75

4.21. Crack width for RC beam, SFRC-RC beams with $15 \mathrm{~kg} / \mathrm{m}^{3}, 30 \mathrm{~kg} / \mathrm{m}^{3}$ and $45 \mathrm{~kg} / \mathrm{m}^{3}$ and the reduction when compared to $w_{d}$ for $\mathrm{RC}$ regarding experimental, numerical 1 and numerical 2 results. . . . . . . . 77

4.22. Mean distance between cracks $s_{r m}$ of RC, RC-SFRC for $15 \mathrm{~kg} / \mathrm{m}^{3}$, $30 \mathrm{~kg} / \mathrm{m}^{3}$ and $45 \mathrm{~kg} / \mathrm{m}^{3}$ and percentage reduction when compared to $\mathrm{RC}$ regarding the experimental, numerical 1 and numerical 2 responses. . . . . . . . . . . . . . . . . . . . 78

4.23. Numerical modeling of four-point bending beams: (a) geometric properties, finite element mesh, load and support conditions; (b) RC beam; (c) RC-SFRC beam with $15 \mathrm{~kg} / \mathrm{m}^{3}$; (d) RC-SFRC beam with $30 \mathrm{~kg} / \mathrm{m}^{3}$ and (e) RC-SFRC beam with $45 \mathrm{~kg} / \mathrm{m}^{3}$. . . . . . . . . . 80

4.24. Force vs. displacement curves. Comparison between numerical responses for RC beam and RC-SFRC beams with fiber content of $15 \mathrm{~kg} / \mathrm{m}^{3}, 30 \mathrm{~kg} / \mathrm{m}^{3}$ and $45 \mathrm{~kg} / \mathrm{m}^{3}$.

4.25. Force vs. displacement curves. Comparison between numerical responses of RC-SFRC beam with fiber content of $30 \mathrm{~kg} / \mathrm{m}^{3}$ for $\tau_{\text {bmax }}=$ $8.5 \mathrm{MPa}$ and $\tau_{\text {bmax }}=12.5 \mathrm{MPa}$. . . . . . . . . . . . . 83

4.26. Crack propagation pattern for: (a) RC; (b) RC-SFRC for $V_{f}=$ $15 \mathrm{~kg} / \mathrm{m}^{3}$; (d) RC-SFRC for $V_{f}=30 \mathrm{~kg} / \mathrm{m}^{3}$; (f) RC-SFRC for $V_{f}=$ $45 \mathrm{~kg} / \mathrm{m}^{3}$ and stress on fibers of (c) RC-SFRC for $V_{f}=15 \mathrm{~kg} / \mathrm{m}^{3}$; (e) RC-SFRC for $V_{f}=30 \mathrm{~kg} / \mathrm{m}^{3}$ and (g) RC-SFRC for $V_{f}=45 \mathrm{~kg} / \mathrm{m}^{3}$ (all the responses are shown for $\delta=12 \mathrm{~mm}$ ). . . . . . . . . . . . 84

4.27. Force vs. displacement curves. Comparison between numerical responses for: RC beam, RC-SFRC beams with fiber content of $15 \mathrm{~kg} / \mathrm{m}^{3}$, $30 \mathrm{~kg} / \mathrm{m}^{3}$ and $45 \mathrm{~kg} / \mathrm{m}^{3}$ and the serviceability and ultimate design loads.

4.28. Crack propagation pattern and number of cracks for: (a) RC beam; and RC-SFRC beams with fiber content of (b) $15 \mathrm{~kg} / \mathrm{m}^{3}$; (c) $30 \mathrm{~kg} / \mathrm{m}^{3}$ and (d) $45 \mathrm{~kg} / \mathrm{m}^{3}$ (All the responses for $\mathrm{P}_{(\mathrm{SLS})}=82 \mathrm{kN}$ ). . . . . . 86 
4.29. Force vs. displacement curves for RC-SFRC beam with fiber content of $45 \mathrm{~kg} / \mathrm{m}^{3}$.

4.30. Numerical model for the simulation of the three-point bending tests according to EN 14651: (a) geometric properties, boundary conditions, applied load and concrete FE mesh; (b) fiber distributions for fiber content of $25 \mathrm{~kg} / \mathrm{m}^{3}$ and (c) fiber distributions for fiber content of $50 \mathrm{~kg} / \mathrm{m}^{3}$. . . . . . . . . . . . . . . . . . 89

4.31. Comparison between numerical and experimental responses: force vs. CMOD curves for plain concrete. . . . . . . . . . . . . . . . . 90 90

4.32. Fiber distributions $1,2,3$ and 4 for SFRC $25 \mathrm{~kg} / \mathrm{m}^{3}$. . . . . . . . 91

4.33. Comparison between mean experimental and numerical responses for 4 fiber distributions: force vs. CMOD curves for SFRC $25 \mathrm{~kg} / \mathrm{m}^{3}$. . . 91

4.34. Calibration of the concrete-fiber interface parameters: (a) bond-slip curves and (b) Force vs. CMOD curves by using the two concretefiber interface laws adopted with fiber content of $25 \mathrm{~kg} / \mathrm{m}^{3}$. . . . . . 91

4.35. Force vs. CMOD curves for fiber content of $50 \mathrm{~kg} / \mathrm{m}^{3}$. . . . . . . . . 92

4.36. Force vs. CMOD curves for all the cases analyzed: Plain Concrete, SFRC $25 \mathrm{~kg} / \mathrm{m}^{3}$ and $50 \mathrm{~kg} / \mathrm{m}^{3}$. . . . . . . . . . . . . . 92

4.37. Numerical models for simulation of the small beams: (a) Reinforced Concrete (RC); (b) RC-SFRC beam for $V_{f}=25 \mathrm{~kg} / \mathrm{m}^{3}$ and (c) RCSFRC beam for $V_{f}=50 \mathrm{~kg} / \mathrm{m}^{3}$. . . . . . . . . . . . . . . 93

4.38. Bond-slip models to describe the interaction between rebars and concrete according to MC2010. . . . . . . . . . . . . . . . . . . 95

4.39. Force vs. displacement curves. Comparison between experimental and numerical responses for RC beams and three bond-slip models: all other bond conditions, good bond conditions and perfect adherence.

4.40. Force vs. displacement curves. Comparison between experimental and numerical responses for RC-SFRC beams with fiber content of $25 \mathrm{~kg} / \mathrm{m}^{3}$ and three bond slip models: all other bond conditions, good bond conditions and perfect adherence. . . . . . . . . . . . . 996

4.41. Force vs. displacement curves. Comparison between numerical responses for RC-SFRC beams with fiber content of $25 \mathrm{~kg} / \mathrm{m}^{3}$ and two fiber distributions $(1$ and 2$) . \ldots \ldots . \ldots . \ldots 97$ 
4.42. Force vs. displacement curves. Comparison between experimental and numerical responses for RC-SFRC beams with fiber content of $50 \mathrm{~kg} / \mathrm{m}^{3}$ and three bond-slip models: all other bond conditions, good bond conditions and perfect adherence. . . . . . . . . . . . . . . 97

4.43. Force vs. displacement curves. Comparison between numerical responses for RC beam, RC-SFRC beam with fiber content of $25 \mathrm{~kg} / \mathrm{m}^{3}$ and RC-SFRC beam with fiber content of $50 \mathrm{~kg} / \mathrm{m}^{3}$. . . . . . . . . 99

4.44. Crack patterns for vertical displacement $\delta=2.5 \mathrm{~mm}$ and for different bond conditions and fiber contents: (a) RC - all other bond conditions; (b) RC beam - good bond conditions; (c) RC beam - perfect adherence; (d) RC-SFRC beam $25 \mathrm{~kg} / \mathrm{m}^{3}$ - all other bond conditions; (e) RCSFRC beam $25 \mathrm{~kg} / \mathrm{m}^{3}$ - good bond conditions; (f) RC-SFRC beam $25 \mathrm{~kg} / \mathrm{m}^{3}$ - perfect adherence; (g) RC-SFRC beam $50 \mathrm{~kg} / \mathrm{m}^{3}$ - all other bond conditions; (h) RC-SFRC beam $50 \mathrm{~kg} / \mathrm{m}^{3}$ - good bond conditions and (i) RC-SFRC beam $50 \mathrm{~kg} / \mathrm{m}^{3}$ - perfect adherence. . . . . . . . 100

4.45. Numerical vs. experimental crack patterns for: (a) RC beam - experimental test; (b) RC beam - numerical response for good bond conditions;(c) RC-SFRC $50 \mathrm{~kg} / \mathrm{m}^{3}$ - experimental test and (d) RC-SFRC beam - numerical response for good bond conditions ( at deflection of $\delta=10 \mathrm{~mm})$.

A.1. Rotational equilibrium for the rigid plastic model: (a) linear elastic stress distribution and (b) constant stress block in tension and concentrated compression force at the top of the cross-section (adapted from fib Model Code 2010 (2013)). . . . . . . . . . . . . . . . . . . . 120

A.2. Linear model approximation: (a) strain diagram and stress distribution for (b) SLS and (c) ULS. (adapted from fib Model Code 2010

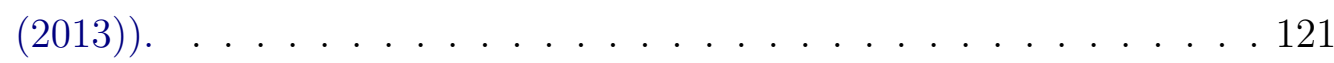

A.3. $k_{a}$ and $k_{b}$ coefficients (adapted from fib Model Code 2010 (2013)). . . 123

B.1. Conventional reinforced rectangular section at ULS: (a) cross-section (b) strain diagram (c) parabolic rectangle stress distribution (d) equivalent stress block. . . . . . . . . . . . . . . . . . . 127 


\section{List of Tables}

1.1. Summary of the standards and guidelines characterization bending test for SFRC. . . . . . . . . . . . . . . . . . 13

2.1. Impl-EX integration scheme for the continuum damage model to describe bond-slip. . . . . . . . . . . . . . . . . . . . . . 23

2.3. Integration scheme for the one-dimensional elastoplastic material model. 28

2.5. Impl-EX integration scheme for the continuum damage model with two damage variables . . . . . . . . . . . . . . . . . . . . . 32

3.1. Design strengths and partial safety factors for SFRC. . . . . . . . . . 45

3.2. Values of $\tau_{b m s}, \beta$ and $\eta_{r}$ for deformed reinforcing bars (adapted from MC2010). ......................... 53

4.1. Geometrical and mechanical properties of the steel fibers. . . . . . . 57

4.2. Characteristics of the three mesh refinements considered. . . . . . . 58

4.3. Concrete parameters for the three-point bending tests - EN 14651. . . 59

4.4. Characteristic data of the finite element meshes. . . . . . . . . . . 64

4.5. Mechanical properties of the conventional rebars adopted. . . . . . . 69

4.6. EN 14651 test results. . . . . . . . . . . . . . . . . . . 71

4.7. Residual strengths for rigid-plastic and linear models: fiber contents of $15 \mathrm{~kg} / \mathrm{m}^{3}, 30 \mathrm{~kg} / \mathrm{m}^{3}$ and $45 \mathrm{~kg} / \mathrm{m}^{3}$. . . . . . . . . . . 73

4.8. Bending reinforcement for RC and RC-SFRC beams. . . . . . . . . . 74

4.9. Shear reinforcement for RC and RC-SFRC beams. . . . . . . . . . 76

4.10. Crack width evaluated based on the experimental and numerical results from EN 14651 tests. . . . . . . . . . . . . . . . . 77

4.11. Mean distance between cracks. . . . . . . . . . . . . . . . . . . 78

4.12. Deflection for RC and RC-SFRC beams. . . . . . . . . . . . . . . 79

4.13. Characteristics of the finite element meshes for the four beam configurations considered. . . . . . . . . . . . . . . . . 81 
4.14. Numerical responses and predictions of MC2010 for crack width, mean crack spacing and deflection at SLS. . . . . . . . . . . . . 86

4.15. Material parameters adopted for the numerical simulations of the small-scale beams. . . . . . . . . . . . . . . . . . . . . . . . 88

4.16. Characteristics of the SFRC finite element meshes. . . . . . . . . . 89

4.17. Characteristics of the finite element meshes adopted for the analyses of the small beams.. . . . . . . . . . . . . . . . . . . . . . 94

4.18. Numerical and experimental results for RC and RC-SFRC beams at

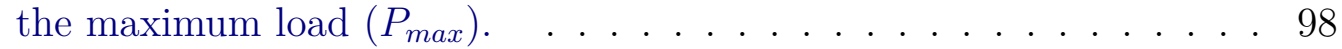

4.19. Numerical and experimental results of deflection $\delta_{P 40}$ for RC and RCSFRC beams. . . . . . . . . . . . . . . . . . . . . . 101

4.20. Numerical and experimental results of maximum crack widths, $w_{\max }$, for RC beam and RC-SFRC beams. . . . . . . . . . . . . . . . . . 102

4.21. Numerical and experimental results of mean cracking spacing $\left(s_{r m}\right)$ for RC beam and RC-SFRC beams. . . . . . . . . . . . . . . . . 103

4.22. Numerical and experimental results of strain $\varepsilon_{H}$ for $\mathrm{RC}$ beam and RC-SFRC beams. . . . . . . . . . . . . . . . . . 104

4.23. Experimental, predictions according to MC2010 and numerical responses for ultimate bending moment. . . . . . . . . . . . . . . 105

4.24. Experimental, predictions according to MC2010 and numerical responses for mean crack spacing. . . . . . . . . . . . . . 105

B.1. Partial safety factors for concrete and conventional reinforcement. . . 125

B.2. Main material parameter for concrete and conventional reinforcement. 126 


\section{Notations}

\section{Symbols}

\section{Greek lower case letters}

$\begin{array}{ll}\alpha_{e} & \text { modular ratio }=E_{s} / E_{c} \\ \beta & \text { coefficient accounting for the influence of the duration of loading } \\ & \text { or repeated loading } \\ \gamma_{c} & \text { partial safety factor for concrete material properties } \\ \gamma_{F} & \text { partial safety factor for fiber reinforced concrete } \\ \gamma_{s} & \text { partial safety factor for the material properties of reinforcing steel } \\ \delta_{I} & \text { deflection calculated assuming the second moment of area } I_{c} \text { of } \\ & \text { the uncracked concrete section } \\ \delta_{I I} & \text { deflection obtained by using the second moment of area in state II } \\ \delta_{d} & I_{I I} \\ \delta_{l i m} & \text { design deflection } \\ \varepsilon_{c m} & \text { limit value of the deflection } \\ \varepsilon_{c s} & \text { average concrete strain over the length } l_{s, \text { max }} \\ \varepsilon_{c u} & \text { strain of the concrete due to (free) shrinkage } \\ \varepsilon_{F u} & \text { ultimate strain of concrete } \\ \varepsilon_{s h} & \text { ultimate strain of fiber reinforced concrete } \\ \varepsilon_{s m} & \text { shrinkage strain } \\ \varepsilon_{s u} & \text { average steel strain over the length } l_{s, m a x} \\ \varepsilon_{u k} & \text { ultimate strain of rebar } \\ \varepsilon_{y k} & \text { characteristic strain at ultimate load } \\ \zeta & \text { characteristic yield strain of reinforcing steel } \\ \eta & \text { interpolation coefficient allowing for the effect of tension stiffening } \\ & \text { at a section }\end{array}$




$\begin{array}{ll}\eta_{r} & \text { coefficient considering the shrinkage contribution } \\ \theta & \text { compressive stress field inclination } \\ \lambda & \text { factor defining the height of the concrete compression zone } \\ \rho_{l} & \text { longitudinal steel reinforcement ratio } \\ \rho_{s} & \text { longitudinal steel reinforcement ratio } \\ \rho_{s, e f} & \text { effective reinforcement ratio } \\ \sigma_{c p} & \text { average stress acting on the concrete cross-section } \\ \sigma_{s} & \text { steel stress in a crack } \\ \sigma_{s r} & \text { maximum steel stress in a crack in the crack formation stage } \\ \tau_{b m} & \text { mean bond strength between steel and concrete } \\ \phi_{s} & \text { nominal diameter of a longitudinal rebar }\end{array}$

\section{Roman lower case letters}

$b \quad$ width of section

$b_{w} \quad$ width of web

$c \quad$ concrete cover

$d \quad$ effective depth to main tension reinforcement

$d^{\prime} \quad$ effective depth to compression reinforcement

f strength

$f_{c d} \quad$ design compressive strength

$f_{c k} \quad$ characteristic compressive strength

$f_{c m} \quad$ mean value of concrete compressive strength

$f_{c t m} \quad$ mean value of tensile strength of concrete

$f_{c t k} \quad$ characteristic value of the tensile strength for concrete

$f_{\text {Fts }} \quad$ serviceability residual strength (post-cracking strength for ultimate crack opening) for fiber reinforced concrete

$f_{\text {Ftsd }} \quad$ design serviceability residual strength

$f_{\text {Ftsm }} \quad$ mean serviceability residual strength

$f_{\text {Ftu }} \quad$ ultimate residual strength (post-cracking strength for ultimate crack opening) for fiber reinforced concrete

$f_{\text {Ftud }} \quad$ design ultimate residual strength

$f_{k} \quad$ characteristic value of strength

$f_{R, j} \quad$ residual flexural tensile strength corresponding to $\mathrm{CMOD}_{\mathrm{j}}$

$f_{R 1} \quad$ residual strength of fiber reinforced concrete significant for serviceability conditions 
$f_{R 3} \quad$ residual strength of fiber reinforced concrete significant for ultimate conditions

$f_{L} \quad$ limit of proportionality in the EN 14951 test EN 14651 (2005)

$f_{y k} \quad$ characteristic value of yield strength of reinforcing steel

$f_{y d} \quad$ design yield strength of reinforcing steel

$f_{y w d} \quad$ design yield strength of the shear reinforcement

$h \quad$ total height

$h_{s p} \quad$ distance between the notch tip and the top of the specimen

$k$ factor that takes into account the size effect for SFRC; an

empirical parameter to take the influence of the concrete cover;

coefficient taking into account of non-uniform self-equilibrating

stresses

$k_{c} \quad$ coefficient taking account of the stress distribution in the

cross-section just before cracking and the change of the inner lever arm

$l \quad$ span length

$l_{c s} \quad$ structural characteristic length (fracture parameter)

$l_{s, \max } \quad$ length over which slip between concrete and steel occurs

$s_{r m} \quad$ mean distance between cracks

$s_{w} \quad$ spacing between stirrups

$w \quad$ crack width

$w_{d} \quad$ design crack width

$w_{\text {lim }} \quad$ nominal limit value of crack width

$w_{u} \quad$ maximum crack opening accepted in structural design

$x \quad$ depth of compression zone

$y \quad$ distance between the neutral axis and the tensile side of the cross section

$z \quad$ internal lever arm

\section{Roman capital letters}

$A_{c, e f} \quad$ effective area of concrete in tension

$A_{c t} \quad$ tensile part of the concrete cross-section, evaluated by considering a stress field at elastic limit

$A_{s} \quad$ area of conventional reinforcement

$A_{s, \min } \quad$ minimum area of longitudinal reinforcement 
$A_{s w, \min } \quad$ minimum area of shear reinforcement

$E_{c i} \quad$ modulus of elasticity at the concrete age of 28 days

$E_{c} \quad$ modulus of elasticity of the concrete

$E_{d} \quad$ design action-effect

$E_{s} \quad$ mean value of the steel modulus of elasticity

$F_{j} \quad$ load corresponding to crack mouth opening displacementCMOD

$I_{c} \quad$ second moment of area of the uncracked concrete cross-section (excluding reinforcement)

$I_{I I} \quad$ second moment of area in state II (including the reinforcement)

$K \quad$ orientation factor

$M_{E d} \quad$ design value of applied moment

$M_{R d} \quad$ design value of resistant moment

$R_{c d} \quad$ resultant compressive force in the concrete

$R_{s d} \quad$ resultant tensile force in the reinforcing steel

$R_{F d} \quad$ resultant tensile force in the reinforcing steel fibers

$R_{d} \quad$ design value of resistance

$V_{R d} \quad$ design shear resistance

$V_{R d, c} \quad$ design shear resistance attributed to the plain concrete

$V_{R d, F} \quad$ design shear resistance provided by SFRC

$V_{R d, s} \quad$ design shear resistance provided by stirrups

$V_{R d, F m i n} \quad$ minimum shear resistance of SFRC

\section{Abbreviations}

CMOD crack mouth opening displacement

FE finite element

FRC fiber reinforced concrete

NSC normal strength concrete

$\mathrm{RC} \quad$ conventional reinforced concrete

RC-SFRC concrete with combined reinforcement of steel fibers and rebars

SFRC steel fiber reinforced concrete

3-PBT 3-point beam bending test 


\section{Contents}

1. Introduction $\quad \mathbf{1}$

1.1. Steel fiber reinforced concrete . . . . . . . . . . . . . . . . 1

1.2. Motivation . . . . . . . . . . . . . . . . 4

1.3. State of the art . . . . . . . . . . . . . 5

1.3.1. Numerical approaches for modeling the post-cracking behavior of $\mathrm{SFRC} \mathrm{\ldots} \mathrm{.} \mathrm{.} \mathrm{.} \mathrm{.} \mathrm{.} \mathrm{.} \mathrm{.} \mathrm{.} \mathrm{.} \mathrm{.} \mathrm{.} \mathrm{.} \mathrm{.} \mathrm{.} \mathrm{.} \mathrm{.} \mathrm{.} 6$

1.3.2. Standards and guidelines for design of SFRC . . . . . . . . 8

1.4. Objectives ... . . . . . . . . . . . . . . . 13

1.5. Overview and hypothesis of the study . . . . . . . . . . . . . . 14

1.6. Structure of the dissertation . . . . . . . . . . . . . . . . . . 15

2. Numerical model 17

2.1. Discrete and explicit representation of reinforcements . . . . . . . . . 17

2.2. Concrete-reinforcement interaction . . . . . . . . . . . . . . . . . . 19

2.2.1. Perfect adherence . . . . . . . . . . . . . . 21

2.2.2. Loss of adherence . . . . . . . . . . . . . . . . . . 21

2.2.3. Continuum damage model to describe bond slip . . . . . . . . 23

2.2.3.1. Concrete-rebar interaction . . . . . . . . . . 25

2.2.3.2. Concrete-steel fiber interaction . . . . . . . . . 26

2.3. Modeling of reinforcements . . . . . . . . . . . . . . . . . . 26

2.3.1. One-dimensional elastoplastic model . . . . . . . . . . . . . . 27

2.3.2. Steel fiber distribution . . . . . . . . . . . . . . . . . 30

2.4. Modeling of concrete . . . . . . . . . . . . . . . . . . . 32

2.4.1. Damage model with two independent damage variables (Cerveral et al., 1996) . . . . . . . . . . . . . . . . . . 32

2.5. Programs employed for numerical simulations . . . . . . . . . 35 
3. Design of RC-SFRC beams according to fib Model Code 2010

3.1. SFRC characterization . . . . . . . . . . . . . . 38

3.1.1. Performance parameters based on EN $14651 \ldots$. . . . . . 39

3.1.2. Classification . . . . . . . . . . . . . . . . . . 41

3.1.3. Constitutive laws for post-cracking behavior . . . . . . . . 41

3.1.3.1. Rigid plastic model . . . . . . . . . . . . . . . . . 42

3.1.3.2. Linear model . . . . . . . . . . . . . . . . . . . 43

3.1.3.3. Constitutive laws for numerical analyses . . . . . . . 43

3.2. Basic aspects for structural design . . . . . . . . . . . . 45

3.2.1. Partial safety factors . . . . . . . . . . . . . . . 45

3.2.2. Minimum requirements . . . . . . . . . . . . . . . 46

3.2.2.1. Bending . . . . . . . . . . . . . . . 46

3.2.2.2. Shear . . . . . . . . . . . . . . 47

3.2.2.3. Stress limitation at SLS . . . . . . . . . . 47

3.2.2.4. Crack control . . . . . . . . . . . . . . . 48

3.3. Design for Ultimate Limit State (ULS) _ . . . . . . . . . . . . 48

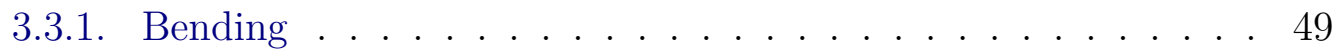

3.3.2. Shear . . . . . . . . . . . . . . . . . . 50

3.4. Verification of Serviceability Limit State (SLS) . . . . . . . . . 52

3.4.1. Crack width . . . . . . . . . . . . . . . 52

3.4.2. Deflection .................... . . 54

4. Applications 56

4.1. Numerical simulation of three-point bending tests - EN $14651 \ldots 57$

4.1.1. Description of the beams . . . . . . . . . . . . . . 57

4.1.2. Mesh sensitivity study: plain concrete . . . . . . . . . 58

4.1.3. Mesoscale model vs. concurrent multiscale model . . . . . . . 60

4.1.4. Convergence study of the Impl-Ex integration scheme . . . . . 62

4.1.5. Effect of the fiber content and distribution . . . . . . . . 63

4.2. Predicting the behavior of RC-SFRC beams . . . . . . . . 68

4.2.1. Design of beams according to fib Model Code 2010 . . . . . 69

4.2.1.1. Post-cracking behavior of SFRC . . . . . . . . 70

4.2.1.2. Ultimate Limit State (ULS) . . . . . . . . . . . 73

4.2.1.3. Serviceability Limit State (SLS) . . . . . . . . . . . 76

4.2.2. Numerical simulation by FEM . . . . . . . . . . . . . . 79

4.2.3. fib Model Code $2010 \mathrm{x}$ numerical responses . . . . . . . . . . 85 
4.3. Analysis of RC-SFRC beams experimentally tested by Conforti et al. (2018) . . . . . . . . . . . . . . . . . . . . 87

4.3.1. Material parameters . . . . . . . . . . . . 88

4.3.2. Calibration of the concrete-fiber interaction . . . . . . . 88

4.3.3. Description of the beams and FE discretization . . . . . . . . 93

4.3.4. Experimental x numerical responses . . . . . . . . . . . . . . . 94

4.3.5. Comparison against fib Model Code 2010 predictions . . . . . 104

5. Conclusions 106

5.1. General conclusions . . . . . . . . . . . . . . 106

5.2. Recommendations for future research . . . . . . . . . . . . . 108

$\begin{array}{ll}\text { Bibliography } & 109\end{array}$

$\begin{array}{lr}\text { A. Appendix } & \mathbf{1 2 0}\end{array}$

A.1. Simplified constitutive laws for SFRC . . . . . . . . . . . . . . . 120

A.1.1. Rigid plastic model . . . . . . . . . . . . . . . . . 120

A.1.2. Linear model . . . . . . . . . . . . . . . . . . . . . . 121

B. Appendix

125

B.1. Design recommendation of $\mathrm{RC}$ beam according to fib Model Code 2010125

B.1.1. Material properties of concrete and conventional reinforcement 125

B.1.2. Design of RC structures under bending . . . . . . . . . . . . 126

C. Appendix

C.1. Design calculation report for RC-SFRC beams according to fib Model Code 2010 (2013) . . . . . . . . . . . . . . . . . . . 128 


\section{Introduction}

\subsection{Steel fiber reinforced concrete}

Concrete is among the most widely used construction material. However, under tensile stress conditions, it presents low strength and strain capacities. To overcome these main drawbacks, different types of discontinuous fibers (steel, glass, synthetic and natural) have been added to concrete, resulting in so-called Fiber Reinforced Concrete (FRC). Due to a high elasticity modulus and a good adherence with the concrete, steel fibers have become the most employed type of fiber and used as primary reinforcement or in combination with conventional rebars in reinforced concrete structural members.

In the past decades, researches have shown that the inclusion of steel fibers is highly beneficial to the overall mechanical behavior of concrete. In other words, Steel Fiber Reinforced Concrete (SFRC) generally exhibits improved toughness, ductility, cracking resistance, and tensile strength relative to normal concrete. According to Bentur and Mindess (2007) the main contribution of the addition of fibers occurs in the post-cracking zone, in which the fibers bridge across the cracked matrix. In other words, these benefits are directly related to their ability to transfer stress across the crack.

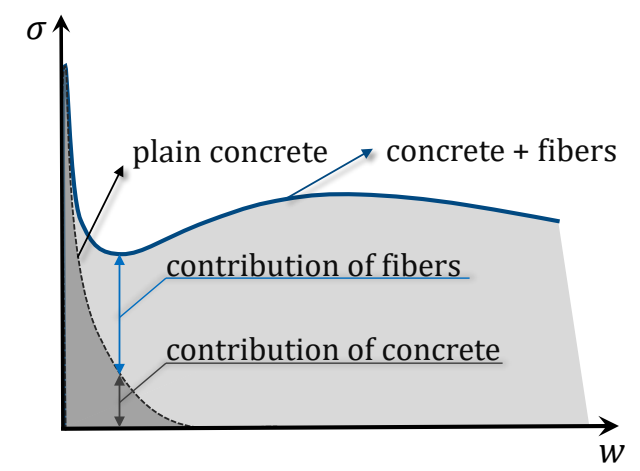

Figure 1.1.: Effect of the addition of steel fibers in concrete: stress $(\sigma)$ vs. crack width $(w)$ curve for concrete and SFRC (adapted from Maya et al. (2012)). 
Figure 1.1 illustrates the stress vs. crack width curves for plain concrete and SFRC. As can be seen, after reaching the stress peak, the SFRC exhibits a certain postpeak bearing capacity, preventing the abrupt collapse of the material, as occurs for plain concrete. The response of the SFRC on the post-cracking behavior is influenced by several parameters such as the concrete matrix; shape and geometry of the steel fiber; fiber content; distribution of the fibers and the fiber-concrete interface structure (Fanella and Naaman, 1985; Bentur and Mindess, 2007).

The concrete-fiber interaction can be described by the transmission of forces between fibers and concrete through the interfacial bond defined as the shearing stress at the interface between the fiber and the surrounding concrete. This process is very complex, since many factors may influence its behavior, such as the mechanical components of the bond, physical and chemical adhesion between the fibers and concrete and the fiber-to-fiber interlock. Therefore, steel fibers with different shapes, exhibit different slip characteristics and pullout energies, even if the same maximum shear stress is obtained (Naaman and Najm, 1991). Many types of steel fibers are available on the market today, such as straight and smooth, hooked or enlarged ends and crimped or deformed along length. Among them, pre-deformed fibers, in particular hooked-end fibers are the most widely used aiming to improve the fiber-concrete interaction by enhancing the mechanical bonding behavior between them.

The short steel fibers are randomly dispersed in the concrete at the time of mixing and form a spatial network around coarse aggregates by acting as ties of imaginary "space trusses" (Singh, 2017). Nowadays, it is well known that the arrangement and orientation of steel fibers have a very high influence on the mechanical behavior of the composite. The properties in the fresh state (Ferrara et al., 2008; Martinie et al., 2010); casting direction (Ferrara et al., 2007); molding procedure (Barnett et al., 2010; Toutanji and Bayasi, 1998; Wille and Parra-Montesinos, 2012) and specimen geometry (wall effect) (Dupont and Vandewalle, 2005; Soroushian and Lee, 1990) are among the main properties that influence the arrangement and orientation of steel fibers. In general, the fiber distribution is determined in hardened concrete by destructive and non-destructive techniques based on direct and indirect measurements (Laranjeira, 2010). According to Singh (2017), these techniques to assess the amount and orientation of the steel fibers in the hardened concrete have given a big boost to the use of the SFRC, confidently, in various engineering applications. 

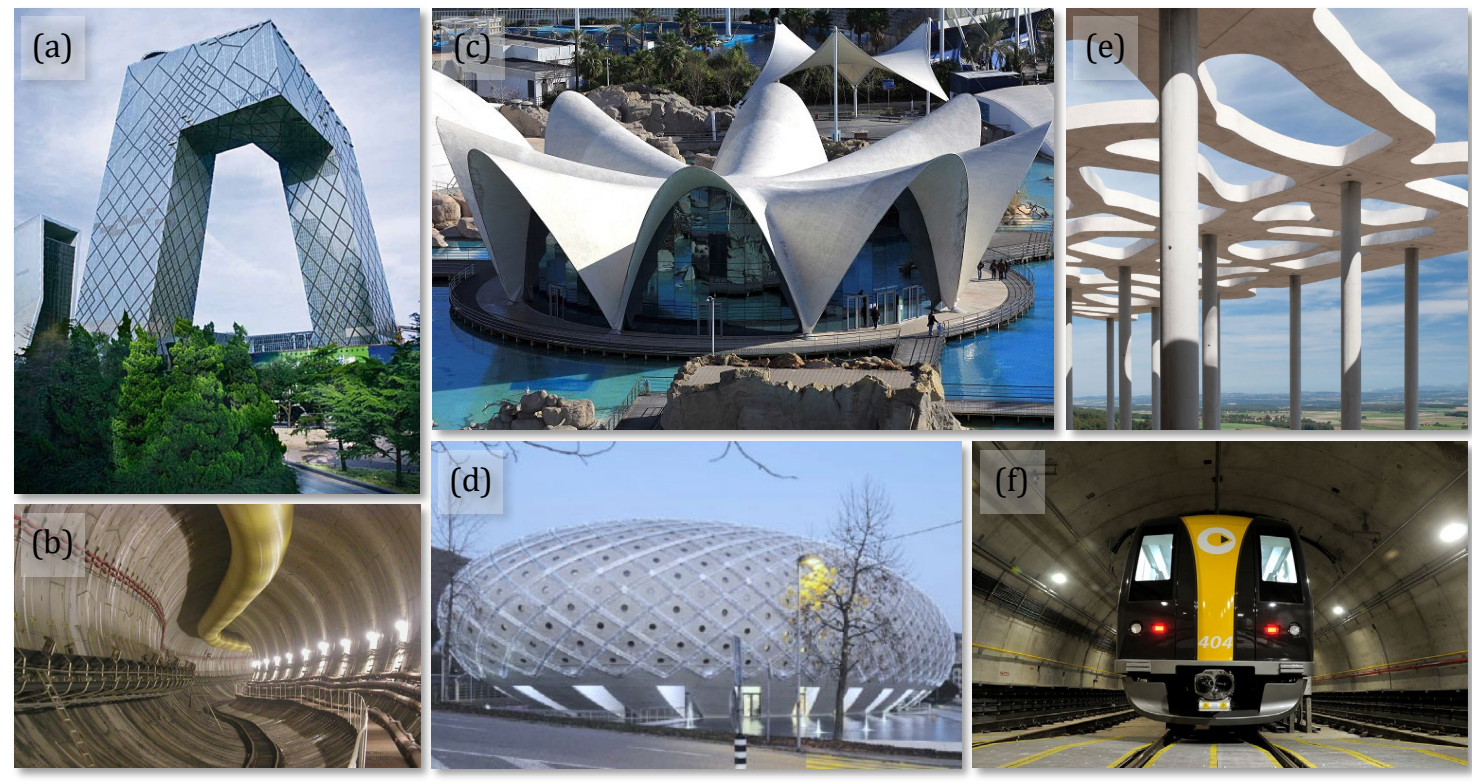

Figure 1.2.: Examples of SFRC applications: (a) CCTV (China Central Television Building) Headquarters, Beijin, China (Brochure Dramix ${ }^{\circledR}$ ); (b) Barcelona metro line 9 tunnel lining, Spain (Maccaferri, 2010); (c) Oceanographic Park in Valencia, Spain (<www.cac.es $>$ ); (d) Centro Ovale Chiasso, Switzerland (Photo: Simone Mengani); (e) Maison de l'Écriture at Montricher, Switzerland (Muttoni et al., 2013) and (f) São Paulo metro line 4 tunnel lining, Brazil (<www.metrocptm.com.br $>$ ).

In recent years, SFRC are being applied for a variety of structural applications. As a first example, the building CCTV Tower in Beijing depicted in Figure 1.2(a) was built using conventional rebars and steel fiber self-compacting concrete (BEKAERT, 2012). Figure 1.2(b) shows the Barcelona metro line 9 tunnel lining constructed with a combination of steel fibers and conventional reinforcement on the pre-cast concrete segments. In this application, the use of $25 \mathrm{~kg} / \mathrm{m}^{3}$ of steel fibers was able to reduce conventional reinforcement content from $120 \mathrm{~kg} / \mathrm{m}^{3}$ to $54 \mathrm{~kg} / \mathrm{m}^{3}$ (Maccaferri, 2010). The shell roof of the Restaurant Submarine at the Oceanographic Museum in Valencia, Spain (Figure 1.2(c)) is another example of application of SFRC. In this structure, $50 \mathrm{~kg} / \mathrm{m}^{3}$ of steel fibers was used with conventional reinforcement mesh to fulfill the flexural stresses and crack control requirements in a roof thickness of $6 \mathrm{~cm}$ (Serna et al., 2009). The fourth example depicted in Figure 1.2(d) is the a mall at Chiasso, Switzerland, where in addition to the use of conventional reinforcement and post-tensioning, $30 \mathrm{~kg} / \mathrm{m}^{3}$ of hooked steel fibers were employed to enhance crack control in the post-tensioned region and to improve the ductility of concrete under high normal and shear forces at the link with the basement (Muttoni et al., 2013). In 
the next application (see Figure Figure 1.2(e)), the concrete canopy of the "Maison de l'Écriture" at Montricher, Switzerland, a fiber content of $20 \mathrm{~kg} / \mathrm{m}^{3}$ was used in some structure regions, allowing to reduce the minimum required reinforcement and helped in regions where conventional reinforcement was difficult to place due to the complexity of the structure geometry (Muttoni, 2014). The last example illustrated in Figure 1.2(f) shows the precast segmental lining of São Paulo Subway line 4 in Brazil, where steel fibers were used as only reinforcement of concrete (Telles and Figueiredo, 2006).

Despite a large number of experimental laboratory tests have been developed since the 1960's (Romualdi and Batson, 1963), researches with a focus on the behavior of FRC structural members are more recent and started approximately 20 years ago. These researches have been demonstrated that SFRC can be used to enhance both the behavior of the structural members at Serviceability Limit State (SLS) (Tiberti et al., 2014; Deluce and Vecchio, 2013), by reducing crack width and crack spacing, which are very important for durability issues, and the structural resistance at Ultimate Limit State (ULS) (Meda et al., 2012; Cucchiara et al., 2004; Conforti et al., 2013; Dinh et al., 2010), by improving the concrete toughness, and consequently, the possibility to replace partially or totally the conventional reinforcement.

\subsection{Motivation}

Based on the above considerations, it is clear the benefits of the addition of steel fibers to concrete, making possible its use as a structural material. However, although the use of SFRC for structural applications is continuously increasing, as illustrated in Figure 1.2, its use among practitioners is still limited with respect to its potentials due to the lack of international building codes (di Prisco et al., 2013a). In this sense, many guidelines have been recently drawn up and one of the most important reference available nowadays is the fib Model Code 2010 (2013), in which FRC and its use as structural material have been introduced in some sections. This guideline was recently used as the main reference for the Brazilian Recommended Practices $(2016 ; 2017)$ developed by the CT 303 - IBRACON/ABECE Committee - "Use of Unconventional Materials for Concrete Structures, Fibers and Fiber Reinforced Concrete".

The lack of confidence to use SFRC as structural material is also directly related to the variability presented by experimental laboratory tests performed on structural 
members and tests of material characterization. In addition, as reported by Bentur and Mindess (2007), the behavior of the composite can be influenced by several parameters such as structure of the concrete matrix; material, shape and geometry of the fiber; fiber content; distribution of the fibers and the fiber-matrix interface structure. Covering all the cases, by using only experimental investigations would be very expensive and time-consuming. As a consequence, in order to contribute to better understanding the behavior of the composite and for the design of structural elements, the application of finite element software has been increased in the last years. However, the models currently available on commercial software packages to describe the post-cracking tension behavior of the composite are based on a macroscopic approach, in which the material is described by its effective properties.

Recently, a number of numerical models have been proposed using an approach that considers the contribution of steel fibers, concrete and concrete-fiber interaction in a fully independent way. These numerical models with a discrete treatment of the fibers may be very useful for simulating a range of cases by varying the type, arrangement and distribution of the fibers and their interaction with the concrete, which is very important on the post-cracking behavior. Not only could an adequate numerical approach contribute to better understanding the behavior of the material but also may be applied for modeling concrete structural members reinforced with conventional rebars and steel fibers in order to verify the predicted behavior obtained in guidelines or standard codes available or in development. Finally, adequate models are also important for fill the gaps left by experimental tests, such as the treatment of problems with arbitrary boundary conditions, problems involving diffuse stress distributions and preferential fibers orientation.

\subsection{State of the art}

In this section a brief literature review of the two main subjects addressed in this work is presented. First, a general description of the strategies available in literature to simulate the post-cracking behavior of SFRC is presented. Then, a summary of the recommendations for the design of SFRC beams is also described. 


\subsubsection{Numerical approaches for modeling the post-cracking behavior of SFRC}

In the recent past, a significant number of numerical models have been proposed for modeling SFRC. In general, the two most important aspects to be considered are the approach used for modeling the failure process and the technique to take into account the presence of fibers. Regarding the first aspect, the crack formation and propagation is usually described in literature by continuum, discrete or lattice models. For the second aspect, recently developed models are using at least one of discrete and explicit representation of steel fibers. This new approach is very appealing, since concrete, fibers and concrete-fiber interaction can be described independently.

In the models using a continuum approach the composite is considered a homogenized material with effective properties calculated according to the proportion between the constituents. These models are usually based on elastoplasticity, damage mechanics and smeared crack approach. In Radtke et al. (2010) the failure process is described by a continuum isotropic damage model and the fibers are represented using a discrete approach by applying forces to the nodes of the matrix background mesh. To represent the fiber-matrix interface, the "fiber-forces" are assumed to be equal to experimental fiber pullout forces and acting in a spread area defined by a radius around the ends of the fibers. In another study, Radtke et al. (2011) developed a model, in which, concrete, fibers and concrete-fiber interaction are modeled separately based on the Partition of Unity Finite Element Method (PUFEM). A continuum damage constitutive model is adopted for the matrix, the fiber-matrix interface is defined through a nonlinear bond-slip law and fibers are assumed to be linear elastic and each fiber is represented using a discrete way by adopting the partition of unity property of finite element shape functions. Cunha et al. (2012) applied a fixed smeared crack model to simulate the matrix failure and embedded discrete fibers in the finite element mesh with perfect adherence. The fiber-matrix interaction is included in the constitutive model by a equivalent stress-strain relation deduced from load-slip curve obtained in experimental pullout tests. The authors employed an algorithm to generate the fiber distribution based on Cunha et al. 2011 approach by considering the wall effect.A novel approach based on the immersed boundary method was proposed by Pros Parés (2011) and Pros et al. (2012) in which the matrix and fibers are discretized into independent meshes. The matrix is described by an isotropic continuum damage model and the fiber-matrix interface by a bond-slip 
constitutive law that depends on the angle between the fiber and the failure pattern. In Fang and Zhang (2013), static and dynamic analysis are performed to analyze the SFRC response based on model in which the matrix is described by a damage model. Fibers are discretely and explicitly represented by truss elements embedded on the matrix and the fiber-matrix interaction is modeled by the bond-slip contact algorithm. Bitencourt Jr. (2015) and Bitencourt Jr. et al. (2018b) developed a model with a discrete and explicit representation of fibers in which the matrix is represented by a continuum damage model with two distinct damage variables for modeling the tension and compression behavior. In this model the interaction between fibers and concrete is described by the use of Coupling Finite Elements (CFEs) (Bitencourt Jr. et al., 2015). Recently, a discrete-continuum coupled modeling approach to simulate fibers, matrix and fiber-matrix interaction individually was published by Zhang et al. (2018). The matrix is described by a continuum damage plasticity model, the fibers are explicitly descretized in beam elements with elastoplastic properties and the fiber-matrix interaction in zero-thickness cohesive elements with softening bond-slip relations. In this model a conforming mesh is generated for fibers and matrix, then the zero-thickness interface elements are inserted between pairs of fiber and matrix to describe the failure processes.

Based on the discrete representation of the composite failure, a certain amount of numerical model were proposed. In these approaches the cracks are represented by incorporating into standard finite elements displacements or strain discontinuities. A discrete crack approach based on zero-thickness interface elements (Carol et al., 1994) was developed by Caggiano et al. (2012) and Etse et al. (2012) to predict failure behavior of FRC. The matrix degradation is represented by means of a fracture energy-based softening law formulated in the framework of the flow theory of plasticity. In this model the aggregates are explicitly discretized and the fibers are discretely but not explicitly represented. The fiber-matrix interaction is incorporated into the interface elements as a discontinuity of the displacement field due to cracking, in which the dowel effect was also incorporated into the formulation, both by means of the Mixture Theory (Truesdell and Toupin, 1960). In Octávio et al. (2016) a Conforming Generalised Strong Discontinuity Approach (CGSDA) for modeling SFRC behavior was proposed. The steel fibers are discretely represented embedded into the finite element mesh with no additional degrees of freedom and the fiber-matrix interaction is considered implicitly in the model. Bitencourt Jr. (2015) and Bitencourt Jr. et al. (2018a) presented a model to simulate the post-cracking behavior of SFRC based on the use of mesh fragmentation technique proposed by 
Manzoli et al. (2016). In this approach the interface finite element (IFE) with high aspect ratio described by a continuum damage model (Manzoli et al., 2012) was used to simulate the failure process of the matrix, while the CFEs (Bitencourt Jr. et al., 2015) was applied to described the fiber-matrix interface allowing a discrete and explicit representation of steel fibers. In Zhan and Meschke (2016) the same IFEs with high aspect ratio proposed by Manzoli et al. (2012) was applied to simulate the failure processes of SFRC taking into account the fiber bridging effect into the cohesive traction model used to describe the crack opening.

In the framework of lattice models, several models have been proposed to simulate the fracture process of FRC. Bolander and Saito (1997) and Kang et al. (2014) developed a lattice model based on the rigid-body-spring concept in which the matrix phase is attached to additional springs considering the bond-slip effect of fibers. In Schauffert and Cusatis (2012) and Schauffert et al. (2012) the Lattice Discrete Particle Model (LDPM) was extended to incorporate the effect of randomly distributed fibers as discrete entities within the matrix where the fiber-matrix interaction is formulated based on micromechanical model. These theoretical bases were recently reviewed in Jin et al. (2016). An additional lattice model based on the Lattice Particle Model (LPM) was enhanced by Montero-Chacón et al. (2017) for the analysis of FRC, where fibers are explicitly modeled. The fiber-matrix interaction is described by interface elements built to connect the fiber ends to matrix nodes and characterized by means of fiber pullout tests.

In this research the numerical model based on the use of CFEs developed by Bitencourt Jr. (2015) and Bitencourt Jr. et al. (2018b) is adopted to represented the SFRC post-cracking behavior. The main advantages of this approach are that the concrete, fiber and concrete-interface can be modeled separately and the use of CFEs to describe the concrete-fiber interface does not introduce additional degrees of freedom to the analysis.

\subsubsection{Standards and guidelines for design of SFRC}

A number of researches on the mechanical behavior of Steel Fiber Reinforced Concrete (SFRC) have been performed over the last five decades. However, the use of SFRC was limited to non-structural applications where fibers are added only for crack control. In addition, only in the last 20 years, researches regarding the structural response of SFRC have been developed (di Prisco et al., 2013a). As a 
consequence, in this period have emerged the first guidelines and standards for the design of SFRC structural members.

An early effort in SFRC standardization was produced by ACI 544 (1996). After that, in order of publication: the German guidelines DVB (2001); the RILEM TC 162-TDF recommendations (2003); the Chinese guidelines (2004); the Italian guidelines CNR-DT 204 (2006); the New Zealand Standard (2006); the American Building Code ACI 318M-08 (2008); the Spanish code EHE-08 (2008); the Guidelines of the German Committee for Reinforced Concrete (DAfStb) (2012); the fib Model Code 2010 (2013); the Sweden Standard (2014); the Denmark design guideline (2014); the Brazilian guideline (CT 303 - Comitê Técnico IBRACON/ABECE, 2016) and the Australian Bridge code DR AS5100.5 (2017) are some of the standards, guidelines and suggested methods of the SFRC design procedure published to date (see Figure 1.3).

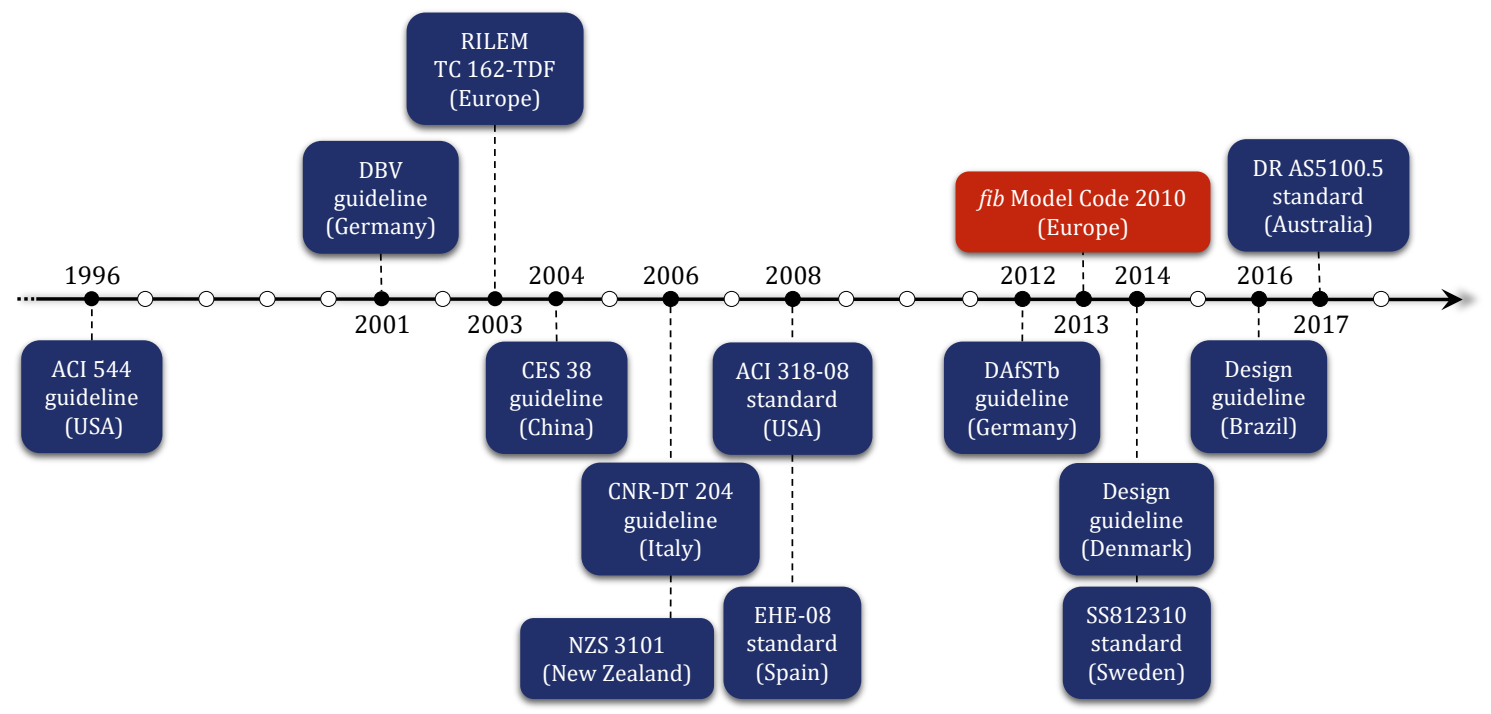

Figure 1.3.: Evolution timeline of the principal design standards, suggested methods and guidelines for SFRC.

Therefore SFRC contribution can be calculated following different codes and guidelines. First of all, the composite must fulfill a minimum mechanical performance and then, it can be used to enhance the behavior of a structural member at the Serviceability Limit State (SLS) by reducing crack width and crack spacing, therefore, improving durability or at Ultimate Limit State (ULS), by improving the concrete toughness and ductility, where the incorporation of steel fibers to concrete can be applied to replace partially or totally the conventional reinforcement. 
The SFRC design procedures are first based on test methods to characterize the SFRC response. For the majority of the design code and standards, after SFRC characterization, a constitutive model is adopted and the parameters obtained from the tests are employed. Finally, based on an adopted constitutive law, the design methods are followed to properly (and safely) design SFRC structural members (see Figure 1.4).

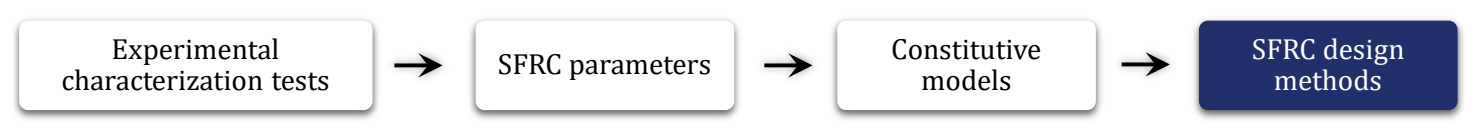

Figure 1.4.: Procedures to design SFRC structural members.

RILEM TC162-TDF (2003) prepared a pioneer recommendation for SFRC design. The committee proposed a three-point bending test (RILEM TC 162-TDF, 2002) of a notched beam specimen for material characterization. The test response is described as force vs. CMOD (Crack Mouth Opening Displacement) and the residual tensile strengths parameters $f_{R, 1}$ and $f_{R, 4}$ are calculated for $\mathrm{CMOD}_{1}=0.5 \mathrm{~mm}$ and $\mathrm{CMOD}_{4}=3.5 \mathrm{~mm}$, corresponding, respectively, at SLS and ULS. The flexural resistance is calculated by considering the tensile strength of SFRC. The shear design of SFRC members comprehends both conventional reinforcement (stirrups) and SFRC, where the shear resistance due to SFRC is taken into account as a separated term using the residual tensile strength parameter $f_{R, 4}$. Minimum reinforcement for crack control and crack opening formulas are also provided considering the fiber effect through the residual tensile strength $f_{R, 1}$. In addition, the partial safety factors are not included in the design strengths and a size-dependent safety factor $\kappa_{h}$ is introduced to compensate the difference between the structural member and the specimen tested.

The ACI-318 Code (2008) allows the contribution of SFRC to replace minimum shear reinforcement in flexural members. A four-point bending test in accordance with ASTM C1609 (2012) must be performed to obtain the residual strength that fulfills the requirements of the code. In addition, SFRC must have a minimum fiber dosage of $60 \mathrm{~kg} / \mathrm{m}^{3}$, concrete compressive strength less than $f_{c}^{\prime} \leq 40 \mathrm{MPa}$, height of member $h \leq 600 \mathrm{~mm}$ and fibers with aspect ratio between 50 and 100. However, the code does not provide a formula in which the effect of the fibers is directly taken into account, only an allowable shear strength that SFRC can withstand.

The German Society for Concrete and Construction Technology (DBV) (2001) has 
published in 2011, the first Germany guideline concerning the design of SFRC. After that, the German Committee for Reinforced Concrete (DAfStb) (2012) published a Guideline on Steel Fiber Reinforced Concrete, in which the design rules to SFRC with or without conventional reinforcement for concrete with compressive strength less than $50 \mathrm{MPa}$ are presented. This guideline supplements with the SFRC recommendations the regular German concrete standard DVB (2008). The material characterization is based on the residual flexural strength (L1 and L2) of a 4-point bending test DIN EN 12390-5 (2009), computing the value corresponding to deflections $\delta_{L 1}=0.5 \mathrm{~mm}$ and $\delta_{L 2}=3.5 \mathrm{~mm}$. The ratio L1 $/ \mathrm{L} 2$ determines which constitutive law will be used: stress block or tri-linear stress-strain. Moreover, the code proposes equations to calculate the design strength, by multiplying a set of factors by the characteristic residual flexural strength. Then, at ULS, the bending and shear resistance can be calculated to define the longitudinal and shear reinforcements. In addition, the code also provides a design approach to calculate the crack width for SLS. Moreover, the DAfStb (2012) is already part of DIN EN1992-1-1/NA (2013) in national level.

The Italian Guideline CNR-DT 204 (2006) allows the SFRC to be applied as reinforcement. To evaluate the tensile behavior, two characterization tests are suggested: uniaxial tension test UNI 11188 (2004) and four-point bending test with a central notch UNI 11188 (2003). The guideline CNR-DT 204 (2006) prescribes two constitutive models: the linear-elastic and the rigid-plastic models concerning the residual post-cracking strengths. Additionally, a partial factor for covering the uncertainties of the assumed model is considered. In ULS design, longitudinal and shear reinforcement can be calculated by considering the steel fiber contribution. For design at SLS, equations to calculate the crack width and minimum reinforcement for crack control are also provided.

In Spain, the Code on Structural Concrete (Spanish abbreviation - EHE) (2008) included the Annex 14 "Recommendations for using concrete with fibers" to consider fibers as a reinforcing material. The post-cracking behavior is determined in accordance with EN 14651 (2005) and two constitutive models for SFRC can be adopted: a rectangular diagram or a multilinear diagram. In addition, the code allows the contributions of steel fiber for structural purposes for both ULS and SLS, where steel fibers can substitute partially or totally the conventional reinforcement.

Despite the release of guidelines and standards in various countries, the implementation of SFRC in the MC2010 represents a milestone for the standardization of 
use of fibers as reinforcement, since MC2010 intends to serve as the basis for future codes for concrete structures. In the code, the contribution of fibers is evaluated thought the residual tensile strengths $f_{R, 1}$ and $f_{R, 3}$ obtained from the suggested characterization test EN 14651 (2005) for $\mathrm{CMOD}_{1}=0.5 \mathrm{~mm}$ and $\mathrm{CMOD}_{3}=2.5 \mathrm{~mm}$. It is important to mention that other tests can be used if a correlation is established with the standard test. As suggested in CNR-DT 204 (2006), MC2010 also adopts two constitutive models: rigid-plastic or linear. In addition, longitudinal and shear reinforcements can be calculated to substitute partially or even totally conventional reinforcement. Equations to calculate the crack width and the minimum reinforcement for crack control are also provided. Furthermore, the publication of the MC2010 regarding the design of SFRC will be potentially used as reference document for development of Eurocodes and national standards (di Prisco et al., 2013a).

The Draft Australian Bridge Code for Concrete Structures DR AS5100.5 (2017) is the first code in Australia to consider SFRC in structural design. The postcracking strength of the material may be obtained by uniaxial tension test, described in DR AS5100.5 (2017), or by a combination of uniaxial tension test and threepoint bending test EN 14651 (2005). For the first test, the residual direct tensile strength $f_{1.5}^{\prime}$ corresponding to a Crack Opening Displacement (COD) of $1.5 \mathrm{~mm}$ is obtained. In the other case, the both tests are performed with the same materials and relationship between them is determined by taking the value of $f_{R, 4}\left(\mathrm{CMOD}_{3}=\right.$ $3.5 \mathrm{~mm}$ ) and considering the boundary effect. Once the relationship is established, the flexural test EN 14651 (2005) can be applied as a control testing. Another alternative to obtain the residual direct tensile strength $f_{1.5}^{\prime}$ can be performed by considering the residual tensile strength $f_{R, 2}$ and $f_{R, 4}$ from EN 14651 (2005). The value of the residual direct tensile strength $f_{1.5}^{\prime}$ is applied to considered the fiber effect in the design for bending, shear at ULS and crack control and deflection at SLS.

In Brazil, guidelines regarding the structural design CT 303 - Comitê Técnico IBRACON/ABECE (2016) and quality control CT 303 - Comitê Técnico IBRACON/ABECE (2017) of fiber reinforced concrete were recently published. They were elaborated by the CT-303 technical committee in a partnership among Brazilian Concrete Institute (IBRACON) and Brazilian Association of Structural Engineering and Consulting (ABECE) which aims to be the base for future normalization in this field. The Brazilian guideline for structural design is based on the MC2010 as 
well as the proposed characterization test for SFRC according to EN 14651 (2005). All the mentioned standards require at least a bending test to characterize the SFRC material (see Table 1.1) and either the results will be used directly in the design formulas or just to establish minimum mechanical performance of the material. As can be seen in Table 1.1, the three-point bending test EN 14651 (2005) is the most used SFRC characterization test.

Table 1.1.: Summary of the standards and guidelines characterization bending test for SFRC.

\begin{tabular}{lll}
\hline Standard/Guideline & Characterization test & Type of bending test \\
\hline \hline RILEM TC162-TDF (2003) & RILEM TEST (2002) & 3PBT (notched) \\
\hline CNR-DT 204 (2006) & UNI 11039 (2003) & 4PBT (notched) \\
\hline EHE-08 (2008) & EN 14651 (2005) & 3PBT (notched) \\
\hline ACI-318 (2008) & ASTM-C1609 (2012) & 4PBT (un-notched) \\
\hline DafStb (2012) & DIN EN 12390-5 (2009) & 4PBT (un-notched) \\
\hline fib Model Code 2010 (2013) & EN 14651 (2005) & 3PBT (notched) \\
\hline IBRACON/ABECE (2016) & EN 14651 (2005) & 3PBT (notched) \\
\hline DR AS5100.5 (2017) & EN 14651 (2005) & 3PBT (notched) \\
\hline
\end{tabular}

Some design methods and characterization tests mentioned above may be applied for different type of fibers. However, in this work only steel fibers are considered on the design of structural members following the MC2010 and the recommended characterization EN 14651 (2005) test. In Chapter 3, there is full description of the design procedure of beam elements according to MC2010.

\subsection{Objectives}

The main purpose of this research is to use the numerical model developed by Bitencourt Jr. (2015) with a discrete and explicit representation of steel fibers for assessing the post-cracking performance of SFRC and its application on the design of RC-SFRC beams. To achieve this, the following objectives are performed:

- To implement in MATLAB ${ }^{\circledR}$ code a numerical approach with a discrete and explicit representation of reinforcements as proposed by Bitencourt Jr. et al. (2018c) (rebars) and Bitencourt Jr. et al. (2018b) (steel fibers). 
- To assess the capability of the numerical model to capture the response of SFRC characterization test according to EN 14651 (2005).

- To obtain the concrete-fiber interface parameters through the numerical simulation of three-point bending tests performed in laboratory according to EN 14651 (2005).

- To assess the numerical responses in three-point bending beams for different fiber contents using as reference the concrete-interface parameters calibrated for an intermediate fiber volume fraction.

- To verify the ability of the numerical model to capture the structural response and failure mode on the simulation of RC and RC-SFRC beams experimentally tested.

- To design RC and RC-SFRC beams following the fib Model Code 2010 (2013) predictions and to perform numerical analyses for all the cases by considering the material parameters calibrated on the simulation of SFRC characterization tests.

- To compare the numerical analyses against design predictions in terms of serviceability and ultimate limit states.

\subsection{Overview and hypothesis of the study}

This research focus on the study of beams reinforced with conventional bars and steel fibers. The numerical model proposed by Bitencourt Jr. (2015) is used for all the numerical analyses under quasi-static loading. The analyses are performed in $2 \mathrm{D}$, since the discrete and explicit representation of steel fibers leads to high computational cost in case of real-scale beams. Consequently, the steel fibers are projected onto the plane of analysis.

As fiber reinforcement, steel fibers are employed for the numerical analyses and on the design of beams. The cloud of steel fibers is considered with an isotropic uniform random distribution. Therefore, effects of casting direction, vibration and flow in the fresh state are not taken into account. In addition, the interaction between fibers (friction) is not considered, although the crossing between them is allowed. The hook in hooked-end steel fiber is taken into account in the bond-slip relationship. Furthermore, the cement paste and aggregates are homogenized into the concrete matrix. 
For the design of beams according to MC2010, normal strength concrete (NSC, $\left.f_{c k} \leq 50 \mathrm{MPa}\right)$ is considered and the fibers orientation factor is taken equal to $K=1$, as isotropic uniform fiber distribution is assumed. The minimum flexural conventional reinforcement is always considered for all the cases, since the amount of fibers is small and the structural redistribution factor $K_{R d}$ that takes into an account structure redundancy is assumed as $K_{R d}=1$.

\subsection{Structure of the dissertation}

The dissertation is subdivided in 6 Chapters and 3 Appendixes. Chapter 1 is an introduction about the research and reviews the existing numerical strategies for modeling the fiber reinforced concrete behavior and the main design standards and recommendations available for SFRC.

Chapters 2 presents the numerical model used for modeling the post-cracking behavior of SFRC. Herein, it is presented the finite elements and constitutive models employed, by including the innovative strategy to describe the concrete-reinforcement interactions based on the use of coupling finite elements with an appropriate damage constitutive model. The algorithm developed and implemented in MATLA $B$ ( language for the generation of a cloud of steel fibers is detailed. Finally, the concrete constitutive law based on a damage model with two damage variables (Cervera et al., 1996) is presented.

In Chapter 3 the design procedure for RC-SFRC beams proposed by MC2010 is presented. First, the SFRC characterization EN 14651 (2005) test is described and the toughness parameters used to define the constitutive law of the material is applied on the design for ultimate and serviceability limit states.

In Chapter 4, the ability of numerical tool for simulation of SFRC behavior is assessed. Firstly, numerical analyses of three-point bending tests according to EN 14651 (2005) are performed and the results are compared with the experimental ones. Secondly, the parameters obtained are used to design RC-SFRC beams according to MC2010. Thirdly, the designed beams are numerically simulated and the responses are compared with the code predictions. Fourthly, the RC-SFRC small scale beams experimentally tested by Conforti et al. (2018) are numerically simulated. In this study, a comparison between numerical, experimental and predicted responses according to MC2010 are performed. 
Finally, the conclusions of this work and suggestions for future research are presented in Chapter 5. 


\section{Numerical model}

In this section the numerical model used for modeling the behavior of beams with combined reinforcement of steel fibers and rebars (RC-SFRC beams) is presented. The rebars and steel fibers are modeled using the same approach by using Coupling Finite Elements (CFEs) as proposed recently by Bitencourt Jr. et al. (2018b) and Bitencourt Jr. et al. (2018c), respectively. A new algorithm for distribution of fibers is proposed for an arbitrary specimen geometry.

\subsection{Discrete and explicit representation of reinforcements}

A discrete and explicit representation of steel fibers and rebars based on the use of CFEs is adopted. The procedure to construct the numerical model is depicted in Figure 2.1. Initially, concrete mesh discretization based on the geometry of the structural member is performed (Figure 2.1(a)). Then, a cloud of fibers (Figure 2.1 (b)) is generated using the concrete mesh as reference and the rebars are drawn (Figure $2.1(\mathrm{c})$ ). In this step the reinforcements are discretized in finite elements in a totally independent way (non-conforming meshes). Finally, CFEs are introduced in order to describe the interaction between reinforcements and concrete as illustrated in Figure 2.1(d). 


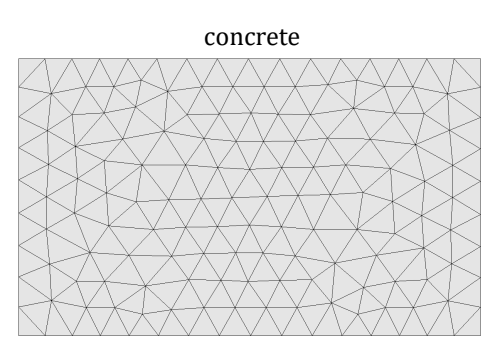

(a)

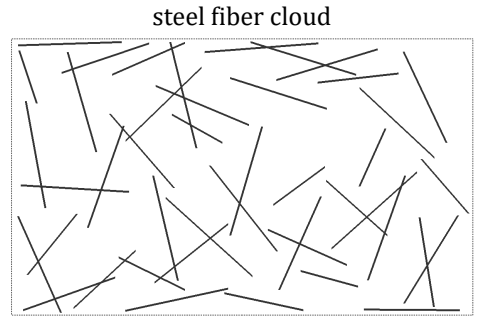

(b)

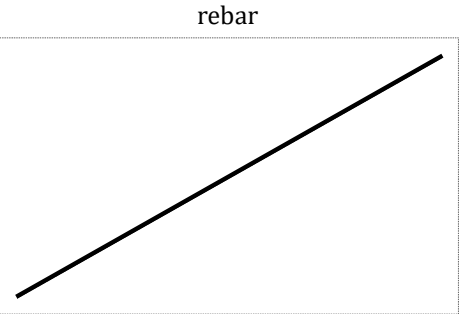

(c)

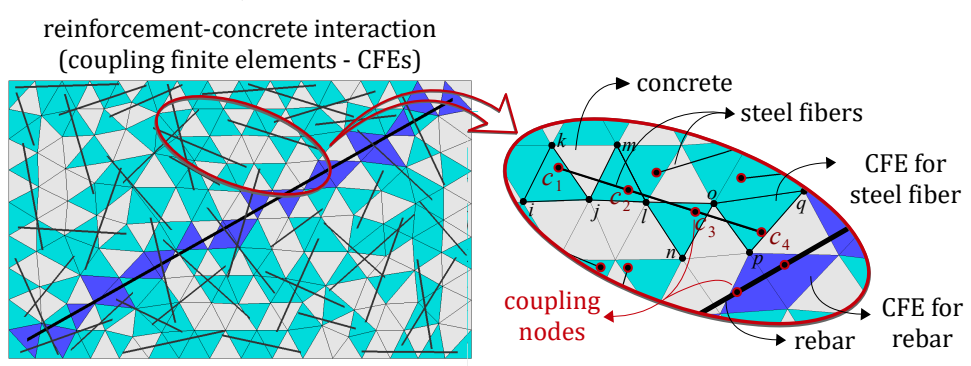

(d)

(e)

Figure 2.1.: Coupling procedure for non-matching finite element meshes: (a) discretization of the concrete in FEs; (b) generation and discretization of a cloud of steel fibers; (c) creation and discretization of rebar; (d) creation and insertion of the CFEs and (e) detail of the coupling in overlapping meshes.

As can be seen in Figure 2.1(e), each CFE has the same nodes of an underlying finite element of the existing mesh and an extra node, coinciding with the loose node (this node is called the coupling node) that belongs to its domain. As a consequence, the CFEs overlap the finite elements of the original mesh around the coupling nodes " $c_{i}$ ". Note that for each loose node, one coupling finite element is required. An example of the addition of a coupling finite element can be seen in Figure 2.1(e), where the coupling finite element $\mathrm{CFE}_{1}=\left\{i, j, k, c_{1}\right\}$ is introduced, whose $c_{1}$ is the coupling node.

These elements that share nodes with both non-matching meshes can be then used to ensure the compatibility of displacements and to transfer interaction forces between non-matching meshes. The interaction forces between the non-matching meshes may also be described by an appropriate constitutive model applied in the CFEs. This is one of the major advantages of the technique, since a rigid (full compatibility of displacements) or non-rigid (degrading interface) coupling can be considered easily. Thus, the use of this technique for modeling reinforcements (rebars and steel fibers) is very appealing, since concrete, reinforcements and concrete-reinforcements interaction can be modeled independently. 
After the application of the coupling procedure (Figure 2.1(c)), the global internal force vector and the stiffness matrix can be written as:

$$
\begin{aligned}
& \mathbf{F}^{\text {int }}=\underbrace{A_{e=1}^{n e l_{C}}\left(\mathbf{F}_{e}^{\text {int }}\right)_{C}}_{\text {concrete elements }}+\underbrace{A_{e=1}^{n e l_{R}}\left(\mathbf{F}_{e}^{i n t}\right)_{R}}_{\text {reinforcements }}+\underbrace{A_{e=1}^{n e l_{C F E}}\left(\mathbf{F}_{e}^{\text {int }}\right)_{C F E}}_{\text {coupling elements }} \\
& \mathbf{K}=\underbrace{A_{e=1}^{\text {nel }}\left(\mathbf{K}_{e}\right)_{C}}_{\text {concrete elements }}+\underbrace{A_{e=1}^{n e l_{R}}\left(\mathbf{K}_{e}\right)_{R}}_{\text {reinforcements }}+\underbrace{A_{e=1}^{\text {nel }} l_{C F E}\left(\mathbf{K}_{e}\right)_{C F E}}_{\text {coupling elements }}
\end{aligned}
$$

where $A$ stands for the finite element assembly operator, the first and second terms of the Eq. 2.1 and Eq.2.2 are related to the subdomains from the concrete $\Omega^{C}$ and reinforcements (steel fibers and rebars) $\Omega^{R}$, respectively, and the third term is tied to the introduction of the CFEs.

\subsection{Concrete-reinforcement interaction}

Based on the use of CFEs, the concrete-reinforcement (rebars or steel fibers) are described for a 2D problems and the coupling scheme are depicted in Figure 2.2.
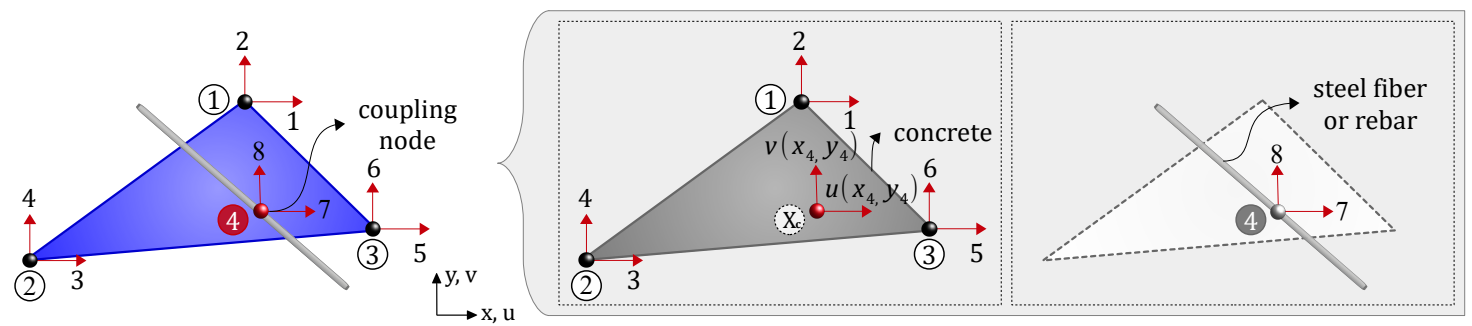

Figure 2.2.: 2D coupling finite elements with linear interpolation functions of displacements: 3 -noded triangle $+C_{\text {node }}$.

The displacement $\overline{\mathbf{U}}$ of a material point $\boldsymbol{X}_{p}=(x, y)$ inside a Constant Strain Triangle (CST) finite element can be defined by the shape functions as:

$$
\overline{\mathbf{U}}\left(\boldsymbol{X}_{p}\right)=\overline{\mathbf{N}}\left(\boldsymbol{X}_{p}\right) \overline{\mathbf{D}}
$$

where $\overline{\mathbf{N}}$ is the shape function matrix with linear interpolation and $\overline{\mathbf{D}}$ the nodal displacements. 
The CFE is a finite element constituted by the nodes of the standard isoparametric finite element (in this case CST) and an additional node, named coupling node $\left(C_{\text {node }}\right)$, situated at the material point of the $\mathrm{FE}$ domain, $\mathbf{X}_{c} \in \Omega^{e}$, as illustrated in Figure 2.2. The relative displacement $\llbracket \mathbf{U} \rrbracket$ is given by the difference between the displacement of the coupling node $\mathbf{D}_{c}$ and the displacement $\overline{\mathbf{U}}$ at the material point $\mathbf{X}_{c}=\left(x_{4}, y_{4}\right)$ as follows:

$$
\llbracket \mathbf{U} \rrbracket\left(\boldsymbol{X}_{c}\right)=\mathbf{D}_{c}-\overline{\mathbf{U}}\left(\boldsymbol{X}_{c}\right)
$$

The system can be written in the matrix form:

$$
\llbracket \mathbf{U} \rrbracket\left(\boldsymbol{X}_{c}\right)=\mathbf{B}_{e}\left(\boldsymbol{X}_{c}\right) \mathbf{D}_{e}
$$

where the matrix $\mathbf{B}_{e}=\left[-\overline{\mathbf{N}}_{1}\left(\mathbf{X}_{c}\right)-\overline{\mathbf{N}}_{2}\left(\mathbf{X}_{c}\right)-\overline{\mathbf{N}}_{3}\left(\mathbf{X}_{c}\right) \mathbf{I}\right]$, I is the identity matrix of order 2 and $\mathbf{D}_{e}=\left\{\begin{array}{llll}\mathbf{D}_{1} & \mathbf{D}_{2} & \mathbf{D}_{3} & \mathbf{D}_{c}\end{array}\right\}$ stores the displacement components of the CFE.

Thus, the internal virtual work of the CFE is given by

$$
\delta W_{e}^{i n t}=\delta \llbracket \mathbf{U} \rrbracket^{T} \mathbf{F}(\llbracket \mathbf{U} \rrbracket),
$$

where $\mathbf{F}(\llbracket \mathbf{U} \rrbracket)$ is the reaction force owing to the relative displacement $\llbracket \mathbf{U} \rrbracket$ and $\delta \llbracket \mathbf{U} \rrbracket$ is an arbitrary virtual relative displacement, compatible with the boundary conditions of the problem. Using the same approximation for the virtual relative displacement as that used for the relative displacement given by Eq. 2.5, i.e., $\delta \llbracket \mathbf{U} \rrbracket=\mathbf{B}_{e} \delta \mathbf{D}_{e}$, the internal force vector of the CFE can be expressed as follows:

$$
\mathbf{F}_{e}^{i n t}=\mathbf{B}_{e}^{T} \mathbf{F}(\llbracket \mathbf{U} \rrbracket)
$$

Accordingly, the corresponding tangent stiffness matrix of the CFE can be obtained by the following expression:

$$
\mathbf{K}_{e}=\frac{\partial \mathbf{F}_{e}^{i n t}}{\partial \mathbf{D}_{e}}=\mathbf{B}_{e}^{T} \mathbf{C}_{t g} \mathbf{B}_{e}
$$

where $\mathbf{C}_{t g}=\partial \mathbf{F}(\llbracket \mathbf{U} \rrbracket) / \partial \llbracket \mathbf{U} \rrbracket$ is the tangent operator of the constitutive relation between reaction force and the relative displacement. 


\subsubsection{Perfect adherence}

By assuming a linear elastic model to describe the relation between the reaction force and the relative displacement:

$$
\mathbf{F}=\mathbf{C} \llbracket \mathbf{U} \rrbracket=\mathbf{C B}_{\mathbf{e}} \mathbf{D}_{e}
$$

where $\mathbf{C}$ is the matrix of elastic constants. The perfect adherence or a rigid coupling enforcing displacement compatibility of two non-matching meshes, can be imposed by assuming a very high value for the elastic stiffness, such that the matrix of elastic constants for $2 \mathrm{D}$ analysis is expressed as follows:

$$
\mathbf{C}=\left[\begin{array}{cc}
\tilde{C} & 0 \\
0 & \tilde{C}
\end{array}\right]
$$

where $\tilde{C}$ stands for a high elastic stiffness value, which plays the role of a penalty variable on the relative displacement. It is important to note that, because of the equilibrium conditions, the interaction force $\mathbf{F}$ in Eq. 2.9 must be bounded. Hence, when the elastic constants tend towards a very high value, the relative displacement components $\llbracket \mathbf{U} \rrbracket$ must tend to zero.

\subsubsection{Loss of adherence}

The loss of adherence is represented through a non-rigid coupling between the nonmatching meshes, allowing a relative displacement between the steel fiber and concrete, and insert an interaction force between these two components.

Since the relative movement of the reinforcement with respect to the concrete matrix is in essence a sliding in the direction of the reinforcement axis, it is necessary to use a local coordinate system, $(\mathbf{n}, \mathbf{s})$, oriented such that the axis $\mathbf{n}$ coincides with the reinforcement axial orientation. Thus, the relative displacement and its corresponding reaction force can be expressed as $[[\mathbf{u}]]=\mathbf{R}[[\mathbf{U}]]$ and $\mathbf{f}=\mathbf{R F}$, respectively, where $\mathbf{R}$ is the orthogonal rotation matrix between the local and global reference systems.

The loss of adherence model can be easily represented by assuming an elastic constitutive model with distinct elastic constants, according to the local coordinate 
system:

$$
\mathbf{c}=\left[\begin{array}{cc}
c_{n} & 0 \\
0 & c_{s}
\end{array}\right], c_{n} \ll c_{s} .
$$

In general, these models are described by a relationship between the local (shear) stress, $\tau$, acting at the reinforcement-matrix interface, and the relative displacement (interface slip), $s$.

Since the CFE introduces into the problem an interaction force between the concrete matrix and the steel reinforcement, at coupling node, one may consider that this force results from the bond (shear) stress, $\tau$, on the bond area (reinforcementmatrix interface) in the vicinity of the couplig node. Therefore, by assuming that the bond (shear) stress is constant in the vicinity of the node and that the size of the vicinity (influence length) that contributes to the resultant force in a specific node corresponds to the average of the half distances between the node " $i$ " and its adjacent nodes of the reinforcement " $j$ " e " $k$ ", the interaction force may be expressed as:

$$
f_{n}=\tau\left(\llbracket u_{n} \rrbracket\right) P L_{j}
$$

where $L_{j}=\left(L_{i j}+L_{j k}\right) / 2$ is the influence length and $P$ is the perimeter of the reinforcement cross-section. Note that the slip, $s$, is given by the relative displacement in direction $n$, i.e., $s=\llbracket u_{n} \rrbracket$. The remaining transverse component of the resultant force can be expressed as:

$$
f_{s}=c_{s} \llbracket u_{s} \rrbracket P L_{j}
$$

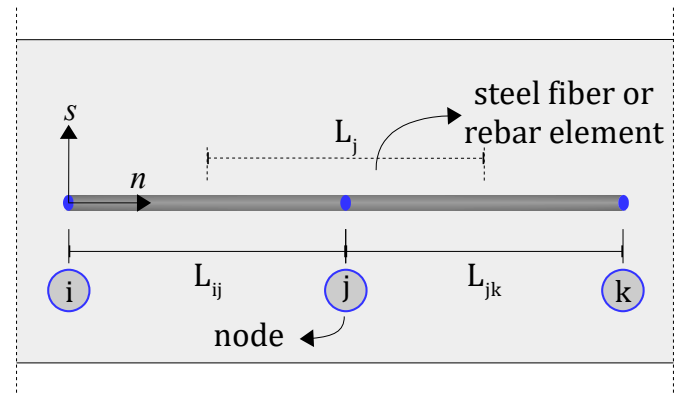

Figure 2.3.: Influence length of the coupling node for steel fiber or rebar. 


\subsubsection{Continuum damage model to describe bond slip}

In the case of partial bond, a constitutive model based on the continuum damage theory is used to describe the constitutive relationship between the shear stress (adherence stress) and the relative sliding. In addition, this constitutive model is integrated by an implicit-explicit integration scheme (Impl-EX) (Oliver et al. (2008) and Prazeres et al. (2015)) in order to avoid problem of convergence. Table 2.1 summarizes the constitutive bond-slip damage model equipped with the Impl-EX scheme.

Table 2.1.: Impl-EX integration scheme for the continuum damage model to describe bond-slip.

INPUT: $\llbracket u_{n_{n+1}} \rrbracket, r_{n}, \Delta r_{n}$

Evaluate the

effective stress $\quad \bar{\tau}_{n+1}=c_{n} \llbracket u_{n_{n+1}} \rrbracket$

tensor

$$
\begin{array}{lc}
\text { Damage criteria } & \\
\text { and the implicit } & \bar{\phi}_{n+1}\left(\bar{\tau}_{n+1}, r_{n}\right)=\left\|\bar{\tau}_{n+1}\right\|-r_{n} \leq 0 \\
\text { calculation stage } & \text { if true } r_{n+1}=r_{n} \\
\text { of the strain-like } & \text { else } r_{n+1}=\left\|\bar{\tau}_{n+1}\right\| \\
\text { variable } &
\end{array}
$$

$$
\begin{aligned}
& \text { Computation of } \\
& \text { the implicit } \\
& \text { strain-like } \\
& \text { variable } \\
& \text { increment }
\end{aligned}
$$

\section{Computation of}

the explicit

linear

extrapolated

$$
\tilde{r}_{n+1}=r_{n}+\frac{\Delta r_{n}}{\Delta t_{n}} \Delta t_{n+1}
$$

strain-like

$$
\Delta t_{n+1}=t_{n+1}-t_{n} \text { and } \Delta t_{n}=t_{n}-t_{n-1}
$$

variable 


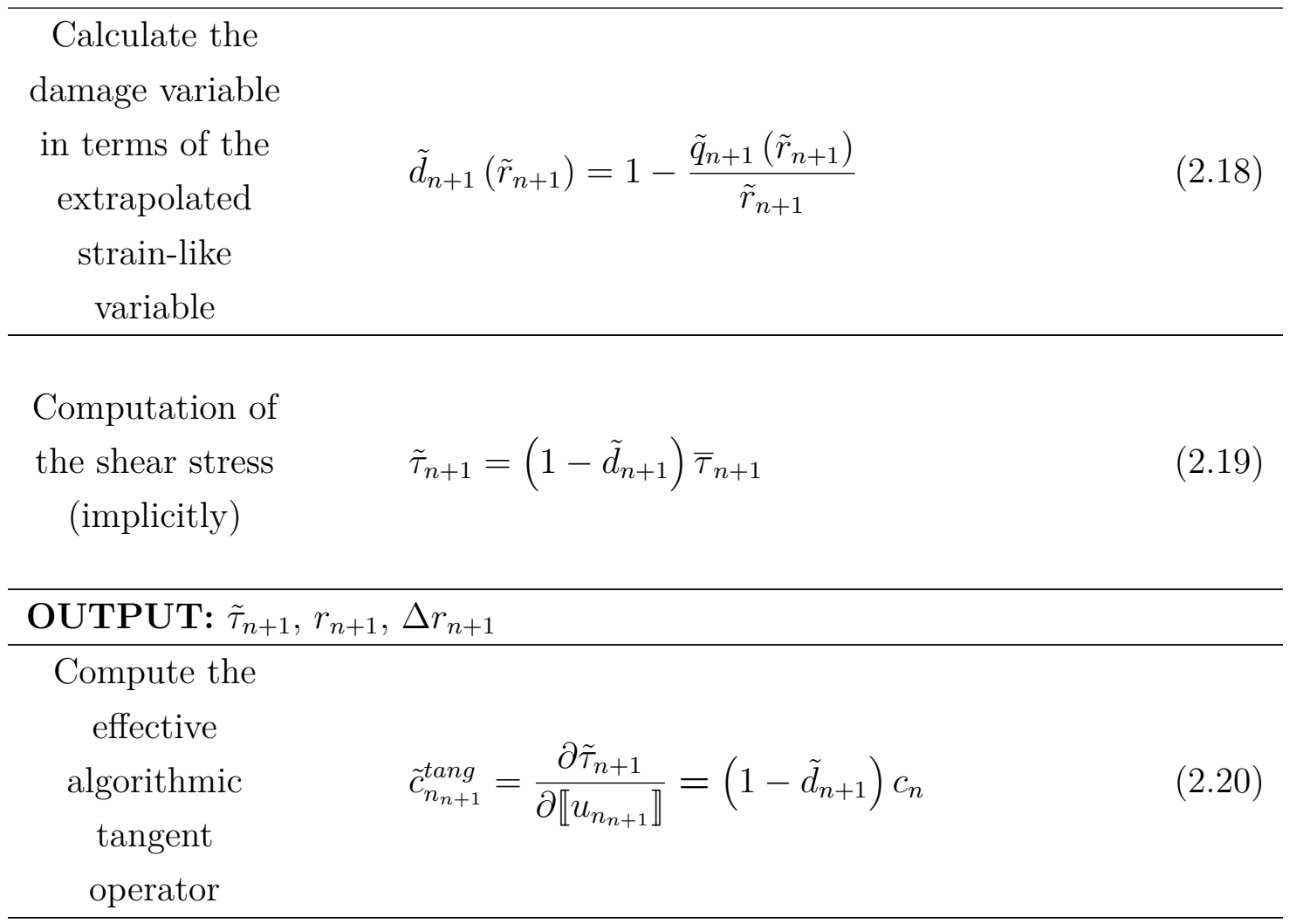

In the current pseudo-time step, $t_{n+1}$, given the relative displacement $\left[\left[u_{n_{n+1}}\right]\right]$ in direction $n$ and the elastic stiffness constant (unit of stress per unit of length) $c_{n}$, the effective shear stress $\bar{\tau}_{n+1}$ is obtained by Eq. 2.14. In Eq. 2.15 the damage criterion is evaluated and the strain-like variable $r_{n+1}$ is saved as a historical value for the next time-step. For the damage evolution rule $\bar{\phi}_{n+1} \leq 0, r_{n+1}$ assumes the value of $r_{n}$ the previous step $t_{n}$, otherwise, it assumes the maximum value reached by $\bar{\tau}_{n+1}$ during the load process $\left(r_{n+1}=\max \left[\bar{\tau}_{n+1}\right]\right)$. The implicit strain-like variable increment is calculated in Eq. 2.16 and used to evaluate explicitly the linear extrapolated strainlike variable $\tilde{r}_{n+1}$ in Eq. 2.17 by using the implicit values $r_{n}$ and $\Delta r_{n}$, obtained in the previously time step. Therefore, the scalar damage variable $\tilde{d}_{n+1}(d \in[0,1])$ is calculated in Eq. 2.18 as a function of the extrapolated strain-like variable $\tilde{r}_{n+1}$, where the function $\tilde{q}_{n+1}\left(\tilde{r}_{n+1}\right)$ represents the hardening/softening law of the constitutive model, and it may be adjusted to fit any bond-slip model of type $\tau(s)$, considering the relationship $q(r)=\tau\left(r / c_{n}\right)$. Then, the shear stress $\tilde{\tau}_{n+1}$ is computed according to Eq. 2.19 and used to evaluate the effective algorithmic tangent operator $\tilde{c}_{n_{n+1}}^{\text {tang }}$ in Eq. 2.20. 
The bond-slip models adopted in this research to describe the concrete-reinforcements interactions are described as follow.

\subsubsection{Concrete-rebar interaction}

The bond-slip relationship proposed by the fib Model Code 2010 (2013) for concreterebar interaction depicted in Figure 2.4 is described by the equations:

$$
\tau(s)=\left\{\begin{array}{ccc}
\tau_{b \max }\left(\frac{s}{s_{1}}\right)^{\alpha} & \text { if } & s \leq s_{1} \\
\tau_{b \max } & \text { if } & s_{1} \leq s \leq s_{2} \\
\tau_{b \max }-\frac{\left(\tau_{b \max }-\tau_{b f}\right)\left(s-s_{2}\right)}{s_{3}-s_{2}} & \text { if } & s_{2} \leq s \leq s_{3} \\
\tau_{b f} & \text { if } & s>s_{3}
\end{array},\right.
$$

and the corresponding hardening/softening law is defined in terms of the stress- and strain-like internal variable as:

$$
q(r)=\left\{\begin{array}{ccc}
\tau_{b \max }\left(\frac{r / c_{n}}{s_{1}}\right)^{\alpha} & \text { se } & r / c_{n} \leq s_{1} \\
\tau_{b \max } & \text { se } & s_{1} \leq r / c_{n} \leq s_{2} \\
\tau_{b \max }-\frac{\left(\tau_{b \max }-\tau_{b f}\right)\left(r / c_{n}-s_{2}\right)}{s_{3}-s_{2}} & \text { se } & s_{2} \leq r / c_{n} \leq s_{3} \\
\tau_{b f} & \text { se } & r / c_{n}>s_{3}
\end{array}\right.
$$

where $\alpha, \tau_{b \max }, \tau_{b f}$ and $s_{i}(i=1,2,3)$ are the parameters of the model, which depend on the concrete strength $f_{c k}$, the bar geometry (ribbed or smooth), the confining situation (confined or unconfined) and bond condition (good or poor).

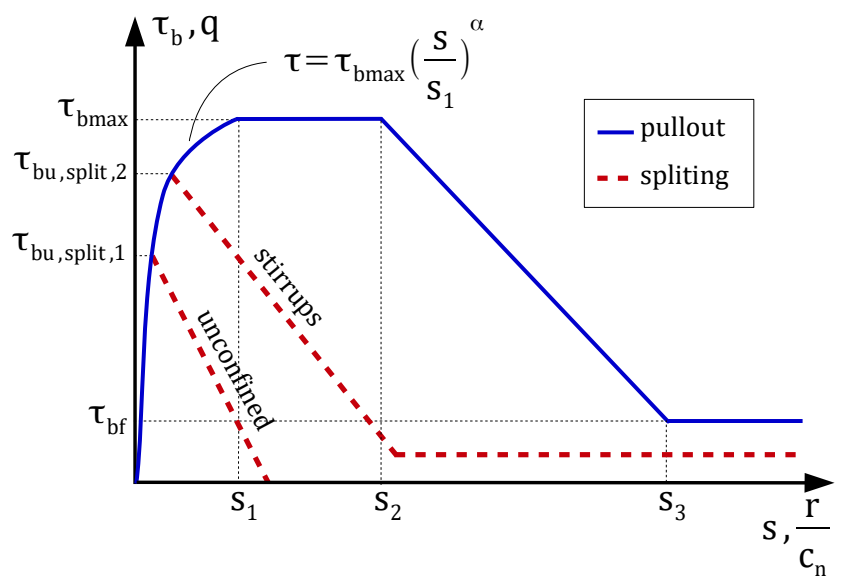

Figure 2.4.: Interface stress bond-slip relationship (monotonic loading) proposed by fib Model Code 2010 (2013). 


\subsubsection{Concrete-steel fiber interaction}

To describe the concrete-fiber interaction, the bond slip law for hooked-end steel fibers suggested by Cunha (2010) and illustrated in Figure 2.5 is adopted. This law is described by the following equations:

$$
\tau(s)=\left\{\begin{array}{ccc}
\tau_{\max }\left(\frac{s}{s_{1}}\right)^{\alpha} & \text { if } & s \leq s_{1} \\
\tau_{\max }-\frac{\left(\tau_{\max }-\tau_{f}\right)\left(s-s_{1}\right)}{s_{2}-s_{1}} & \text { if } & s_{1} \leq s \leq s_{2} \\
\tau_{f} & \text { if } & s>s_{2}
\end{array},\right.
$$

and the corresponding stress-like stress hardening/softening function $q(r)$ is defined in terms of the strain-like internal variable $r$ as:

$$
q(r)=\left\{\begin{array}{ccc}
\tau_{\max }\left(\frac{r / c_{n}}{s_{1}}\right)^{\alpha} & \text { se } & 0 \leq r / c_{n} \leq s_{1} \\
\tau_{\max }-\frac{\left(\tau_{\max }-\tau_{f}\right)\left(r / c_{n}-s_{1}\right)}{s_{2}-s_{1}} & \text { se } & s_{1} \leq r / c_{n} \leq s_{2} \\
\tau_{f} & \text { se } & r / c_{n}>s_{2}
\end{array} .\right.
$$

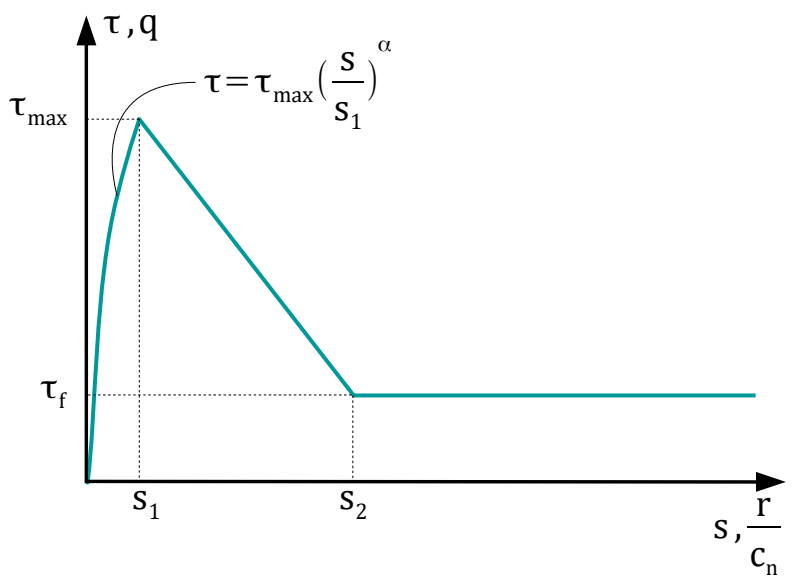

Figure 2.5.: Interface stress bond-slip relationship (monotonic loading).

\subsection{Modeling of reinforcements}

The reinforcements are represented by two-node finite elements (truss finite element) and their behavior is described by the one-dimensional elastoplastic material model. 


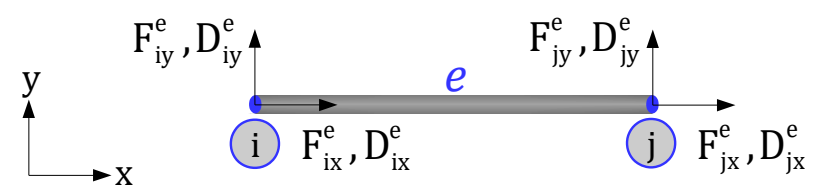

Figure 2.6.: Truss finite element in 2D.

Figure 2.6 illustrates a truss finite element in 2D. This element allows strain only in the direction of its axis (extensional deformation), and as a consequence, its local stiffness matrix and internal force vector are constructed considering only the nodal displacement components in the direction of the element axis (x-direction).

\subsubsection{One-dimensional elastoplastic model}

The one-dimensional elastoplastic material model adopted to describe the behavior of the truss finite elements is depicted in Figure 2.7. As can be seen, this model is composed by a linear elastic branch, followed by a branch with plastic deformation (permanent), after the yield stress $\sigma_{y}$ is reached. The material behavior in this second branch is usually defined as hardening $(H>0)$, perfectly plastic $(H=0)$ or softening $(H<0)$.

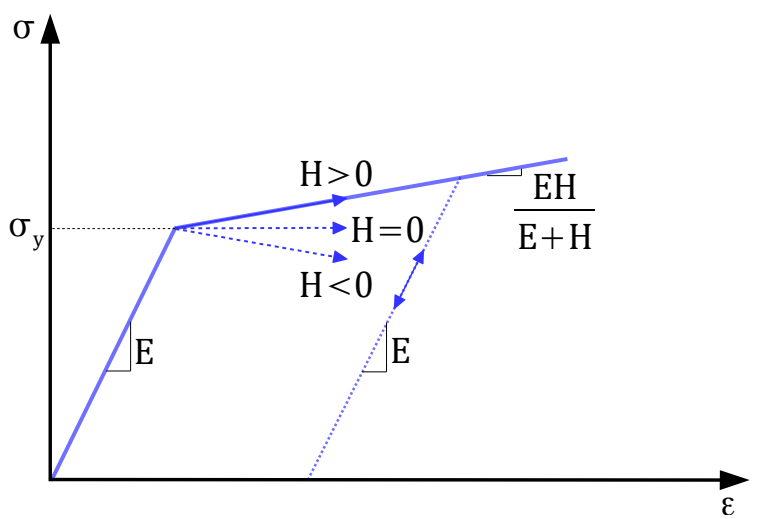

Figure 2.7.: One-dimensional elastoplastic material model (adapted from Bitencourt Jr. (2015)).

A one-dimensional elastoplasticity problem can be defined by five basic components: strain decomposition, $\varepsilon=\varepsilon^{e}+\varepsilon^{p}$, where $\varepsilon^{e}$ is the elastic (reversible) component and $\varepsilon^{p}$ the plastic (permanent) component; an elastic law, $\sigma=E\left(\varepsilon-\varepsilon^{p}\right)=E \varepsilon^{e}$, where $\sigma$ is the stress tensor and $E$ the Young's modulus of the material; a yield criterion, 
$\phi(\sigma, \alpha)=|\sigma|-\sigma_{y}+H \alpha \leq 0$, where $\sigma_{y}$ is the yield stress, $H$ is the hardening modulus and $\alpha$ is the hardening internal variable (which determines the size of the yield surface); a plastic flow rule, $\dot{\varepsilon}^{p}=\dot{\lambda} \operatorname{sign}(\sigma)$, defining the evolution of the plastic strain, where $\dot{\lambda}$ is the plastic multiplier and sign is the signum function defined as 1 for $\sigma \geq 0$ and -1 for $\sigma<0$; and finally by a hardening law, $\dot{\alpha}=\dot{\lambda}$ characterizing the evolution of the yield limit. In addition, the Kuhn-Tucker loading/unloading conditions are applied $\phi(\sigma, q) \leq 0, \quad \dot{\lambda} \geq 0$ and $\dot{\lambda} \phi(\sigma, q)=0$ as well as the consistency condition $\dot{\lambda} \dot{\phi}(\sigma, q)=0$. Regarding the theory of elatoplasticity, a more comprehensive treatment can be found in Simo and Hugles (1998); de Souza Neto et al. (2008).

A summary of integration scheme applying the elastic predictor/plastic corrector algorithm for the one-dimensional elastoplastic material model is given in Table 2.3.

Table 2.3.: Integration scheme for the one-dimensional elastoplastic material model.

INPUT: $\varepsilon_{n+1}, \varepsilon_{n}^{p}, \alpha_{n}$

$\begin{array}{cl}\text { Evaluate the } & \sigma_{n+1}^{\text {trial }}=E\left(\varepsilon_{n+1}-\varepsilon_{n}^{p}\right) \\ \text { elastic trial } & \varepsilon_{n+1}^{p \text { trial }}=\varepsilon_{n}^{p} \\ \text { state } & \alpha_{n+1}^{\text {trial }}=\alpha_{n}\end{array}$

Evaluate the yield criterion

$$
\phi_{n+1}^{\text {trial }}=\left|\sigma_{n+1}^{\text {trial }}\right|-\left(\sigma_{y}+H \alpha_{n}\right) \leq 0
$$

if true (elastic predictor)

$$
\begin{aligned}
& \sigma_{n+1}=\sigma_{n+1}^{\text {trial }} \\
& \varepsilon_{n+1}^{p}=\varepsilon_{n+1}^{\text {trial }} \\
& \alpha_{n+1}=\alpha_{n+1}^{\text {trial }}
\end{aligned}
$$

else (plastic corrector)

$$
\begin{aligned}
& \Delta \lambda=\phi_{n+1}^{\text {trial }} /(E+H) \\
& \sigma_{n+1}=\sigma_{n+1}^{\text {trial }}-\Delta \lambda E \operatorname{sign}\left(\sigma_{\mathrm{n}+1}^{\text {trial }}\right) \\
& \varepsilon_{n+1}^{p}=\varepsilon_{n}^{p}+\Delta \lambda \operatorname{sign}\left(\sigma_{\mathrm{n}+1}^{\text {trial }}\right) \\
& \alpha_{n+1}=\alpha_{n}+\Delta \lambda
\end{aligned}
$$


OUTPUT: $\sigma_{n+1}, \varepsilon_{n+1}, \varepsilon_{n+1}^{p}, \alpha_{n+1}$

$\begin{array}{ll}\text { Compute the } & E_{n+1}^{\text {tang }}=\partial \sigma_{n+1} / \partial \varepsilon_{n+1} \\ \begin{array}{c}\text { consistent } \\ \text { tangent }\end{array} & = \begin{cases}E & \text { (elastic and unloading) } \\ E H /(E+H) & \text { (plastic loading) }\end{cases} \end{array}$

To find an approximate solution for the one-dimensional elastoplastic problem, the implicit backward-Euler method is applied in a two-step algorithm that involves the elastic predictor and the plastic corrector (return mapping). The use of a two-step algorithm is related to the presence of the plastic (irreversible) response and its mathematical modeling through the Kuhn-Tucker conditions and the consistency condition. First, a purely elastic (trial) step is assumed by freezing plastic flow (incremental plastic multiplier $\Delta \lambda=0$ ), which is not necessarily the actual solution, and the elastic stress trial state is computed as in Eq. 2.25 in terms of the elastic stress trial state $\sigma_{n+1}^{\text {trial }}$, for a total strain $\varepsilon_{n+1}$ at the current pseudo-time, $t_{n+1}$, and the plastic strain $\varepsilon_{n}^{p}$ at the previously pseudo-time $t_{n}$; as well as the trial plastic strain $\varepsilon_{n+1}^{p \text { trial }}$ and hardening internal variable $\alpha_{n+1}^{\text {trial }}$. Then, the yield trial criterion, $\phi_{n+1}^{\text {trial }}$, is evaluated according to Eq. 2.26 to check if the elastic trial state lies within the elastic domain or on the yield surface, for $\phi_{n+1}^{\text {trial }} \leq 0$ it corresponds that an elastic/unloading state has taken place and $(\cdot)_{n+1}=(\cdot)_{n+1}^{\text {trial }}$ is updated. Otherwise, $\phi_{n+1}^{\text {trial }}>0$ characterizes the plastic step $(\Delta \lambda>0)$ and the the values of incremental plastic multiplier $\Delta \lambda$, stress $\sigma_{n+1}$, plastic strain $\varepsilon_{n+1}^{p}$ and hardening internal variable $\alpha_{n+1}$ is calculated (Eq. 2.26) considering the plastic deformation.

Note that for the case in which the elastic trial stress $\sigma_{n+1}^{\text {trial }}$ lies outside the plastically admissible domain $\left(\sigma_{n+1}^{\text {trial }}>0\right)$, which violates one of the Kuhn-Tucker conditions, the calculation of the $\sigma_{n+1}$ for the plastic step ensures that at the end of the current step $t_{n+1}$ the stress values lies on the updated yield surface, for the case of perfectplastic $\sigma_{n+1}^{\text {trial }}$ returns to a fixed surface.

Furthermore, Eq. 2.27 presents the consistent tangent modulus for the two considered cases: elastic or unloading and plastic loading scheme. 


\subsubsection{Steel fiber distribution}

The algorithm proposed by Bitencourt Jr. (2015) for generation of uniform isotropic random distribution of fibers has been extended in this work to consider an arbitrary geometry by using the concrete finite element mesh as reference. The pseudo code of the algorithm implemented in MATLAB language is shown in Figure 2.8.

This code reads the input data from a file containing the concrete mesh information to define the geometry of the specimen. In addition, the parameters of the composite, such as the number of fibers $N_{F}$ and the length of a fiber $l_{F}$ are defined. Then, the procedure for fiber generation follows as described in Figure 2.8.

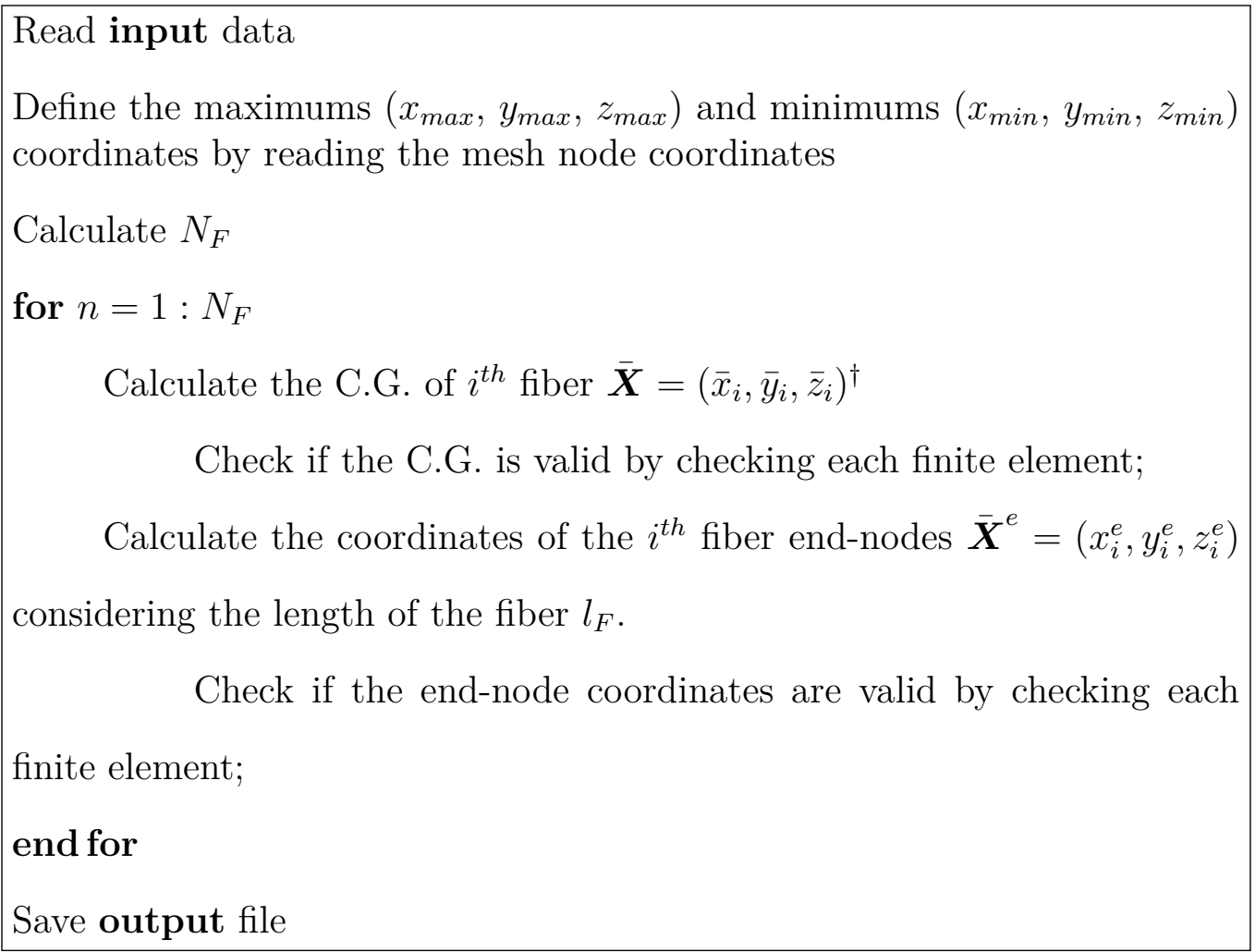

Figure 2.8.: Pseudo code of the algorithm developed for generating steel fibers in a random geometry.

${ }^{\dagger} \overline{\boldsymbol{X}}=\left(\bar{x}_{i}, \bar{y}_{i}, \bar{z}_{i}\right)$ is the position center of gravity (C.G.) of each fiber $i^{\text {th }}$ and is 
computed the following equations:

$$
\begin{aligned}
& \bar{x}_{i}=x_{\text {min }}+\eta_{x}\left(x_{\text {max }}-x_{\text {min }}\right) \\
& \bar{y}_{i}=y_{\text {min }}+\eta_{y}\left(y_{\max }-y_{\text {min }}\right) \\
& \bar{z}_{i}=z_{\text {min }}+\eta_{z}\left(z_{\max }-z_{\text {min }}\right)
\end{aligned}
$$

where, $\eta_{x}, \eta_{y}$ and $\eta_{z}$, are three numbers randomly generated between 0 and 1 .

Figure 2.9 illustrate the generation of fibers in 3D and its projection on a plane.

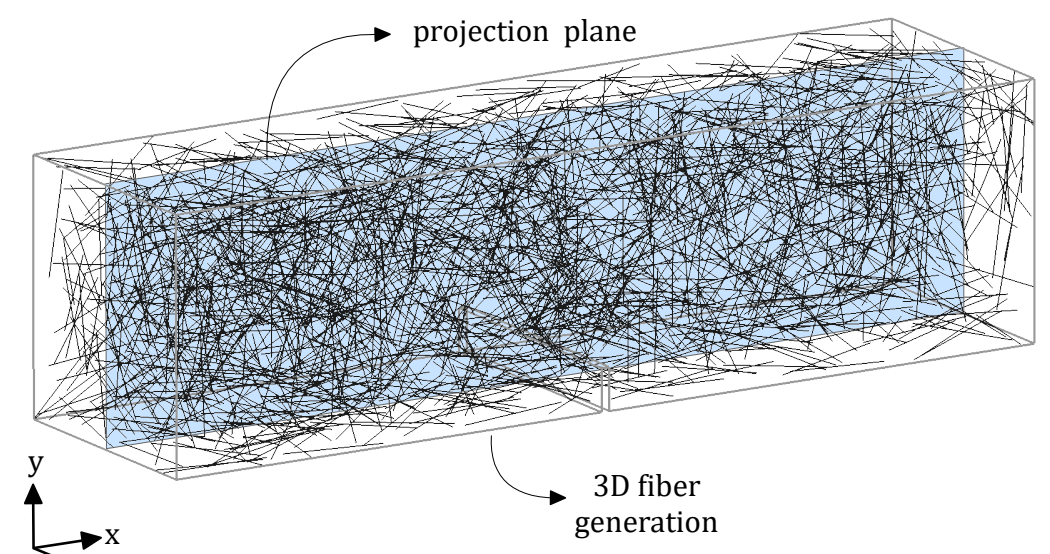

(a)

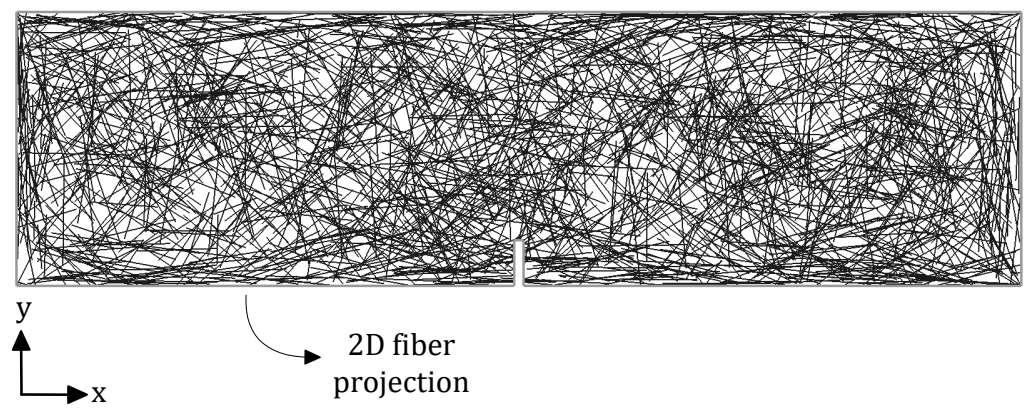

(b)

Figure 2.9.: Generation of fibers: (a) 3D distribution and (b) projection of the fibers onto a plane. 


\subsection{Modeling of concrete}

\subsubsection{Damage model with two independent damage variables (Cerveral et al., 1996)}

To describe the crack initiation and propagation in concrete, the rate-independent version of the constitutive model based on the Continuum Damage Mechanics Theory (CDMT) proposed by Cervera et al. (1996) was used. To describe distinct responses of the material when submitted to tension or compression, its ingredients such as damage variable, damage criterion, equivalent stress, and damage evolution rule, are defined separately, with the aid of the indices $(+)$ and $(-)$, for tension and compression, respectively.

In order to avoid problem of convergence, a modified Impl-EX integration scheme is used for the integration of the damage constitutive model described above and the main ingredients are described in Table 2.5. The main difference between the ImplEX integration scheme developed by Oliver et al. (2008) and the modified Impl-EX (Prazeres et al., 2015) is related to the choice of the internal variable to be updated, while the first uses the internal strain-like variable $r$, the second uses the inelastic strain tensor $\varepsilon^{d}$, which results a constant tangent constitutive matrix $C^{\text {tang }}$.

Table 2.5.: Impl-EX integration scheme for the continuum damage model with two damage variables .

INPUT: $\varepsilon_{n+1}, \varepsilon_{n}^{d}, \Delta \varepsilon_{n}^{d}, r_{n}^{+}, r_{n}^{-}$

Evaluate the

effective stress tensor

$$
\overline{\boldsymbol{\sigma}}_{n+1}=\mathbf{C}: \boldsymbol{\varepsilon}_{n+1}
$$

Split the effective

$$
\overline{\boldsymbol{\sigma}}_{n+1}=\overline{\boldsymbol{\sigma}}_{n+1}^{+}+\overline{\boldsymbol{\sigma}}_{n+1}^{-}=
$$

stress tensor

$$
\begin{array}{lc}
\overline{\boldsymbol{\sigma}}^{+}=\langle\overline{\boldsymbol{\sigma}}\rangle=\sum_{i=1}^{3}\left\langle\overline{\boldsymbol{\sigma}}_{i}\right\rangle \boldsymbol{p}_{i} \otimes \boldsymbol{p}_{i} & \text { (tensile) } \\
\overline{\boldsymbol{\sigma}}^{-}=\overline{\boldsymbol{\sigma}}-\overline{\boldsymbol{\sigma}}^{+} & \text {(compression) }
\end{array}
$$


Equivalent effective

$$
\begin{array}{ccc}
\overline{\boldsymbol{\tau}}_{n+1}^{+}=\sqrt{\overline{\boldsymbol{\sigma}}^{+}: \mathbf{C}^{-\mathbf{1}}: \overline{\boldsymbol{\sigma}}^{+}} & \text {(tensile) } \\
\overline{\boldsymbol{\tau}}_{n+1}^{-}=\sqrt{\sqrt{3}\left(K \bar{\sigma}_{\text {oct }}^{-}+\bar{\tau}_{\text {oct }}^{-}\right)} & (\text {compression })
\end{array}
$$$$
\text { norms }
$$

Damage criteria and

$$
\bar{\phi}_{n+1}^{+/-}\left(\bar{\tau}_{n+1}^{+/-}, r_{n}^{+/-}\right)=\bar{\tau}_{n+1}^{+/-}-r_{n}^{+/-} \leq 0
$$

calculation of the

if true $r_{n+1}^{+/-}=r_{0}^{+/-}$

strain-like variable

$$
\text { else } r_{n+1}^{+/-}=\bar{\tau}_{n+1}^{+/-}
$$

Calculate the damage variable in

terms of the

strain-like variable

$$
\begin{array}{rlr}
d^{+}= & 1-\frac{r_{0}^{+}}{r_{n+1}^{+}} e^{A^{+}\left(1-\frac{r_{n+1}^{+}}{r_{0}^{+}}\right)} \quad \text { (tensile) } \\
d^{-}= & 1-\frac{r_{0}^{-}}{r_{n+1}^{-}}\left(1-A^{-}\right) & \text {(compression) } \\
& +A^{-} e^{B^{-}\left(1-\frac{r_{n+1}^{-}}{r_{0}^{-}}\right)}
\end{array}
$$

Computation of the

Cauchy stress tensor

$$
\boldsymbol{\sigma}_{n+1}=\left(1-d_{n+1}^{+}\right) \overline{\boldsymbol{\sigma}}_{n+1}^{+}+\left(1-d_{n+1}^{-}\right) \overline{\boldsymbol{\sigma}}_{n+1}^{-}
$$

(implicitly)

Computation of the
inelastic stress
$\boldsymbol{\varepsilon}_{n+1}^{d}=\mathbf{C}^{-1}\left(\overline{\boldsymbol{\sigma}}_{n+1}+\boldsymbol{\sigma}_{n+1}\right)$
tensor and its

$$
\text { and } \Delta \varepsilon_{n+1}^{d}=\varepsilon_{n+1}^{d}-\varepsilon_{n}^{d}
$$
increment
(implicitly) 
Computation of the explicit linear

$$
\begin{gathered}
\tilde{\varepsilon}_{n+1}^{d}=\varepsilon_{n}^{d}+\frac{\Delta \varepsilon_{n}^{d}}{\Delta t_{n}} \Delta t_{n+1} \\
\Delta t_{n+1}=t_{n+1}-t_{n} ; \Delta t_{n}=t_{n}-t_{n-1} ; \\
\Delta \varepsilon_{n}^{d}=\varepsilon_{n}^{d}-\varepsilon_{n-1}^{d}
\end{gathered}
$$$$
\text { inelastic strain }
$$$$
\text { tensor }
$$

Computation of the

stress tensor

$$
\tilde{\boldsymbol{\sigma}}_{n+1}=\mathbf{C}\left(\varepsilon_{n+1}-\tilde{\varepsilon}_{n+1}^{d}\right)
$$

(explicitly)

OUTPUT: $\tilde{\boldsymbol{\sigma}}_{n+1}, \boldsymbol{\varepsilon}_{n+1}^{d}, \Delta \boldsymbol{\varepsilon}_{n+1}^{d}, r_{n+1}^{+}, r_{n+1}^{-}$

Computation of the effective algorithmic tangent operator

$$
\tilde{\mathbf{C}}_{n+1}^{\operatorname{tang}}=\frac{\partial \tilde{\boldsymbol{\sigma}}_{n+1}}{\partial \boldsymbol{\varepsilon}_{n+1}}=\mathbf{C}
$$

First, the implicit stage is performed and the effective stress tensor, $\overline{\boldsymbol{\sigma}}_{n+1}$, for the current pseudo-time step $t_{n+1}$, is evaluated as written in Eq. 2.31, where $\mathbf{C}$ is the fourth order linear-elastic constitutive tensor and $\varepsilon_{n+1}$ is the second order strain tensor. The effective stress tensor is split into the tension, $\overline{\boldsymbol{\sigma}}_{n+1}^{+}$, and compression, $\overline{\boldsymbol{\sigma}}_{n+1}^{+}$contributions according to Eq. 2.32, where $\overline{\boldsymbol{\sigma}}_{i}$ denotes the $i$ th principal stress value from tensor $\overline{\boldsymbol{\sigma}}$ and $\boldsymbol{p}_{i}$ represents the unit vector associated with its respective principal direction. The symbols $\langle\cdot\rangle$ are the Macaulay brackets, giving the value of the enclosed expression when positive, and setting a zero value if negative.

The equivalent effective norms defines the concepts of loading, unloading and reloading conditions and the values for compression $\overline{\boldsymbol{\tau}}_{n+1}^{+}$and tension $\overline{\boldsymbol{\tau}}_{n+1}^{-}$are defined in Eq. 2.33, where the normal octahedral stress $\bar{\sigma}_{\text {oct }}^{-}$is calculated as $\bar{\sigma}_{\text {oct }}^{-}=\frac{1}{3} I_{1}$ and the shear octahedral stress as $\bar{\tau}_{\text {oct }}^{-}=\sqrt{\frac{2}{3} J_{2}}$, where $I_{1}$ is the first invariant of stress tensor and $J_{2}$ is the second invariant of deviatoric stress tensor. $K=\sqrt{2}(\beta-1) /(2 \beta-1)$ is a material property, which depends on the ratio between the biaxial and uniaxial 
compressive strengths of the concrete, $\beta$. According to Cervera et al. (1996), typical values for concrete are $\beta=1.16$ e $K=0.171$.

The damage criteria is verified according to Eq. 2.34 for tension and compression, independently. The strain-like internal variables $r^{+}$and $r^{-}$, which act as the current damage thresholds, being updated continuously to control the size of the expanding damage surface. At the onset of the analysis, the initial value attributed to damage thresholds are $r_{0}^{+}=f_{t}$ and $r_{0}^{-}=f_{c 0}$, where $f_{t}$ is the tensile strength and $f_{c 0}$ the compression stress threshold for damage. The evolution of the damage thresholds can be expressed in a closed form, always using the highest values reached by $\bar{\tau}^{+}$ and $\bar{\tau}^{-}$, during the loading process, i.e., $r^{+}=\max \left(r_{0}^{+}, \bar{\tau}^{+}\right)$and $r^{-}=\max \left(r_{0}^{-}, \bar{\tau}^{-}\right)$. The computation of the implicit damage variables for tension, $d^{+}$, and compression, $d^{-}$, is calculated in Eq. 2.35. The parameters $A^{-}$and $B^{-}$are defined so that the stress-strain curve of the quasi-brittle material satisfies two previously selected points of a uniaxial experimental test. The softening parameter $A^{+}$in Eq. 2.35 defined by the expression $A^{+}=1 /\left((1 / 2 \bar{H})\left(1 / l_{c h}-\bar{H}\right)\right)$, where $\bar{H}=f_{t}^{2} / 2 E G_{f}$ is written in terms of the material tensile strength $f_{t}$, elastic modulus $E$ and fracture energy $G_{f}$. The characteristic length $l_{c s}$ is the square root of the finite element area in $2 \mathrm{D}$ analysis and is limited to $l_{c h} \leq 1 / \bar{H}$.

The Cauchy stress tensor $\boldsymbol{\sigma}_{n+1}$ is computed implicitly according to Eq. 2.36 using the damage variables for tension $\left(d^{+}\right)$and compression $\left(d^{-}\right)$, and the effective stress tensor $\overline{\boldsymbol{\sigma}}_{n+1}^{+/-}$. Then, in Eq. 2.37 the inelastic stress tensor $\varepsilon_{n+1}^{d}$ and its increment $\Delta \varepsilon_{n+1}^{d}$ are calculated.

Second, an explicit linear extrapolated computation of the inelastic strain tensor $\tilde{\varepsilon}_{n+1}^{d}$ is performed using the implicit values $\left(\varepsilon_{n-1}^{d}\right.$ and $\left.\varepsilon_{n}^{d}\right)$ obtained in the previous time steps, $t_{n-1}$ and $t_{n}$, as demonstrated in Eq. 2.38. Furthermore, the stress tensor $\tilde{\boldsymbol{\sigma}}_{n+1}$ is obtained explicitly using Eq. 2.39 and applied to compute the effective algorithmic tangent operator according to Eq. 2.40.

\subsection{Programs employed for numerical simulations}

The numerical analyses are performed in three stages: preprocessing, processing and postprocessing. At the pre and postprocessing stages, the program GiD ${ }^{\complement}$ (CIMNE) is used to create the numerical model and visualize the results of the analyses, respectively. In the preprocessing stage, two more programs are used: a program 
to generate a cloud of fibers and other to couple the concrete and reinforcements meshes, both developed in MATLAB ${ }^{\circledR}$ language. The numerical approach for modeling RC-SFRC beams was implemented in MATLAB ${ }^{\circledR}$ language in a program based on the finite element method. The solver reads the input file (or neutral file) generated in the preprocessing stage that contains all the information of the problem. After the numerical analysis, an output file is created to be read in the postprocessing stage in order to visualize the responses. The steps of a numerical analyses and the integration between the programs employed are depicted in Figure 2.10.

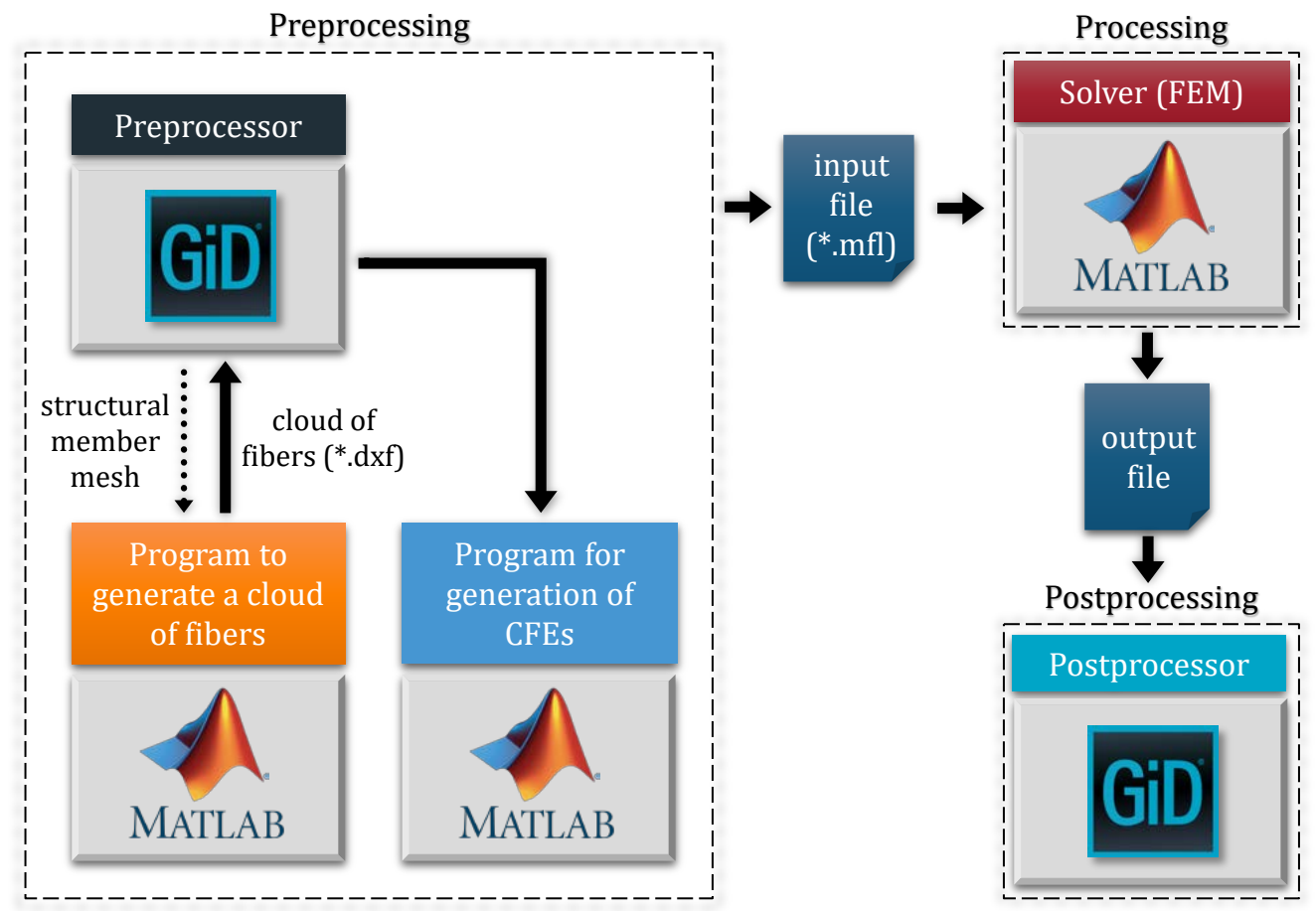

Figure 2.10.: Numerical analysis using the computational platform. 


\section{Design of RC-SFRC beams according to fib Model Code 2010}

The fib Model Code 2010 (2013) (MC2010) provides a guideline to design steel fiber reinforced concrete structural members at Serviceability Limit State (SLS) and Ultimate Limit State (ULS). At SLS, fibers are introduced to improve structure durability by reducing crack width and crack spacing, while at ULS, the fibers can replace partially, or even totally the conventional reinforcement.

The first step in the design of beams reinforced with steel fibers comprises the characterization of the material behavior in tension. In this sense, three-point bending test on a notched beam according to EN 14651 (2005) test is recommend by MC2010, as the standard test to obtain the material performance parameters, and consequently, to define the material class and its post-cracking constitutive law.

Once the material post-cracking behavior is defined, the structural member design have to be performed in terms of ULS and SLS, fulfilling the following condition:

$$
E_{d}<R_{d}
$$

where $E_{d}$ denotes the design action-effect and $R_{d}$ the design resistance. At ULS, beams are designed for bending moment and shear forces, taking account the Steel Fiber Reinforced Concrete (SFRC) behavior. Additionally, for the SLS, the main design principles are: the limit state of cracking $w_{d} \leq w_{l i m}$ and the limit state of deflection $\delta_{d} \leq \delta_{\text {lim }}$, where $w_{d}$ is the designed crack width, $w_{\text {lim }}$ is the limit value of crack width, $\delta_{d}$ is the designed deflection and $\delta_{\text {lim }}$ is the limit value of the deflection considered. Figure 3.1 summarizes the main steps in the design of beams reinforced with steel fibers according to MC2010. 


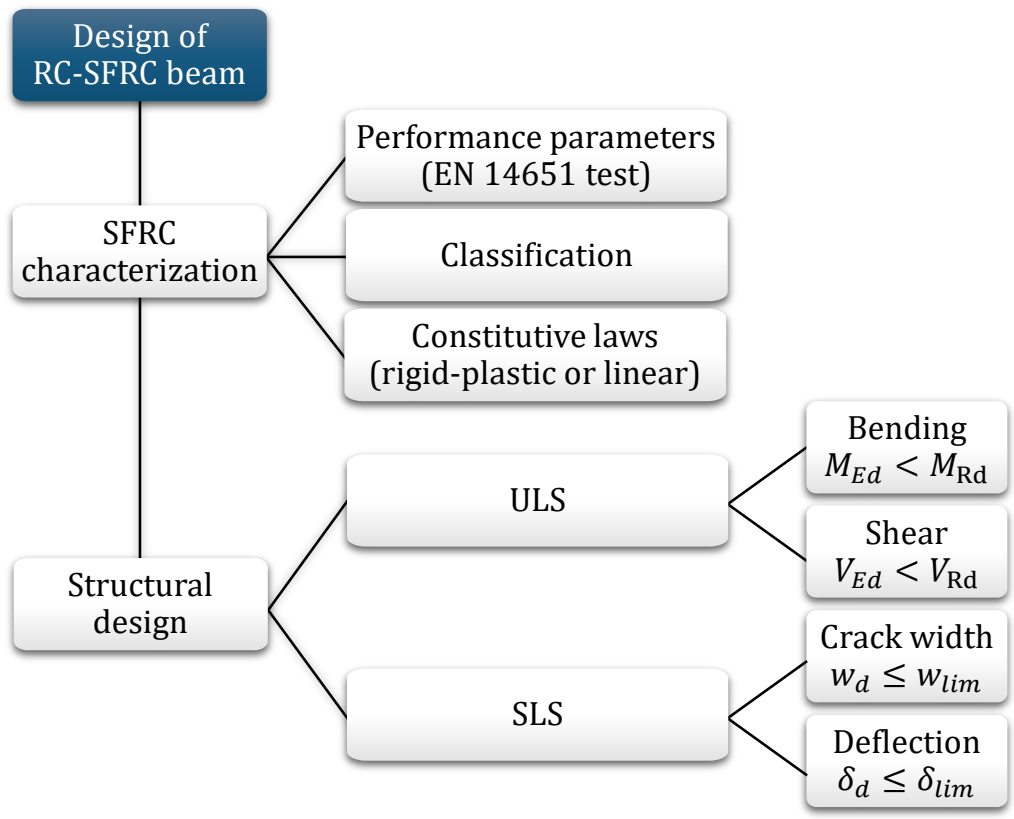

Figure 3.1.: Main steps in the design of beams reinforced with fibers according to MC2010.

\subsection{SFRC characterization}

The use of SFRC as a structural material requires a minimum mechanical performance. According to MC2010, under compression, the SFRC behavior can be described by the same relations usually applied to plain concrete. This assumption is reasonable in this research, since according to di Prisco et al. (2013a), the addition of fibers to concrete does not significantly change the compressive strength for a volume fraction up to $1 \%$ (approximately a fiber content of $80 \mathrm{~kg} / \mathrm{m}^{3}$ ).

The main mechanical property of SFRC is related to the residual post-cracking tensile strength, in witch the composite exhibits a strain hardening, by increasing the load capacity after the first crack, or strain softening behavior, by decreasing the load capacity after the first crack. The SFRC tensile response can be obtained straightforward by carrying out a uniaxial tensile test. However, due to the experimental difficulties related to perform this test, alternative indirect test methods are usually needed to characterize the SFRC performance. Thus, the three-point bending test (3-PBT) according to EN 14651 (2005) test is recommend by the MC2010 as standard test to obtain a stress crack opening relation $(\sigma-w)$ by inverse analysis. Furthermore, due to the difference between uniaxial tensile test and bending test, 
it is possible that a softening behavior in tension may exhibit a hardening behavior in bending. For this reason, when a composite with strain hardening is required by the design, a uniaxial tensile test on unnotched specimens must be performed ( $f i b$ Model Code 2010, 2013).

\subsubsection{Performance parameters based on EN 14651}

The tension performance parameters of SFRC are determined according to the European Standard EN 14651 (2005) test by using a 3-PBT on notched prisms with a $500 \mathrm{~mm}$ span, 150x150 $\mathrm{mm}^{2}$ cross-section and a notch $25 \mathrm{~mm}$ deep located at midspan of the beam, as illustrated in Figure 3.2. Based on this test, a curve of applied force $(\mathrm{F})$ versus deformation is produced, being the deformation usually expressed in terms of Crack Mouth Opening Displacement (CMOD), which corresponds to the opening of the notch at the bottom face of the beam (see Figure 3.2). A typical F vs. CMOD curve for SFRC is depicted in Figure 3.3.

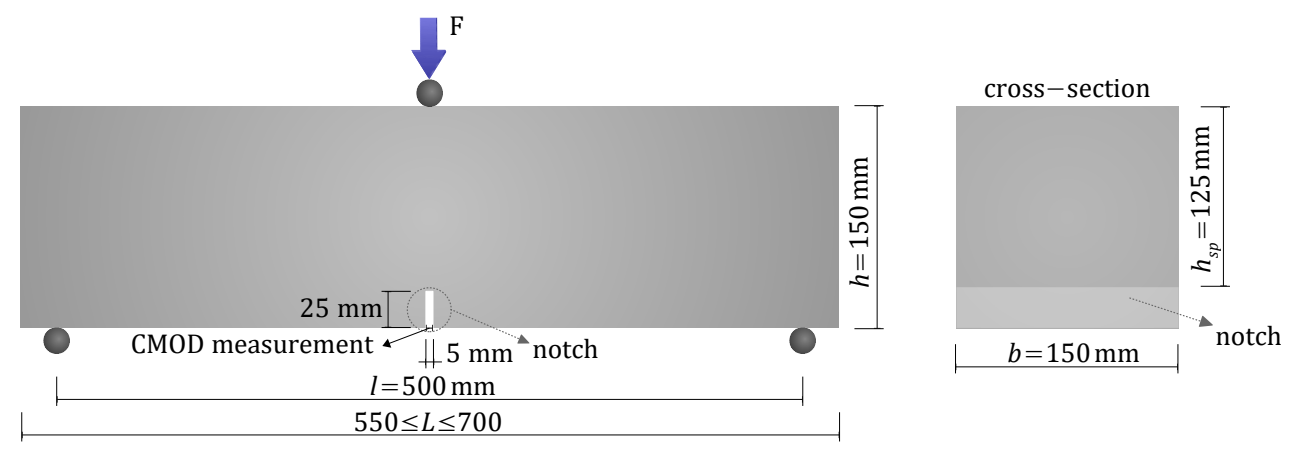

Figure 3.2.: Typical arrangement of the three-point bending test according to EN 14651.

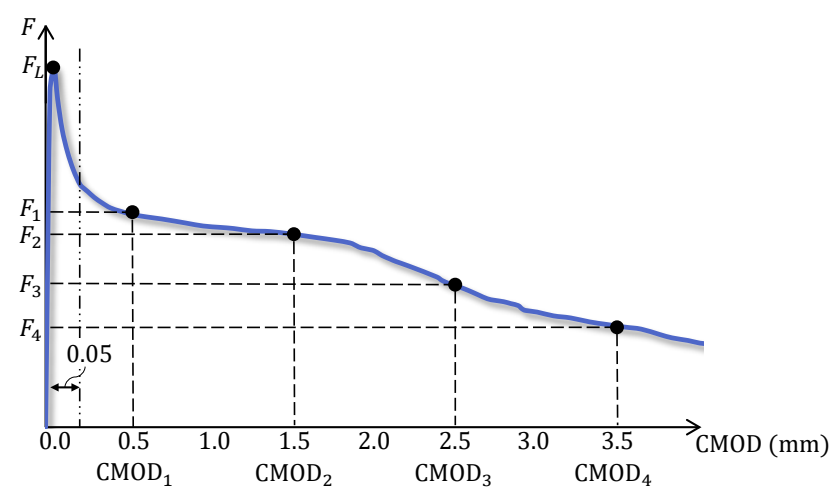

Figure 3.3.: Typical load vs. CMOD curve for SFRC according to EN 14651. 
In this way, by assuming an uncracked mid-span section and a linear stress distribution, as shown in Figure 3.4, the performance in tension of SFRC must be expressed in terms of residual flexural tensile strength $f_{R, j}(j=1,2,3,4)$ corresponding to $\mathrm{CMOD}_{\mathrm{j}}\left(\mathrm{CMOD}_{1}=0.5 \mathrm{~mm}, \mathrm{CMOD}_{2}=1.5 \mathrm{~mm}, \mathrm{CMOD}_{3}=2.5 \mathrm{~mm}\right.$ and $\mathrm{CMOD}_{1}=3.5 \mathrm{~mm}$ ) by the following equation:

$$
f_{R, j}=\frac{M_{j} \cdot y}{I}=\frac{\left(\frac{F_{j} \cdot l}{4}\right) \cdot\left(\frac{h_{s p}}{2}\right)}{\frac{b \cdot h_{s p}^{3}}{12}}=\frac{3 F_{j} l}{2 b h_{s p}^{2}}
$$

where, $M_{j}$ is the bending moment at mid-span of the test specimen corresponding to the central point load $F_{j}, y$ is the distance between the tip of the notch and the neutral axis, $I$ is the moment of inertia, $l$ is the span length, $b$ is the width and $h_{s p}$ is the distance between the tip of the notch and the top of the beam in the mid-span section.

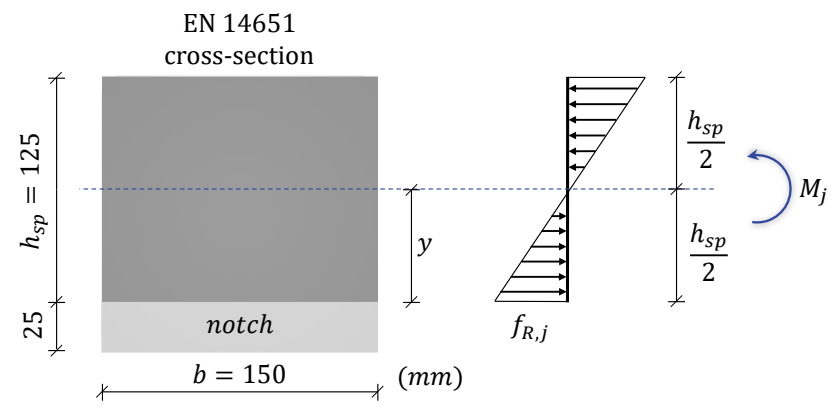

Figure 3.4.: Linear stress distribution in the mid-span section of the beam..

The limit of proportionality $f_{L}$ is another important performance parameter used in the SFRC design to verify the possibility in substitute (totally or partially) the conventional reinforcement by fibers (see Section 3.3) and can be determined by applying the following equation:

$$
f_{L}=\frac{3 F_{L} l}{2 b h_{s p}^{2}}
$$

where $F_{L}$ is the highest value load between $0 \leq \mathrm{CMOD} \leq 0.05 \mathrm{~mm}$, as illustrated in Figure 3.5. 


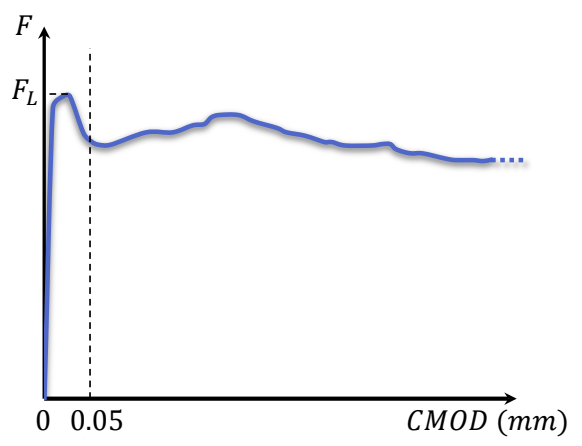

Figure 3.5.: Definition of $F_{L}$ from $F$ vs. CMOD curve (adapted from EN 14651 $(2005))$.

In this research only the 3-PBT proposed by EN 14651 (2005) test is used to obtain the performance parameters of SFRC, however, the MC2010 also allows other tests if correlation factors with parameters EN 14651 are proven.

\subsubsection{Classification}

In MC2010 the parameters adopted to classify the post-cracking behavior and to design SFRC are based on the characteristic residual flexural tensile strengths: $f_{R 1 k}$ (corresponding to $\mathrm{CMOD}_{1}=0.5 \mathrm{~mm}$ ) and $f_{R 3 k}$ (corresponding to $\mathrm{CMOD}_{3}=$ $2.5 \mathrm{~mm}$ ), which are significant for the design at SLS and ULS, respectively.

The first parameter is defined by the strength interval based on $f_{R 1 k}$ value as shown in Figure 3.6. The residual strength ratio $f_{R 3 k} / f_{R 1 k}$ defines the second parameter represented by a letter $(a, b, c, d$ and $e$ ) according to Figure 3.7. Therefore, a SFRC " $4 c$ " has $4 \mathrm{MPa} \leq f_{R 1 k}<5 \mathrm{MPa}$ and $0.9 \leq f_{R 3 k} / f_{R 1 k}<1.1$.

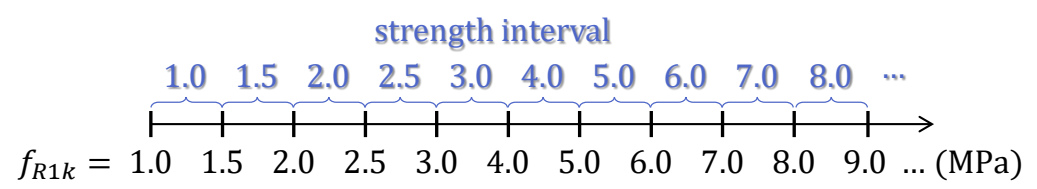

Figure 3.6.: Definition of the first parameter defined by the strength interval based on $f_{R 1 k}$.

\subsubsection{Constitutive laws for post-cracking behavior}

The MC2010 proposes two simplified uniaxial constitutive laws (stress vs. crack opening) deduced from the bending test results: a rigid plastic model and a linear 


\begin{tabular}{|c|c|c|c|}
\hline Class & $f_{R 3 k} / f_{R 1 k}$ & \multicolumn{2}{|r|}{$f_{P 3 k}=1.3 f_{P 1 k}$} \\
\hline$a$ & $0.5 \leq \frac{f_{R 3 k}}{f_{R 1 k}}<0.7$ & & 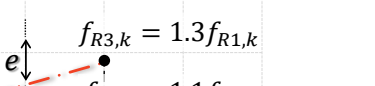 \\
\hline$b$ & $0.7 \leq \frac{f_{R 3 k}}{f_{R 1 k}}<0.9$ & $f_{R 1, k}$ & \\
\hline$c$ & $0.9 \leq \frac{f_{R 3 k}}{f_{R 1 k}}<1.1$ & & \\
\hline$d$ & $1.1 \leq \frac{f_{R 3 k}}{f_{R 1 k}}<1.3$ & & \\
\hline$e$ & $1.3 \leq \frac{f_{R 3 k}}{f_{R 1 k}}$ & \begin{tabular}{|l|} 
\\
$C M O D_{1}=0.5$
\end{tabular} & $\frac{\vdots}{\mathrm{CMOD}_{3}=2.5 \quad C M O D}(\mathrm{~mm})$ \\
\hline
\end{tabular}

Figure 3.7.: Definition of the second parameter based on residual strength ratio $f_{R 3 k} / f_{R 1 k}$.

post-cracking model, as illustrated in Figure 3.8(a) and (b), respectively. In this figure, $f_{F t s}$ is the serviceability residual strength defined for a crack opening representative for SLS, while $f_{F t u}$ is the ultimate residual strength corresponding to a ultimate crack opening $w_{u}$. In addition, the values of $f_{F t s}$ and $f_{F t u}$ are calculated by adopting the residual flexural tensile strengths $f_{R 1}$ and $f_{R 3}$ according to Section 3.1.1.

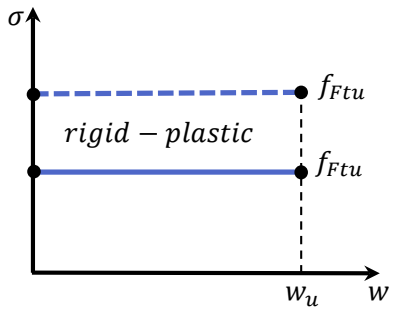

(a)

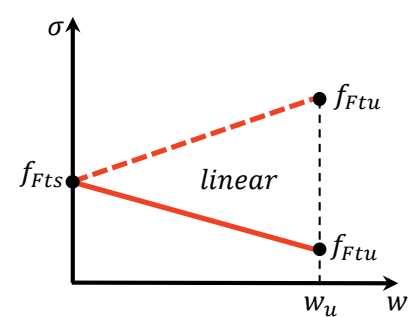

(b)

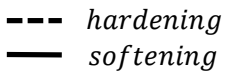

softening

Figure 3.8.: Simplified constitutive laws (stress vs. crack opening): (a) rigidplastic model and (b) linear model.

\subsubsection{Rigid plastic model}

The value of ultimate residual tensile strength $f_{F t u}$ is sufficient to define the rigidplastic model depicted in Figure 3.8(a) and is determined as:

$$
f_{F t u}=\frac{f_{R 3}}{3}
$$

where $f_{R 3}$ is the residual flexural tensile strength corresponding to $\mathrm{CMOD}_{3}=$ $2.5 \mathrm{~mm}$.

The assumptions adopted to deduce the rigid-plastic model are described in Section A.1. 


\subsubsection{Linear model}

As illustrated in Figure 3.8(b), the linear model requires the identification of two reference values: serviceability residual strength $f_{F t s}$ and ultimate residual strength $f_{\text {Ftu }}$, which are defined through residual values of flexural strength by using the following expressions:

$$
\begin{aligned}
& f_{F t s}=0.45 f_{R 1} \\
& f_{F t u}=f_{F t s}-\frac{w_{u}}{\mathrm{CMOD}_{3}}\left(f_{F t s}-0.5 f_{R 3}+0.2 f_{R 1}\right) \geq 0
\end{aligned}
$$

where $w_{u}$ is the maximum crack opening and depends on the ductility required.

The values that the ultimate residual strength $f_{F t u}$ can assume for the linear model by varying the ultimate crack opening $w_{u}$ are depicted in Figure 3.9. Furthermore, the assumptions adopted to deduce this model is described in Section A.1.

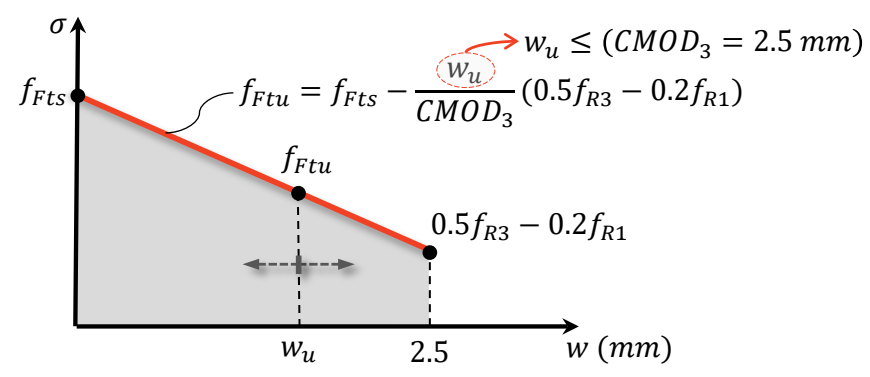

Figure 3.9.: Stress-crack opening graph for linear post-cracking constitutive model (adapted from fib Model Code 2010 (2013)).

\subsubsection{Constitutive laws for numerical analyses}

As recommended by MC2010, a more advanced constitutive law that takes into account the pre-peak stage and is defined by stress vs. strain $(\sigma-\varepsilon)$ law is required to perform a numerical analysis, specially in the framework by using smeared crack models.

For softening materials, the strain, $\varepsilon$, is obtained by the definition of the crack width, $w$, and the corresponding structural characteristic length, $l_{c s}$, according to 
the following expression:

$$
\varepsilon=w / l_{c s}
$$

This concept, initially proposed by Hillerborg et al. (1976), connects continuous mechanics, which is governed by a stress-strain constitutive law $(\sigma-\varepsilon)$, to fracture mechanics, governed by stress-crack opening relation $(\sigma-w)$.

For SFRC, the ultimate crack opening $w_{u}$ is calculated as:

$$
w_{u}=l_{c s} \cdot \varepsilon_{F u} \leq 2.5 \mathrm{~mm}
$$

where $\varepsilon_{F u}$ value depends on the strain distribution along the cross-section:

$$
\varepsilon_{F u}= \begin{cases}2 \% & \text { for a neutral axis crossing the cross section } \\ 1 \% & \text { for a neutral axis external to the cross section }\end{cases}
$$

and the structural characteristic length $l_{c s}$ is defined as:

$$
l_{c s}=\min \left\{s_{r m}, y\right\}
$$

The mean distance between cracks, $s_{r m}$, is not explicitly mentioned in MC2010. Hence, in this work the relation deduced by Tiberti et al. (2014) is used:

$$
s_{r m}=1.17 \cdot l_{s, \max }
$$

where $l_{s, \max }$ is calculated according to Eq. 3.31 and $y$ is the distance between the neutral axis and the tensile side of the cross section, evaluated at SLS in the cracked phase by neglecting the tensile strength of SFRC for structural elements with conventional reinforcement (see Figure 3.10(a)) and for sections without traditional reinforcement under bending or under combined tensile-flexural or compressivelflexural forces with resulting force external to the section $y=h$ can be assumed, where $h$ is the section height as illustrated in Figure 3.10(b).

For hardening materials, an uniaxial tensile test in unnotched specimens must be performed to characterize the material behavior. Therefore, the definition of crack opening is not necessary, since the strain can be determined directly by the test.

In addition, SFRC is considered a hardening strain material when shows a tension 


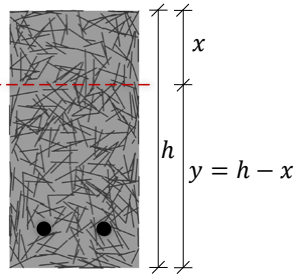

(a)

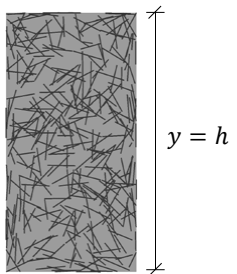

(b)

Figure 3.10.: Definition of the parameter $y$ for SFRC sections (a) with traditional reinforcement and (b) without traditional reinforcement.

behavior up to $1 \%$ and the value of $\varepsilon_{F u}$ depends on the strain distribution along the cross-section and assumes the sames values as given in Eq.3.9 for softening materials.

\subsection{Basic aspects for structural design}

Structural design requires the use of the partial safety factors to calculate the design strengths and to satisfy the minimum structural requirements recommended by fib Model Code 2010 (2013).

\subsubsection{Partial safety factors}

The design strengths and partial safety factors for SFRC at SLS and ULS are listed in Table 3.1.

Table 3.1.: Design strengths and partial safety factors for SFRC.

\begin{tabular}{|c|c|c|c|c|}
\hline & \multirow{3}{*}{ Design strengths } & \multicolumn{3}{|c|}{ Partial safety factors $(\gamma)$} \\
\hline & & \multicolumn{2}{|c|}{ ULS } & \multirow[b]{2}{*}{ SLS } \\
\hline & & $\begin{array}{c}\text { persistent } \\
\text { and transient } \\
\text { situations }\end{array}$ & $\begin{array}{l}\text { accidental } \\
\text { situations }\end{array}$ & \\
\hline $\begin{array}{c}\text { SFRC in } \\
\text { compression }\end{array}$ & \multirow[t]{2}{*}{$f_{F t u d}=f_{F t u k} / \gamma_{F}$} & $\begin{array}{l}\text { As plain } \\
\text { concrete }\end{array}$ & \multirow{2}{*}{$\begin{array}{l}\text { As plain } \\
\text { concrete } \\
(1.2)\end{array}$} & \multirow{2}{*}{1.0} \\
\hline $\begin{array}{l}\text { SFRC in tension } \\
\text { (limit of linearity) }\end{array}$ & & $(1.5)$ & & \\
\hline $\begin{array}{l}\text { SFRC in tension } \\
\text { (residual strength) }\end{array}$ & $f_{F t s d}=f_{F t s k} / \gamma_{F}$ & & & \\
\hline
\end{tabular}


A value of $\gamma_{F} \geq 1.3$ can be adopted if improved control procedures is applied for SFRC.

\subsubsection{Minimum requirements}

\subsubsection{Bending}

- SFRC with minimum conventional reinforcement

The ductility requirement in bending is satisfied when a minimum conventional reinforcement is adopted. Thus, the minimum area of longitudinal reinforcement must be:

$$
A_{s, \min } \geq 0.26 \frac{f_{c t m}}{f_{y k}} b_{w} d
$$

where $f_{c t m}$ is the mean value of tensile strength of concrete; $f_{y k}$ is the characteristic value of yield strength of reinforcing steel ; $b_{w}$ is the width of web and $d$ is the effective depth to main tension reinforcement

- SFRC without minimum conventional reinforcement

To consider structural members without minimum conventional reinforcement, the following condition must be satisfied:

$$
\delta_{u} \geq 20 \delta_{S L S} \quad \text { and } \quad \delta_{\text {peak }} \geq 5 \delta_{S L S}
$$

where $\delta_{u}$ is the ultimate displacement or the structure maximum deformation; $\delta_{\text {peak }}$ is the displacement at the maximum load; $\delta_{S L S}$ is the displacement for the maximum serviceability load calculated by considering a linear analysis and assuming an uncracked concrete and initial elastic modulus. In addition, the ultimate load $P_{u}$ has to be higher than the load at the first crack $P_{c r}$ and higher than the maximum serviceability load $P_{S L S}$ (see Figure 3.11). 


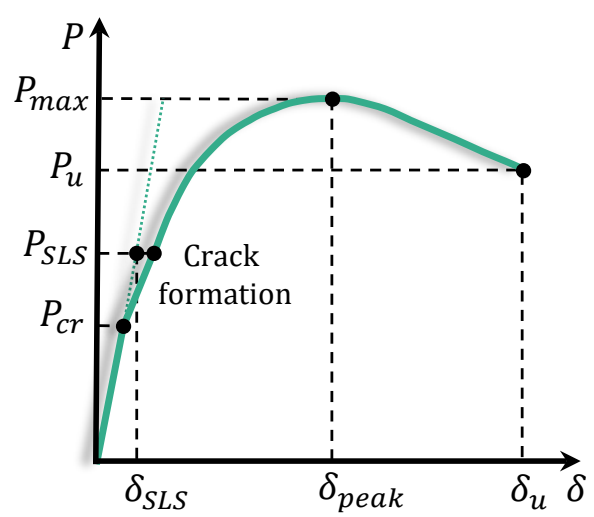

Figure 3.11.: Typical curve of load $P$ vs. displacement $\delta$ for FRC structure (MC2010).

\subsubsection{Shear}

A minimum shear reinforcement should be provided by either fibers or stirrups. Conventional shear reinforcements (stirrups) are not required for SFRC structural members if the following condition is fulfilled:

$$
f_{\text {Ftuk }} \geq 0.08 \sqrt{f_{c k}}
$$

where $f_{F t u k}$ is the characteristic value of the ultimate residual tensile strength for SFRC, calculated according to Eq. 3.6 by considering $w_{u}=1.5 \mathrm{~mm}$.

Otherwise, conventional shear reinforcement (stirrups) must be considered and the minimum area of shear reinforcement must be:

$$
A_{s w, \min } \geq 0.08 \sqrt{f_{c k}} \frac{b_{w} s_{w}}{f_{y k}}
$$

The SFRC shear resistance $V_{R d, F}$ is assumed to be not smaller than the minimum value, $V_{R d, F m i n}$ :

$$
V_{R d, F \min }=\left\{0.035 \cdot k^{3 / 2} \cdot f_{c k}^{1 / 2}+0.15 \cdot \sigma_{c p}\right\} \cdot b_{w} \cdot d
$$

\subsubsection{Stress limitation at SLS}

In structural SFRC structural member having a tension softening behavior after cracking, the tensile stress verification is not necessary if the member is verified at 
the ULS, while having a tension hardening behavior after cracking, the following stress limitation must be applied:

$$
\sigma_{1} \leq 0.6 \cdot f_{F t s k}
$$

where $\sigma_{1}$ is the principal tensile stress and $f_{F t s k}$ is the characteristic value of the serviceability residual strength $f_{F t s}$.

\subsubsection{Crack control}

For controlling the crack width in SFRC beams under bending, if needed, a minimum reinforcement should be applied, at least equal to:

$$
A_{s, \min }=k_{c} \cdot k \cdot\left(f_{c t m}-f_{F t s m}\right) \frac{A_{c t}}{\sigma_{s}}
$$

where $f_{c t m}$ is the mean value of axial tensile strength of concrete; $f_{F t s m}$ is the average value of the residual strength of SFRC; $A_{c t}$ is the tensile part of the concrete crosssection, evaluated by considering a stress field at elastic limit; $\sigma_{s}$ is the maximum tensile stress in the reinforcement in the cracked state, that can be considered equal to the yielding stress of the steel, $k_{c}$ is a coefficient taking account of the stress distribution in the cross-section just before cracking and the change of the inner lever arm; for rectangular cross-sections $k_{c}=1, k$ is a coefficient taking into account of non-uniform self-equilibrating stresses, leading to a reduction of the cracking force, $k=1.0$ for webs with $h \leq 300 \mathrm{~mm}$ or flanges with width $\leq 300 \mathrm{~mm}$ and $k=0.65$ for webs with $h \leq 800 \mathrm{~mm}$ or flanges with width $\geq 800 \mathrm{~mm}$, for intermediate values interpolation can be applied. Finally, when $A_{s, \min }$ is negative, the minimum reinforcement can be due only to the fiber reinforcement.

\subsection{Design for Ultimate Limit State (ULS)}

According to fib Model Code 2010 (2013) fiber reinforcement can replace conventional reinforcement partially or totally at ULS if the following relations are fulfilled:

$$
\frac{f_{R 1 k}}{f_{L k}}>0.4 \quad \text { and } \quad \frac{f_{R 3 k}}{f_{R 1 k}}>0.5
$$


where $f_{R 1 k}$ and $f_{R 3 k}$ are the characteristic residual flexural tensile strengths corre-

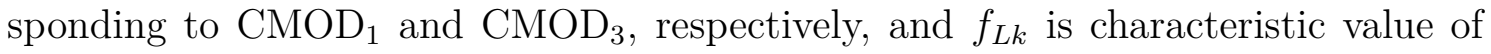
the limit of proportionality, defined in Section 3.1.1.

\subsubsection{Bending}

The basic assumptions for the ultimate bending resistance of RC-SFRC sections (di Prisco, 2009) are: plane sections perpendicular to the axis of bending remain plane after deformation; the tensile stresses in SFRC are derived from the design stress vs. strain relationship in fib Model Code 2010 (2013); at the same level, the strain in reinforcing bars, $\varepsilon_{s}$, is assumed to be the same as in concrete $\varepsilon_{c}$ (perfect bond between reinforcement and concrete); the compression in SFRC is the same as for plain concrete.

The design of RC-SFRC structures under bending follows the same procedures as for RC structures, although including the fibers effect through the ultimate residual flexural strength $f_{F t u}$, in which the contribution of the fibers is approximated to a rectangular stress block acting on the tensile side of the section as illustrated in Figure 3.12(d). Therefore, the bending failure is considered when one of the following conditions is obtained:

- attainment of the maximum compressive strength, $\varepsilon_{c u}$, in SFRC;

- attainment of the maximum tensile strength $\varepsilon_{s u}$, in steel (if present);

- attainment of the maximum tensile strength, $\varepsilon_{F u}$, in SFRC.

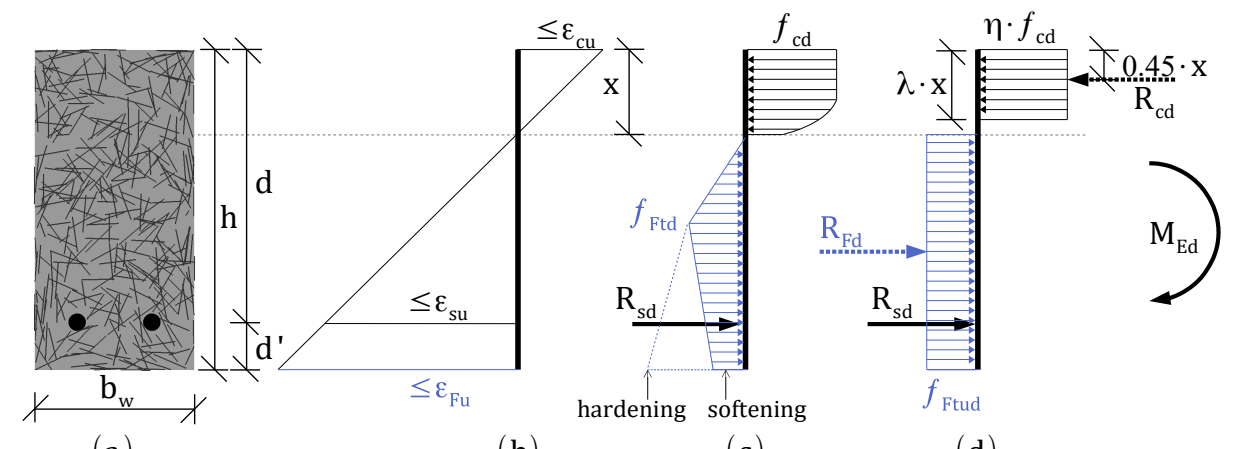

(a)

(b)

(c)

(d)

Figure 3.12.: ULS for bending moment: (a) cross-section; (b) strain diagram; (c) stress distribution and (d) simplified stress distribution. 
In Figure 3.12(d), the resultant compressive force $R_{c d}$ in SFRC is given by:

$$
R_{c d}=\eta \cdot f_{c d} \cdot \lambda \cdot x \cdot b_{w}
$$

where the values of the coefficients are $\lambda=0.8$ and $\eta=1.0$ for $f_{c k} \leq 50 \mathrm{MPa} ; f_{c d}$ is the design compressive strength of SFRC; $b_{w}$ is the width of web and $x$ the depth of compression zone.

$R_{F d}$ is the resultant tensile force in SFRC for the equivalent stress distribution evaluated as:

$$
R_{F d}=f_{F t u d} \cdot(h-x) \cdot b_{w}
$$

where $f_{F t u d}$ is the design ultimate residual tensile strength and $h$ is the total height. The resultant tensile force in the steel reinforcement, $R_{s d}$, is calculated by multiplying the area of the reinforcing $A_{s}$ by the assumption of yielding stress on the steel:

$$
R_{s d}=f_{y d} \cdot A_{s}
$$

Taking moments about the centroid of the steel in tension, the following equation is obtained:

$$
M_{E d}=\eta \cdot f_{c d} \cdot \lambda \cdot x \cdot b_{w} \cdot(d-0.45 \cdot x)-f_{F t u d} \cdot(h-x) \cdot b_{w} \cdot\left[\frac{(h-x)}{2}-d^{\prime}\right]
$$

where $M_{E d}$ is the design moment. The solution of Eq. 3.23 gives the depth of the neutral axis $x$. Finally, by taking the moments about the point of the applied resultant compressive force, the area of the conventional reinforcement is

$$
A_{s}=\frac{M_{E d}-f_{F t u d} \cdot(h-x) \cdot b_{w} \cdot\left[\frac{(h-x)}{2}+(x-0.45 \cdot x)\right]}{f_{y d} \cdot(d-0.45 \cdot x)}
$$

\subsubsection{Shear}

One of the main advantages of using SFRC in beams is with respect to shear reinforcement, where the use of fibers represents an additional distributed reinforcement able to enhance the shear resisting mechanisms in beams with and without stirrups 
(di Prisco, 2009). The shear resistance $V_{R d}$ for beams considering the conventional shear reinforcement and SFRC is determined as:

$$
V_{R d}=V_{R d, F}+V_{R d, s} \geq V_{E d}
$$

where $V_{R d, F}$ and $V_{R d, s}$ are the resistances attributed to the SFRC and stirrups, respectively, and must be greater than the design shear force $V_{E d}$.

In MC2010 the design value of the shear resistance for SFRC can be calculated according to two approaches. The first one was recently developed by Minelli (2015) and validated while the second is a revised formula from shear design for conventional reinforced concrete (RC) elaborated by Foster (2010). In this work only the first approach is adopted. Therefore,the shear resistance $V_{R d, F}$ is defined by:

$$
V_{R d, F}=\left\{\frac{0.18}{\gamma_{c}} \cdot k \cdot\left[100 \cdot \rho_{l} \cdot\left(1+7.5 \cdot \frac{f_{F t u k}}{f_{c t k}}\right) \cdot f_{c k}\right]^{\frac{1}{3}}+0.15 \cdot \sigma_{c p}\right\} \cdot b_{w} \cdot d
$$

(stresses and strengths in $\mathrm{MPa}$ )

where $f_{F t u k}$ is the characteristic value of the ultimate residual tensile strength according to Eq. 3.6 by considering $w_{u}=1.5 \mathrm{~mm} ; \gamma_{c}$ is the partial safety factor for the concrete without fibers; $k$ is a factor that takes into account the size effect calculated as $k=1+\sqrt{200 / d} \leq 2.0$ for the effective depth of the cross-section, $d$, in $\mathrm{mm}$; the longitudinal reinforcement ratio is defined as $\rho_{l}=A_{s l} /\left(b_{w} d\right) ; A_{s l}$ is the cross-sectional area of the reinforcement, bonded beyond the considered section; $f_{c t k}$ is the characteristic value of the tensile strength for the concrete without fibers; $f_{c k}$ is the characteristic value of cylindrical compressive strength; $\sigma_{c p}=\frac{N_{E d}}{A_{c}}<0.2 f_{c d}$ is the average stress acting on the concrete cross-section $A_{c}\left(\mathrm{~mm}^{2}\right)$ for an axial force $(\mathrm{N})$, due to loading or prestressing actions $\left(N_{E d}>0\right.$ for compression) and $b_{w}$ is the smallest width of the cross-section in the tensile area in $\mathrm{mm}$.

In Eq. 3.25, the contribution of the SFRC was introduced by modifying the longitudinal reinforcement ratio by means of the characteristic ultimate residual tensile strength for SFRC $f_{F t u k}$ and can be used for beams without steel fibers by considering $f_{F t u k}=0$ to calculate design shear resistance attributed to the plain concrete $V_{R d, c}$.

The design shear resistance provided by conventional reinforcement $V_{R d, s}$ for stirrups 
that are inclined relative to the beam axis is computed as:

$$
V_{R d, s}=\frac{A_{s w}}{s_{w}} z \cdot f_{y w d} \cot (\theta)
$$

where $A_{s w}$ is the area of shear reinforcement; $s_{w}$ is the spacing between stirrups $\left(s_{w} \leq\right.$ $0.75 d$ or $500 \mathrm{~mm}) ; f_{y w d}$ denotes the design yield strength of the shear reinforcement and $\theta$ is the compressive stress field inclination, taken as $\theta=45^{\circ}$.

- Beams without reinforcement (longitudinal and shear)

For structural members without longitudinal and shear reinforcements, when a tensile hardening behavior is considered the following consideration must be applied:

$$
\sigma_{1} \leq \frac{f_{F t u k}}{\gamma_{F}}
$$

where $\sigma_{1}$ is the principal tensile stress in $\mathrm{MPa}, f_{F t u k}$ is the characteristic value of the ultimate residual tensile strength of FRC determined on Eq. 3.6 for $w_{u}=1.5 \mathrm{~mm}$ and SFRC partial safety factor $\gamma_{F}$ can be found in Table 3.1.

\subsection{Verification of Serviceability Limit State (SLS)}

\subsubsection{Crack width}

For all stages of cracking, the design crack width $w_{d}$ for RC-SFRC structural members can be calculated as:

$$
w_{d}=2\left\{k \cdot c+\frac{1}{4} \frac{\phi_{s}}{\rho_{s, e f}} \cdot \frac{\left(f_{c t m}-f_{F t s m}\right)}{\tau_{b m}}\right\} \cdot\left(\frac{\sigma_{s}-\beta \cdot \sigma_{s r}}{E_{s}}+\eta_{r} \cdot \varepsilon_{s h}\right)
$$

where $f_{F t s m}$ is defined as $f_{F t s m}=\frac{f_{F t s k}}{0.7} ; f_{F t s k}$ is the characteristic value of the serviceability residual tensile strength; $k$ is an empirical parameter to take the influence of the concrete cover into consideration (as a simplification $k=1.0$ can be assumed); $c$ is the concrete cover; $\phi_{s}$ is the nominal diameter of a reinforcement bar; $\rho_{s, \text { ef }}$ is the effective reinforcement ratio given by $\rho_{s, e f}=A_{s} / A_{c, e f}$; the effective area of concrete in tension, $A_{c, e f}$. is illustrated in Figure $3.13 ; f_{c t m}$ is the mean value of axial tensile strength of concrete; $\tau_{b m}$ is mean bond strength between steel and concrete (see Table 3.2). 


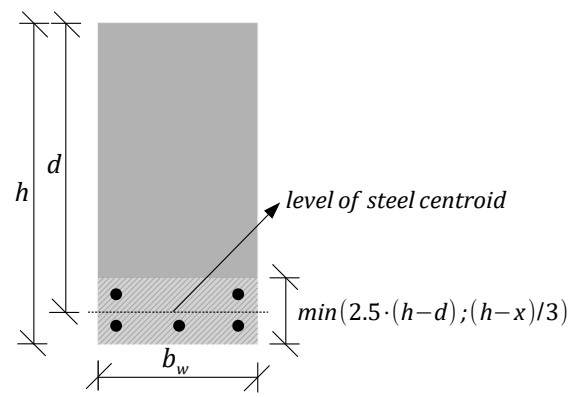

Figure 3.13.: Definition of effective area $A_{c, e f}$ for beams.

Table 3.2.: Values of $\tau_{b m s}, \beta$ and $\eta_{r}$ for deformed reinforcing bars (adapted from MC2010).

\begin{tabular}{cccccccc}
\hline & \multicolumn{3}{c}{ Single crack formation } & \multicolumn{3}{c}{ Stabilized cracking } \\
\hline \hline & $\tau_{b m s}$ & $\beta$ & $\eta_{r}$ & $\tau_{b m s}$ & $\beta$ & $\eta_{r}$ \\
\hline $\begin{array}{c}\text { Short term/ } \\
\text { instantaneous loading }\end{array}$ & $1.8 \cdot f_{c t m}$ & 0.6 & 0 & $1.8 \cdot f_{c t m}$ & 0.6 & 0 \\
\hline $\begin{array}{c}\text { Long term/ repeated } \\
\text { loading }\end{array}$ & $1.35 \cdot f_{c t m}$ & 0.6 & 0 & $1.8 \cdot f_{c t m}$ & 0.4 & 1 \\
\hline
\end{tabular}

$E_{s}$ is the modulus of elasticity of reinforcing steel; $\beta$ is an empirical coefficient to assess the mean strain over $l_{s, \max }$ depending on the type of loading (see Table 3.2); $\eta_{r}$ is a coefficient for considering the shrinkage contribution (see Table 3.2 ); $\varepsilon_{s h}$ is the shrinkage strain; $\sigma_{s r}$ is the maximum steel stress in a crack in the crack formation stage, which, for pure tension, is:

$$
\sigma_{s r}=\left(f_{c t m}-f_{F t s m}\right) \cdot \frac{\left(1+\alpha_{e} \cdot \rho_{s}\right)}{\rho_{s, e f}}
$$

where $\alpha_{e}$ is the modular ratio, define as: $\alpha_{e}=\frac{E_{s}}{E_{c}}$. In MC2010, the value of the steel stress in a crack $\sigma_{s}$ needs to take into account the effect of the fibers. For this purpose, firstly, the depth of the neutral axis $x$ needs to be determined. In $\mathrm{RC}$ beams it can be calculated directly by considering the equilibrium of the crosssection and stress-strain compatibility. However, for RC-SFRC beams an iterative procedure is required, since the the stress due to the fibers, $f_{F t s m}$, is independent of stress-strain relation of the cross-section as illustrated in Figure 3.14(b) and (c). Details of this procedure can be found in Amin et al. (2017). Hence, with the value of $x$, it is possible to calculate the value of the steel strain in a crack $\varepsilon_{s}$ and the 
corresponding steel stress $\sigma_{s}$.

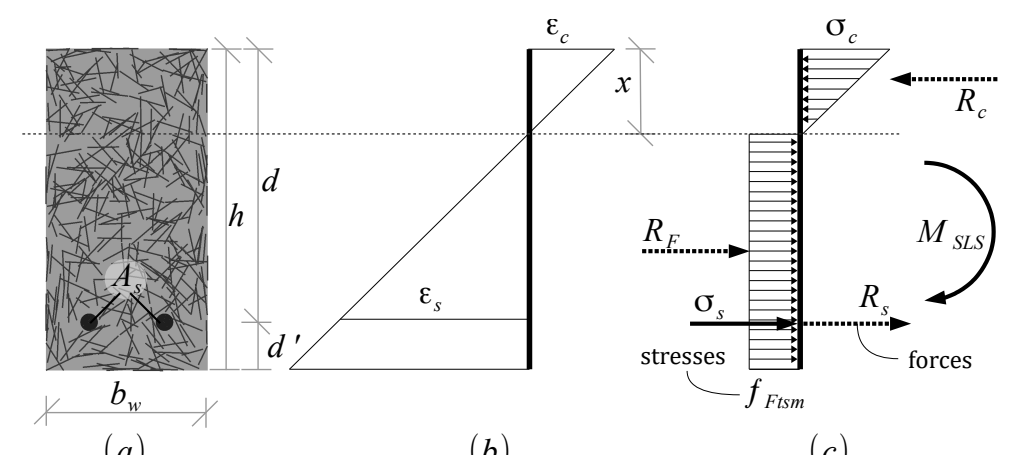

(a)

(b)

(c)

Figure 3.14.: Strains and stresses of RC-SFRC cross-section in bending: (a) crosssection (b) strain diagram at crack (c) stresses and forces at crack.

In addition, as aforementioned, since the mean distance between cracks, $s_{r m}$, is not explicitly mentioned in MC2010, in this work the relation deduced by Tiberti et al. (2014) is used:

$$
s_{r m}=1.17 \cdot l_{s, \max }
$$

where the length over which slip between concrete and steel occurs $l_{s, \max }$ for RCSFRC structural members can be calculated as:

$$
l_{s, \max }=\left(k \cdot c+\frac{1}{4} \frac{\phi_{s}}{\rho_{s, e f}} \cdot \frac{\left(f_{c t m}-f_{F t s m}\right)}{\tau_{b m}}\right)
$$

\subsubsection{Deflection}

Deflections due to bending are obtained by the integration of curvatures along the member length. For structural members subjected mainly to flexural, a simplified method for RC structures recommended in MC2010. The deflection is given by the expression:

$$
\delta=\zeta \cdot \delta_{I I}+(1+\zeta) \cdot \delta_{I}
$$

where $\delta_{I}$ is deflection calculated by assuming the second moment of area $I_{c}$ of the uncracked concrete section; $\delta_{I I}$ is the deflection obtained by using the second moment of area $I_{I I}$ of the fully cracked section; $\zeta$ is an interpolation coefficient (allowing for 
the effect of tension stiffening at a section) and is given by the expression:

$$
\zeta=1-\beta \cdot\left(\frac{\sigma_{s r}}{\sigma_{s}}\right)^{2}
$$

$\beta$ is a coefficient accounting for the influence of the duration of loading or repeated loading; $\beta=1.0$ for a single short term loading and $\beta=0.5$ for sustained loads or multiple cycles of repeated loading; $\sigma_{s}$ is the stress in the tension reinforcement calculated on for a cracked section under the considered load for SLS and $\sigma_{s r}$ is the stress in the tension reinforcement calculated for the loading conditions that cause the first crack.

MC2010 does not explicitly describe a procedure to calculate the deflection for SFRC. In this work, the deflection due to bending of RC-SFRC beams are obtained by modifying the parameter $\delta_{I I}$, which is calculated using value of the neutral axis $x$, as illustrated in Figure 3.14, where the effect of the fibers is considered. In addition, the stresses $\sigma_{s}$ and $\sigma_{s r}$ in Eq. 3.33 are determined as described in Section 3.4.1. 


\section{Applications}

In this chapter, some applications are presented using the approach for modeling RC-SFRC as reported in Chapter 2. Firstly, the ability of the numerical model to simulate three-point bending tests according to EN 14651 (2005) is verified in Section 4.1. These analyses are important to obtain the parameters used in the design of RC-SFRC structural members and for calibrating the material parameters of the concrete-fiber interaction to be used in the simulation of RC-SFRC beams. In Section 4.2, the parameters obtained in the previous analyses (Section 4.1) are used to design RC-SFRC beams for different fiber contents following the fib Model Code 2010 (2013) (MC2010) predictions. These beams are also numerically analyzed and the results are compared to the designed ones in terms of crack width, mean crack spacing, deflection and ultimate and service loads. Finally, Section 4.3 shows the application of the numerical model in the analyses of RC-SFRC small scale beams experimentally tested by Conforti et al. (2018).

All the numerical analyses performed in this research were carried out considering plane stress conditions. Thus, only the projection of each fiber length on this plane is considered in order to allow a fair comparison between the physical and numerical models. The cloud of fibers is generated using an isotropic uniform random distribution, as reported in Section 2.3.2. The concrete bulk is discretized in three-noded triangular finite elements and its behavior is described by the damage constitutive model proposed by Cervera et al. (1996) (see Section 2.4). The reinforcements (steel fibers and rebars) are elastic perfectly plastic and they are discretized using two-noded (one-dimensional) truss finite elements for all the cases, as presented in Section 2.3. The coupling between these two independent meshes of the concrete bulk and reinforcements is carried out by four-noded triangular coupling finite elements with the non-rigid procedure outlined in Section 2.2 . 


\subsection{Numerical simulation of three-point bending tests - EN 14651}

\subsubsection{Description of the beams}

To characterize the behavior in tension of SFRC, a series of three-point bending beams were experimentally tested at the Laboratory of Structures and Structural Materials at the University of São Paulo (Figure 4.1). These tests were carried out according to EN 14651 (2005) on prismatic beams of $500 \mathrm{~mm}$ span length, a total length of $550 \mathrm{~mm}$ and cross-section of $150 \times 150 \mathrm{~mm}^{2}$. A total of twelve beams were tested, four of each with fiber contents of $15 \mathrm{~kg} / \mathrm{m}^{3}, 30 \mathrm{~kg} / \mathrm{m}^{3}$ and $45 \mathrm{~kg} / \mathrm{m}^{3}(0.19$, 0.38 and $0.58 \%$ by volume, respectively). Table 4.1 summarizes the geometrical and mechanical properties of the steel fibers used.

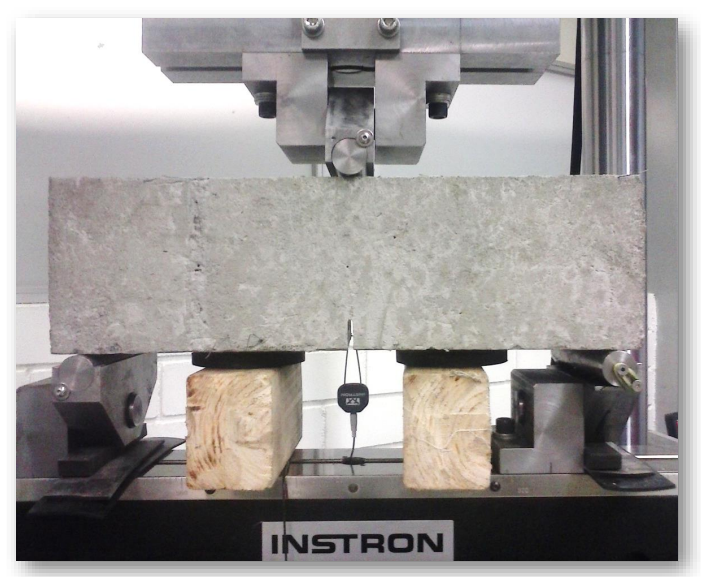

Figure 4.1.: Setup of the three-point bending beams tested according to EN 14651 (2005) at the Laboratory of Structures and Structural Materials at the University of São Paulo.

Table 4.1.: Geometrical and mechanical properties of the steel fibers.

\begin{tabular}{cc}
\hline Type of fiber & DRAMIX ${ }^{\circledR} \mathrm{RC} 80 / 60 \mathrm{BN}$ \\
\hline Length $l_{F}$ & $60 \mathrm{~mm}$ \\
\hline Diameter $d_{F}$ & $0.75 \mathrm{~mm}$ \\
\hline Yield stress $\sigma_{Y}$ & $1225 \mathrm{MPa}$ \\
\hline Young's modulus $E_{F}$ & $210 \mathrm{GPa}$ \\
\hline
\end{tabular}




\subsubsection{Mesh sensitivity study: plain concrete}

In order to verify the capability of the damage model proposed by Cervera et al. (1996) in capturing the crack propagation process in three-point bending tests and its influence on the structural response, a mesh sensitivity study is performed for plain concrete by considering three mesh refinements according to Table 4.2 .

Table 4.2.: Characteristics of the three mesh refinements considered.

\begin{tabular}{cc}
\hline Mesh & $\begin{array}{c}\text { Number of three-noded } \\
\text { triangular finite elements }\end{array}$ \\
\hline \hline 1 (coarse) & 2311 \\
\hline 2 (medium) & 5173 \\
\hline 3 (fine) & 20758 \\
\hline
\end{tabular}

Figure 4.2 shows the geometrical properties, boundary conditions and discretization in finite elements (mesh 2 - medium). The concrete parameters adopted in the analyses are summarized in Table 4.3. The characteristic compressive strength, $f_{c k}$, was obtained experimentally, while the Young's modulus, $E_{c}$, and Poisson's ratio, $v$, were estimated using the MC2010 recommendations. The tensile strength of concrete, $f_{c t}$, and the fracture energy, $G_{f}$, were defined by calibrating the numerical model to fit the mean experimental response for a fiber content of $30 \mathrm{~kg} / \mathrm{m}^{3}$ in the three-point bending tests. The compressive parameters $A^{-}$and $B^{-}$are typical values for concrete, as recommended by Cervera et al. (1996).

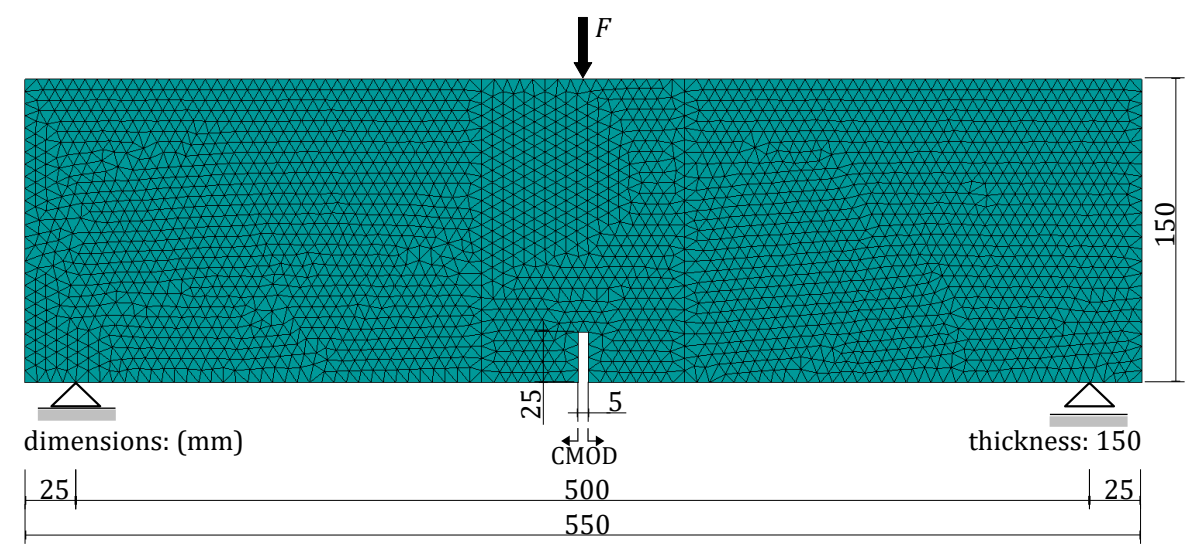

Figure 4.2.: Geometrical properties, boundary conditions and FE discretization (Mesh 2 - medium) of the three-point bending tests performed for plain concrete. 
Table 4.3.: Concrete parameters for the three-point bending tests - EN 14651.

\begin{tabular}{cc}
\hline Characteristic compressive strength $f_{c k}$ & $35 \mathrm{MPa}$ \\
\hline Tensile strength $f_{c t}$ & $2.35 \mathrm{MPa}$ \\
\hline Young's modulus $E_{c}$ & $35 \mathrm{GPa}$ \\
\hline Poisson's ratio $v$ & 0.2 \\
\hline Fracture energy $G_{f}$ & $100 \mathrm{~N} / \mathrm{m}$ \\
\hline Compressive parameters & $A^{-}=1.0$ and $B^{-}=0.89$ \\
\hline
\end{tabular}

The crack patterns for the three meshes considered are illustrated in Figure 4.3. As can be noted, the results do not present significant mesh dependency. Moreover, the structural responses illustrated in Figure 4.4 are similar. Based on these results, the intermediate mesh is adopted in the following sections, since the crack pattern can be obtained precisely, and less time-consuming when compared to the finest mesh.

(a) Mesh 1

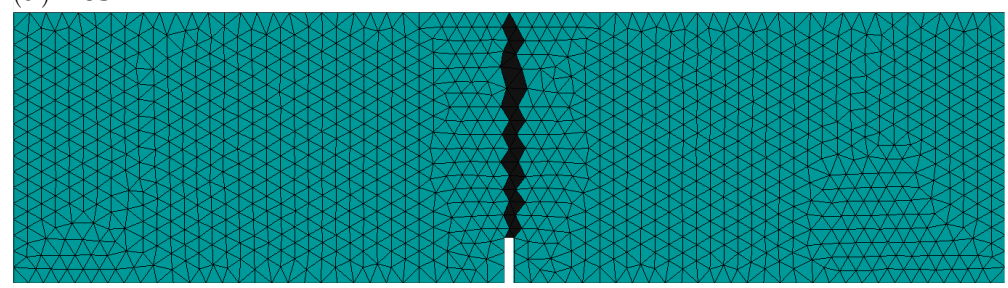

(b) Mesh 2

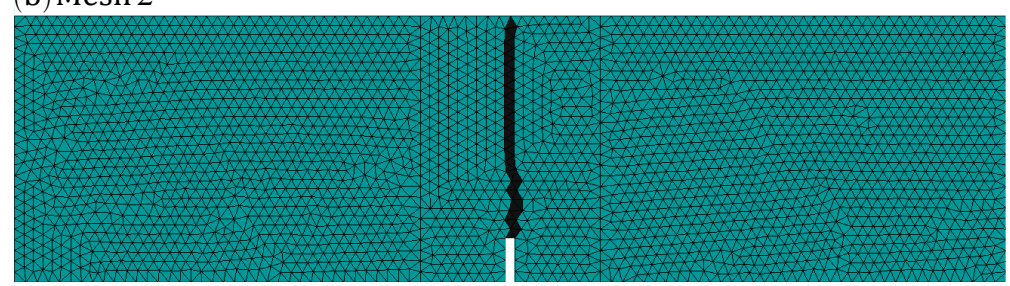

(c) Mesh 3

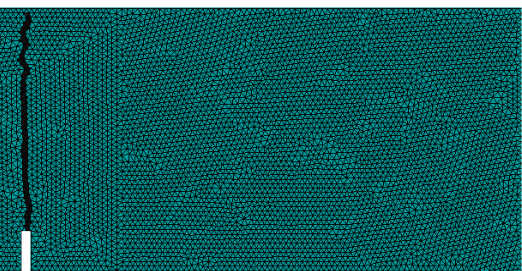

Figure 4.3.: Crack patterns obtained for: (a) Mesh 1 (coarse); (b) Mesh 2 (medium) and (c) Mesh 3 (fine). 


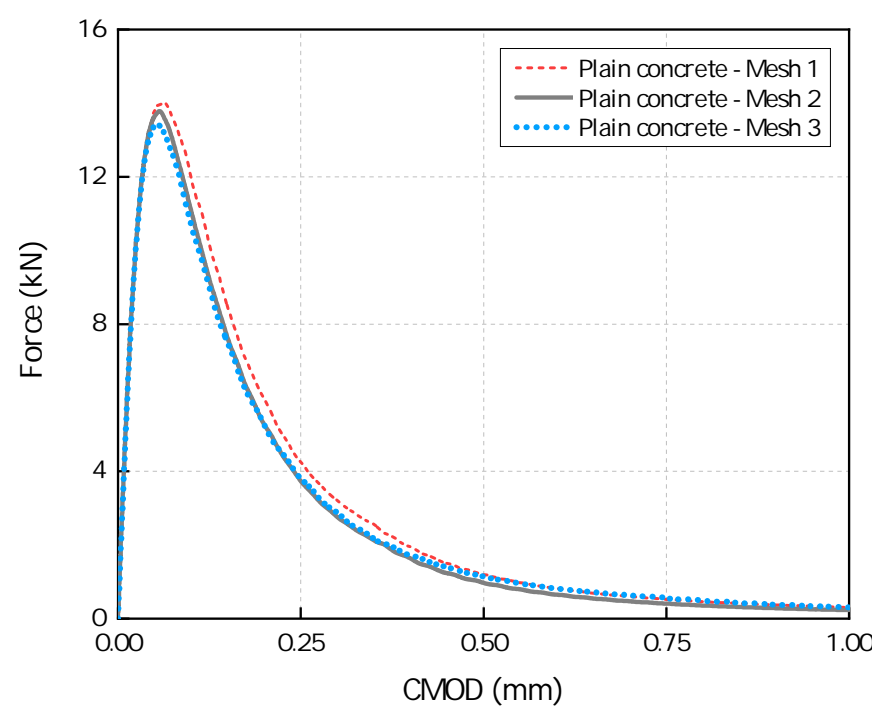

Figure 4.4.: Force vs. CMOD (Crack Mouth Opening Displacement) curves for the three mesh refinements adopted.

\subsubsection{Mesoscale model vs. concurrent multiscale model}

In this section, the equivalence among mesoscale and concurrent multiscale models in the numerical analysis of three-point bending tests is investigated for the case with a fiber content of $30 \mathrm{~kg} / \mathrm{m}^{3}$. These two models are illustrated in Figure 4.5 . In the macroscale subdomains, the SFRC is considered as a homogeneous elastic isotropic material characterized by effective material parameters. In this research, the Mixture Theory (Truesdell and Toupin, 1960) was employed to calculate these parameters (Young's modulus and Poisson's ratio) according to the following relation:

$$
P_{e f}=V_{F} P_{F}+V_{C} P_{C}
$$

where $P_{e f}$ is the effective Young's modulus $\left(E_{e f}\right)$ or the Poisson's ratio $\left(\nu_{e f}\right) ; P_{F}$ and $P_{C}$ are the Young's modulus or the Poisson's ratio of the fibers and concrete, respectively; while $V_{F}$ and $V_{C}$ are the volume fractions of the fibers and concrete, respectively. Therefore, in the macroscale regions, a Young's modulus of $E_{e f}=$ $35600 \mathrm{MPa}$ and Poisson's ratio of $\nu_{\text {ef }}=0.2$ were adopted. 


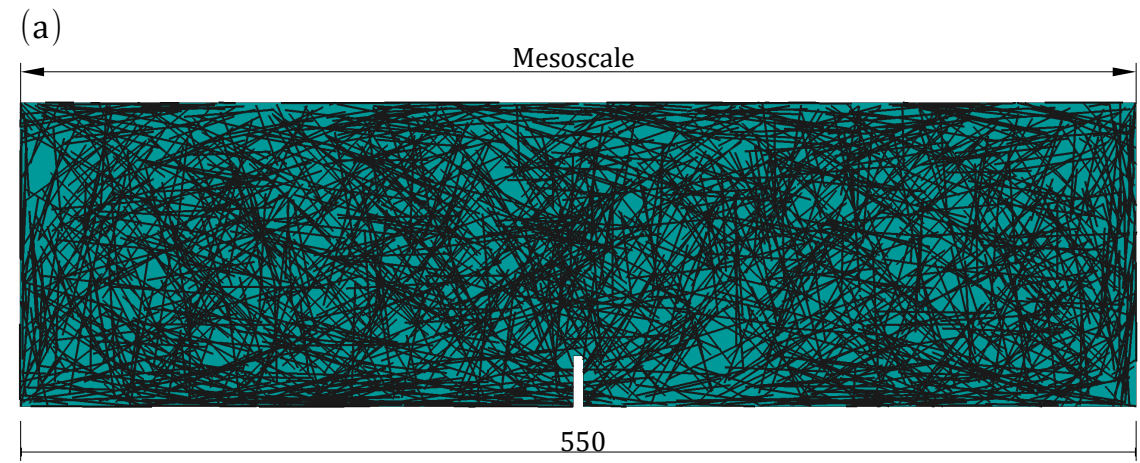

(b)

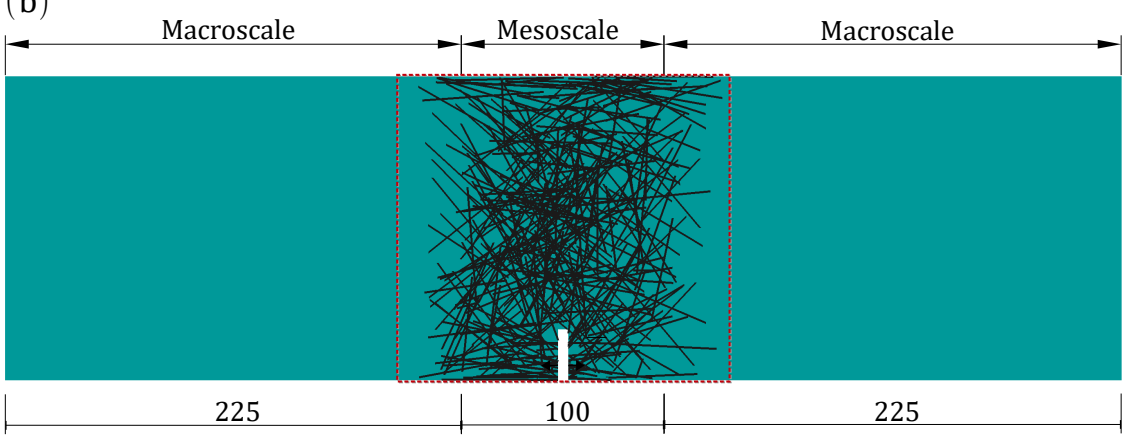

Figure 4.5.: Three-point bending beam for steel fiber content of $30 \mathrm{~kg} / \mathrm{m}^{3}$ simulated using: (a) mesoscale model and (b) concurrent multiscale model (dimensions in $\mathrm{mm}$ ).

In the mesoscale regions, the steel fibers are individually represented. Hence, the material parameters of the concrete, fibers and concrete-fiber interaction are defined separately. The intermediate concrete mesh (Mesh 2) proposed in the previous section is adopted and the material parameters are given in Table 4.3. Each steel fiber is discretized in 6 finite elements, respecting a ratio of approximately 1.5, between the sizes of the fiber and concrete elements.

In the absence of pullout tests to characterize the concrete-fiber interaction, the parameters of these regions were calibrated based on the mean experimental result of force vs. CMOD (Crack Mouth Opening Displacement) curve. Thus, the parameters adopted were: $\tau_{b \max }=8.5 \mathrm{MPa}, \tau_{b f}=4.5 \mathrm{MPa}, \alpha=0.4, s_{1}=0.01 \mathrm{~mm}, s_{2}=$ $6.5 \mathrm{~mm}, c_{n}=10^{3} \mathrm{MPa} / \mathrm{mm}$ and $c_{s}=10^{6} \mathrm{MPa} / \mathrm{mm}$.

Figure 4.6 shows the force vs. CMOD curves for the three-point bending tests. As can be seen, the numerical curves are identical. In addition, using appropriate values for the parameters that describe concrete-fiber interaction, the curves obtained by the numerical models practically overlap the mean experimental curve. As expected, a concurrent multiscale model may be used for this type of test since the fibers 
outside the crack plane practically have no influence on the final response.

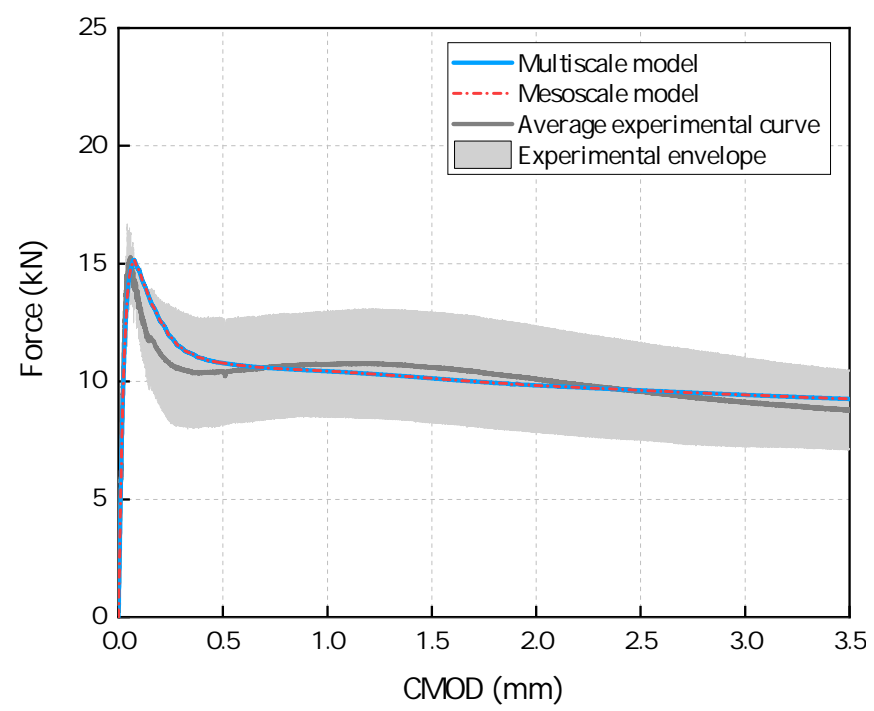

Figure 4.6.: Force vs. CMOD curves. Comparison between numerical (mesoscale and multiscale) and experimental responses for fiber content of $30 \mathrm{~kg} / \mathrm{m}^{3}$.

\subsubsection{Convergence study of the Impl-Ex integration scheme}

A study of convergence to assess the accuracy and robustness of the Implicit/Explicit (Impl-Ex) integration scheme is performed. The three-point bending tests for plain concrete with intermediate concrete mesh (Mesh 2) described in Section 4.1.2 and the concurrent multiscale model $\left(30 \mathrm{~kg} / \mathrm{m}^{3}\right)$ described in Section 4.1 .3 were numerically analyzed by considering 2500; 5000; 8000 and 10000 load steps.

Figure 4.7(a) and (b) show the force vs. CMOD curves obtained in the numerical analyses. As expected, there is an error associated with the use of this integration scheme when a small number of load steps is adopted. Thus, a total of 10000 load steps have been employed in the following analyses performed in this research. 

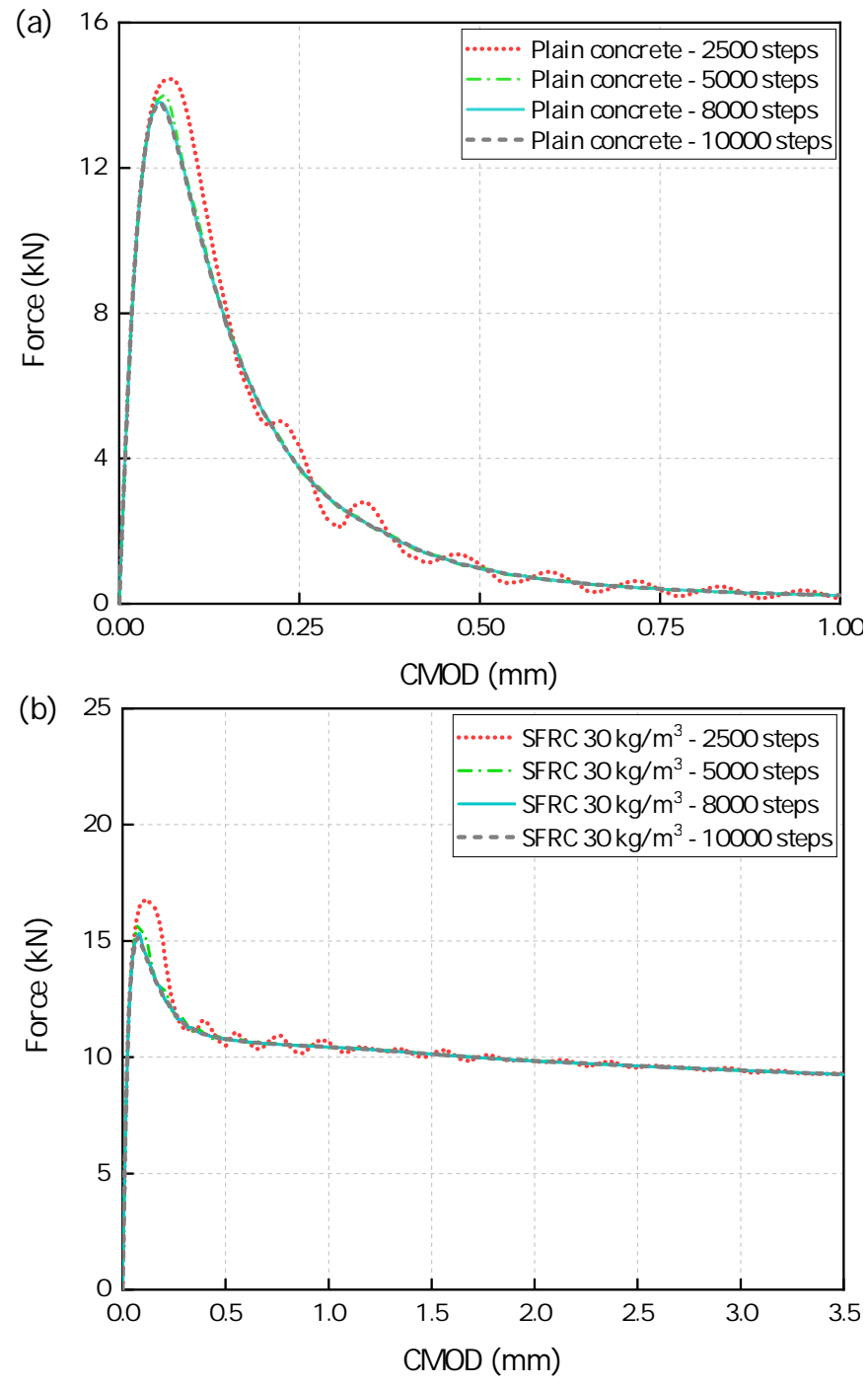

Figure 4.7.: Force vs. CMOD curves for the different number of load steps: (a) plain concrete and (b) concurrent multiscale model with a $30 \mathrm{~kg} / \mathrm{m}^{3}$ fiber content.

\subsubsection{Effect of the fiber content and distribution}

In this study, the proposed model is applied to simulate three-point bending beams for different fiber contents using the concurrent multiscale approach presented in Section 4.1.3. The SFRC beam of $30 \mathrm{~kg} / \mathrm{m}^{3}$ is used as a reference, by including the same concrete-fiber interface parameters calibrated in that section to capture the average curve obtained experimentally. Herein, these parameters are used in the simulation of another two beams with fiber contents of $15 \mathrm{~kg} / \mathrm{m}^{3}$ and $45 \mathrm{~kg} / \mathrm{m}^{3}$.

The fiber distributions for the three cases analyzed are depicted in Figure 4.8. The 
characteristic data of the finite element meshes employed are listed in Table 4.4.
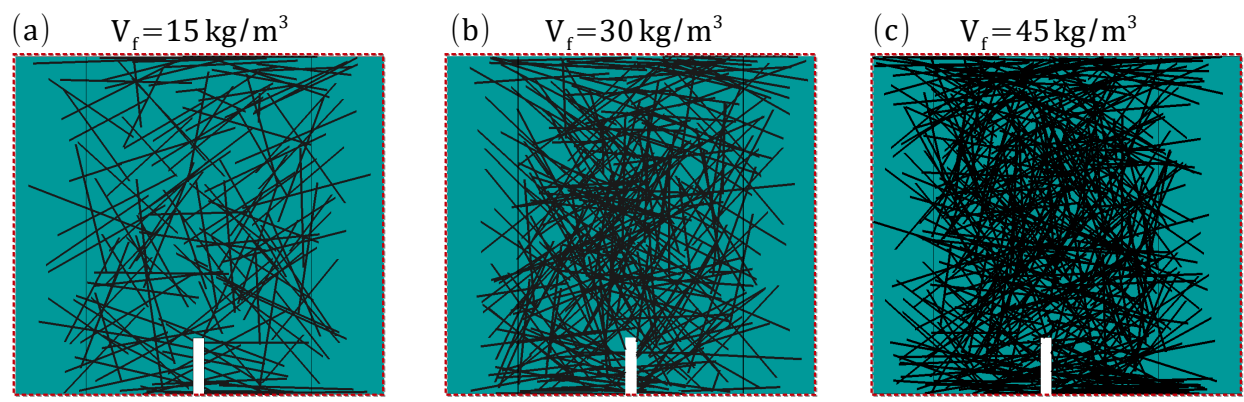

Figure 4.8.: Fiber distributions for the three fiber contents considered:

(a) $15 \mathrm{~kg} / \mathrm{m}^{3}$; (b) $30 \mathrm{~kg} / \mathrm{m}^{3}$ and (c) $45 \mathrm{~kg} / \mathrm{m}^{3}$.

Table 4.4.: Characteristic data of the finite element meshes.

\begin{tabular}{cllll}
\hline \multirow{2}{*}{ Fiber content $V_{f}$} & \multicolumn{4}{c}{ Number of elements } \\
\cline { 2 - 5 } & $\begin{array}{l}\text { two-noded } \\
\text { trusses }\end{array}$ & $\begin{array}{l}\text { three- } \\
\text { noded } \\
\text { triangular }\end{array}$ & $\begin{array}{l}\text { four-noded } \\
\text { triangular } \\
\text { CFEs }\end{array}$ & $\begin{array}{l}\text { total } \\
\text { number of } \\
\text { elements }\end{array}$ \\
\hline \hline $15 \mathrm{~kg} / \mathrm{m}^{3}$ & 783 & 5173 & 953 & 6909 \\
\hline $30 \mathrm{~kg} / \mathrm{m}^{3}$ & 1578 & 5173 & 1923 & 8674 \\
\hline $45 \mathrm{~kg} / \mathrm{m}^{3}$ & 2380 & 5173 & 2885 & 10438 \\
\hline
\end{tabular}

First, an investigation of the variability in the responses for $30 \mathrm{~kg} / \mathrm{m}^{3}$ fiber content is performed. Besides the analysis described in Section 4.1.3 and used here as the reference (distribution 1 - calibration), another three other distributions (2, 3 and 4) are generated and the numerical simulations are carried out using the same material parameters.

The results for the 4 cases are illustrated in Figure 4.9. As expected, there is a range of possible numerical responses in the post-cracking stage due to the randomness of the position of the fibers and, consequently, of the number of fibers crossing a crack. For instance, the lowest numerical response obtained for distribution 2 may be justified for the presence of 101 steel fibers crossing the crack, while for distribution 1 (reference) there were 117 fibers in that region, as shown in Figure 4.10. In addition, despite the variability in the numerical responses, the curves obtained lie well within the experimental range. 


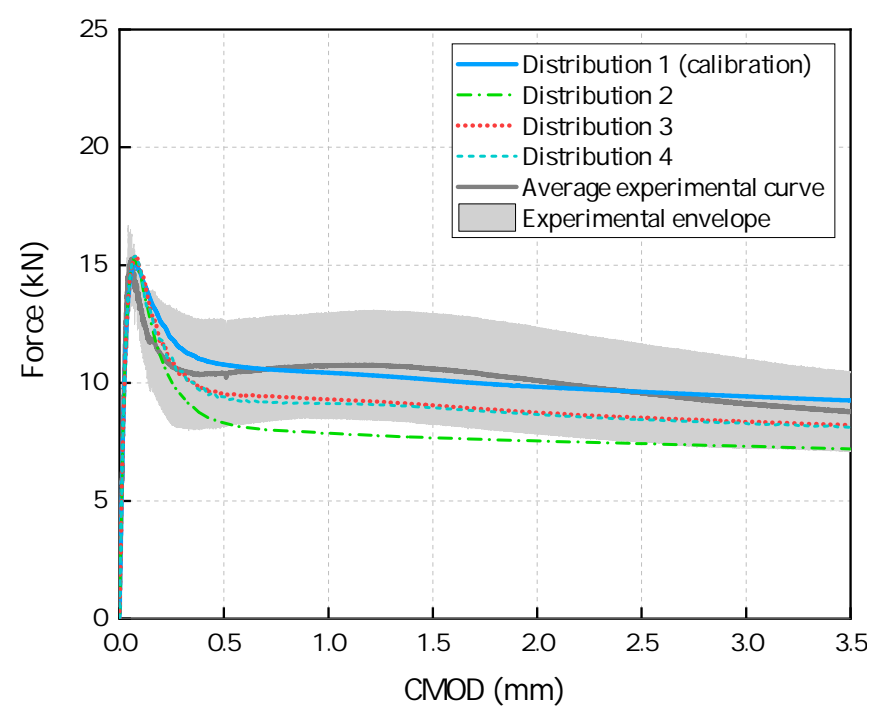

Figure 4.9.: Force vs. CMOD curves. Comparison between numerical and experimental responses for fiber content of $30 \mathrm{~kg} / \mathrm{m}^{3}$.

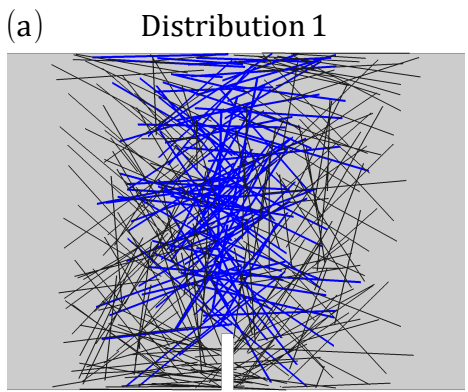

117 fibers

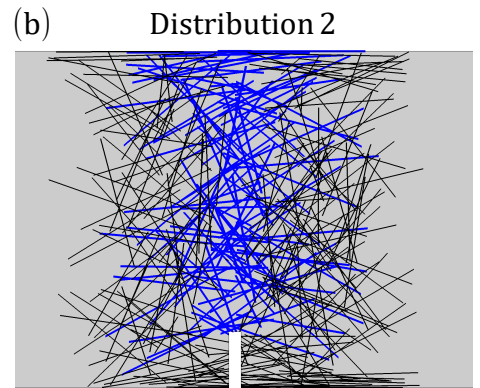

101 fibers

Figure 4.10.: Number of steel fibers crossing the crack plane for fiber distributions 1 and 2 .

Secondly, numerical analyses for fiber contents of $15 \mathrm{~kg} / \mathrm{m}^{3}$ and $45 \mathrm{~kg} / \mathrm{m}^{3}$ are carried out. The two laws illustrated in Figure 4.11 are adopted to describe the concretefiber interaction. The solid blue line represents the interface parameters adopted in the previous numerical simulations for the four fiber distributions, while the dashed green line was defined by adjusting the maximum bond stress $\left(\tau_{\text {bmax }}\right)$ parameter of this law (from $8.5 \mathrm{MPa}$ to $12.5 \mathrm{MPa}$ ) in order to translate the numerical response obtained using distribution 2 (lowest curve) to the mean experimental curve, as can be seen in Figure 4.12. 


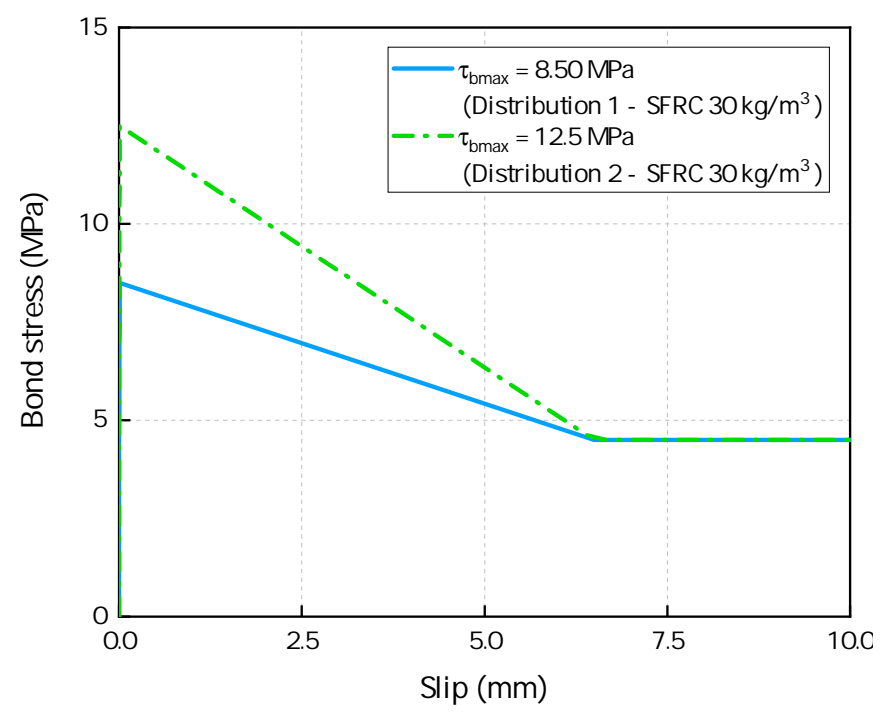

Figure 4.11.: Concrete-fiber interaction laws for analyses with fiber contents of $15 \mathrm{~kg} / \mathrm{m}^{3}$ and $45 \mathrm{~kg} / \mathrm{m}^{3}$.

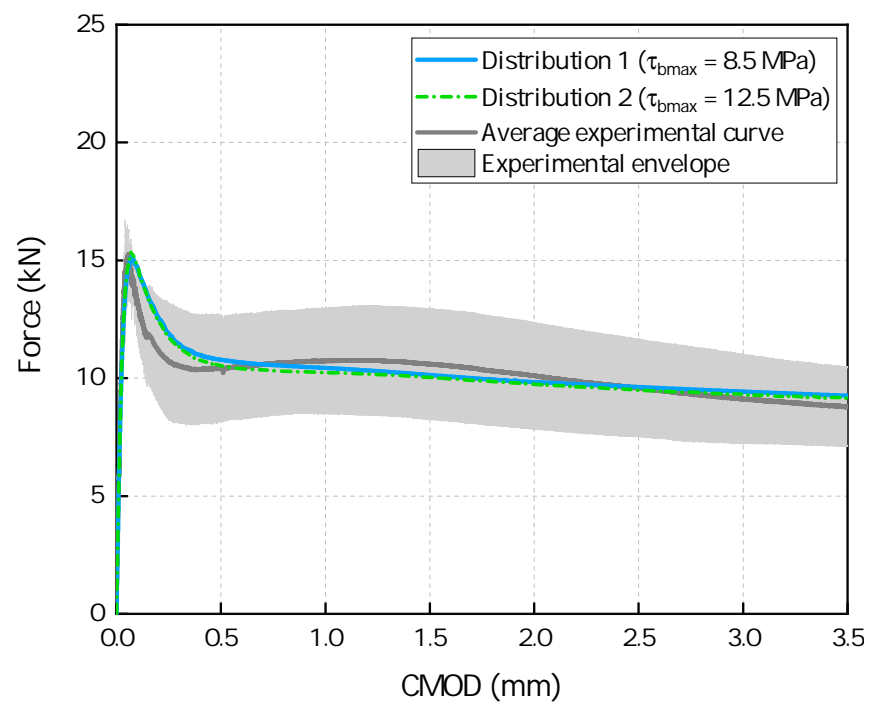

Figure 4.12.: Force vs. CMOD curves obtained for fiber distributions 1 and 2 by adopting the interface laws defined in Figure 4.11.

Figure 4.13 and Figure 4.14 show the responses for fiber contents of $15 \mathrm{~kg} / \mathrm{m}^{3}$ and $45 \mathrm{~kg} / \mathrm{m}^{3}$, respectively. Both are smaller than the average experimental responses. Clearly, the responses for the two cases adopting the interface law defined by the dashed green line (see Figure 4.11) are closest to the mean experimental curves. The effect of this difference on the RC-SFRC beam responses will be discussed in the next section. 


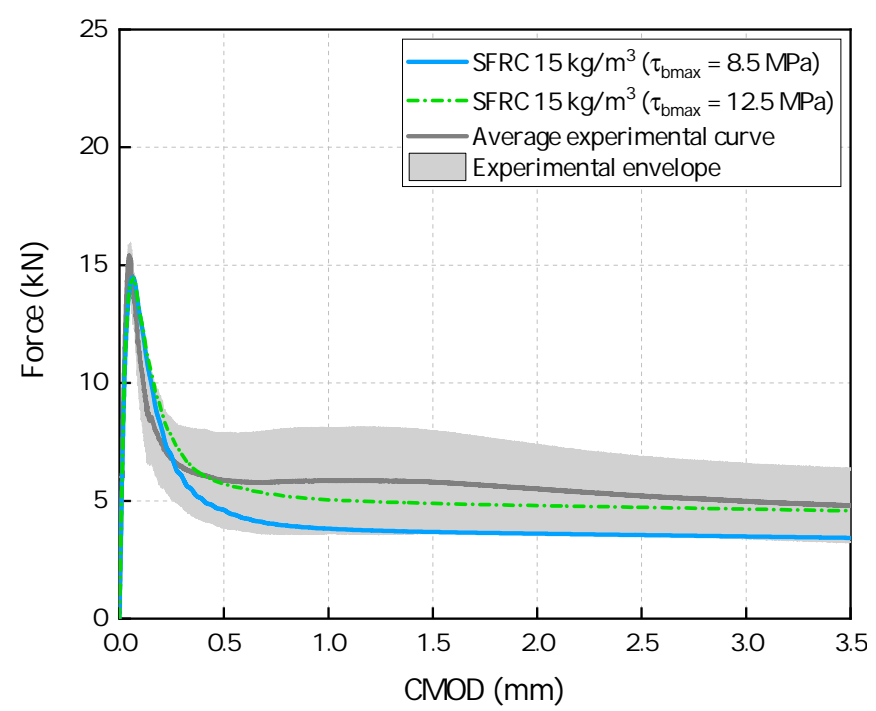

Figure 4.13.: Force vs. CMOD curves for fiber content of $15 \mathrm{~kg} / \mathrm{m}^{3}$.

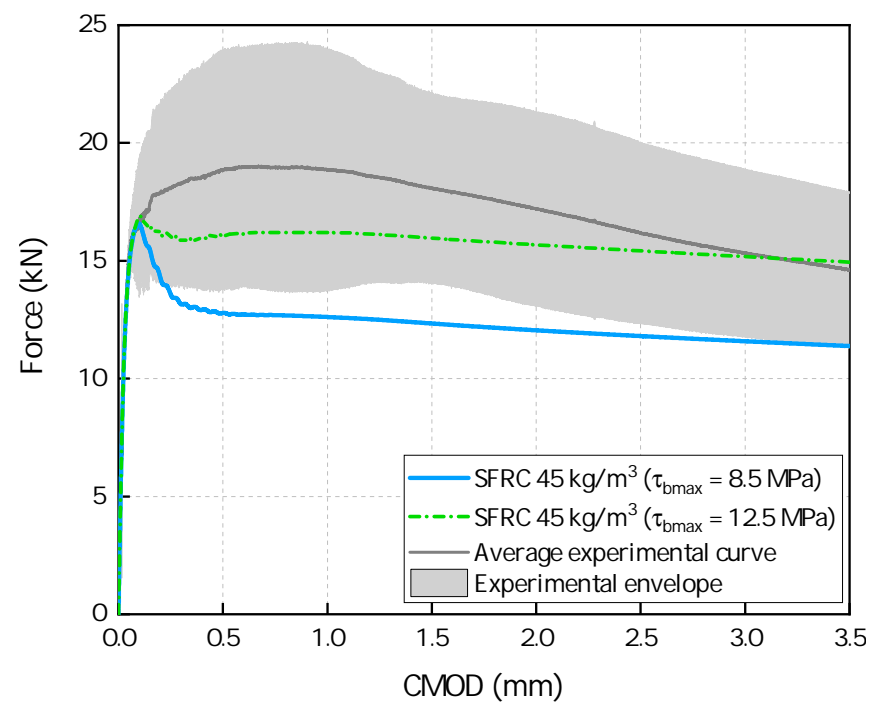

Figure 4.14.: Force vs. CMOD curves for fiber content of $45 \mathrm{~kg} / \mathrm{m}^{3}$.

The numerical results obtained for the three fiber contents are exhibited in Figure 4.15 by adopting two concrete-fiber interface laws. In addition, the response for plain concrete is also plotted to highlight the contribution of the fibers. 


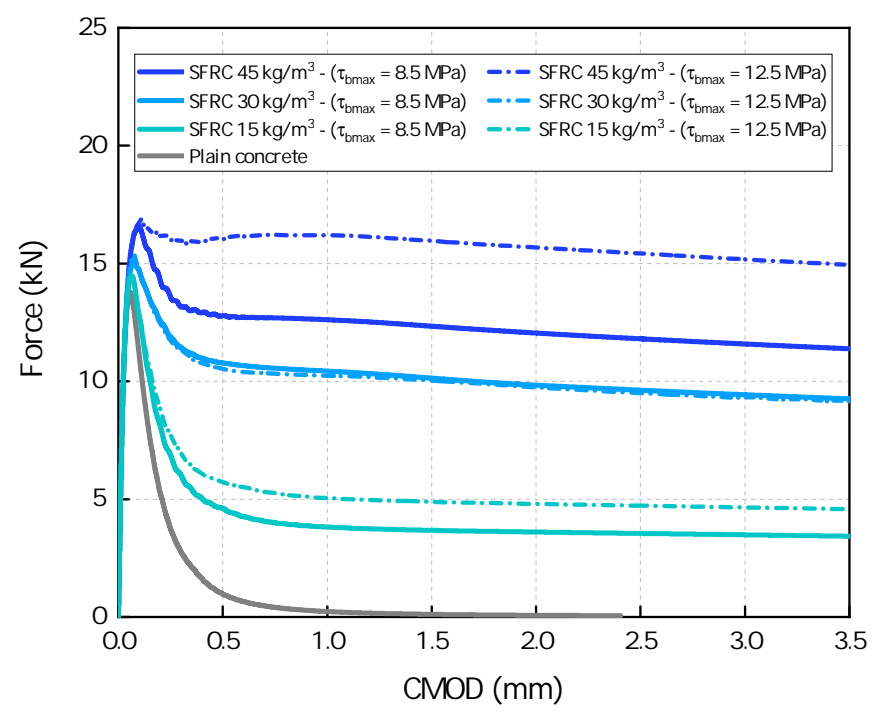

Figure 4.15.: Force vs. CMOD curves. Numerical responses for the three different fiber contents $\left(15 \mathrm{~kg} / \mathrm{m}^{3}, 30 \mathrm{~kg} / \mathrm{m}^{3}\right.$ and $\left.45 \mathrm{~kg} / \mathrm{m}^{3}\right)$ by adopting two interface laws and for plain concrete.

Figure 4.16 shows the crack propagation in Mode-I for different values of CMOD, which are important to characterize the material behavior by the residual flexural tensile strengths.
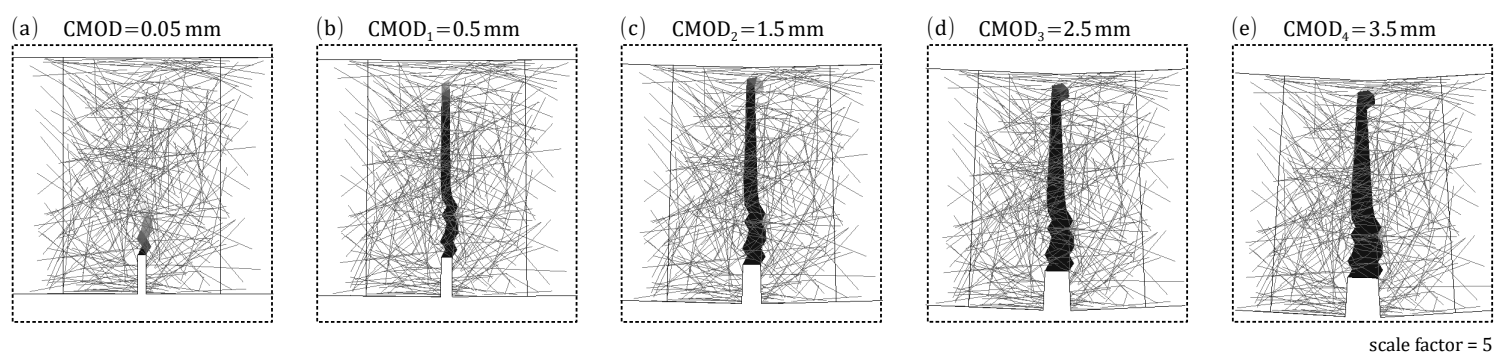

Figure 4.16.: Typical crack propagation in mode-I obtained in three-point bending tests for important CMOD (scale factor of 5).

\subsection{Predicting the behavior of RC-SFRC beams}

In this application, RC and RC-SFRC beams are designed according to MC2010. The RC-SFRC beams are designed by using both experimental and numerical results of EN 14651 (2005) tests presented in the previous section in order to study the 
influence of adopting these parameters. Further, the beams designed are numerically simulated and the results are compared with the design predictions.

\subsubsection{Design of beams according to fib Model Code 2010}

Simply supported beams under four-point bending are designed according to MC2010 (see Figure 4.17). Four reinforcement configurations are calculated: an RC beam (used as reference) and three RC beams reinforced by the same fiber contents as presented in Section $4.1\left(15 \mathrm{~kg} / \mathrm{m}^{3}, 30 \mathrm{~kg} / \mathrm{m}^{3}\right.$ and $\left.45 \mathrm{~kg} / \mathrm{m}^{3}\right)$. Both rigid-plastic and linear constitutive models are considered in the post-cracking stage. These models are defined based on the mean values of the SFRC characterization tests.

Figure 4.17 shows the geometry, boundary conditions and loading scheme for a total load considered of $\mathrm{F}=123 \mathrm{kN}$. The specimens are $125 \mathrm{~mm}$ wide, $250 \mathrm{~mm}$ deep, a total length of $2000 \mathrm{~mm}$ with the span of $1800 \mathrm{~mm}$ and clear concrete cover of $25 \mathrm{~mm}$ (exposure class XC2).

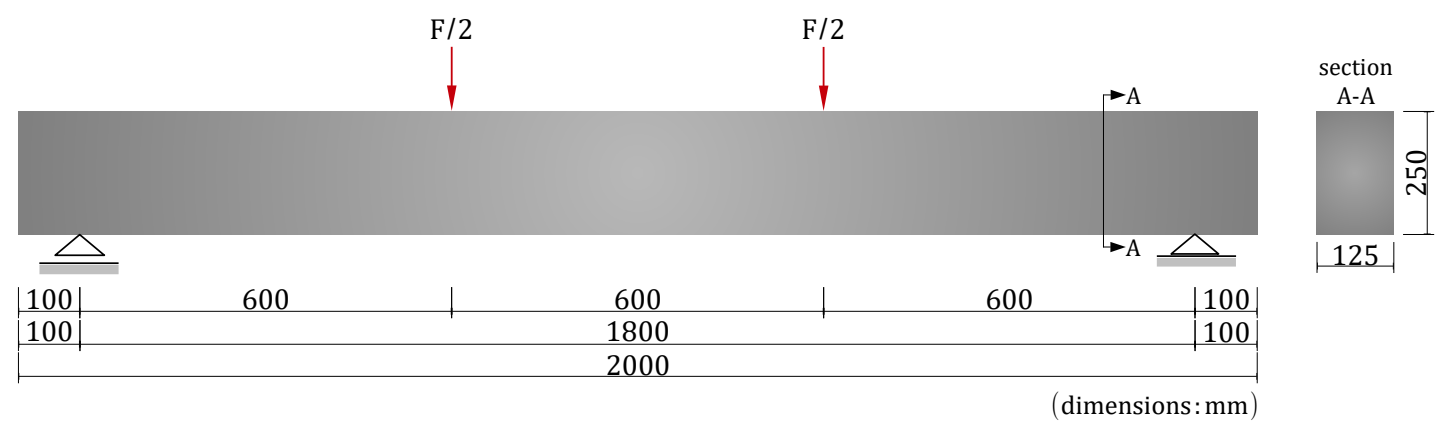

Figure 4.17.: Setup of the four-point bending tests: geometry, boundary conditions and loads.

The steel fiber and concrete properties are the same presented in the SFRC characterization tests and listed in Table 4.1 and Table 4.3, respectively. Table 4.5 shows the mechanical properties of the rebars adopted.

Table 4.5.: Mechanical properties of the conventional rebars adopted.

\begin{tabular}{cc}
\hline Yield strength $f_{y}$ (for rebars with $\left.\phi 5.0\right)$ & $600 \mathrm{MPa}$ \\
\hline Yield strength $f_{y}$ (for all other rebars) & $500 \mathrm{MPa}$ \\
\hline Young's modulus $E_{s}$ & $200 \mathrm{GPa}$ \\
\hline
\end{tabular}


The SFRC parameters employed in the design of the RC-SFRC beams are described next.

\subsubsection{Post-cracking behavior of SFRC}

The nominal values of the SFRC properties used to design the RC-SFRC beams are based on the results of the three-point bending tests described in Section 4.1. A summary of the diagrams in terms of Force vs. CMOD responses for the three fiber contents is illustrated in Figure 4.18. As verified in this figure, three curves, one experimental and two numerical responses for each fiber content are considered. The experimental curves correspond to average responses obtained in laboratory tests (gray lines), while the numerical ones, can be described by those obtained for fiber content of $30 \mathrm{~kg} / \mathrm{m}^{3}$ by using two fiber generations (which correspond to distributions 1 and 2), and the others for fiber contents of $15 \mathrm{~kg} / \mathrm{m}^{3}$ and $45 \mathrm{~kg} / \mathrm{m}^{3}$ obtained by adopting two distinct concrete-fiber interface laws, for $\tau_{b \max }=8.5 \mathrm{MPa}$ (numerical 1 - blue lines) and $\tau_{b \max }=12.5 \mathrm{MPa}$ (numerical 2 - green lines) as depicted in Figure 4.11. As mentioned in Section 4.1, these parameters have been defined for the intermediate fiber content of $30 \mathrm{~kg} / \mathrm{m}^{3}$ to calibrate the numerical responses for the two distributions to the mean experimental curve as shown in Figure 4.12.

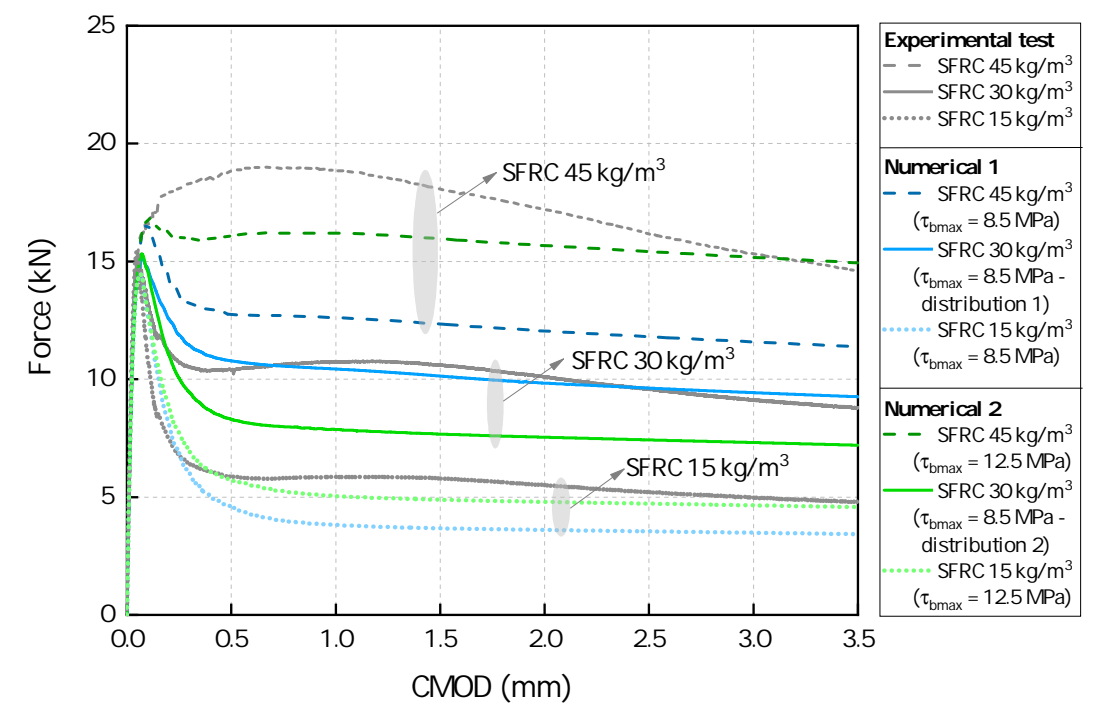

Figure 4.18.: Force vs. CMOD average curves of the experimental and numerical responses for $15 \mathrm{~kg} / \mathrm{m}^{3}, 30 \mathrm{~kg} / \mathrm{m}^{3}$ and $45 \mathrm{~kg} / \mathrm{m}^{3}$.

Based on the curves plotted in Figure 4.18, the performance parameters to design 
SFRC beams are obtained and listed in Table 4.6. Thus, residual flexural tensile strengths $f_{R 1}$ and $f_{R 3}$, limit of proportionality $f_{L}$, as well as the SFRC classification are defined for each fiber content for the three cases considered: experimental, numerical 1 and numerical 2.

Table 4.6.: EN 14651 test results.

\begin{tabular}{cccccc}
\hline \multirow{2}{*}{ Results from } & $\begin{array}{c}\text { Fiber content } \\
\left(\mathrm{kg} / \mathrm{m}^{3}\right)\end{array}$ & $\begin{array}{c}f_{L} \\
(\mathrm{MPa})\end{array}$ & $\begin{array}{c}f_{R 1} \\
(\mathrm{MPa})\end{array}$ & $\begin{array}{c}f_{R 3} \\
(\mathrm{MPa})\end{array}$ & Classification \\
\hline \hline \multirow{3}{*}{ Experimental tests } & $15 \mathrm{~kg} / \mathrm{m}^{3}$ & 4.96 & 1.88 & 1.67 & $1.5 \mathrm{~b}$ \\
\cline { 2 - 6 } & $30 \mathrm{~kg} / \mathrm{m}^{3}$ & 4.84 & 3.34 & 3.07 & $3.0 \mathrm{c}$ \\
\cline { 2 - 6 } & $45 \mathrm{~kg} / \mathrm{m}^{3}$ & 4.85 & 6.04 & 5.17 & $6.0 \mathrm{c}$ \\
\hline \hline \multirow{3}{*}{ Numerical 1 } & $15 \mathrm{~kg} / \mathrm{m}^{3}$ & 4.63 & 1.48 & 1.13 & $1.5 \mathrm{~b}$ \\
\cline { 2 - 6 } & $30 \mathrm{~kg} / \mathrm{m}^{3}$ & 4.90 & 3.45 & 3.08 & $3.0 \mathrm{c}$ \\
\hline \hline & $45 \mathrm{~kg} / \mathrm{m}^{3}$ & 5.31 & 4.09 & 3.78 & $4.0 \mathrm{c}$ \\
\cline { 2 - 6 } Numerical 2 & $15 \mathrm{~kg} / \mathrm{m}^{3}$ & 4.63 & 1.83 & 1.51 & $1.5 \mathrm{~b}$ \\
\cline { 2 - 6 } & $30 \mathrm{~kg} / \mathrm{m}^{3}$ & 4.90 & 2.66 & 2.38 & $3.0 \mathrm{c}$ \\
\cline { 2 - 6 } & $45 \mathrm{~kg} / \mathrm{m}^{3}$ & 5.41 & 5.13 & 4.93 & $5.0 \mathrm{c}$ \\
\hline
\end{tabular}

The beams are designed by considering for the post-cracking behavior of SFRC the rigid-plastic and linear constitutive models as proposed by MC2010. The ultimate and serviceability residual tensile strengths, $f_{F t u}$ and $f_{F t s}$, respectively, that define these models are illustrated in Figure 4.19 and listed in Table 4.7. 
(a)

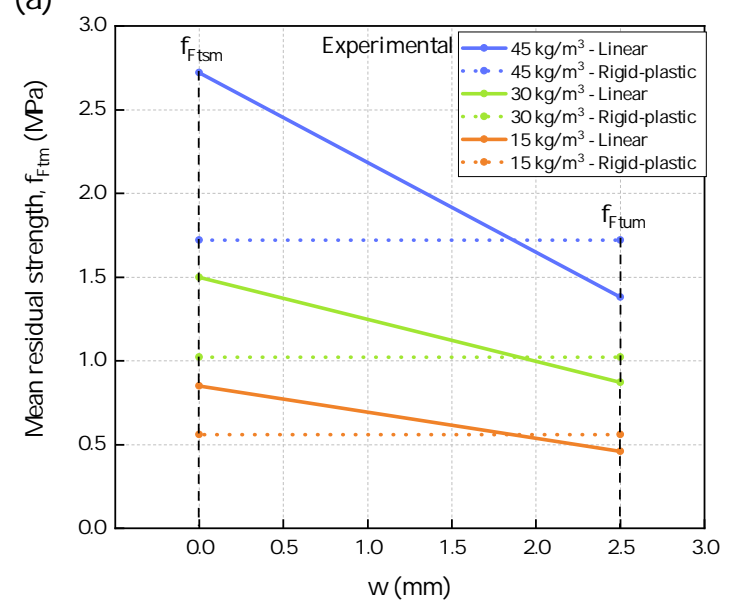

(b)

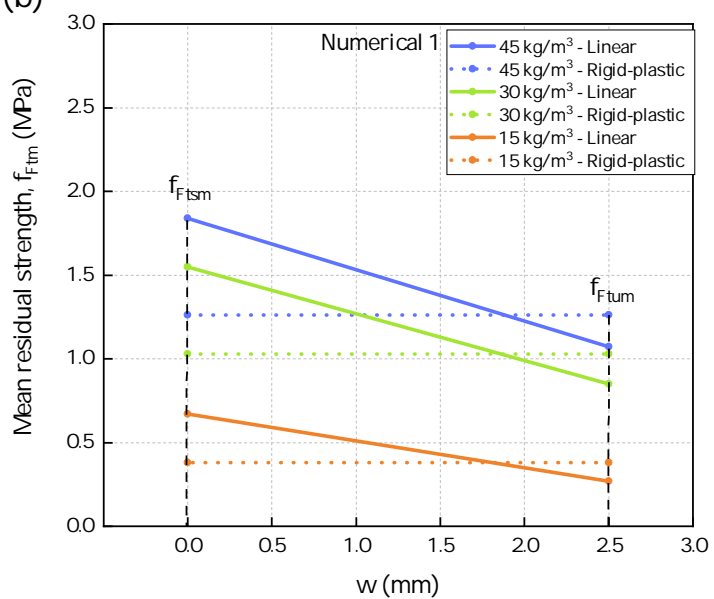

(c)

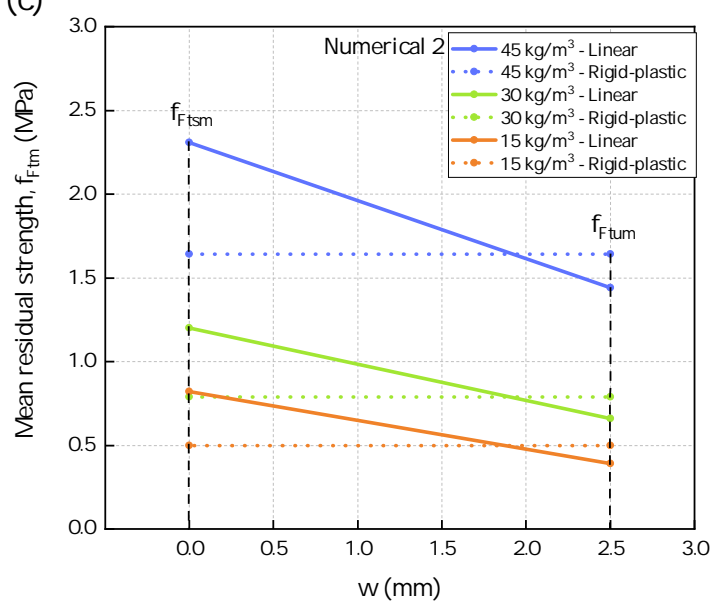

Figure 4.19.: Post-cracking behavior of SFRC described by rigid-plastic and linear constitutive models defined by parameters obtained from: (a) experimental tests; (b) numerical analyses 1 and (c) numerical analyses 2 . 
Table 4.7.: Residual strengths for rigid-plastic and linear models: fiber contents of $15 \mathrm{~kg} / \mathrm{m}^{3}, 30 \mathrm{~kg} / \mathrm{m}^{3}$ and $45 \mathrm{~kg} / \mathrm{m}^{3}$.

\begin{tabular}{ccccc}
\hline \multirow{2}{*}{ Results from } & Fiber content & Rigid-plastic & \multicolumn{2}{c}{ Linear } \\
\cline { 2 - 5 } & $\left(\mathrm{kg} / \mathrm{m}^{3}\right)$ & $\begin{array}{c}f_{F t u} \\
(\mathrm{MPa})\end{array}$ & $\begin{array}{c}f_{F t s} \\
(\mathrm{MPa})\end{array}$ & $\begin{array}{c}f_{F t u} \\
(\mathrm{MPa})\end{array}$ \\
\hline \hline \multirow{3}{*}{ Experimental tests } & $15 \mathrm{~kg} / \mathrm{m}^{3}$ & 0.56 & 0.85 & 0.46 \\
\cline { 2 - 5 } & $30 \mathrm{~kg} / \mathrm{m}^{3}$ & 1.02 & 1.50 & 0.87 \\
\cline { 2 - 5 } & $45 \mathrm{~kg} / \mathrm{m}^{3}$ & 1.72 & 2.72 & 1.38 \\
\hline \hline \multirow{3}{*}{ Numerical 1 } & $15 \mathrm{~kg} / \mathrm{m}^{3}$ & 0.38 & 0.67 & 0.27 \\
\cline { 2 - 5 } & $30 \mathrm{~kg} / \mathrm{m}^{3}$ & 1.03 & 1.55 & 0.85 \\
\cline { 2 - 5 } & $45 \mathrm{~kg} / \mathrm{m}^{3}$ & 1.26 & 1.84 & 1.07 \\
\hline \hline \multirow{2}{*}{ Numerical 2 } & $15 \mathrm{~kg} / \mathrm{m}^{3}$ & 0.50 & 0.82 & 0.39 \\
\cline { 2 - 5 } & $30 \mathrm{~kg} / \mathrm{m}^{3}$ & 0.79 & 1.20 & 0.66 \\
\cline { 2 - 5 } & $45 \mathrm{~kg} / \mathrm{m}^{3}$ & 1.64 & 2.31 & 1.44 \\
\hline
\end{tabular}

\subsubsection{Ultimate Limit State (ULS)}

In the Ultimate Limit State (ULS), the beams are designed for bending moment and shear forces with the strength reduction factors $\gamma=1.0$. The contribution of the steel fibers in the shear and bending design formulation is included as a function of the ultimate residual tensile strength $f_{F t u}$. This parameter is based on the experimental tests, numerical 1 and numerical 2 responses (see Table 4.7).

Firstly, the amount of longitudinal reinforcement $A_{s}$ is calculated for the RC beam by assuming the yielding of rebars. Secondly, the effect of fibers is introduced and a new longitudinal steel area $A_{s}$ is calculated by using the ultimate residual tensile strength $f_{F t u}$ defined in Table 4.7 for each fiber content. Table 4.8 summarizes the results obtained for the RC and RC-SFRC beams. Furthermore, a reduction factor $\left(\Delta \%=\left((\bullet)_{\mathrm{RC}}-(\bullet)_{\mathrm{RC}-\mathrm{SFRC}}\right) /(\bullet)_{\mathrm{RC}}\right)$ is also calculated for the RC-SFRC beams by taking the $\mathrm{RC}$ beam as a reference.

The results show that for $15 \mathrm{~kg} / \mathrm{m}^{3}$ fiber content, the steel fibers cannot replace conventional reinforcement since the requirement $f_{R 1} / f_{L}>0.4$ is not met (see Section 3.3). In addition, despite the longitudinal reinforcing steel areas $A_{s}$ for RC-SFRC beams for fiber contents of $30 \mathrm{~kg} / \mathrm{m}^{3}$ and $45 \mathrm{~kg} / \mathrm{m}^{3}$ exhibit a slight de- 
crease when compared to the $\mathrm{RC}$ beam; this reduction is not high enough to change the amount of bending reinforcement adopted.

Table 4.8.: Bending reinforcement for RC and RC-SFRC beams.

\begin{tabular}{|c|c|c|c|c|c|c|}
\hline \multirow[b]{2}{*}{$f_{\text {Ftu }}$ based on } & \multirow[b]{2}{*}{ Beam } & \multicolumn{2}{|c|}{ Rigid-plastic } & \multicolumn{2}{|c|}{ Linear model } & \multirow[b]{2}{*}{ Adopted } \\
\hline & & $\begin{array}{c}A_{s} \\
\left(\mathrm{~cm}^{2}\right)\end{array}$ & $\Delta \%$ & $\begin{array}{c}A_{s} \\
\left(\mathrm{~cm}^{2}\right)\end{array}$ & $\Delta \%$ & \\
\hline- & $\mathrm{RC}$ & & $A_{s}=$ & $.0 \mathrm{~cm}^{2}$ & & $\begin{array}{c}2 \cdot \phi_{16.0} \\
\left(4.0 \mathrm{~cm}^{2}\right)\end{array}$ \\
\hline \multirow{3}{*}{$\begin{array}{l}\text { Experimental } \\
\text { tests }\end{array}$} & "RC-SFRC $15 \mathrm{~kg} / \mathrm{m}^{3}$ & & & & & \multirow{3}{*}{$\begin{array}{l}2 \cdot \phi_{16.0} \\
\left(4.0 \mathrm{~cm}^{2}\right)\end{array}$} \\
\hline & RC-SFRC $30 \mathrm{~kg} / \mathrm{m}^{3}$ & 3.67 & $8 \%$ & 3.71 & $7 \%$ & \\
\hline & RC-SFRC $45 \mathrm{~kg} / \mathrm{m}^{3}$ & 3.45 & $14 \%$ & 3.56 & $11 \%$ & \\
\hline \multirow{3}{*}{ Numerical 1} & RC-SFRC $15 \mathrm{~kg} / \mathrm{m}^{3}$ & & & 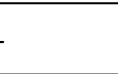 & & \multirow{3}{*}{$\begin{array}{l}2 \cdot \phi_{16.0} \\
\left(4.0 \mathrm{~cm}^{2}\right)\end{array}$} \\
\hline & RC-SFRC $30 \mathrm{~kg} / \mathrm{m}^{3}$ & 3.66 & $9 \%$ & 3.72 & $7 \%$ & \\
\hline & RC-SFRC $45 \mathrm{~kg} / \mathrm{m}^{3}$ & 3.59 & $10 \%$ & 3.65 & $9 \%$ & \\
\hline \multirow{3}{*}{ Numerical 2} & RC-SFRC $15 \mathrm{~kg} / \mathrm{m}^{3}$ & & & & & \multirow{3}{*}{$\begin{array}{l}2 \cdot \phi_{16.0} \\
\left(4.0 \mathrm{~cm}^{2}\right)\end{array}$} \\
\hline & RC-SFRC $30 \mathrm{~kg} / \mathrm{m}^{3}$ & 3.74 & $6 \%$ & 3.78 & $6 \%$ & \\
\hline & RC-SFRC $45 \mathrm{~kg} / \mathrm{m}^{3}$ & 3.48 & $13 \%$ & 3.54 & $12 \%$ & \\
\hline
\end{tabular}

The shear reinforcements are calculated for two regions of the beam: the middle third span of the beam with no shear force $V_{\min }=0$, where a minimum quantity of shear reinforcement must be provided, and the regions between the support and the concentrated load where shear forces present a constant value of $V_{\max }=61.5 \mathrm{kN}$, and, consequently, shear reinforcement is required.

First, the reference beam (RC) is designed for the conventional transverse reinforcement, by resulting in $\phi 6.3 \mathrm{~mm}$ stirrups spaced at $150 \mathrm{~mm}$ within the regions between the support and the concentrated load (maximum shear reinforcement) and $\phi 5.0 / 150 \mathrm{~mm}$ placed in the central part of the beam (minimum shear reinforcement). The final shear reinforcement configuration for the $\mathrm{RC}$ beam is illustrated in Figure 4.20. 


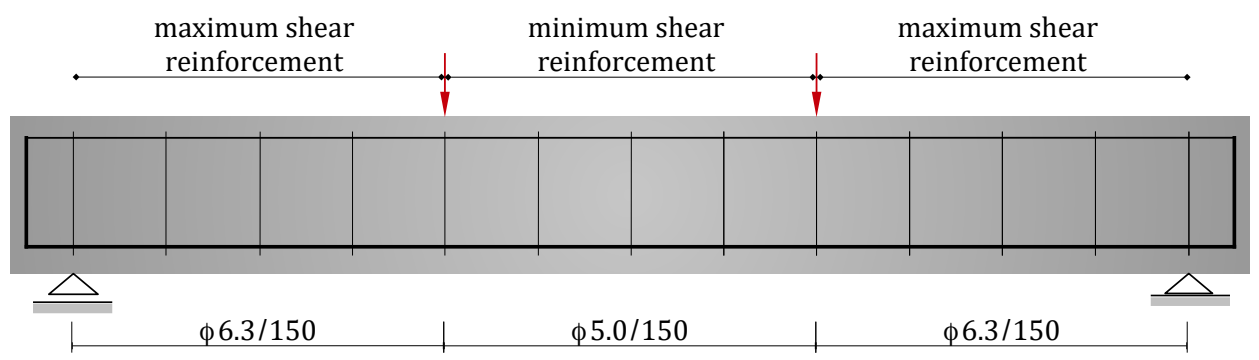

Figure 4.20.: Stirrups distribution along the RC beam.

As aforementioned, for RC-SFRC beam with fiber content of $15 \mathrm{~kg} / \mathrm{m}^{3}$, the steel fibers cannot replace the conventional reinforcement (stirrups). However, for RCSFRC beams with $30 \mathrm{~kg} / \mathrm{m}^{3}$ and $45 \mathrm{~kg} / \mathrm{m}^{3}$ the shear contribution of steel fibers can be calculated. In the region requiring the minimum amount of transverse reinforcement, steel fibers completely satisfy the shear reinforcing requirements for both fiber contents. In the region of maximum shear forces, with the addition of the fiber content of $30 \mathrm{~kg} / \mathrm{m}^{3}$, the amount of stirrups is reduced to $\phi 5.0 / 150 \mathrm{~mm}(\phi 6.3 / 150 \mathrm{~mm}$ for $\mathrm{RC}$ beam) while for $45 \mathrm{~kg} / \mathrm{m}^{3}$ the stirrups are totally replaced by steel fibers.

Table 4.9 summarizes the minimum and maximum shear reinforcement. Note that, the reinforcement calculated for the different responses of $f_{F t u}$ (see Table 4.7) gives the same shear reinforcement configuration. Moreover, the addition of $30 \mathrm{~kg} / \mathrm{m}^{3}$ of steel fibers results in an overall reduction of $47 \%$, while for the steel fiber content of $45 \mathrm{~kg} / \mathrm{m}^{3}, 100 \%$ of the conventional shear reinforcements are replaced by steel fibers. 
Table 4.9.: Shear reinforcement for RC and RC-SFRC beams.

\begin{tabular}{ccccc}
\hline$f_{F t u}$ based on & \multicolumn{1}{c}{ Beam } & Max & Min & $\Delta \%$ \\
\hline \hline \multirow{2}{*}{ Experimental tests } & RC & $\phi 6.3 / 150$ & $\phi 5.0 / 150$ & \\
\hline \hline & RC-SFRC $15 \mathrm{~kg} / \mathrm{m}^{3}$ & - & - & - \\
\cline { 2 - 5 } & RC-SFRC $30 \mathrm{~kg} / \mathrm{m}^{3}$ & $\phi 5.0 / 150$ & steel fibers & $47 \%$ \\
\cline { 2 - 5 } Numerical 1 & RC-SFRC $45 \mathrm{~kg} / \mathrm{m}^{3}$ & steel fibers & steel fibers & $100 \%$ \\
\hline \hline \multirow{3}{*}{ Numerical 2 } & RC-SFRC $15 \mathrm{~kg} / \mathrm{m}^{3}$ & - & - & - \\
\cline { 2 - 6 } & RC-SFRC $45 \mathrm{~kg} / \mathrm{m}^{3}$ & steel fibers & steel fibers & $100 \%$ \\
\hline \hline & RC-SFRC $15 \mathrm{~kg} / \mathrm{m}^{3}$ & - & & - \\
\cline { 2 - 5 } & RC-SFRC $30 \mathrm{~kg} / \mathrm{m}^{3}$ & $\phi 5.0 / 150$ & steel fibers & $47 \%$ \\
\cline { 2 - 5 } & RC-SFRC $45 \mathrm{~kg} / \mathrm{m}^{3}$ & steel fibers & steel fibers & $100 \%$ \\
\hline
\end{tabular}

\subsubsection{Serviceability Limit State (SLS)}

At the Serviceability Limit State (SLS) the crack widths, mean crack spacings and deformations are evaluated for a load corresponding to $\mathrm{P}_{(\mathrm{SLS})}=82 \mathrm{kN}$ and the contributions of the steel fibers is calculated as a function of the serviceability residual tensile strengths, $f_{F t s}$, for the linear constitutive model (see Table 4.7), as recommended by MC2010.

First, the crack widths are calculated for the four beams configurations and depicted in Table 4.10. The crack width for the $\mathrm{RC}$ beam $\left(w_{d}=0.26 \mathrm{~mm}\right)$ is smaller than the allowable crack width $w_{\text {lim }}=0.3 \mathrm{~mm}$ (exposure class XC2 ( $f i b$ Model Code 2010, 2013)), which means that the amount of conventional reinforcement adopted was enough to fulfill the crack width limit. Furthermore, the crack widths for RCSFRC beams are also estimated, although, within the limit, the predictions following the MC2010 demonstrate that the crack widths reduce with the addition of steel fibers, showing a maximum reduction of $69 \%$ for the RC-SFRC beam with $45 \mathrm{~kg} / \mathrm{m}^{3}$. Nevertheless, it is worth noting that the numerical and experimental test responses show very similar tendencies (see Figure 4.21). 
Table 4.10.: Crack width evaluated based on the experimental and numerical results from EN 14651 tests.

\begin{tabular}{clcc}
\hline Reference values & \multicolumn{1}{c}{ Beam } & $w_{d}(\mathrm{~mm})$ & $\Delta \%$ \\
\hline \hline \multirow{4}{*}{ Experimental tests } & \multicolumn{1}{c}{ RC } & 0.26 & - \\
\cline { 2 - 4 } & RC-SFRC $15 \mathrm{~kg} / \mathrm{m}^{3}$ & 0.18 & $31 \%$ \\
\cline { 2 - 4 } & RC-SFRC $30 \mathrm{~kg} / \mathrm{m}^{3}$ & 0.14 & $46 \%$ \\
\hline \hline \multirow{3}{*}{ Numerical 1 } & RC-SFRC $45 \mathrm{~kg} / \mathrm{m}^{3}$ & 0.08 & $69 \%$ \\
\cline { 2 - 4 } & RC-SFRC $15 \mathrm{~kg} / \mathrm{m}^{3}$ & 0.20 & $23 \%$ \\
\cline { 2 - 4 } & RC-SFRC $30 \mathrm{~kg} / \mathrm{m}^{3}$ & 0.13 & $50 \%$ \\
\hline \hline \multirow{3}{*}{ Numerical 2 } & RC-SFRC $45 \mathrm{~kg} / \mathrm{m}^{3}$ & 0.11 & $58 \%$ \\
\cline { 2 - 4 } & RC-SFRC $30 \mathrm{~kg} / \mathrm{m}^{3}$ & 0.16 & $38 \%$ \\
\cline { 2 - 4 } & RC-SFRC $45 \mathrm{~kg} / \mathrm{m}^{3}$ & 0.08 & $69 \%$ \\
\hline
\end{tabular}

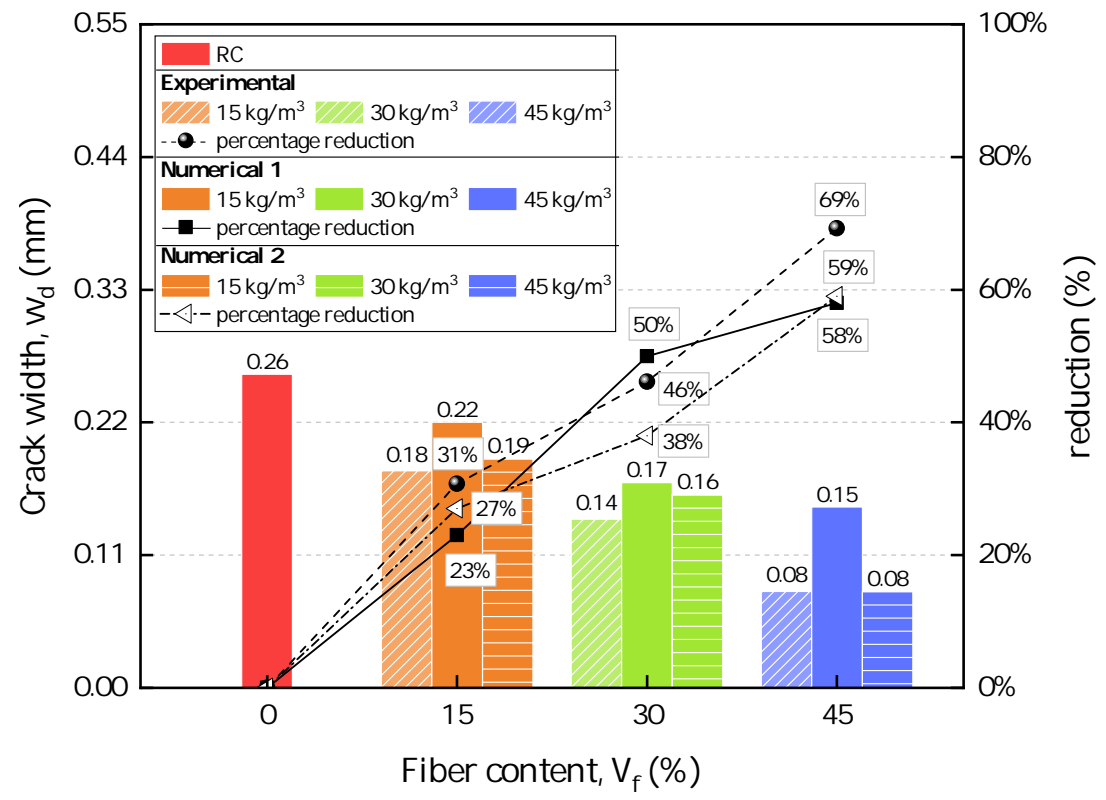

Figure 4.21.: Crack width for RC beam, SFRC-RC beams with $15 \mathrm{~kg} / \mathrm{m}^{3}$, $30 \mathrm{~kg} / \mathrm{m}^{3}$ and $45 \mathrm{~kg} / \mathrm{m}^{3}$ and the reduction when compared to $w_{d}$ for RC regarding experimental, numerical 1 and numerical 2 results.

The mean crack spacing is also estimated following the MC2010 predictions and the results are shown in Table 4.11. These results illustrate the effect of adding fibers to 
concrete by decreasing the mean distance between cracks $s_{r m}$; for example, a fiber content of $45 \mathrm{~kg} / \mathrm{m}^{3}$ for the experimental results presents a reduction of $62 \%$ of $s_{r m}$ when compared to RC beam for the experimental tests results. (see Figure 4.22).

Table 4.11.: Mean distance between cracks.

\begin{tabular}{|c|c|c|c|}
\hline Reference values & Beam & $s_{r m}(\mathrm{~mm})$ & $\Delta \%$ \\
\hline- & $\mathrm{RC}$ & 76 & - \\
\hline \multirow{3}{*}{ Experimental tests } & RC-SFRC $15 \mathrm{~kg} / \mathrm{m}^{3}$ & 58 & $24 \%$ \\
\hline & RC-SFRC $30 \mathrm{~kg} / \mathrm{m}^{3}$ & 45 & $41 \%$ \\
\hline & RC-SFRC $45 \mathrm{~kg} / \mathrm{m}^{3}$ & 29 & $62 \%$ \\
\hline \multirow{3}{*}{ Numerical 1} & RC-SFRC $15 \mathrm{~kg} / \mathrm{m}^{3}$ & 62 & $18 \%$ \\
\hline & RC-SFRC $30 \mathrm{~kg} / \mathrm{m}^{3}$ & 44 & $42 \%$ \\
\hline & RC-SFRC $45 \mathrm{~kg} / \mathrm{m}^{3}$ & 39 & $49 \%$ \\
\hline \multirow{3}{*}{ Numerical 2} & RC-SFRC $15 \mathrm{~kg} / \mathrm{m}^{3}$ & 59 & $22 \%$ \\
\hline & RC-SFRC $30 \mathrm{~kg} / \mathrm{m}^{3}$ & 51 & $33 \%$ \\
\hline & RC-SFRC $45 \mathrm{~kg} / \mathrm{m}^{3}$ & 30 & $61 \%$ \\
\hline
\end{tabular}

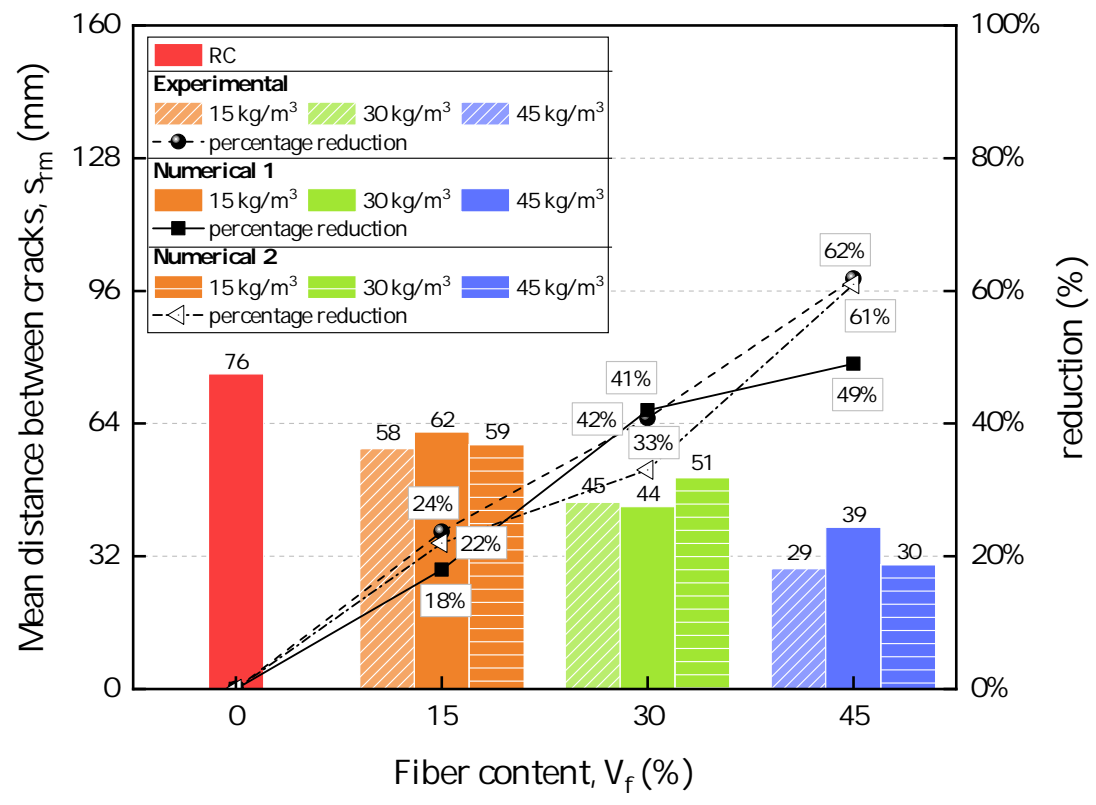

Figure 4.22.: Mean distance between cracks $s_{r m}$ of RC, RC-SFRC for $15 \mathrm{~kg} / \mathrm{m}^{3}$, $30 \mathrm{~kg} / \mathrm{m}^{3}$ and $45 \mathrm{~kg} / \mathrm{m}^{3}$ and percentage reduction when compared to RC regarding the experimental, numerical 1 and numerical 2 responses. 
The short-term deflections of the RC and RC-SFRC beams are calculated and compared with the serviceability specifications. The limit deflection in this application is $\delta_{\text {lim }}=7.2 \mathrm{~mm}$ (estimated as $\delta_{\text {lim }}=\ell / 250$ ) for quasi-permanent loads, where $\ell$ is the beam span. As can be seen in Table 4.12 the value of the limit deflection is already low for RC and the addition of fiber shows the highest reduction of $21 \%$ by considering the experimental response for RC-SFRC beam with $45 \mathrm{~kg} / \mathrm{m}^{3}$.

Table 4.12.: Deflection for RC and RC-SFRC beams.

\begin{tabular}{|c|c|c|c|}
\hline Reference values & Beam & $\delta_{\mathrm{SLS}}(\mathrm{mm})$ & $\Delta \%$ \\
\hline- & $\mathrm{RC}$ & 4.31 & \\
\hline \multirow{3}{*}{ Experimental tests } & RC-SFRC $15 \mathrm{~kg} / \mathrm{m}^{3}$ & 4.03 & $6 \%$ \\
\hline & RC-SFRC $30 \mathrm{~kg} / \mathrm{m}^{3}$ & 3.80 & $12 \%$ \\
\hline & RC-SFRC $45 \mathrm{~kg} / \mathrm{m}^{3}$ & 3.41 & $21 \%$ \\
\hline \multirow{3}{*}{ Numerical 1} & RC-SFRC $15 \mathrm{~kg} / \mathrm{m}^{3}$ & 4.09 & $5 \%$ \\
\hline & RC-SFRC $30 \mathrm{~kg} / \mathrm{m}^{3}$ & 3.78 & $12 \%$ \\
\hline & RC-SFRC $45 \mathrm{~kg} / \mathrm{m}^{3}$ & 3.69 & $14 \%$ \\
\hline \multirow{3}{*}{ Numerical 2} & RC-SFRC $15 \mathrm{~kg} / \mathrm{m}^{3}$ & 4.03 & $6 \%$ \\
\hline & RC-SFRC $30 \mathrm{~kg} / \mathrm{m}^{3}$ & 3.91 & $9 \%$ \\
\hline & RC-SFRC $45 \mathrm{~kg} / \mathrm{m}^{3}$ & 3.54 & $18 \%$ \\
\hline
\end{tabular}

The expressions to design RC-SFRC beams according to MC2010 are given in Chapter 3 and all the calculations of this section are demonstrated step-by-step in Section C.1.

\subsubsection{Numerical simulation by FEM}

The beams designed in Section 4.2.1 are numerically analyzed. The setup test, geometry and concrete mesh are illustrated in Figure 4.23(a) and the reinforcement configurations for the numerical analyses are: RC beam (Figure 4.23(b)), RC-SFRC beam with $15 \mathrm{~kg} / \mathrm{m}^{3}$ (Figure $4.23(\mathrm{c})$ ), RC-SFRC beam with $30 \mathrm{~kg} / \mathrm{m}^{3}$ (Figure $4.23(\mathrm{~d})$ ) and RC-SFRC beam with $45 \mathrm{~kg} / \mathrm{m}^{3}$ (Figure $4.23(\mathrm{e})$ ). Note that for RC-SFRC beam with $15 \mathrm{~kg} / \mathrm{m}^{3}$ (see Figure $4.23(\mathrm{c})$ ), the rebars configuration remains the same as in $\mathrm{RC}$ beam, as already mentioned. For this fiber content, 
it is not possible to substitute, not even partially, the conventional reinforcement. Therefore, the purpose of this analysis is related to the Serviceability Limit State (SLS).
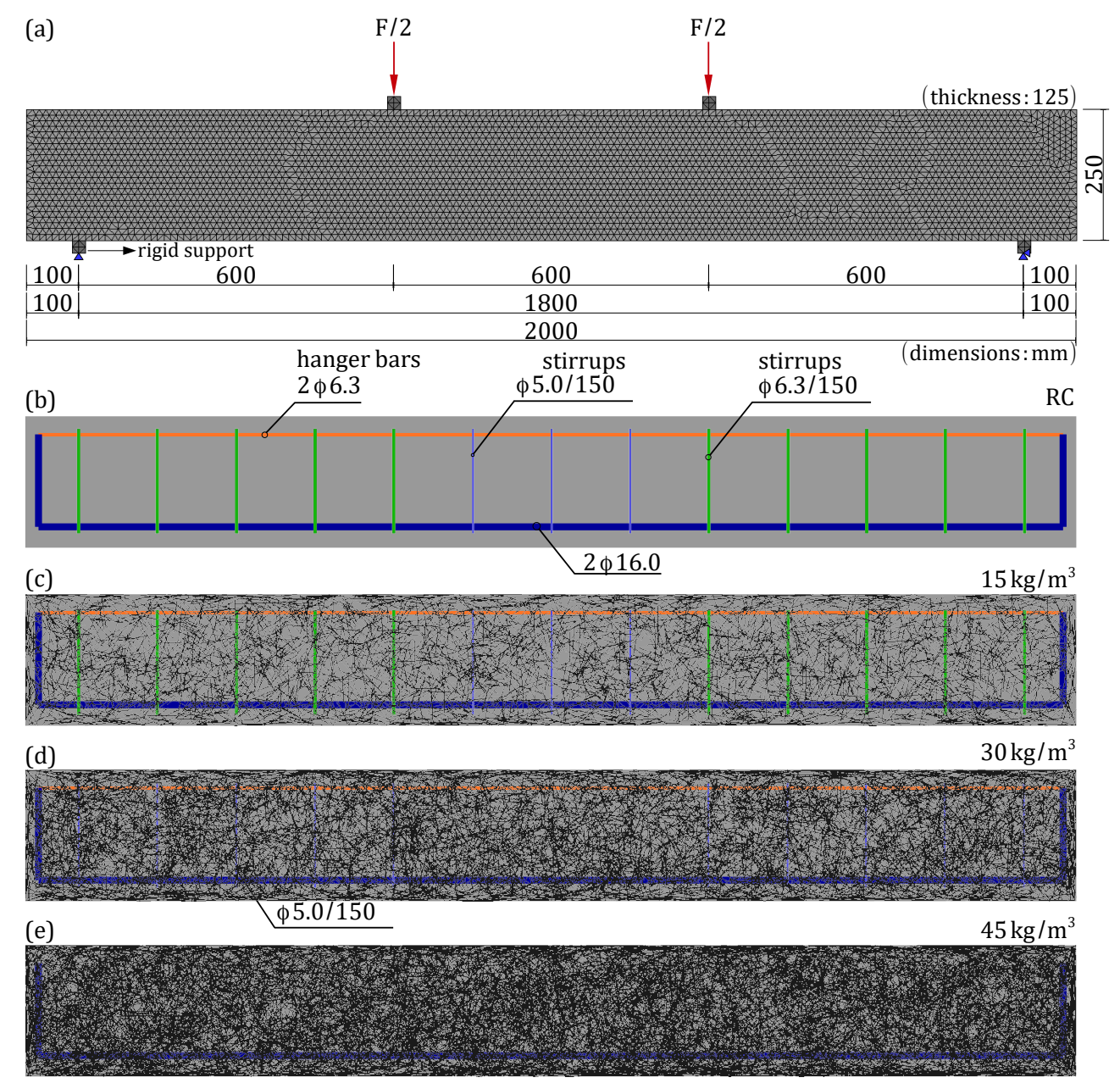

Figure 4.23.: Numerical modeling of four-point bending beams: (a) geometric properties, finite element mesh, load and support conditions; (b) RC beam; (c) RC-SFRC beam with $15 \mathrm{~kg} / \mathrm{m}^{3}$; (d) RC-SFRC beam with $30 \mathrm{~kg} / \mathrm{m}^{3}$ and (e) RCSFRC beam with $45 \mathrm{~kg} / \mathrm{m}^{3}$.

The material parameters for concrete, steel fibers and fiber-concrete interface were the same as adopted in Section 4.1. For the stirrups, a rigid bond-slip is assumed while good bond conditions (according to MC2010 for pull-out failure mode) are adopted for the longitudinal reinforcement with the following interface parameters: $\tau_{b \max }=14.8 \mathrm{MPa}, \tau_{b f}=5.9 \mathrm{MPa}, \alpha=0.4, s_{1}=1.0 \mathrm{~mm}, s_{2}=2.0 \mathrm{~mm}, s_{3}=$ $10.0 \mathrm{~mm}, c_{n}=10^{3} \mathrm{MPa} / \mathrm{mm}$ and $c_{s}=10^{6} \mathrm{MPa} / \mathrm{mm}$.

The conventional reinforcements were discretized in two-noded truss finite elements 
with the size of each element around $\approx 15$. Each fiber was discretized in 3 truss finite elements and the ratio between steel fiber and concrete meshes is around $\approx 1.5$. The number of elements for each beam configuration is shown in Table 4.13.

Table 4.13.: Characteristics of the finite element meshes for the four beam configurations considered.

\begin{tabular}{ccccc}
\hline \multirow{2}{*}{ Type of beam } & \multicolumn{4}{c}{ Number of elements } \\
\cline { 2 - 5 } & $\begin{array}{c}\text { two-noded } \\
\text { trusses }\end{array}$ & $\begin{array}{c}\text { three- } \\
\text { noded } \\
\text { triangular }\end{array}$ & $\begin{array}{c}\text { four-noded } \\
\text { triangular } \\
\text { CFEs }\end{array}$ & $\begin{array}{c}\text { total } \\
\text { number of } \\
\text { elements }\end{array}$ \\
\hline \hline $\mathrm{RC}$ & 375 & 7266 & 388 & 8029 \\
\hline RC-SFRC $15 \mathrm{~kg} / \mathrm{m}^{3}$ & 12145 & 7266 & 16692 & 36127 \\
\hline RC-SFRC $30 \mathrm{~kg} / \mathrm{m}^{3}$ & 23713 & 7266 & 32792 & 63771 \\
\hline RC-SFRC $45 \mathrm{~kg} / \mathrm{m}^{3}$ & 35362 & 7266 & 48966 & 91594 \\
\hline
\end{tabular}

The numerical results of force vs. displacement curves are illustrated in Figure 4.24. The response for RC-SFRC $15 \mathrm{~kg} / \mathrm{m}^{3}$, when compared to RC curve, shows a slight increase of bearing capacity with the addition of fibers. It is important to mention that these responses were obtained for the same conventional reinforcement configuration. As verified, the same tendency is observed for RC and RC-SFRC $30 \mathrm{~kg} / \mathrm{m}^{3}$, although the stirrups are reduced and fibers are used in the place where minimum reinforcement is required. For RC-SFRC $45 \mathrm{~kg} / \mathrm{m}^{3}$, all stirrups are replaced by steel fiber and the response still demonstrates a ductile behavior, not brittle (typical failure in the case which does not include any stirrups). The numerical results may demonstrate that steel fibers, if provided in sufficient quantity, could reduce or even replace the shear reinforcement, as allowed in MC2010 and additionally improve the bearing capacity. 


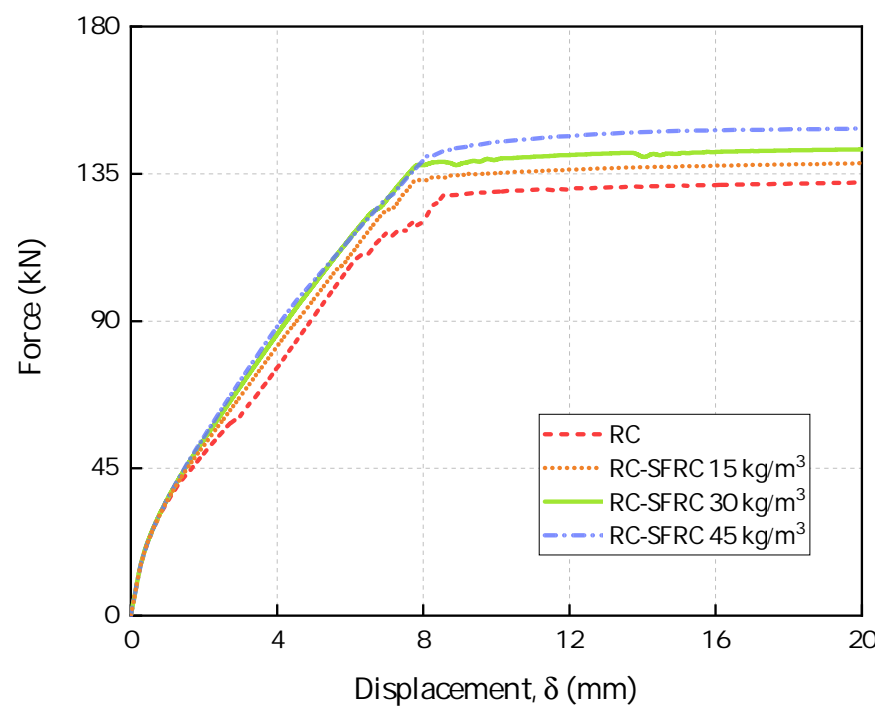

Figure 4.24.: Force vs. displacement curves. Comparison between numerical responses for RC beam and RC-SFRC beams with fiber content of $15 \mathrm{~kg} / \mathrm{m}^{3}$, $30 \mathrm{~kg} / \mathrm{m}^{3}$ and $45 \mathrm{~kg} / \mathrm{m}^{3}$.

In Section 4.1, two values of maximum bond stress are used to describe the fiberconcrete interface: $\tau_{b \max }=8.5 \mathrm{MPa}$ and $12.5 \mathrm{MPa}$ (see Figure 4.12). The structural response for RC-SFRC $30 \mathrm{~kg} / \mathrm{m}^{3}$ by adopting both values is shown in Figure 4.25 . As can be seen, there is a small difference in the responses, even if the most or the least favorable distribution is considered, meaning that even with the variability in the characterization test results, the structural response is not significantly affected (considering a uniform distribution of fibers). 


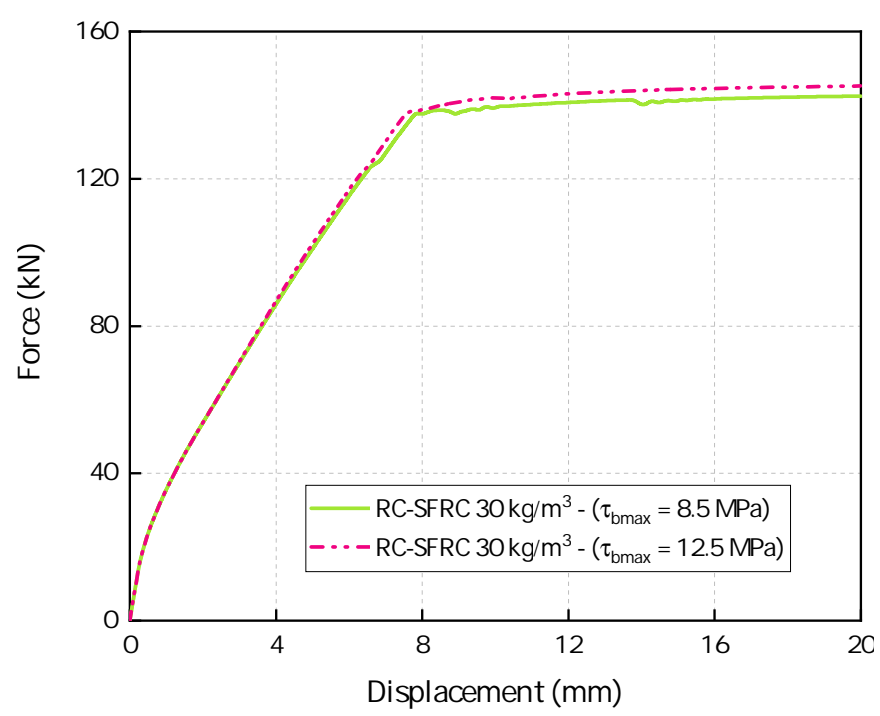

Figure 4.25.: Force vs. displacement curves. Comparison between numerical responses of RC-SFRC beam with fiber content of $30 \mathrm{~kg} / \mathrm{m}^{3}$ for $\tau_{\text {bmax }}=8.5 \mathrm{MPa}$ and $\tau_{\text {bmax }}=12.5 \mathrm{MPa}$.

Figure 4.26 depicts the crack propagation patterns and steel fiber stresses. A comparison between the crack patterns for RC beam and RC-SFRC beam with fiber content of $15 \mathrm{~kg} / \mathrm{m}^{3}$ (see Figure 4.26(a) and (b)) shows slightly more cracks with the addition of $15 \mathrm{~kg} / \mathrm{m}^{3}$ of steel fibers. In addition, more cracks arise by increasing the fiber content, especially for the RC-SFRC beam with fiber content of $45 \mathrm{~kg} / \mathrm{m}^{3}$ (see Figure 4.26(f)).

Note that the stresses on fibers follow the same pattern as the cracks propagation for all RC-SFRC beams: Figure 4.26(b) and (c) for $15 \mathrm{~kg} / \mathrm{m}^{3}$, Figure $4.26(\mathrm{~d})$ and (e) for $30 \mathrm{~kg} / \mathrm{m}^{3}$ and Figure $4.26(\mathrm{f})$ and (g) for $45 \mathrm{~kg} / \mathrm{m}^{3}$. These figures can also allow observing the effect of the fiber bridging of cracks. 
(a)

$\mathrm{RC}$

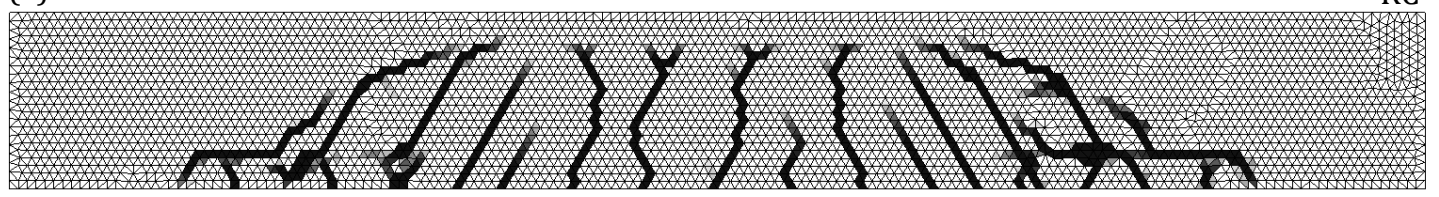

(b)

$\mathrm{RC}-\mathrm{SFRC} 15 \mathrm{~kg} / \mathrm{m}^{3}$

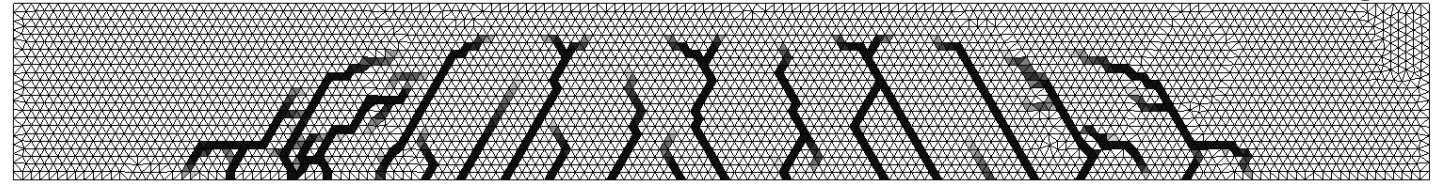

(c)

$\mathrm{RC}-\mathrm{SFRC} 15 \mathrm{~kg} / \mathrm{m}^{3}$

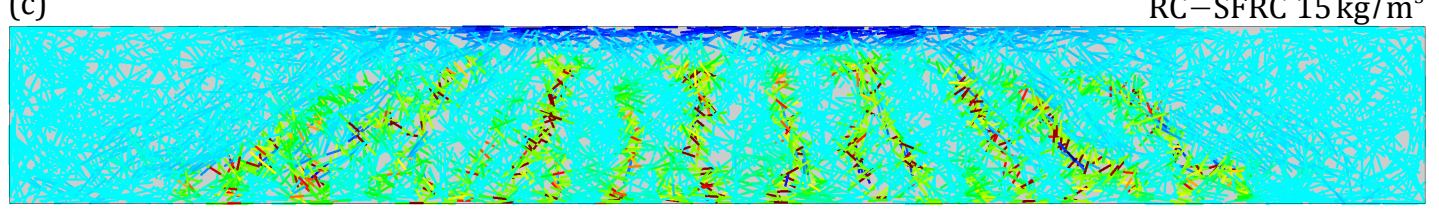

(d)

$\mathrm{RC}-\mathrm{SFRC} 30 \mathrm{~kg} / \mathrm{m}^{3}$

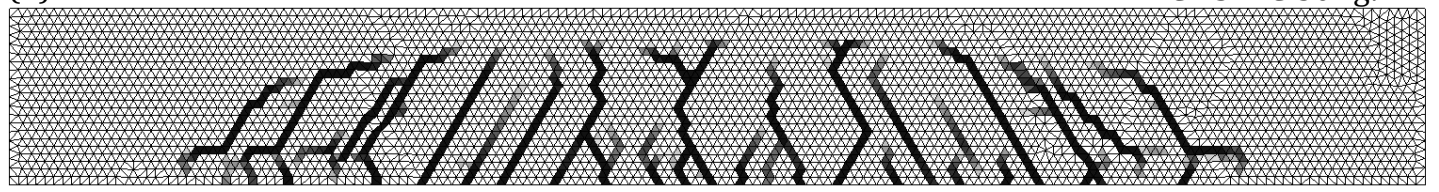

(e)

$\mathrm{RC}-\mathrm{SFRC} 30 \mathrm{~kg} / \mathrm{m}^{3}$

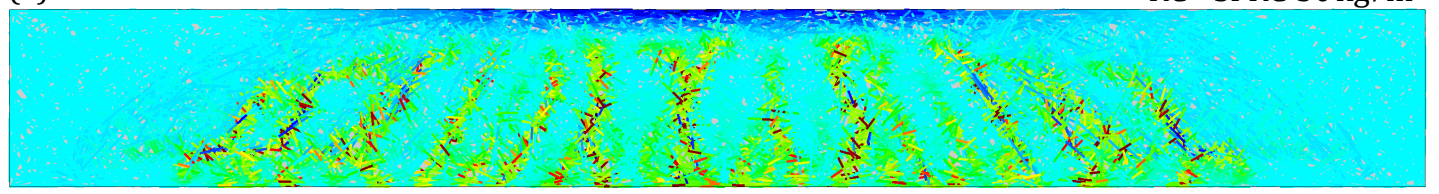

(f)

$\mathrm{RC}-\mathrm{SFRC} 45 \mathrm{~kg} / \mathrm{m}^{3}$

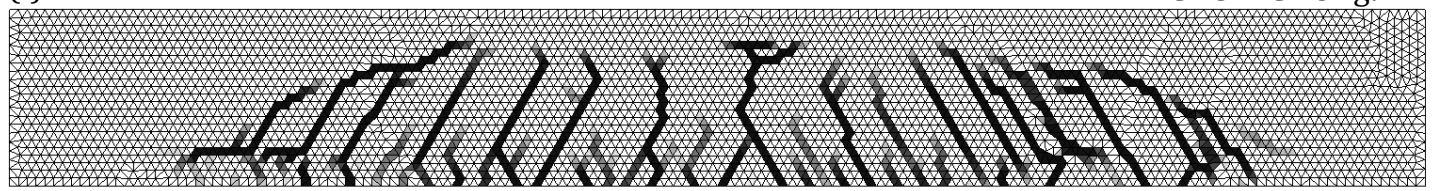

(g)

$\mathrm{RC}-\mathrm{SFRC} 45 \mathrm{~kg} / \mathrm{m}^{3}$

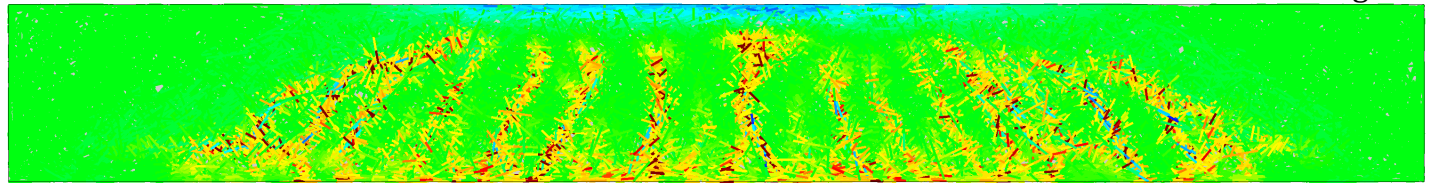

Figure 4.26.: Crack propagation pattern for: (a) RC; (b) RC-SFRC for $V_{f}=$ $15 \mathrm{~kg} / \mathrm{m}^{3}$; (d) RC-SFRC for $V_{f}=30 \mathrm{~kg} / \mathrm{m}^{3}$; (f) RC-SFRC for $V_{f}=45 \mathrm{~kg} / \mathrm{m}^{3}$ and stress on fibers of (c) RC-SFRC for $V_{f}=15 \mathrm{~kg} / \mathrm{m}^{3}$; (e) RC-SFRC for $V_{f}=30 \mathrm{~kg} / \mathrm{m}^{3}$ and (g) RC-SFRC for $V_{f}=45 \mathrm{~kg} / \mathrm{m}^{3}$ (all the responses are shown for $\delta=12 \mathrm{~mm}$ ). 


\subsection{3. fib Model Code $2010 \times$ numerical responses}

The numerical models discussed herein are compared against the predictions of the MC2010. In Figure 4.27, the design load for ultimate limit state, $\mathrm{P}_{(\mathrm{ULS})}$, and serviceability limit state, $\mathrm{P}_{(\mathrm{SLS})}$, are plotted against the numerical responses. The numerical curves for the RC and RC-SFRC beams show good prediction responses when compared with the ultimate load, $\mathrm{P}_{(\mathrm{ULS})}$. Note that the addition of fibers results in an increment of the bearing capacity.

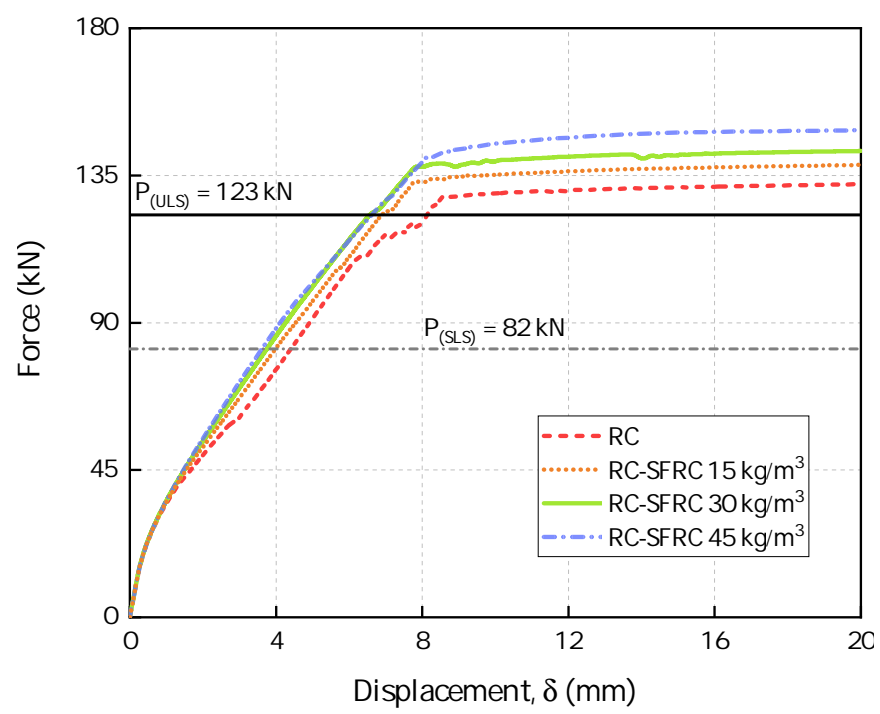

Figure 4.27.: Force vs. displacement curves. Comparison between numerical responses for: RC beam, RC-SFRC beams with fiber content of $15 \mathrm{~kg} / \mathrm{m}^{3}, 30 \mathrm{~kg} / \mathrm{m}^{3}$ and $45 \mathrm{~kg} / \mathrm{m}^{3}$ and the serviceability and ultimate design loads.

The number of cracks, the crack spacing and mean distance between cracks were also taken at the load level corresponding to the serviceability load $\mathrm{P}_{(\mathrm{SLS})}=82 \mathrm{kN}$. The number of cracks was measured at the level of the longitudinal reinforcement $d^{\prime}$ and the quantity of each beam is shown in Figure 4.28. As expected, the number of cracks increases with the addition of fibers (see Figure 4.28(a), (b), (c) and (d)). The mean crack spacing is obtained by computing the distance between the principal cracks presented in Figure 4.28. In addition, the crack width was calculated by applying the equation discussed in Chapter 3 given by the formula $w=l_{c s} \cdot \varepsilon$, where $\varepsilon$ is the principal strain, $l_{c s}$ is the characteristic length assumed equals to $l_{c s}=\sqrt{A}$ (Cervera et al., 1996) being $A$ the area of the element. 
(a) RC No. of cracks: $18 \bullet \delta=4.40 \mathrm{~mm}$

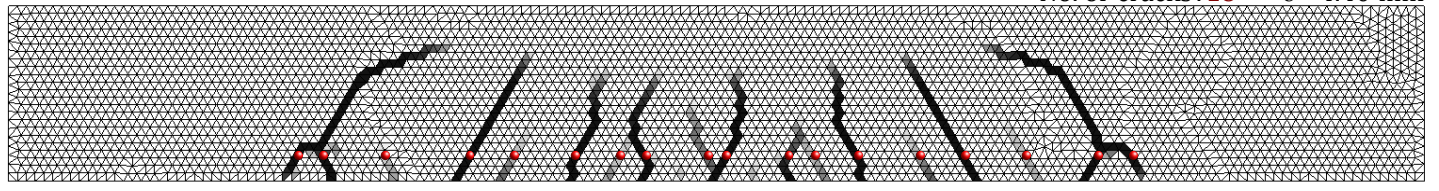

(b) RC-SFRC $15 \mathrm{~kg} / \mathrm{m}^{3}$

No. of cracks: $22 \bullet \quad \delta=3.98 \mathrm{~mm}$

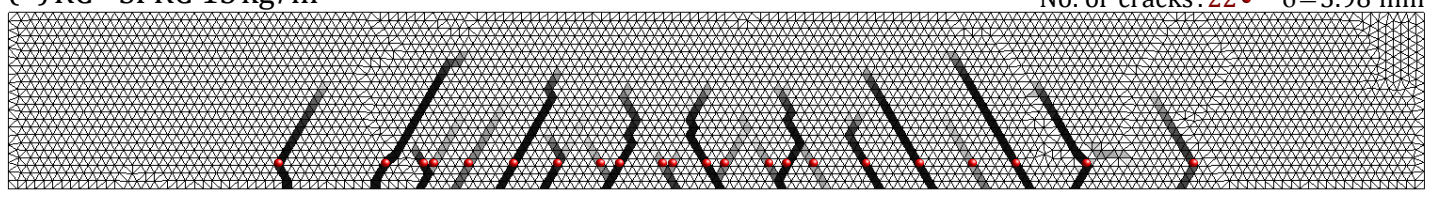

(c) RC-SFRC $30 \mathrm{~kg} / \mathrm{m}^{3}$

No. of cracks : $28 \bullet \quad \delta=3.75 \mathrm{~mm}$

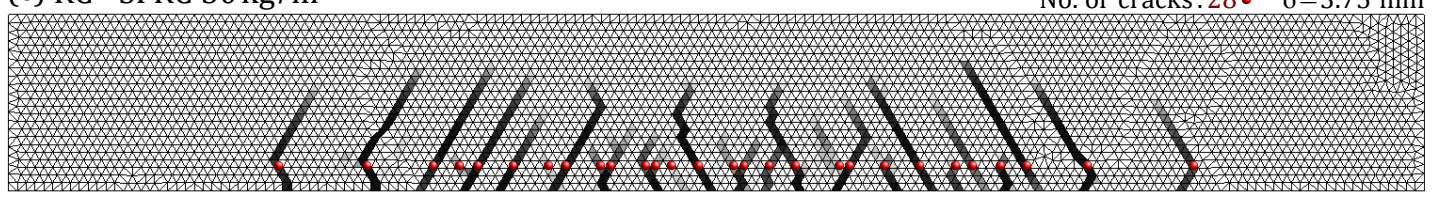

(d) RC-SFRC $45 \mathrm{~kg} / \mathrm{m}^{3}$

No. of cracks: $35 \bullet \delta=3.61 \mathrm{~mm}$

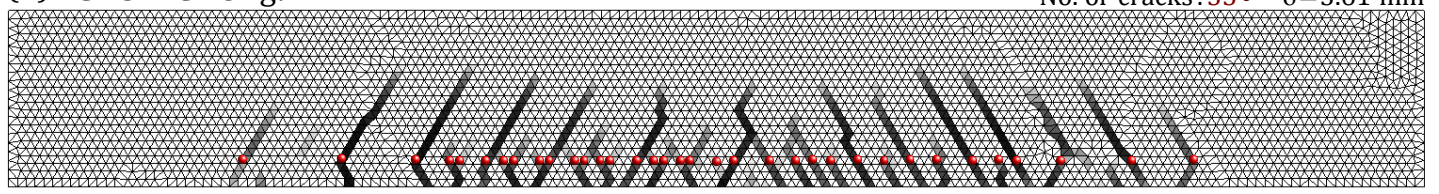

Figure 4.28.: Crack propagation pattern and number of cracks for: (a) RC beam; and RC-SFRC beams with fiber content of (b) $15 \mathrm{~kg} / \mathrm{m}^{3}$; (c) $30 \mathrm{~kg} / \mathrm{m}^{3}$ and (d) $45 \mathrm{~kg} / \mathrm{m}^{3}$ (All the responses for $\mathrm{P}_{(\mathrm{SLS})}=82 \mathrm{kN}$ ).

Table 4.14 summarizes the values of crack width, $w$, mean crack spacing, $s_{r m}$, and deflection at SLS, $\delta_{S L S}$, for the numerical model and MC2010 predictions (using the experimental test results of EN 14651 (2005)).

Table 4.14.: Numerical responses and predictions of MC2010 for crack width, mean crack spacing and deflection at SLS.

\begin{tabular}{ccccccc}
\hline Beam & $\begin{array}{c}w_{\text {num }} \\
(\mathrm{mm})\end{array}$ & $\begin{array}{c}w_{M C 2010} \\
(\mathrm{~mm})\end{array}$ & $\begin{array}{c}s_{\text {rm,num }} \\
(\mathrm{mm})\end{array}$ & $\begin{array}{c}s_{\text {rm, MC 2010 }} \\
(\mathrm{mm})\end{array}$ & $\begin{array}{c}\delta_{S L S, \text { num }} \\
(\mathrm{mm})\end{array}$ & $\begin{array}{c}\delta_{S L S, M C 2010} \\
(\mathrm{~mm})\end{array}$ \\
\hline \hline $\mathrm{RC}$ & 0.34 & 0.26 & 69 & 76 & 4.40 & 4.31 \\
\hline $\begin{array}{c}\mathrm{RC}-\mathrm{SFRC} \\
15 \mathrm{~kg} / \mathrm{m}^{3}\end{array}$ & 0.24 & 0.18 & 62 & 58 & 3.98 & 4.03 \\
\hline $\begin{array}{c}\mathrm{RC}-\mathrm{SFRC} \\
30 \mathrm{~kg} / \mathrm{m}^{3}\end{array}$ & 0.12 & 0.14 & 48 & 45 & 3.75 & 3.80 \\
\hline $\begin{array}{c}\mathrm{RC}-\mathrm{SFRC} \\
45 \mathrm{~kg} / \mathrm{m}^{3}\end{array}$ & 0.10 & 0.08 & 38 & 29 & 3.61 & 3.41 \\
\hline
\end{tabular}

The numerical results in Table 4.14 illustrate that crack width, mean crack spacing and deflection are in good agreement with those predicted by MC2010. Moreover, 
the same tendency for both cases can be observed with the addition of fibers: decrease of the crack width, mean crack spacing and deflection.

Finally, the relation of the crack propagation process with the structural response is illustrated in Figure 4.29 for the RC-SFRC beam with fiber content of $45 \mathrm{~kg} / \mathrm{m}^{3}$. As observed in this figure, the first cracks appear at the middle bottom of the beam for a load of approximately $11 \mathrm{kN}$ (point (a)). Point (b) corresponds to the crack pattern for the service load evaluated by MC2010. Points (c) and (d) show the crack patterns at the loads corresponding to the yielding of the rebar and deflection of $\delta=20 \mathrm{~mm}$, respectively.

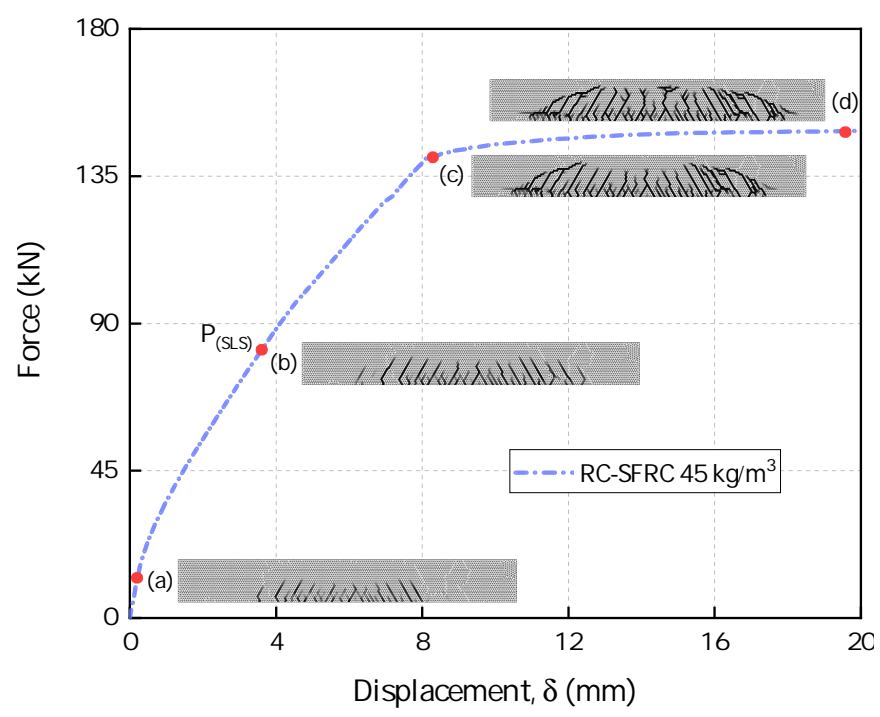

Figure 4.29.: Force vs. displacement curves for RC-SFRC beam with fiber content of $45 \mathrm{~kg} / \mathrm{m}^{3}$.

\subsection{Analysis of RC-SFRC beams experimentally tested by Conforti et al. (2018)}

To evaluate the predictive capabilities of the proposed model, small-scale beams experimentally tested by Conforti et al. (2018) are numerically simulated. In addition, the SFRC post-cracking properties were determined through three-point bending beams tested according to EN 14651 (2005). 


\subsubsection{Material parameters}

The material properties adopted in the numerical simulations for the concrete, conventional reinforcement and steel fibers are given in Table 4.15. The mean concrete compressive strength, $f_{c m}$, and yield stresses for the steel reinforcement bars $(\phi 6 \mathrm{~mm}$ and $\phi 10 \mathrm{~mm}$ ) were determined experimentally by Conforti et al. (2018), while the concrete Young's modulus, $E_{c}$, was estimated according to the MC2010 formula. The tensile strength of the concrete matrix, $f_{c t}$, and the fracture energy, $G_{f}$, were defined by calibrating the numerical model to fit the mean response obtained for plain concrete in the experimental three-point bending tests, as shown in Figure 4.31 and the compressive parameters $A^{-}$and $B^{-}$are typical values for concrete, as recommended by Cervera et al. (1996).

Table 4.15.: Material parameters adopted for the numerical simulations of the small-scale beams.

\begin{tabular}{|c|c|c|}
\hline \multirow{6}{*}{ Concrete } & Mean compressive strength $f_{c m}$ & $43.6 \mathrm{MPa}$ \\
\hline & Tensile strength $f_{c t}$ & $1.8 \mathrm{MPa}$ \\
\hline & Young's modulus $E_{c}$ & $37 \mathrm{GPa}$ \\
\hline & Poisson's ratio $v$ & 0.2 \\
\hline & Fracture energy $G_{f}$ & $100 \mathrm{~N} / \mathrm{m}$ \\
\hline & Compression parameters & $A^{-}=1.0 / B^{-}=0.89$ \\
\hline \multirow{3}{*}{$\begin{array}{l}\text { Conventional } \\
\text { reinforcement }\end{array}$} & Young's modulus $E_{s}$ & $210.0 \mathrm{GPa}$ \\
\hline & Yield stress $f_{y}$ (for rebars with $\left.\phi 6 \mathrm{~mm}\right)$ & $469.40 \mathrm{MPa}$ \\
\hline & Yield stress $f_{y}$ (for rebars with $\left.\phi 10 \mathrm{~mm}\right)$ & $562.30 \mathrm{MPa}$ \\
\hline \multirow{5}{*}{ Steel fiber } & Type of fiber & hooked - end \\
\hline & Length $l_{F}$ & $50 \mathrm{~mm}$ \\
\hline & Diameter $d_{F}$ & $1.0 \mathrm{~mm}$ \\
\hline & Yield stress $\sigma_{Y}$ & $1100 \mathrm{MPa}$ \\
\hline & Young's modulus $E_{F}$ & $210 \mathrm{GPa}$ \\
\hline
\end{tabular}

\subsubsection{Calibration of the concrete-fiber interaction}

The parameters adopted to describe the concrete-fiber interaction were defined following the same procedure described in Section 4.1. Therefore, the three-point 
bending tests experimentally tested by Conforti et al. (2018) according to EN 14651 (2005) were first numerically simulated. The geometric properties of the beams, boundary conditions, applied load, concrete FE mesh and the fiber distributions for each fiber content of $25 \mathrm{~kg} / \mathrm{m}^{3}$ and $50 \mathrm{~kg} / \mathrm{m}^{3}$ (0.32 and $0.64 \%$ by volume) are illustrated in Figure 4.30. The characteristics of the FE meshes adopted are summarized in Table 4.16. Each steel fiber was discretized in 6 truss finite elements.
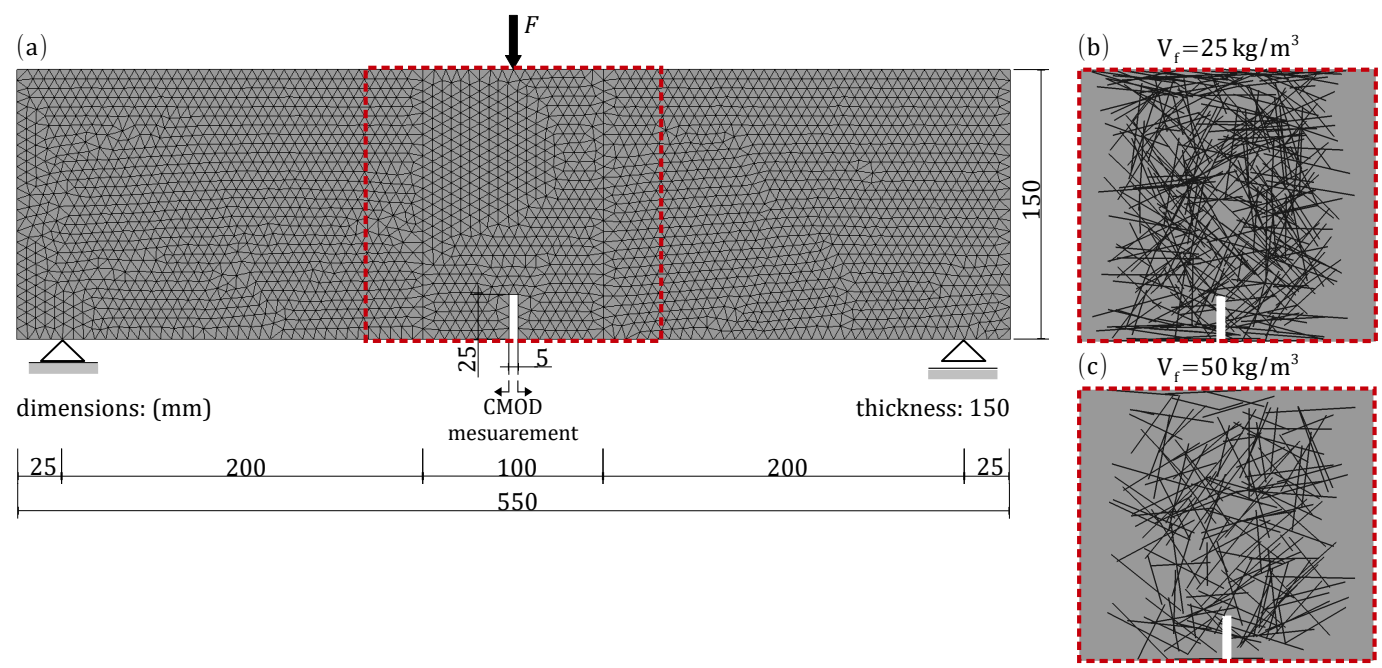

Figure 4.30.: Numerical model for the simulation of the three-point bending tests according to EN 14651: (a) geometric properties, boundary conditions, applied load and concrete FE mesh; (b) fiber distributions for fiber content of $25 \mathrm{~kg} / \mathrm{m}^{3}$ and (c) fiber distributions for fiber content of $50 \mathrm{~kg} / \mathrm{m}^{3}$.

Table 4.16.: Characteristics of the SFRC finite element meshes.

\begin{tabular}{lcccc}
\hline Numerical & \multicolumn{4}{c}{ Number of elements } \\
\cline { 2 - 5 } model & $\begin{array}{c}\text { two-node } \\
\text { trusses }\end{array}$ & $\begin{array}{c}\text { three- } \\
\text { noded } \\
\text { triangular }\end{array}$ & $\begin{array}{c}\text { four-noded } \\
\text { triangular } \\
\text { CFEs }\end{array}$ & $\begin{array}{c}\text { total } \\
\text { number of } \\
\text { elements }\end{array}$ \\
\hline \hline Plain concrete & - & 5633 & - & 5633 \\
\hline SFRC $25 \mathrm{~kg} / \mathrm{m}^{3}$ & 809 & 5633 & 981 & 7423 \\
\hline SFRC $50 \mathrm{~kg} / \mathrm{m}^{3}$ & 1677 & 5633 & 2031 & 9341 \\
\hline
\end{tabular}




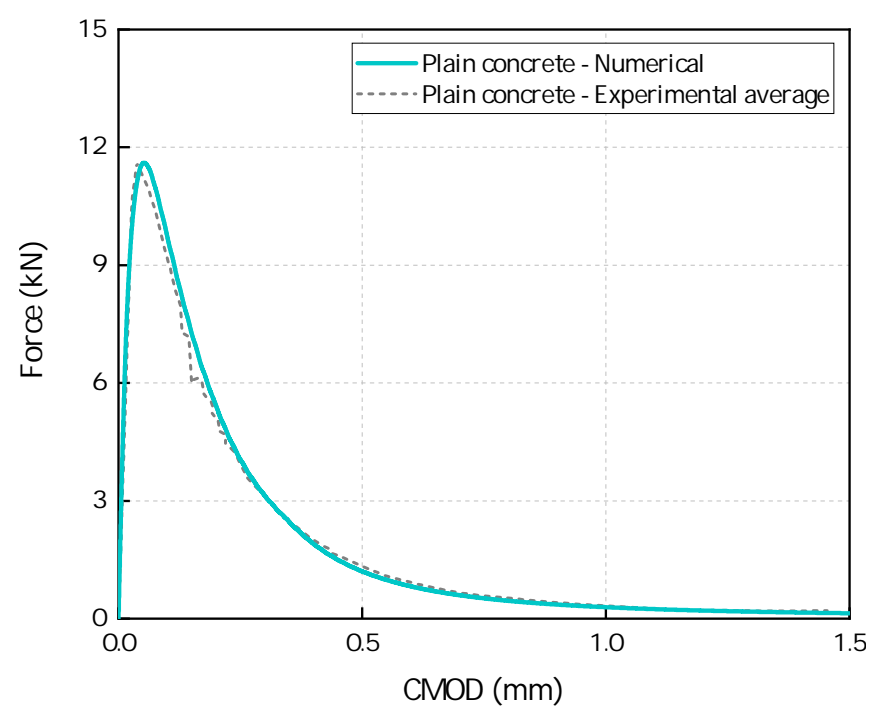

Figure 4.31.: Comparison between numerical and experimental responses: force vs. CMOD curves for plain concrete.

The parameters that describe the concrete-fiber interaction are obtained by fitting the numerical response with fiber content of $25 \mathrm{~kg} / \mathrm{m}^{3}$ to the mean experimental curve of force vs. CMOD, as shown in Figure 4.33. Then, by considering this first fiber distribution (used for calibration - see Figure 4.30(b)), the parameters for the concrete-fiber interface were defined as: $\tau_{b \max }=20 \mathrm{MPa}, \tau_{b f}=4.5 \mathrm{MPa}, \alpha=0.4$, $s_{1}=0.01 \mathrm{~mm}, s_{2}=5 \mathrm{~mm}$, and coupling parameters of $c_{n}=10^{3} \mathrm{MPa} / \mathrm{mm}$ and $c_{s}=10^{6} \mathrm{MPa} / \mathrm{mm}$.

After, three additional fiber distributions were generated to study the variability in the responses for fiber content of $25 \mathrm{~kg} / \mathrm{m}^{3}$. The distributions 2,3 and 4 are depicted in Figure 4.32 and the corresponding responses are plotted in Figure 4.33. Thus, following the same procedure described in Section 4.1 to define the interval of possible values to be applied for the concrete-fiber interfaces, the maximum bond stress $\left(\tau_{b \max }\right)$ parameter of the less favorable response (dashed red line - distribution 2 ) is modified from $\tau_{b \max }=20.0 \mathrm{MPa}$ to $\tau_{b \max }=55.0 \mathrm{MPa}$ (Figure $4.34(\mathrm{a})$ ) in order to translate this curve to the mean experimental one, as illustrated in Figure 4.34(b). 

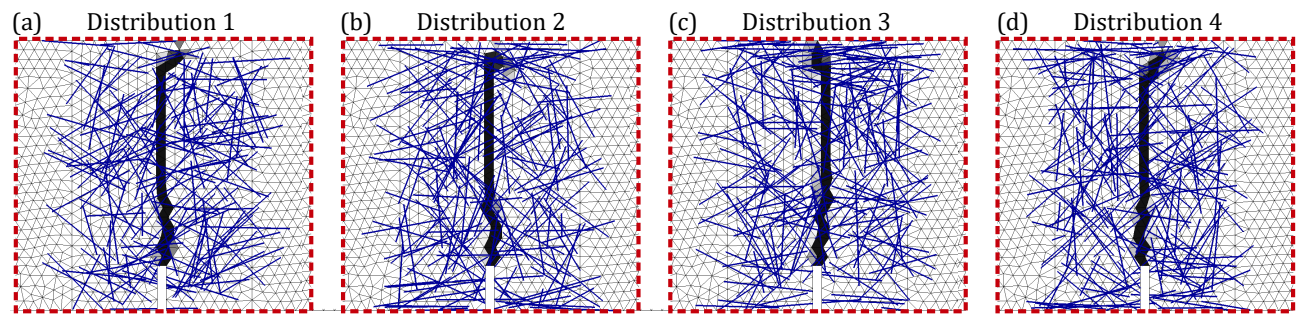

Figure 4.32.: Fiber distributions 1, 2, 3 and 4 for SFRC $25 \mathrm{~kg} / \mathrm{m}^{3}$.

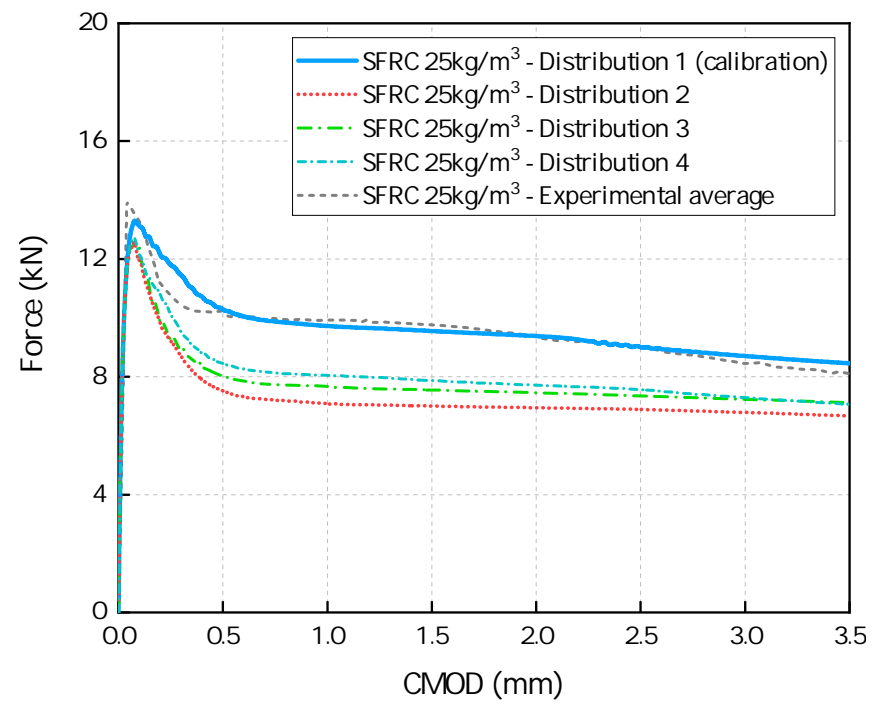

Figure 4.33.: Comparison between mean experimental and numerical responses for 4 fiber distributions: force vs. CMOD curves for SFRC $25 \mathrm{~kg} / \mathrm{m}^{3}$.

(a)

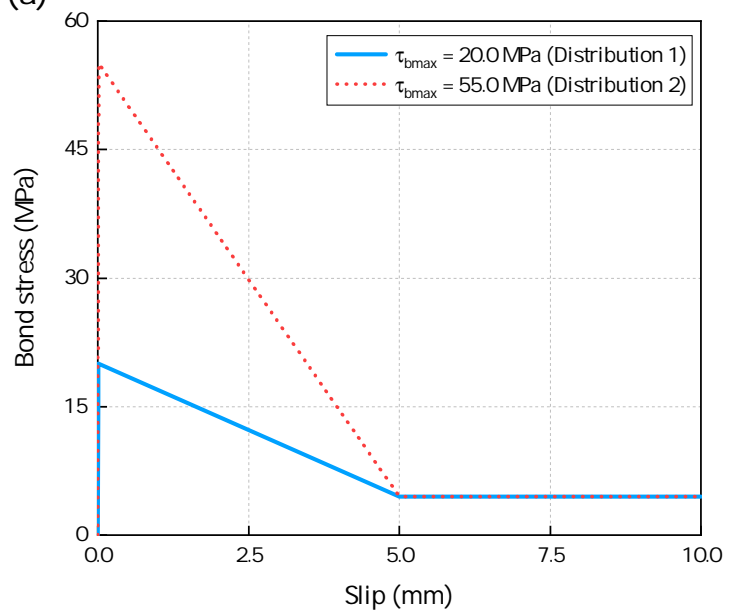

(b)

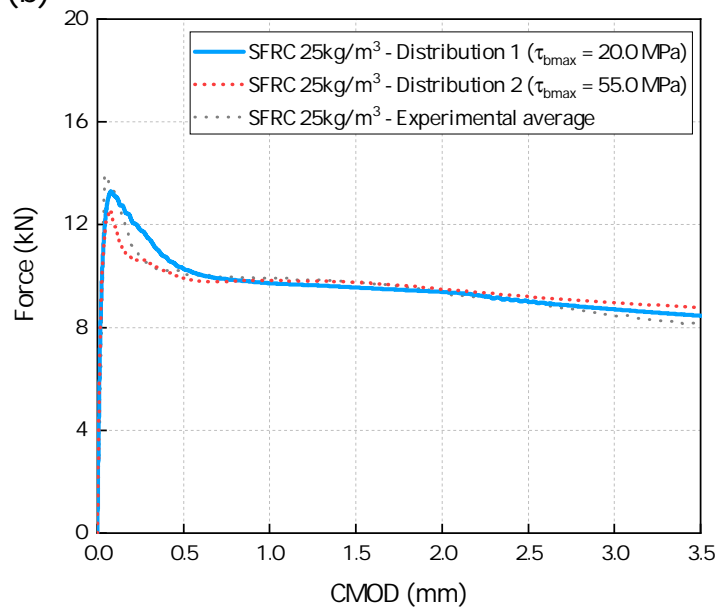

Figure 4.34.: Calibration of the concrete-fiber interface parameters: (a) bond-slip curves and (b) Force vs. CMOD curves by using the two concrete-fiber interface laws adopted with fiber content of $25 \mathrm{~kg} / \mathrm{m}^{3}$. 
Finally, numerical analyses for fiber content of $50 \mathrm{~kg} / \mathrm{m}^{3}$ are performed by using the two interface laws defined previously. The numerical responses for the two cases are shown in Figure 4.35. As can be noted, the experimental curve is approximately the mean numerical response.

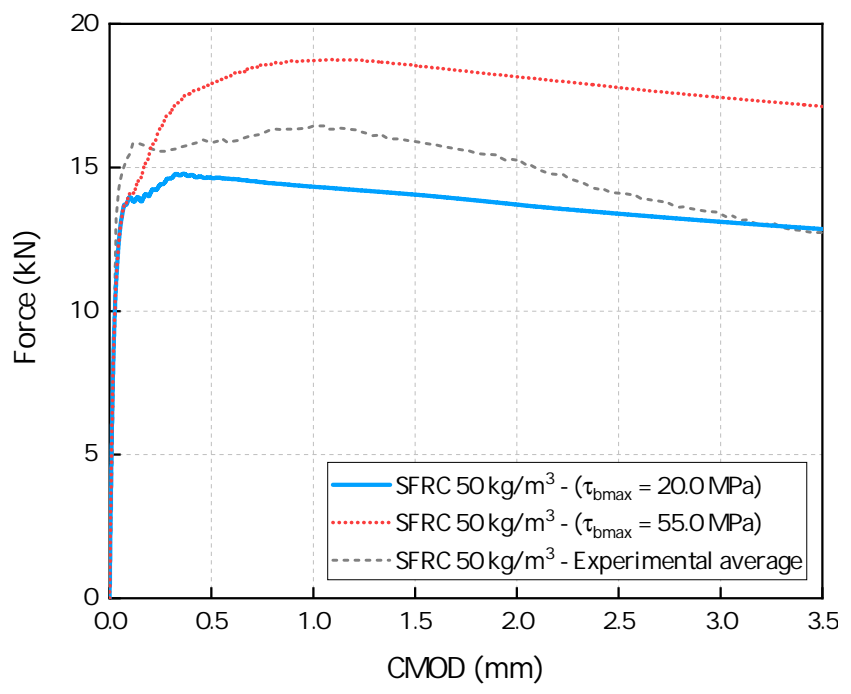

Figure 4.35.: Force vs. CMOD curves for fiber content of $50 \mathrm{~kg} / \mathrm{m}^{3}$.

Figure 4.36 shows the numerical and experimental responses for all the cases analyzed (plain concrete, SFRC $25 \mathrm{~kg} / \mathrm{m}^{3}$ and SFRC $50 \mathrm{~kg} / \mathrm{m}^{3}$ ). As can be seen, on the post-cracking branches, the addition of steel fibers to concrete matrix increases the material ductility and toughness.

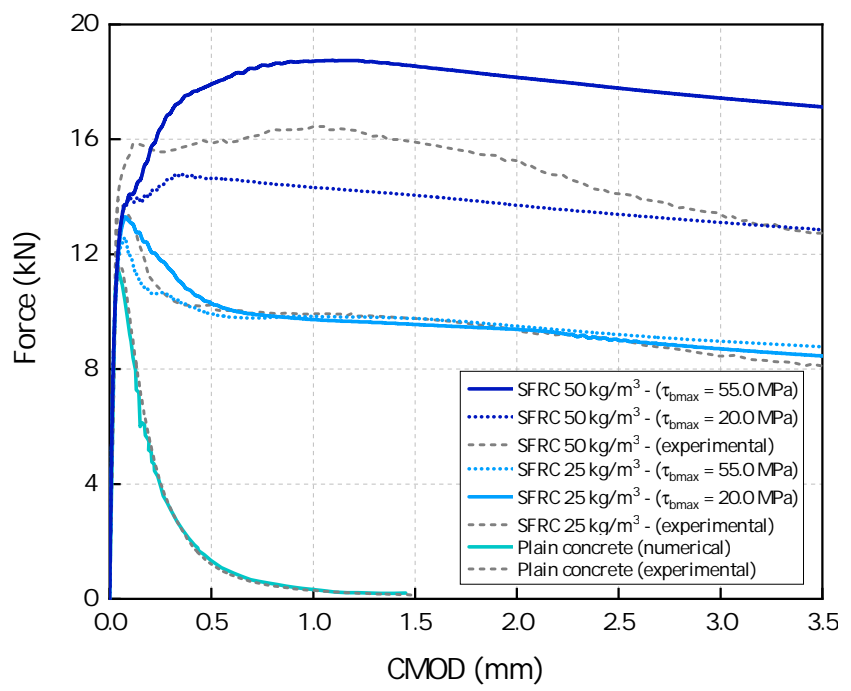

Figure 4.36.: Force vs. CMOD curves for all the cases analyzed: Plain Concrete, SFRC $25 \mathrm{~kg} / \mathrm{m}^{3}$ and $50 \mathrm{~kg} / \mathrm{m}^{3}$. 


\subsubsection{Description of the beams and FE discretization}

Three types of small-scale beams experimentally tested by Conforti et al. (2018) are numerically simulated: RC and RC-SFRC beams with fiber contents of $25 \mathrm{~kg} / \mathrm{m}^{3}$ and $50 \mathrm{~kg} / \mathrm{m}^{3}$. The beams have a rectangular cross-section of $150 \times 150 \mathrm{~mm}^{2}$, length of $900 \mathrm{~mm}$ and a free span of $840 \mathrm{~mm}$. The specimens were subjected to four-point loading configuration with a distance between the applied loads equal to $280 \mathrm{~mm}$. Figure 4.37 illustrates the beam test setup, dimensions, conventional reinforcements adopted, steel fiber contents and the finite element mesh.

The longitudinal reinforcement was positioned in one layer with a reinforcement ratio of $\rho_{s}=0.87 \%$ (corresponding to $2 \phi 10$ ) and the clear cover of $25 \mathrm{~mm}$. 2-leg stirrups of $2 \phi 6$ were placed near the support and spaced at $50 \mathrm{~mm}$. The steel fibers were generated randomly for fiber contents of $25 \mathrm{~kg} / \mathrm{m}^{3}$ and $50 \mathrm{~kg} / \mathrm{m}^{3}$.
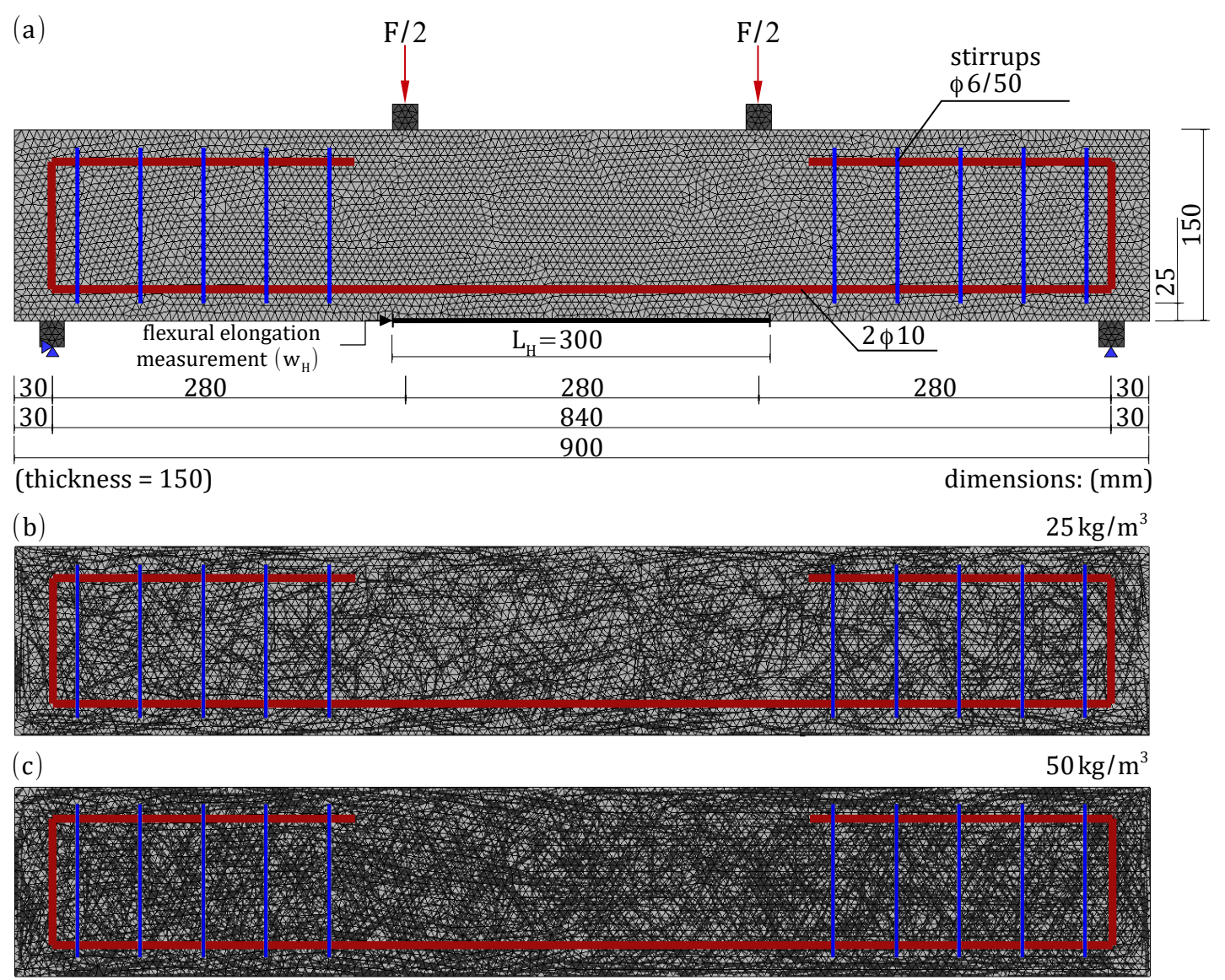

Figure 4.37.: Numerical models for simulation of the small beams: (a) Reinforced Concrete (RC); (b) RC-SFRC beam for $V_{f}=25 \mathrm{~kg} / \mathrm{m}^{3}$ and (c) RC-SFRC beam for $V_{f}=50 \mathrm{~kg} / \mathrm{m}^{3}$. 
The conventional reinforcement is discretized in truss finite elements with size of approximately 12, while each steel fiber is discretized in 3 truss finite elements, respecting a ratio of approximately 1.5, between the sizes of the fiber and concrete meshes. The characteristics of the finite element meshes adopted are listed in Table 4.17

Table 4.17.: Characteristics of the finite element meshes adopted for the analyses of the small beams..

\begin{tabular}{ccccc}
\hline \multirow{2}{*}{ Type of beam } & \multicolumn{4}{c}{ Number of elements } \\
\cline { 2 - 5 } & $\begin{array}{c}\text { two-noded } \\
\text { trusses }\end{array}$ & $\begin{array}{c}\text { three- } \\
\text { noded } \\
\text { triangular }\end{array}$ & $\begin{array}{c}\text { four-noded } \\
\text { triangular } \\
\text { CFEs }\end{array}$ & $\begin{array}{c}\text { total } \\
\text { number of } \\
\text { elements }\end{array}$ \\
\hline $\mathrm{RC}$ & 226 & 8633 & 237 & 9096 \\
\hline RC-SFRC $25 \mathrm{~kg} / \mathrm{m}^{3}$ & 4328 & 8633 & 5992 & 18953 \\
\hline RC-SFRC $50 \mathrm{~kg} / \mathrm{m}^{3}$ & 8451 & 8633 & 11768 & 28852 \\
\hline
\end{tabular}

\subsubsection{Experimental $x$ numerical responses}

The numerical results are compared against the experimental measurements performed by Conforti et al. (2018). The interaction between longitudinal reinforcement bars and concrete is estimated according to MC2010 (considering pull-out failure mode), for two cases: good bond conditions: $\tau_{b \max }=17.9 \mathrm{MPa}, \tau_{b f}=7.1 \mathrm{MPa}, \alpha=$ $0.4, s_{1}=1 \mathrm{~mm}, s_{2}=2 \mathrm{~mm}, s_{3}=4 \mathrm{~mm}, c_{n}=10^{3} \mathrm{MPa} / \mathrm{mm}$ and $c_{s}=10^{6} \mathrm{MPa} / \mathrm{mm}$; and for all other bond conditions: $\tau_{\text {bmax }}=8.9 \mathrm{MPa}, \tau_{b f}=3.6 \mathrm{MPa}, \alpha=0.4$, $s_{1}=1.8 \mathrm{~mm}, s_{2}=3.6 \mathrm{~mm}, s_{3}=4 \mathrm{~mm}, c_{n}=10^{3} \mathrm{MPa} / \mathrm{mm}$ and $c_{s}=10^{6} \mathrm{MPa} / \mathrm{mm}$ (see Figure 4.38). In addition, perfect adherence is also considered by adopting $c_{n}=c_{s}=10^{6} \mathrm{MPa} / \mathrm{mm}$. 


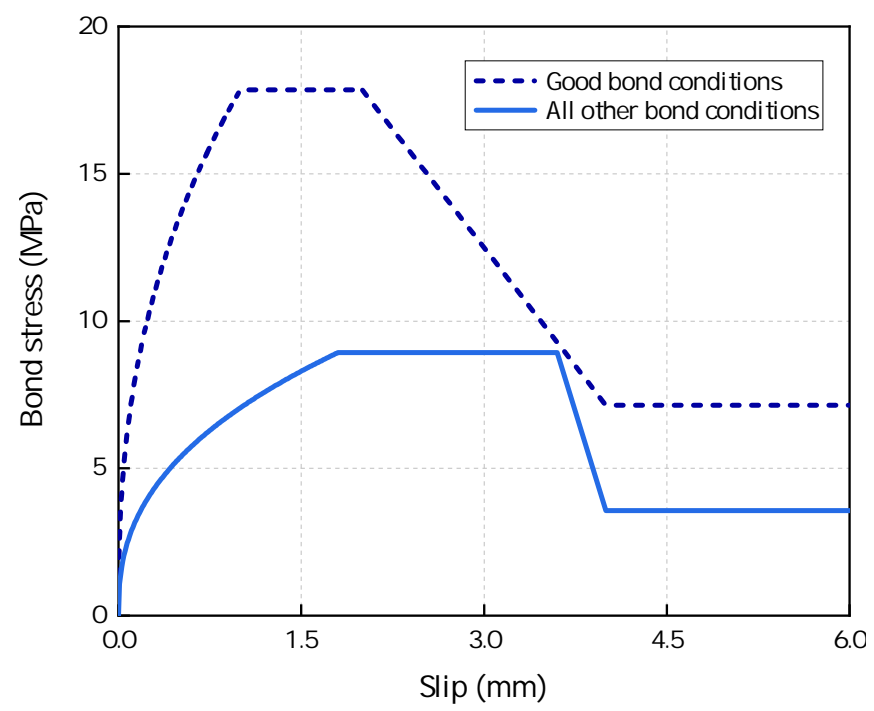

Figure 4.38.: Bond-slip models to describe the interaction between rebars and concrete according to MC2010.

Figure 4.39 shows the numerical responses for the three bond conditions adopted. It can be seen that the numerical responses are in good agreement with the mean experimental one, mainly for the case of all other bond conditions, in which the stiffness is closer to the experimental curve.

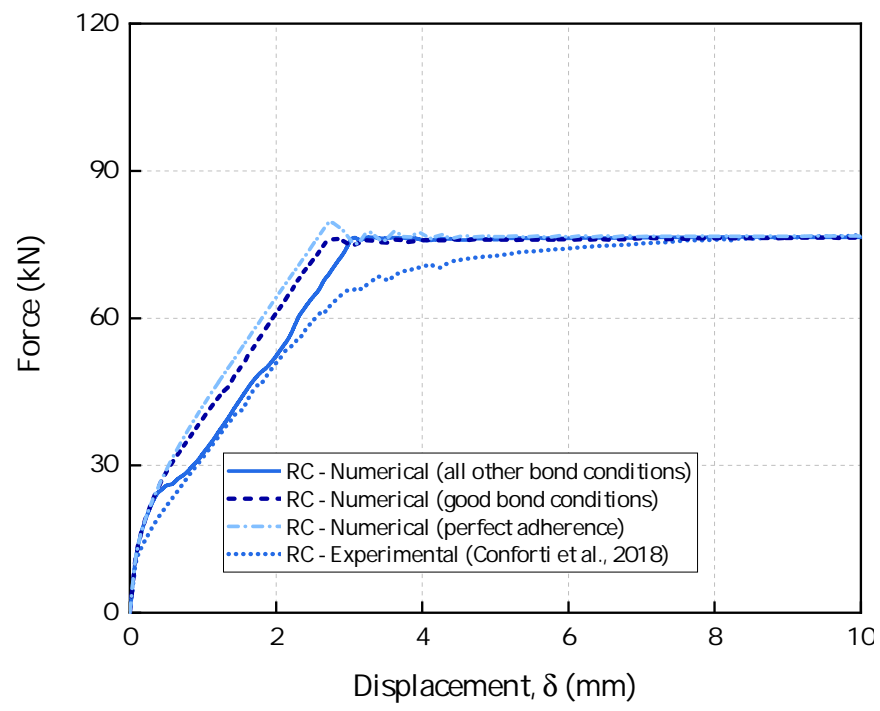

Figure 4.39.: Force vs. displacement curves. Comparison between experimental and numerical responses for RC beams and three bond-slip models: all other bond conditions, good bond conditions and perfect adherence.

The force vs. displacement curves of the experimental and numerical responses obtained for RC-SFRC beams with fiber content of $25 \mathrm{~kg} / \mathrm{m}^{3}$ and three bond conditions 
are shown in Figure 4.40. Again, the numerical models were able to predict with good accuracy the experimental behavior. However, for all the cases, the numerical results present a stiffness greater than the experimental result in the pre-peak branch.

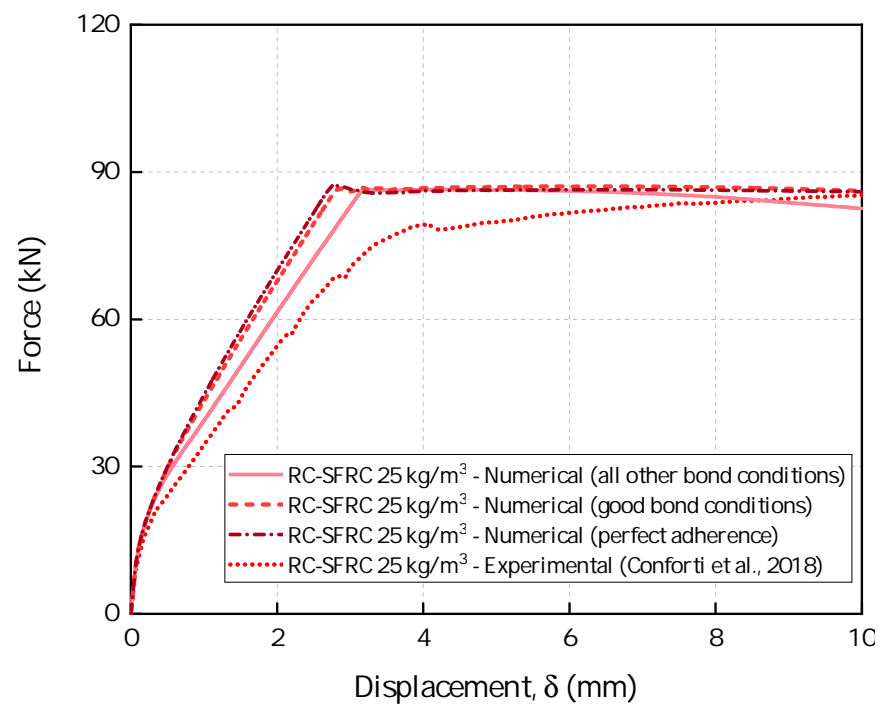

Figure 4.40.: Force vs. displacement curves. Comparison between experimental and numerical responses for RC-SFRC beams with fiber content of $25 \mathrm{~kg} / \mathrm{m}^{3}$ and three bond slip models: all other bond conditions, good bond conditions and perfect adherence.

In addition, another distribution (2) for RC-SFRC beam with fiber content of $25 \mathrm{~kg} / \mathrm{m}^{3}$ was generated to verify the influence of the low fiber content in the overall structural response. Figure 4.41 shows that a small difference between the two numerical responses was obtained. 


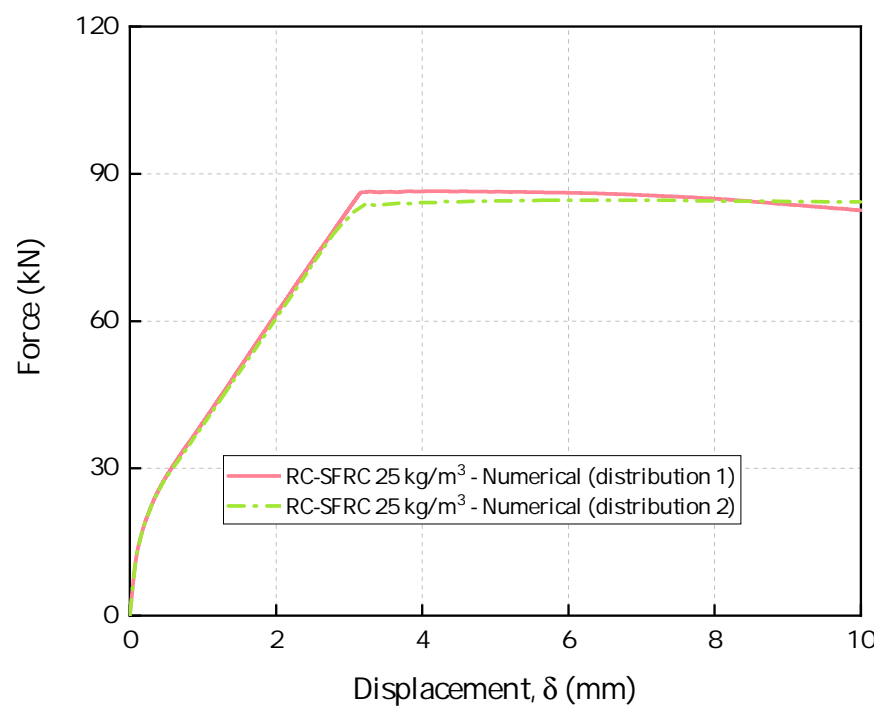

Figure 4.41.: Force vs. displacement curves. Comparison between numerical responses for RC-SFRC beams with fiber content of $25 \mathrm{~kg} / \mathrm{m}^{3}$ and two fiber distributions (1 and 2).

In Figure 4.40 the numerical results for RC-SFRC beams with fiber content of $50 \mathrm{~kg} / \mathrm{m}^{3}$ are compared with the experimental responses. Note that the numerical results show a slightly higher curve, although, the peak load of the numerical response is only $9 \%$ overestimated (see Table 4.18 ).

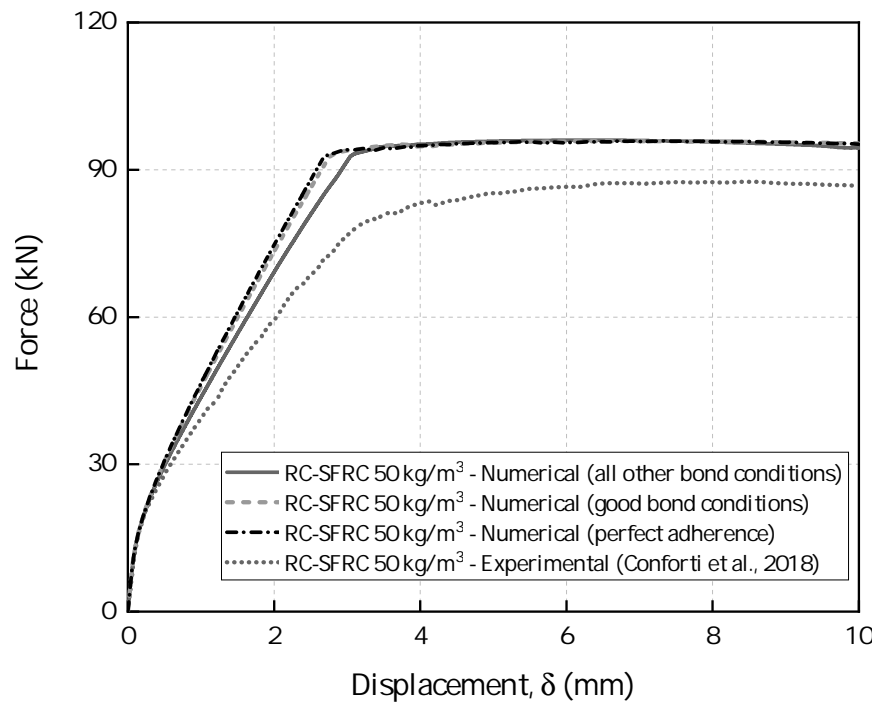

Figure 4.42.: Force vs. displacement curves. Comparison between experimental and numerical responses for RC-SFRC beams with fiber content of $50 \mathrm{~kg} / \mathrm{m}^{3}$ and three bond-slip models: all other bond conditions, good bond conditions and perfect adherence. 
In general, a good agreement between experimental and numerical responses can be observed since all the beams show flexural failure, initiated by the yielding of the longitudinal reinforcement. Moreover, the results of the three bond conditions show smaller differences between the curves for higher fiber contents.

Table 4.18 shows the maximum loads, $P_{\max }$, for three types of beams analyzed and the reduction percentage $(\Delta \%)$, calculated as $\Delta \%(\bullet)=\left((\bullet)_{\text {num }}-(\bullet)_{\text {exp }}\right) /(\bullet)_{\text {exp }}$. Note that the numerical models were able to capture the peak load and the maximum difference between the experimental one is about $9 \%$ for RC-SFRC beams with fiber content of $50 \mathrm{~kg} / \mathrm{m}^{3}$. The increment of bearing capacity with the addition of steel fibers can be observed in numerical responses plotted in Figure 4.43.

Table 4.18.: Numerical and experimental results for RC and RC-SFRC beams at the maximum load $\left(P_{\max }\right)$.

\begin{tabular}{|c|c|c|c|c|}
\hline Series & Results & Bond conditions & $\begin{array}{l}P_{\max } \\
(\mathrm{kN})\end{array}$ & $\begin{array}{c}\Delta \%\left(P_{\max }\right) \\
(\%)\end{array}$ \\
\hline \multirow{4}{*}{$\mathrm{RC}$} & Experimental & & 77.5 & - \\
\hline & \multirow{3}{*}{ Numerical } & All other bond conditions & 76.6 & $-1 \%$ \\
\hline & & Good bond conditions & 76.5 & $-1 \%$ \\
\hline & & Perfect adherence & 79.6 & $+3 \%$ \\
\hline \multirow{4}{*}{$\begin{array}{l}\text { RC-SFRC } \\
25 \mathrm{~kg} / \mathrm{m}^{3}\end{array}$} & Experimental & & 85.4 & - \\
\hline & \multirow{3}{*}{ Numerical } & All other bond conditions & 86.5 & $+1 \%$ \\
\hline & & Good bond conditions & 87.1 & $+2 \%$ \\
\hline & & Perfect adherence & 87.3 & $+2 \%$ \\
\hline \multirow{4}{*}{$\begin{array}{l}\text { RC-SFRC } \\
50 \mathrm{~kg} / \mathrm{m}^{3}\end{array}$} & Experimental & & 87.9 & - \\
\hline & \multirow{3}{*}{ Numerical } & All other bond conditions & 96.0 & $+9 \%$ \\
\hline & & Good bond conditions & 95.9 & $+9 \%$ \\
\hline & & Perfect adherence & 95.9 & $+9 \%$ \\
\hline
\end{tabular}




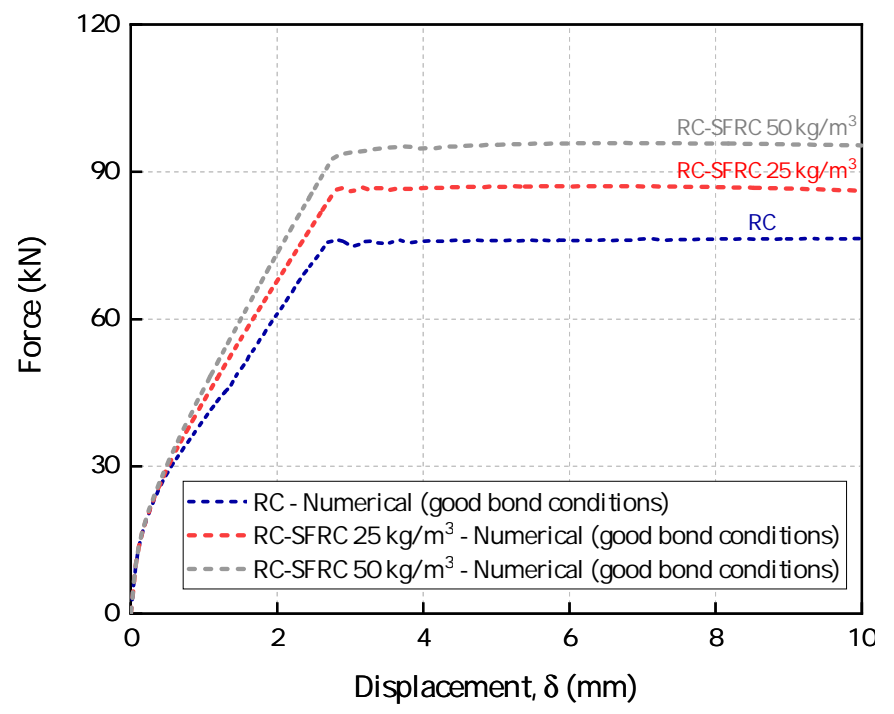

Figure 4.43.: Force vs. displacement curves. Comparison between numerical responses for RC beam, RC-SFRC beam with fiber content of $25 \mathrm{~kg} / \mathrm{m}^{3}$ and RCSFRC beam with fiber content of $50 \mathrm{~kg} / \mathrm{m}^{3}$.

The crack pattern of each beam is illustrated in Figure 4.44 for the three bond conditions (all other bond conditions - Figure 4.44(a), (d) and (g), good bond conditions - Figure 4.44(b), (e) and (h) and perfect adherence - Figure 4.44(c), (f) and (i)) at the crack stabilized stage $(\delta=2.5 \mathrm{~mm})$ according to experimental response. As expected, the number of cracks increases for higher adherence between concrete and rebar and with the addition of steel fibers.

The final crack patterns for the numerical responses with good bond conditions are also compared with the experimental ones for the RC beam and RC-SFRC beam with fiber content of $50 \mathrm{~kg} / \mathrm{m}^{3}$, as illustrated in Figure 4.45 . As can be seen in this figure, a good agreement between numerical and experimental crack patterns was obtained for RC beam (Figure 4.45(a) and (b)), while for RC-SFRC beam with fiber content of $50 \mathrm{~kg} / \mathrm{m}^{3}$ shows more cracks than the experimental one (Figure $4.45(\mathrm{c})$ and $(\mathrm{d}))$. Furthermore, the experimental result shows only one crack localization while for the numerical response there are two main cracks. 


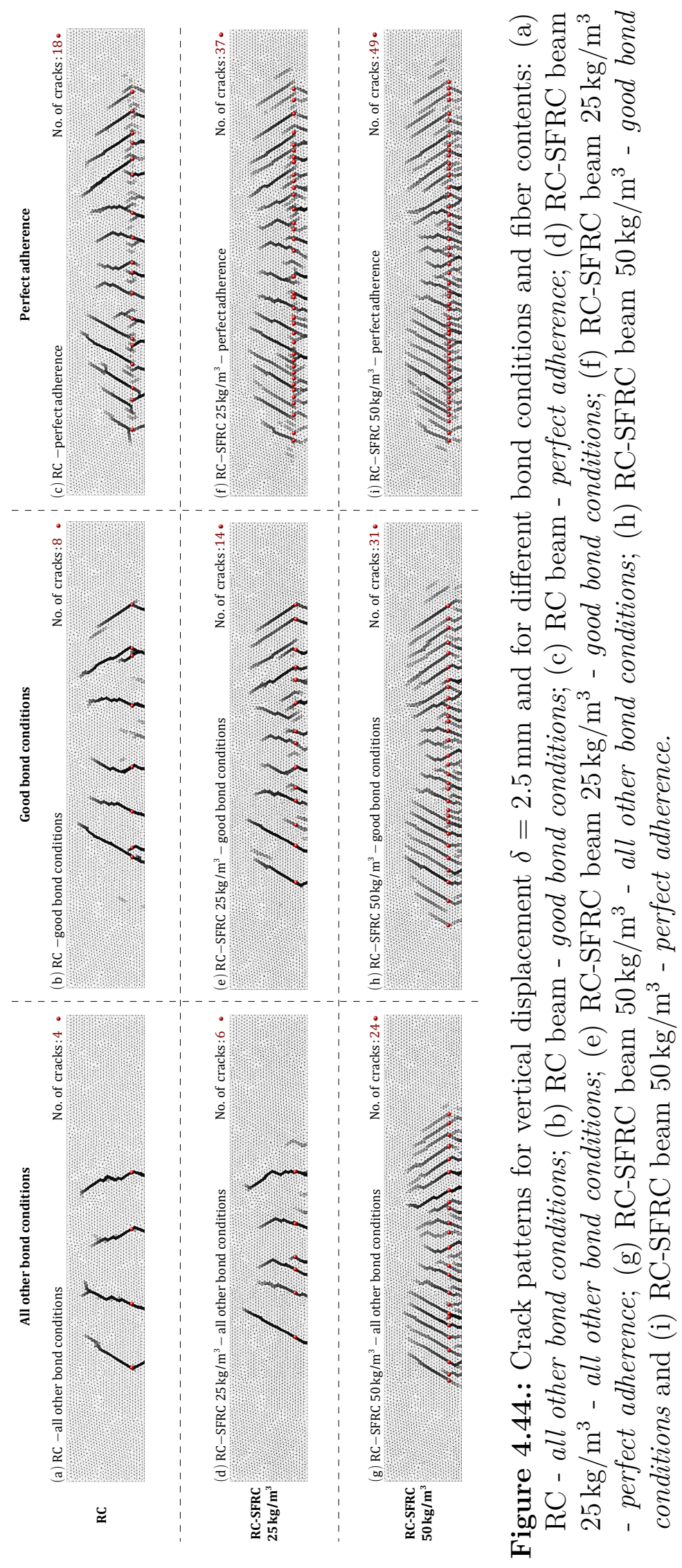


(a) RC-experimental

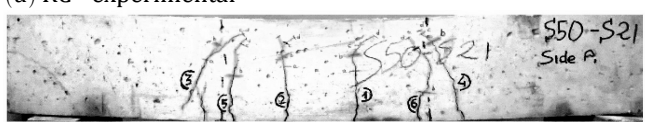

(b) RC-numerical (good bond conditions)

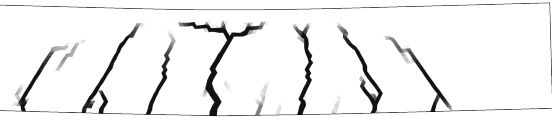

(c) RC-SFRC $50 \mathrm{~kg} / \mathrm{m}^{3}$-experimental

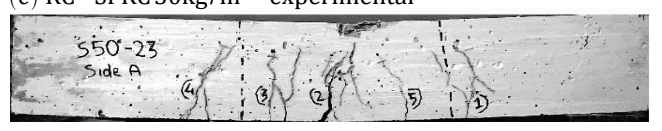

(d) RC-SFRC $50 \mathrm{~kg} / \mathrm{m}^{3}$ - numerical (good bond conditions)

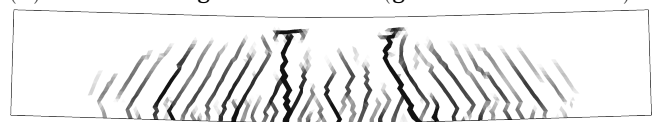

Figure 4.45.: Numerical vs. experimental crack patterns for: (a) RC beam - experimental test; (b) RC beam - numerical response for good bond conditions;(c) RC-SFRC $50 \mathrm{~kg} / \mathrm{m}^{3}$ - experimental test and (d) RC-SFRC beam - numerical response for good bond conditions ( at deflection of $\delta=10 \mathrm{~mm}$ ).

Table 4.19 lists the numerical and mean experimental responses at load $P=40 \mathrm{kN}$, where $\Delta(\bullet)=\left((\bullet)_{\text {num }}-(\bullet)_{\text {exp }}\right)$ is the difference between numerical and experimental responses. The numerical responses show smaller values of deflection, $\delta_{P 40}$, when compared with the experimental ones. In addition, the higher the adherence is, the lower the deflection for the same load stage $(P=40 \mathrm{kN})$, as can be also noted in Figure 4.39 (RC beams), Figure 4.40 (RC-SFRC $\left.25 \mathrm{~kg} / \mathrm{m}^{3}\right)$ and Figure 4.42 (RCSFRC $\left.50 \mathrm{~kg} / \mathrm{m}^{3}\right)$.

Table 4.19.: Numerical and experimental results of deflection $\delta_{P 40}$ for RC and RCSFRC beams.

\begin{tabular}{|c|c|c|c|c|}
\hline Series & Results & Bond conditions & $\begin{array}{c}\delta_{P 40} \\
(\mathrm{~mm})\end{array}$ & $\begin{array}{c}\Delta \\
(\mathrm{mm})\end{array}$ \\
\hline \multirow{4}{*}{$\mathrm{RC}$} & Experimental & & 1.43 & - \\
\hline & \multirow{3}{*}{ Numerical } & All other bond conditions & 1.36 & -0.07 \\
\hline & & Good bond conditions & 1.02 & -0.41 \\
\hline & & Perfect adherence & 0.91 & -0.52 \\
\hline \multirow{4}{*}{$\begin{array}{l}\text { RC-SFRC } \\
25 \mathrm{~kg} / \mathrm{m}^{3}\end{array}$} & Experimental & & 1.26 & - \\
\hline & \multirow{3}{*}{ Numerical } & All other bond conditions & 1.03 & -0.23 \\
\hline & & Good bond conditions & 0.87 & -0.39 \\
\hline & & Perfect adherence & 0.84 & -0.42 \\
\hline \multirow{4}{*}{$\begin{array}{l}\text { RC-SFRC } \\
50 \mathrm{~kg} / \mathrm{m}^{3}\end{array}$} & Experimental & & 1.03 & - \\
\hline & \multirow{3}{*}{ Numerical } & All other bond conditions & 0.86 & -0.17 \\
\hline & & Good bond conditions & 0.80 & -0.23 \\
\hline & & Perfect adherence & 0.79 & -0.24 \\
\hline
\end{tabular}


Table 4.20 shows the numerical and experimental maximum crack widths measured at two different load stages: $40 \mathrm{kN}$ and $56 \mathrm{kN}$. These values correspond to $50 \%$ and $70 \%$, respectively, of the flexural bearing capacity of the $\mathrm{RC}$ beam experimentally tested. The numerical values of the crack width are calculated following the same procedure as in Section 4.2.3.

As verified, the numerical results for good bond conditions of the $\mathrm{RC}$ beam and RC-SFRC beam with fiber content of $25 \mathrm{~kg} / \mathrm{m}^{3}$ compare well with the experimental data. However, the numerical response of the RC-SFRC beam with fiber content of $50 \mathrm{~kg} / \mathrm{m}^{3}$ exhibits lower values than the experimental one.

Table 4.20.: Numerical and experimental results of maximum crack widths, $w_{\max }$, for RC beam and RC-SFRC beams.

\begin{tabular}{|c|c|c|c|c|c|c|}
\hline Series & Results & $\begin{array}{l}\text { Bond } \\
\text { conditions }\end{array}$ & $\begin{array}{l}w_{\max , P 40} \\
\quad(\mathrm{~mm})\end{array}$ & $\begin{array}{c}\Delta \\
(\mathrm{mm})\end{array}$ & $\begin{array}{l}w_{\max , P 56} \\
(\mathrm{~mm})\end{array}$ & $\begin{array}{c}\Delta \\
(\mathrm{mm})\end{array}$ \\
\hline \multirow{4}{*}{$\mathrm{RC}$} & Experimental & & 0.15 & - & 0.22 & - \\
\hline & \multirow{3}{*}{ Numerical } & $\begin{array}{l}\text { All other bond } \\
\text { conditions }\end{array}$ & 0.45 & +0.30 & 0.59 & +0.37 \\
\hline & & $\begin{array}{l}\text { Good bond } \\
\text { conditions }\end{array}$ & 0.16 & +0.01 & 0.23 & +0.01 \\
\hline & & $\begin{array}{c}\text { Perfect } \\
\text { adherence }\end{array}$ & 0.06 & -0.09 & 0.11 & -0.11 \\
\hline \multirow{4}{*}{$\begin{array}{l}\text { RC-SFRC } \\
25 \mathrm{~kg} / \mathrm{m}^{3}\end{array}$} & Experimental & & 0.10 & - & 0.17 & - \\
\hline & \multirow{3}{*}{ Numerical } & $\begin{array}{l}\text { All other bond } \\
\text { conditions }\end{array}$ & 0.19 & +0.09 & 0.38 & +0.21 \\
\hline & & $\begin{array}{l}\text { Good bond } \\
\text { conditions }\end{array}$ & 0.05 & -0.05 & 0.12 & -0.05 \\
\hline & & $\begin{array}{l}\text { Perfect } \\
\text { adherence }\end{array}$ & 0.04 & -0.06 & 0.10 & -0.07 \\
\hline \multirow{4}{*}{$\begin{array}{l}\text { RC-SFRC } \\
50 \mathrm{~kg} / \mathrm{m}^{3}\end{array}$} & Experimental & & 0.07 & - & 0.13 & - \\
\hline & \multirow{3}{*}{ Numerical } & $\begin{array}{l}\text { All other bond } \\
\text { conditions }\end{array}$ & 0.03 & -0.04 & 0.07 & -0.06 \\
\hline & & $\begin{array}{l}\text { Good bond } \\
\text { conditions }\end{array}$ & 0.02 & -0.05 & 0.05 & -0.08 \\
\hline & & $\begin{array}{c}\text { Perfect } \\
\text { adherence }\end{array}$ & 0.02 & -0.05 & 0.04 & -0.09 \\
\hline
\end{tabular}


The mean cracking spacing $s_{r m}$ at the crack stabilized stage, which according to the experimental results, corresponds to a deflection around $2.5 \mathrm{~mm}$, are presented in Table 4.21. The numerical values are calculated for the crack patterns shown in Figure 4.44. Regarding the RC beam, the numerical response for good bond conditions gives the best agreement with the experimental result, while for the RCSFRC beam with fiber content of $25 \mathrm{~kg} / \mathrm{m}^{3}$, the experimental values of mean cracking spacing results are closer to the numerical response for all other bond conditions. As seen in Figure 4.45, the numerical analysis of RC-SFRC beam with fiber content of $50 \mathrm{~kg} / \mathrm{m}^{3}$ shows more cracks than the experimental test, and consequently, smaller cracking spacing.

Table 4.21.: Numerical and experimental results of mean cracking spacing $\left(s_{r m}\right)$ for RC beam and RC-SFRC beams.

\begin{tabular}{|c|c|c|c|c|}
\hline Series & Results & Bond conditions & $\begin{array}{c}s_{r m} \\
(\mathrm{~mm})\end{array}$ & $\begin{array}{c}\Delta \\
(\mathrm{mm})\end{array}$ \\
\hline \multirow{4}{*}{$\mathrm{RC}$} & Experimental & & 88 & - \\
\hline & \multirow{3}{*}{ Numerical } & All other bond conditions & 120 & +32 \\
\hline & & Good bond conditions & 70 & -18 \\
\hline & & Perfect adherence & 38 & -50 \\
\hline \multirow{4}{*}{$\begin{array}{l}\text { RC-SFRC } \\
25 \mathrm{~kg} / \mathrm{m}^{3}\end{array}$} & Experimental & & 69 & - \\
\hline & \multirow{3}{*}{ Numerical } & All other bond conditions & 65 & -4 \\
\hline & & Good bond conditions & 41 & -28 \\
\hline & & Perfect adherence & 19 & -50 \\
\hline \multirow{4}{*}{$\begin{array}{l}\text { RC-SFRC } \\
50 \mathrm{~kg} / \mathrm{m}^{3}\end{array}$} & Experimental & & 62 & - \\
\hline & \multirow{3}{*}{ Numerical } & All other bond conditions & 22 & -40 \\
\hline & & Good bond conditions & 21 & -41 \\
\hline & & Perfect adherence & 14 & -48 \\
\hline
\end{tabular}

The numerical and experimental strains, $\varepsilon_{H}$, measured at the bottom middle third of the beam (see Figure 4.37) were also compared. This parameter was calculated (for the load stages of $40 \mathrm{kN}$ and $56 \mathrm{kN}$ ) as $\varepsilon_{H}=w_{H} / L_{H}$, where $w_{H}$ is the flexural elongation and $L_{H}$ the length of the middle third of the beam, as depicted in Table 4.22. The numerical results for good bond conditions demonstrate the best correlation with the experimental responses. 
Table 4.22.: Numerical and experimental results of strain $\varepsilon_{H}$ for RC beam and RC-SFRC beams.

\begin{tabular}{|c|c|c|c|c|c|c|}
\hline Series & Results & Bond conditions & $\varepsilon_{H, P 40}$ & $\Delta$ & $\varepsilon_{H, P 56}$ & $\Delta$ \\
\hline \multirow{4}{*}{$\mathrm{RC}$} & Experimental & & 1.54 & - & 2.47 & - \\
\hline & \multirow{3}{*}{ Numerical } & $\begin{array}{l}\text { All other bond } \\
\text { conditions }\end{array}$ & 3.09 & +1.55 & 4.94 & +2.47 \\
\hline & & $\begin{array}{l}\text { Good bond } \\
\text { conditions }\end{array}$ & 1.44 & -0.10 & 2.27 & -0.20 \\
\hline & & $\begin{array}{c}\text { Perfect } \\
\text { adherence }\end{array}$ & 1.23 & -0.31 & 2.01 & -0.46 \\
\hline \multirow{4}{*}{$\begin{array}{l}\text { RC-SFRC } \\
25 \mathrm{~kg} / \mathrm{m}^{3}\end{array}$} & Experimental & & 1.33 & - & 2.11 & - \\
\hline & \multirow{3}{*}{ Numerical } & $\begin{array}{l}\text { All other bond } \\
\text { conditions }\end{array}$ & 1.55 & +0.22 & 2.73 & +0.62 \\
\hline & & $\begin{array}{l}\text { Good bond } \\
\text { conditions }\end{array}$ & 1.24 & -0.09 & 2.03 & -0.08 \\
\hline & & $\begin{array}{c}\text { Perfect } \\
\text { adherence }\end{array}$ & 1.24 & -0.09 & 2.08 & -0.03 \\
\hline \multirow{4}{*}{$\begin{array}{l}\text { RC-SFRC } \\
50 \mathrm{~kg} / \mathrm{m}^{3}\end{array}$} & Experimental & & 1.15 & - & 2.00 & - \\
\hline & \multirow{3}{*}{ Numerical } & $\begin{array}{c}\text { All other bond } \\
\text { conditions }\end{array}$ & 1.33 & +0.18 & 2.32 & +0.32 \\
\hline & & $\begin{array}{l}\text { Good bond } \\
\text { conditions }\end{array}$ & 1.16 & +0.01 & 1.96 & -0.04 \\
\hline & & $\begin{array}{c}\text { Perfect } \\
\text { adherence }\end{array}$ & 1.13 & -0.02 & 1.89 & -0.11 \\
\hline
\end{tabular}

\subsubsection{Comparison against fib Model Code 2010 predictions}

The results of the finite element modeling are compared with the experimental responses and the predictions according to MC2010. Table 4.23 and Table 4.24 summarizes the results of ultimate bending moment, $M_{u}$, and mean crack spacing, $s_{r m}$, respectively. Regarding the $M_{u}$, the numerical responses exhibit a good agreement with both experimental and analytical results. For the $s_{r m}$, the numerical responses present better agreement with the code predictions than with the experimental results, particularly for the case good bond conditions. 
Table 4.23.: Experimental, predictions according to MC2010 and numerical responses for ultimate bending moment.

\begin{tabular}{cccccc}
\hline Series & $\begin{array}{c}M_{u, \text { exp }} \\
(\mathrm{kN} . \mathrm{m})\end{array}$ & $\begin{array}{c}M_{u, M C 2010} \\
(\mathrm{kN} . \mathrm{m})\end{array}$ & $\begin{array}{c}M_{u, \text { num all other }} \\
(\mathrm{kN} . \mathrm{m})\end{array}$ & $\begin{array}{c}M_{u, \text { num }} \\
(\mathrm{kN} . \mathrm{m})\end{array}$ & $\begin{array}{c}M_{u, \text { num }} \text { perfect } \\
(\mathrm{kN} . \mathrm{m})\end{array}$ \\
\hline \hline $\mathrm{RC}$ & 10.8 & 10.1 & 10.7 & 10.7 & 11.1 \\
\hline $\begin{array}{c}\mathrm{RC}-\mathrm{SFRC} \\
25 \mathrm{~kg} / \mathrm{m}^{3}\end{array}$ & 12.0 & 11.5 & 12.1 & 12.2 & 12.2 \\
\hline $\begin{array}{l}\mathrm{RC}-\mathrm{SFRC} \\
50 \mathrm{~kg} / \mathrm{m}^{3}\end{array}$ & 12.3 & 12.2 & 13.4 & 13.4 & 13.4 \\
\hline
\end{tabular}

Table 4.24.: Experimental, predictions according to MC2010 and numerical responses for mean crack spacing.

\begin{tabular}{cccccc}
\hline Series & $\begin{array}{c}s_{\text {rm,exp }} \\
(\mathrm{mm})\end{array}$ & $\begin{array}{c}s_{\text {rm, MC 2010 }} \\
(\mathrm{mm})\end{array}$ & $\begin{array}{c}s_{\text {rm,num all other }} \\
(\mathrm{mm})\end{array}$ & $\begin{array}{c}s_{\text {rm,num }} \\
(\mathrm{mm})\end{array}$ & $\begin{array}{c}s_{\text {rm,num }} \text { perfect } \\
(\mathrm{mm})\end{array}$ \\
\hline \hline $\mathrm{RC}$ & 88 & 82 & 120 & 70 & 38 \\
\hline $\begin{array}{c}\mathrm{RC}-\mathrm{SFRC} \\
25 \mathrm{~kg} / \mathrm{m}^{3}\end{array}$ & 69 & 58 & 65 & 41 & 19 \\
\hline $\begin{array}{c}\mathrm{RC}-\mathrm{SFRC} \\
50 \mathrm{~kg} / \mathrm{m}^{3}\end{array}$ & 62 & 44 & 22 & 21 & 14 \\
\hline
\end{tabular}




\section{Conclusions}

\subsection{General conclusions}

In this research, a mesoscale model with a discrete and explicit representation of steel fibers was used to simulate the post-cracking behavior of SFRC in order to contribute on the design of beam elements.

As previously stated, in the adopted numerical strategy proposed by Bitencourt Jr. et al., 2018b, the behavior of the concrete, steel fibers and concrete-fiber interaction is described separately. The program responsible for the generation of a cloud of fibers was improved to consider specimens with arbitrary geometries based on the concrete finite element mesh. Furthermore, the design procedure according to fib Model Code 2010 (2013) recommendations were applied on the design of RC-SFRC beams. A total of three applications using the numerical tool were performed to verify the ability of the numerical strategy in predict the structural behavior of RC-SFRC beams.

As a first application, three-point bending tests (EN 14651, 2005) recommended by MC2010 to characterize the SFRC behavior were numerically analyzed and the results compared with experimental ones obtained in the laboratory at the University of São Paulo. Three fiber contents of $15 \mathrm{~kg} / \mathrm{m}^{3}, 30 \mathrm{~kg} / \mathrm{m}^{3}$ and $45 \mathrm{~kg} / \mathrm{m}^{3}$ were considered and the intermediate dosage $\left(30 \mathrm{~kg} / \mathrm{m}^{3}\right)$ was used to calibrate the fiber-concrete interface parameters. Then, the same parameters were adopted for the simulations of fiber contents 15 and $45 \mathrm{~kg} / \mathrm{m}^{3}$. The results show that despite the variability of the numerical responses for the different fiber distributions, the SFRC post-cracking behavior is well captured by the presented model.

In the second example, RC and RC-SFRC beams were designed and numerically simulated. The numerical and experimental results of EN 14651 tests obtained in the previous example were used on the design of beams. First, an RC beam was designed and the contribution of the addition of $15 \mathrm{~kg} / \mathrm{m}^{3}, 30 \mathrm{~kg} / \mathrm{m}^{3}$ and $45 \mathrm{~kg} / \mathrm{m}^{3}$ of 
fiber contents were evaluated according to MC2010. The results show that the design values estimated in terms of bending, shear, crack width, mean crack spacing and deflection using the parameters obtained in the numerical simulation of three-point bending tests according to EN 14651 (2005) exhibit similar values when compared to those using the experimental responses. Afterwards, the designed beams were simulated applying the numerical tool and the results are compared with the design predictions in terms of serviceability and ultimate limit states. The numerical results are found in good agreement with MC2010 predictions and show the potential of the numerical approach to consider the influence of addition of steel fibers on the post-cracking material response and to predict the behavior of structural elements.

The last example, RC-SFRC small-scale beams experimentally tested by Conforti et al. (2018) were numerically simulated. Three types of beams were analyzed: a RC beam and RC-SFRC beams with steel fiber contents of $25 \mathrm{~kg} / \mathrm{m}^{3}$ and $50 \mathrm{~kg} / \mathrm{m}^{3}$. In this example, the three-point bending beams experimentally tested by the authors according to EN 14651 (2005) were also numerically analyzed in order to calibrate the parameters of concrete-fiber interface. In addition, different bond conditions between longitudinal reinforcement and concrete were adopted to very the influence of these parameters on the structural response. The numerical results were compared to the experimental ones in terms of maximum loads, deflections, maximum cracks widths, mean cracking spacing and those predicted by the MC2010 for mean crack spacing and the ultimate bending moment. The response obtained in the finite element simulation replicates the experimental ones satisfactorily.

The results have shown that the use of this numerical approach is very appealing to be employed on the design of SFRC structural elements. Additional information such as crack pattern, load vs. displacement curves, failure mode and stresses on reinforcements obtained in these analyses might contribute to better comprehend the effects of the different aspects involving the failure process of SFRC. In special, the numerical approach can be used for extrapolating the conditions considered at the laboratory and to contribute on the design of structural members reinforced with both conventional and steel fibers reinforcements, aiming at optimizing structural solutions. 


\subsection{Recommendations for future research}

Some recommendations for future research and possible extensions of this work are summarized as follows:

- Development of a interface model that considers the effect of hook in the endhooked steel fiber explicitly;

- To predict the behavior of the characterization test EN 14651 (2005), proposed by MC2010, using the concrete-fiber interface response from pullout tests of straight and end-hooked steel fibers;

- Development of an algorithm for generation and distribution of steel fibers to taking into account the effect of segregation of fibers, direction of the material casting and molding procedure, and the influence of these fiber distributions on the design of structural members;

- To study the influence of dowel action, matrix micro-spalling and the interaction between fibers (friction) on the behavior of the composite;

- Adaptive mesh refinement could be contemplated in the context of the proposed model in order to reduce the high computational cost due to multiscale analyses;

- To use the numerical tool for modeling of high performance fiber reinforced concrete;

- To apply the proposed model for the numerical analyses of other structural members, as for example, slabs, walls and tunnel lining segments;

- Numerical analysis of others SFRC characterization tests, as for instance, Barcelona test (UNE 83515, 2010), DEWS test (di Prisco et al., 2013b), Montevideo test (Segura-Castillo et al., 2018) and Round panel test (ASTM C-1550, 2003) in order to contribute in the correlation between these tests and the standard EN 14651 test, as proposed by MC2010;

- To perform the experimental test of the numerically simulated beam presented in Section 4.2. 


\section{Bibliography}

ACI 318M-08. Building Code Requirements for Structural Concrete and Commentary. American Concrete Institute, USA, 2008.

ACI Committee 544.1R-96. Design considerations for steel Fiber Reinforced Concrete. American Concrete Institute, USA, 1996.

Amin, A., Foster, S. J., and Kaufmann, W. Instantaneous deflection calculation for steel fibre reinforced concrete one way members. Engineering Structures, 131: 438 - 45, 2017. ISSN 0141-0296. doi: 10.1016/j.engstruct.2016.10.041. URL https://doi.org/10.1016/j.engstruct.2016.10.041.

ASTM C-1550. Standard test method for flexural toughness of fibre reinforced concrete (using a centrally loaded round panel). American Society for Testing and Materials, West Conshohoken, 2003.

ASTM C1609 / C1609M-12. Standard Test Method for Flexural Performance of Fiber-Reinforced Concrete (Using Beam With Third-Point Loading). ASTM International, West Conshohocken, PA, USA, 2012.

Barnett, S. J., Lataste, J.-F., Parry, T., Millard, S. G., and Soutsos, M. N. Assessment of fibre orientation in ultra high performance fibre reinforced concrete and its effect on flexural strength. Materials and Structures, 43(7):10091023, 2010. ISSN 1359-5997. doi: 10.1617/s11527-009-9562-3. URL http: //dx.doi.org/10.1617/s11527-009-9562-3.

BEKAERT. Brochure Dramix steel fiber concrete reinforcement. Brochure, 2012. URL https://www . bekaert.com.

Bentur, A. and Mindess, S. Fibre Reinforced Cementitious Composites. Modern Concrete Technology Series, 2007. ISBN 9780415250481.

Bitencourt Jr., L. A. G., Trindade, Y., Bittencourt, T. N., Manzoli, O. L., and Rodrigues, E. A. Multiscale modeling of steel fiber reinforced concrete based on the use of coupling finite elements and mesh fragmentation technique. In Meschke, G., 
Pichler, B., and Rots, J. G., editors, Computational Modelling of Concrete Structures, pages 877-888. CRC Press, 2018a. URL https://www.taylorfrancis. com/books/9781351726764.

Bitencourt Jr., L. A. G. Numerical Modeling of Failure Processes in Steel Fiber Reinforced Cementitious Materials. PhD thesis, Polytechnic School at the University of Sao Paulo, University of Sao Paulo, Brazil, 2015.

Bitencourt Jr., L. A. G., Manzoli, O. L., Prazeres, P. G. C., Rodrigues, E. A., and Bittencourt, T. N. A coupling technique for non-matching finite element meshes. Computer Methods in Applied Mechanics and Engineering, 290:19 - 44, 2015. ISSN 0045-7825. doi: 10.1016/j.cma.2015.02.025. URL http://dx.doi.org/10. $1016 / j$.cma. 2015.02 .025 .

Bitencourt Jr., L. A. G., Manzoli, O. L., Bittencourt, T. N., and Vecchio, F. J. Numerical modeling of steel fiber reinforced concrete with a discrete and explicit representation of steel fibers. International Journal of Solids and Structures, 2018b. doi: 10.1016/j.ijsolstr.2018.09.028. URL https://doi.org/10.1016/j . ijsolstr.2018.09.028. In Press.

Bitencourt Jr., L. A. G., Manzoli, O. L., Trindade, Y. T., Rodrigues, E. A., and da Costa, D. D. Modeling reinforced concrete structures using coupling finite elements for discrete representation of reinforcements. Finite Elements in Analysis and Design, 149:32 - 44, 2018c. ISSN 0168-874X. doi: 10.1016/j.finel.2018.06.004. URL https://doi.org/10.1016/j.finel.2018.06.004.

Bolander, J. and Saito, S. Discrete modeling of short-fiber reinforcement in cementitious composites. Advanced Cement Based Materials, 6(3):76 - 86, 1997. ISSN 1065-7355. doi: 10.1016/S1065-7355(97)90014-6. URL https://doi.org/10 . 1016/S1065-7355(97)90014-6.

Caggiano, A., Etse, G., and Martinelli, E. Zero-thickness interface model formulation for failure behavior of fiber-reinforced cementitious composites. Computers ES Structures, 98-99:23 - 32, 2012. ISSN 0045-7949. doi: \{10.1016/j.compstruc. 2012.01.013\}. URL https://doi.org/10.1016/j.compstruc.2012.01.013.

Carol, I., Rizzi, E., and Willam, K. A unified theory of elastic degradation and damage based on a loading surface. International Journal of Solids and Structures, 31(20):2835 - 2865, 1994. ISSN 0020-7683. doi: 10.1016/0020-7683(94)90072-8. URL https://doi.org/10.1016/0020-7683(94)90072-8. 
CECS 38:2004. Technical Specification for Fiber Reinforced Concrete Structures. Association of Chinese Construction Standardization, China, 2004.

Cervera, M., Oliver, J., and Manzoli, O. A rate-dependent isotropic damage model for the seismic analysis of concrete dams. Earthquake Engineering and Structural Dynamics, 25(9):987-1010, 1996. ISSN 1096-9845. doi: \{10.1002/(SICI) 1096-9845(199609)25:9<987::AID-EQE599>3.0.CO;2-X\}. URL https://doi . org/10 . 1002/(SICI) 1096-9845 (199609) 25: 9<987: :AID-EQE599>3 . 0. CO;2-X.

CIMNE. GiD. URL http://gid.cimne.upc.es/.

CNR-DT 204. Guide for the Design and Construction of Fiber-Reinforced Concrete Structures. Italian National Research Council, Italian, 2006.

Conforti, A., Minelli, F., and Plizzari, G. A. Wide-shallow beams with and without steel fibres: A peculiar behaviour in shear and flexure. Composites Part B: Engineering, 51:282 - 290, 2013. ISSN 1359-8368. doi: 10.1016/j.compositesb.2013. 03.033. URL https://doi.org/10.1016/j.compositesb. 2013.03.033.

Conforti, A., Zerbino, R., and Plizzari, G. A. Influence of steel, glass and polymer fibers on the cracking behavior of reinforced concrete beams under flexure. Structural Concrete, 0(0), 7 2018. doi: 10.1002/suco.201800079. URL https://doi.org/10.1002/suco.201800079.

CT 303 - Comitê Técnico IBRACON/ABECE. Práticas recomendadas IBRACON/ABECE: Projeto de estruturas de concrete reforçado com fibras. Brazil, 2016. In Portuguese.

CT 303 - Comitê Técnico IBRACON/ABECE. Contrôle de qualidade do concreto reforçado com fibras: Práticas recomendadas IBRACON/ABECE. Brazil, 2017. In Portuguese.

Cucchiara, C., Mendola, L. L., and Papia, M. Effectiveness of stirrups and steel fibres as shear reinforcement. Cement and Concrete Composites, 26(7):777 - 786, 2004. ISSN 0958-9465. doi: 10.1016/j.cemconcomp.2003.07.001. URL https: //doi.org/10.1016/j. cemconcomp. 2003.07.001.

Cunha, V. Steel fibre reinforced self-compacting concrete - from micromechanics to composite behaviour. PhD thesis, Department of Civil Engineering, University of Minho, Portugal, 2010.

Cunha, V., Barros, J., and Sena-Cruz, J. An integrated approach for modelling the tensile behaviour of steel fibre reinforced self-compacting concrete. Cement 
and Concrete Research, 41(1):64 - 76, 2011. ISSN 0008-8846. doi: 10.1016/ j.cemconres.2010.09.007. URL https://doi.org/10.1016/j.cemconres. 2010 . 09.007.

Cunha, V., Barros, J., and Sena-Cruz, J. A finite element model with discrete embedded elements for fibre reinforced composites. Computers $\&$ Structures, 94 95(0):22 - 33, 2012. ISSN 0045-7949. doi: 10.1016/j.compstruc.2011.12.005. URL http://dx.doi.org/10.1016/j. compstruc.2011.12.005.

DAfStb. Deutscher Ausschuss für Stahlbeton (DAfStb): Richtlinie Stahlfaserbeton. Germany, 2012. In German.

DBV. Deutscher Beton und Bautechnik-Verein E.V. (DBV): Merkblatt Stahlfaserbeton. Germany, 2001. In German.

de Souza Neto, E., Perić, D., and Owen, D. R. J. Computational methods for plasticity: theory and applications. Wiley, 2008. ISBN 9780470694527.

Deluce, J. R. and Vecchio, F. J. Cracking behavior of steel fiber-reinforced concrete members containing conventional reinforcement. Structural Journal, 110(3): 481 - 490, 2013. doi: 10.14359/51685605. URL https://doi.org/10.14359/ 51685605.

di Prisco, M. FRC: structural applications and standards. Materials and Structures, 42(9):1169, Aug 2009. ISSN 1871-6873. doi: 10.1617/s11527-009-9545-4. URL https://doi .org/10.1617/s11527-009-9545-4.

di Prisco, M., Colombo, M., and Dozio, D. Fibre-reinforced concrete in fib model code 2010: principles, models and test validation. Structural Concrete, 14(4): 342-361, 2013a. ISSN 1751-7648. doi: 10.1002/suco.201300021. URL http: //dx.doi.org/10.1002/suco.201300021.

di Prisco, M., Ferrara, L., and Lamperti, M. G. L. Double edge wedge splitting (DEWS): an indirect tension test to identify post-cracking behaviour of fibre reinforced cementitious composites. Materials and Structures, 46(11):18931918, 2013b. ISSN 1871-6873. doi: 10.1617/s11527-013-0028-2. URL https: //doi.org/10.1617/s11527-013-0028-2.

DIN 1045-1:2008-08. Concrete, reinforced and prestressed concrete structures - Part 1: Design and construction. German Institute for Standardisation, Germany, 2008.

DIN EN 12390-5:2009-07. Testing hardened concrete - Part 5: Flexural strength of test specimens; German version. German Institute for Standardisation, 2009. 
DIN EN 1992-1-1/NA:2013-04. National Annex - Nationally determined parameters

- Eurocode 2: Design of concrete structures - Part 1-1: General rules and rules for buildings, 2013. German version.

Dinh, H. H., Parra-Montesinos, G. J., and Wight, J. K. Shear behavior of steel fiberreinforced concrete beams without stirrup reinforcement. Structural Journal, 107 (5):597 - 606, 2010. doi: 10.14359/51663913. URL https://doi.org/10.14359/ 51663913.

DR AS5100.5. Bridge design part 5: concrete. Australian Standard. Standards Association of Australia, Sydney, Australia, 2017.

Dupont, D. and Vandewalle, L. Distribution of steel fibres in rectangular sections. Cement and Concrete Composites, 27(3):391 - 398, 2005. ISSN 0958-9465. doi: 10.1016/j.cemconcomp.2004.03.005. URL http://dx.doi.org/10.1016/j . cemconcomp.2004.03.005.

EHE-08. Instruccion del Hormigon Estructural EHE-08. CPH - Comision Permanente del Hormigon, Spain, 2008.

EN 14651. Test method for metallic fiber concrete - Measuring the Flexural Tensile Strength (Limit of Proportionality (LOP), Residual). European Committee for Standardization (CEN), Brussels, Belgium, 2005.

Etse, G., Caggiano, A., and Vrech, S. Multiscale failure analysis of fiber reinforced concrete based on a discrete crack model. International Journal of Fracture, 178 (1-2):131-146, 2012. ISSN 0376-9429. doi: 10.1007/s10704-012-9733-z. URL http://dx.doi.org/10.1007/s10704-012-9733-z.

Fanella, D. A. and Naaman, A. E. Stress-strain properties of fiber reinforced mortar in compression. ACI Journal, 82(4):475 - 483, 1985. doi: 10.14359/10359. URL https://doi.org/10.14359/10359.

Fang, Q. and Zhang, J. Three-dimensional modelling of steel fiber reinforced concrete material under intense dynamic loading. Construction and Building Materials, 44:118 - 132, 2013. ISSN 0950-0618. doi: 10.1016/j.conbuildmat.2013.02.067. URL https://doi.org/10.1016/j.conbuildmat.2013.02.067.

Ferrara, L., Park, Y., and Shah, S. Correlation among fresh state behavior, fiber dispersion, and toughness properties of SFRCs. Journal of Materials in Civil Engineering, 20(7):493-501, 2008. doi: 10.1061/(ASCE)0899-1561(2008)20:7(493). URL http://dx.doi.org/10.1061/(ASCE)0899-1561(2008) 20:7 (493). 
Ferrara, L., Park, Y.-D., and Shah, S. P. A method for mix-design of fiber-reinforced self-compacting concrete. Cement and Concrete Research, 37(6):957 -971, 2007. ISSN 0008-8846. doi: 10.1016/j.cemconres.2007.03.014. URL http://dx.doi. org/10.1016/j.cemconres .2007.03.014.

fib Model Code 2010. fib Model Code for Concrete Structures 2010. International Federation for Structural Concrete ( $f i b)$, Berlin, Germany, 2013.

Foster, S. Design of FRC beams for shear using the VEM and the draft model code approach. fib Bull, 57:195 - 210, 2010.

Hillerborg, A., ModÃ@er, M., and Petersson, P.-E. Analysis of crack formation and crack growth in concrete by means of fracture mechanics and finite elements. Cement and Concrete Research, 6(6):773 - 781, 1976. ISSN 0008-8846. doi: 10. 1016/0008-8846(76)90007-7. URL https://doi.org/10.1016/0008-8846(76) 90007-7.

Jin, C., Buratti, N., Stacchini, M., Savoia, M., and Cusatis, G. Lattice discrete particle modeling of fiber reinforced concrete: Experiments and simulations. European Journal of Mechanics - A/Solids, 57:85 - 107, 2016. ISSN 09977538. doi: 10.1016/j.euromechsol.2015.12.002. URL https://doi.org/10.1016/ j.euromechsol.2015.12.002.

Kang, J., Kim, K., Lim, Y. M., and Bolander, J. E. Modeling of fiber-reinforced cement composites: Discrete representation of fiber pullout. International Journal of Solids and Structures, 51(10):1970 - 1979, 2014. ISSN 0020-7683. doi: https: //doi.org/10.1016/j.ijsolstr.2014.02.006. URL http://www.sciencedirect.com/ science/article/pii/S0020768314000547.

Laranjeira, F. Design-oriented constitutive model for steel fiber reinforced concrete. PhD thesis, Universidad Politécnica de Cataluña, Barcelona - Spain, 2010.

Maccaferri, O. CH-TL-IT-SFRC segment tunnel lining, Line 9 Barcelona Metro. Case Histories, 2010. URL https://www.maccaferri.com/download/ ch-tl-sfrc-segment-tunnel-lining-line-9-barcelona-metro/?wpdmdl= 5066 .

Manzoli, O., Gamino, A., Rodrigues, E., and Claro, G. Modeling of interfaces in twodimensional problems using solid finite elements with high aspect ratio. Computers and Structures, 94-95(0):70-82, 2012. ISSN 0045-7949. doi: 10.1016/j.compstruc. 2011.12.001. URL https://doi .org/10.1016/j . compstruc.2011.12.001. 
Manzoli, O. L., Maedo, M. A., Bitencourt Jr., L. A., and Rodrigues, E. A. On the use of finite elements with a high aspect ratio for modeling cracks in quasibrittle materials. Engineering Fracture Mechanics, 153:151 - 170, 2016. ISSN 0013-7944. doi: 10.1016/j.engfracmech.2015.12.026. URL https://doi.org/10. 1016/j .engfracmech.2015.12.026.

Martinie, L., Rossi, P., and Roussel, N. Rheology of fiber reinforced cementitious materials: classification and prediction. Cement and Concrete Research, 40(2): 226 - 234, 2010. ISSN 0008-8846. doi: 10.1016/j.cemconres.2009.08.032. URL http://dx.doi.org/10.1016/j.cemconres.2009.08.032.

Maya, L., Ruiz, M. F., Muttoni, A., and Foster, S. Punching shear strength of steel fibre reinforced concrete slabs. Engineering Structures, 40:83 - 94, 2012. ISSN 0141-0296. doi: 10.1016/j.engstruct.2012.02.009. URL https://doi.org/ $10.1016 / j$.engstruct . 2012.02.009.

Meda, A., Minelli, F., and Plizzari, G. A. Flexural behaviour of rc beams in fibre reinforced concrete. Composites Part B: Engineering, 43(8):2930 - 2937, 2012. ISSN 1359-8368. doi: 10.1016/j.compositesb.2012.06.003. URL https://doi . org/10.1016/j.compositesb. 2012.06.003.

Minelli, F. Plain and Fiber Reinforced Concrete Beams under Shear Loading: Structural Behavior and Design Aspects. PhD thesis, "Department of Civil Engineering, University of Brescia, Brescia, Italy, 2015.

Montero-Chacón, F., Cifuentes, H., and Medina, F. Mesoscale characterization of fracture properties of steel fiber-reinforced concrete using a lattice-particle model. Materials, 10(2), 2017. ISSN 1996-1944. doi: 10.3390/ma10020207. URL https: //doi.org/10.3390/ma10020207.

Muttoni, A. New approaches for conceptual design and construction: Centro Ovale concrete shell at Chiasso and Maison de l'Ecriture at Montricher (Switzerland). In Nolting, U. and Haist, M., editors, Gestalteter Beton - Konstruieren in Einklang von Form und Funktion : 10. Symposium Baustoffe und Bauwerkserhaltung, Karlsruher Institut fuer Technologie (KIT), volume 4 of 5, pages 67-74. KIT Scientific Publishing, 2014.

Muttoni, A., Lurati, F., and Fernández Ruiz, M. Concrete shells towards efficient structures: construction of an ellipsoidal concrete shell in switzerland. Structural Concrete, 14(1):43-50, 2013. ISSN 1751-7648. doi: 10.1002/suco.201200058. URL http://dx.doi.org/10.1002/suco. 201200058. 
Naaman, A. E. and Najm, H. S. Bond-slip mechanisms of steel fibers in concrete. ACI Materials Journal, 88(2):135-145, 1991. doi: 10.14359/1896. URL https: //doi.org/10.14359/1896.

NZS 3101. New Zealand Standard - Concrete structures standard - Part 1: The design of concrete structures - Part 2: Commentary on the design of concrete structures. P301 Concrete Design Committe for the Standard Council, New Zealand, 2006.

Octávio, C., Dias-da-Costa, D., Alfaiate, J., and Júlio, E. Modelling the behaviour of steel fibre reinforced concrete using a discrete strong discontinuity approach. Engineering Fracture Mechanics, 154:12 - 23, 2016. ISSN 00137944. doi: 10.1016/j.engfracmech.2016.01.006. URL https://doi.org/10.1016/ j.engfracmech.2016.01.006.

Oliver, J., Huespe, A., and Cante, J. An implicit/explicit integration scheme to increase computability of non-linear material and contact/friction problems. Computer Methods in Applied Mechanics and Engineering, 197:1865-1889, 2008. ISSN 0045-7825. doi: 10.1016/j.cma.2007.11.027. URL http://doi.org/10.1016/j . cma.2007.11.027.

Prazeres, P. G. C., Bitencourt Jr., L. A. G., Bittencourt, T. N., and Manzoli, O. L. A modified implicit-explicit integration scheme: an application to elastoplasticity problems. Journal of the Brazilian Society of Mechanical Sciences and Engineering, pages 1-11, 2015. ISSN 1678-5878. doi: 10.1007/s40430-015-0343-3. URL http://dx.doi.org/10.1007/s40430-015-0343-3.

Pros, A., Diez, P., and Molins, C. Modeling steel fiber reinforced concrete: numerical immersed boundary approach and a phenomenological mesomodel for concretefiber interaction. International Journal for Numerical Methods in Engineering, 90 (1):65-86, 2012. ISSN 1097-0207. doi: 10.1002/nme.3312. URL http://dx.doi . org/10.1002/nme.3312.

Pros Parés, A. Numerical Approach for Modeling Steel Fiber Reinforced Concrete. PhD thesis, Universidad Politécnica de Cataluña, Barcelona - Spain, 2011.

Radtke, F. K. F., Simone, A., and Sluys, L. J. A partition of unity finite element method for simulating non-linear debonding and matrix failure in thin fibre composites. International Journal for Numerical Methods in Engineering, 86(4-5):453 - 476, 2011. ISSN 1097-0207. doi: 10.1002/nme.3056. URL http://dx.doi.org/10.1002/nme.3056. 
Radtke, F., Simone, A., and Sluys, L. A computational model for failure analysis of fibre reinforced concrete with discrete treatment of fibres. Engineering Fracture Mechanics, 77(4):597 - 620, 2010. ISSN 0013-7944. doi: 10.1016/j.engfracmech. 2009.11.014. URL http://dx.doi.org/10.1016/j.engfracmech.2009.11.014.

RILEM TC 162-TDF. Recommendations of RILEM TC 162-TDF: Test and design methods for steel fibre reinforced concrete: bending test. Materials and Structures, 35:579 - 582, 2002. ISSN 1359-5997.

RILEM TC 162-TDF. Final recommendation of RILEM TC 162-TDF: Test and design methods for steel fibre reinforced concrete: $\sigma-\varepsilon$ design method. Materials and Structures, 36:560 - 567, 2003. ISSN 1359-5997.

Romualdi, J. P. and Batson, G. B. Behavior of reinforced concrete beams with closely spaced reinforcement. Journal Proceedings, 60(6):775-790, 1963. doi: 10. 14359/7878. URL https://doi.org/10.14359/7878.

Schauffert, E. A. and Cusatis, G. Lattice discrete particle model for fiber-reinforced concrete. i: Theory. Journal of Engineering Mechanics, 138(7):826 - 833, 2012. doi: 10.1061/(ASCE)EM.1943-7889.0000387. URL https://doi.org/10.1061/ (ASCE) EM. 1943-7889.0000387.

Schauffert, E. A., Cusatis, G., Pelessone, D., O'Daniel, J. L., and Baylot, J. T. Lattice discrete particle model for fiber-reinforced concrete. ii: Tensile fracture and multiaxial loading behavior. Journal of Engineering Mechanics, 138(7):834 - 841, 2012. doi: 10.1061/(ASCE)EM.1943-7889.0000392. URL https://doi . org/10.1061/(ASCE) EM.1943-7889.0000392.

Segura-Castillo, L., Monte, R., and de Figueiredo, A. D. Characterisation of the tensile constitutive behaviour of fibre-reinforced concrete: A new configuration for the wedge splitting test. Construction and Building Materials, 192:731 - 741, 2018. ISSN 0950-0618. doi: 10.1016/j.conbuildmat.2018.10.101. URL https: //doi.org/10.1016/j.conbuildmat.2018.10.101.

Serna, P., Arango, S., Ribeiro, T., Núñez, A. M., and Garcia-Taengua, E. Structural cast-in-place SFRC: technology, control criteria and recent applications in spain. Materials and Structures, 42(9):1233, Jul 2009. ISSN 1871-6873. doi: 10.1617/ s11527-009-9540-9. URL https://doi.org/10.1617/s11527-009-9540-9.

SFRC Consortium. Design guideline for structural applications of steel fibre reinforced concrete. Denmark, 2014. 
Simo, J. and Hugles, T. J. R. Computational Inelasticity. Springer, 1998.

Singh, H. Steel Fiber Reinforced Concrete: Behavior, Modelling and Design. Springer Singapore, 2017. ISBN 978-981-10-2507-5. doi: 10.1007/ 978-981-10-2507-5. URL https://doi .org/10.1007/978-981-10-2507-5.

Soroushian, P. and Lee, C.-D. Distribution and orientation of fibers in steel fiber reinforced concrete. ACI Materials Journal, 87(5):433-439, 1990. doi: 10.14359/ 1803. URL https://doi.org/10.14359/1803.

SS-812310:2014. Fibre Concrete - Design of Fibre Concrete Structures. SIS - Bygg och anläggning, Sweden, 2014.

Telles, R. C. D. and Figueiredo, A. D. d. Possibilidades de incorporação de novas tecnologias em anel de concreto pré-fabricado para túneis com tuneladora. Concreto $\&$ Construção, XXXIII(41):30 - 35, 2006. In Portuguese.

Tiberti, G., Minelli, F., and Plizzari, G. Cracking behavior in reinforced concrete members with steel fibers: A comprehensive experimental study. Cement and Concrete Research, 68, 11 2014. doi: 10.1016/j.cemconres.2014.10.011. URL https://doi.org/10.1016/j. cemconres.2014.10.011.

Toutanji, H. and Bayasi, Z. Effects of manufacturing techniques on the flexural behavior of steel fiber-reinforced concrete. Cement and Concrete Research, 28(1): 115 - 124, 1998. ISSN 0008-8846. doi: 10.1016/S0008-8846(97)00213-5. URL http://dx.doi.org/10.1016/S0008-8846(97)00213-5.

Truesdell, C. and Toupin, R. The Classical Field Theories. Springer Berlin Heidelberg, Berlin, Heidelberg, 1960. ISBN 978-3-642-45943-6. doi: 10.1007/ 978-3-642-45943-6_2. URL https://doi.org/10.1007/978-3-642-45943-6_2.

UNE 83515. Hormigones con fibras. Determinacion de la resistencia a fisuracion, tenacidad y resistencia residual a traccion (Metodo Barcelona). AENOR, Spain, 2010.

UNI 11039. Calcestruzzo rinforzato con fibre d'acciaio; (1a) Parte I: Definizioni, classificazione e designazione; (1b) Parte II: Metodo di prova per la determinazione della resistenza di prima fessurazione e degle indici di duttilitá. Ente Italiano di Normazione (UNI), Italy, 2003. in Italian.

UNI 11188. Elementi strutturali in calcestruzzo rinforzato con fibre d'acciaio: progettazione esecuzione e controllo. Ente Italiano di Normazione (UNI), Italy, 2004. 
Wille, K. and Parra-Montesinos, G. J. Effect of beam size, casting method, and support conditions on flexural behavior of ultra-high-performance fiber-reinforced concrete. ACI Materials Journal, 109(3):379-388, 2012. doi: 10.14359/51683829. URL https://doi.org/10.14359/51683829.

Zhan, Y. and Meschke, G. Multilevel computational model for failure analysis of steel-fiber-reinforced concrete structures. Journal of Engineering Mechanics, 142 (11):04016090, 2016. doi: 10.1061/(ASCE)EM.1943-7889.0001154. URL https: //doi.org/10.1061/(ASCE) EM.1943-7889.0001154.

Zhang, H., Huang, Y., Yang, Z., Xu, S., and Chen, X. A discrete-continuum coupled finite element modelling approach for fibre reinforced concrete. Cement and Concrete Research, 106:130 - 143, 2018. ISSN 0008-8846. doi: 10.1016/j.cemconres. 2018.01.010. URL https://doi.org/10.1016/j . cemconres.2018.01.010. 


\section{A. Appendix}

\section{A.1. Simplified constitutive laws for SFRC}

\section{A.1.1. Rigid plastic model}

The rigid plastic model is based on the assumption that the compressive stress distribution is concentrated on the top fiber of the cross-section, while the tensile post-crack residual stress is uniformly distributed over the whole critical crosssection. This relation can be obtained by rotational equilibrium at ULS, as shown in Figure A.1, by assuming $w_{u}=\mathrm{CMOD}_{3}=2.5 \mathrm{~mm}$ (di Prisco et al., 2013a).

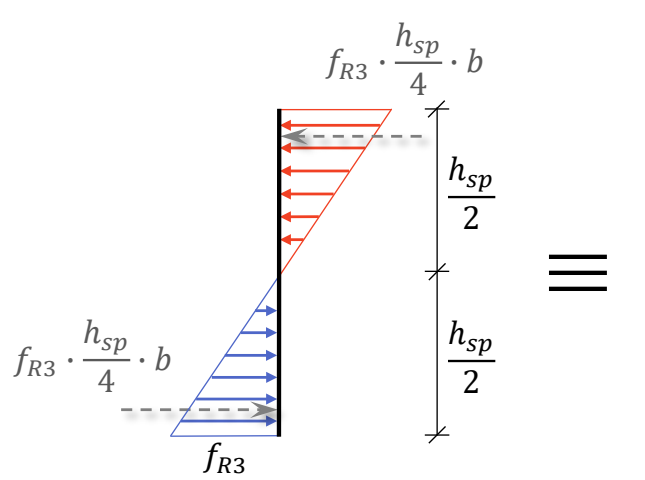

(a)

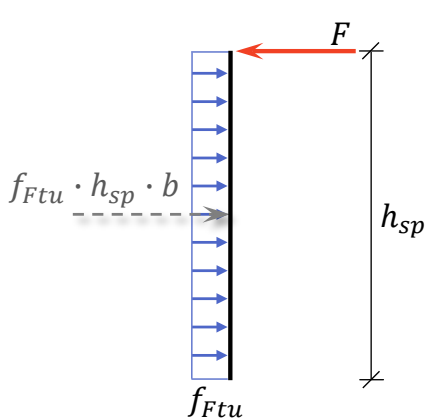

(b)

Figure A.1.: Rotational equilibrium for the rigid plastic model: (a) linear elastic stress distribution and (b) constant stress block in tension and concentrated compression force at the top of the cross-section (adapted from fib Model Code 2010 (2013)).

The external bending moment, $M_{u, e x t}$, acting on the section for the stress distribution as illustrated in Figure A.1(a) is calculated by:

$$
M_{u, e x t}=\frac{f_{R 3} \cdot h_{s p} \cdot b}{4} \cdot\left(\frac{2}{3} \cdot \frac{h_{s p}}{2}+\frac{2}{3} \cdot \frac{h_{s p}}{2}\right)=\frac{f_{R 3} \cdot h_{s p}^{2} \cdot b}{6}
$$


where $f_{R 3}$ is the residual flexural tensile strength corresponding to $\mathrm{CMOD}_{3}=$ $2.5 \mathrm{~mm}, h_{s p}$ is the distance between the tip of the notch and the top of the beam in the mid-span section and $b$ is the width of section.

The internal bending moment, $M_{u, i n t}$, corresponding to the stress distribution depicted in Figure A.1(b) is defined as:

$$
M_{u, i n t}=f_{F t u} \cdot h_{s p} \cdot b \cdot\left(\frac{h_{s p}}{2}\right)=\frac{f_{F t u} \cdot h_{s p}^{2} \cdot b}{2}
$$

Equating the internal, $M_{u, i n t}$, and external, $M_{u, e x t}$, moments, the ultimate residual strength, $f_{F t u}$, is expressed as follows:

$$
f_{F t u}=\frac{f_{R 3}}{3}
$$

\section{A.1.2. Linear model}

The linear model requires the identification of two reference values: the serviceability residual strength $f_{F t s}$ and the ultimate residual strength $f_{F t u}$, which are obtained by assuming a strain and stress distribution for SLS as illustrated in Figure A.2(a) and (b), respectively, and for ULS, a stress distribution shown in Figure A.2 (c) (di Prisco et al., 2013a).

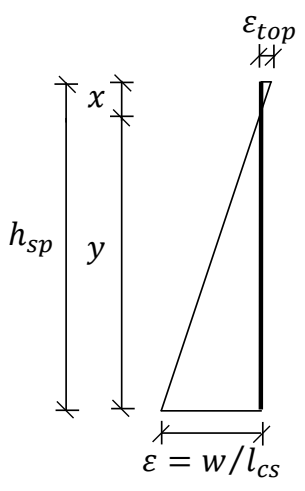

(a)

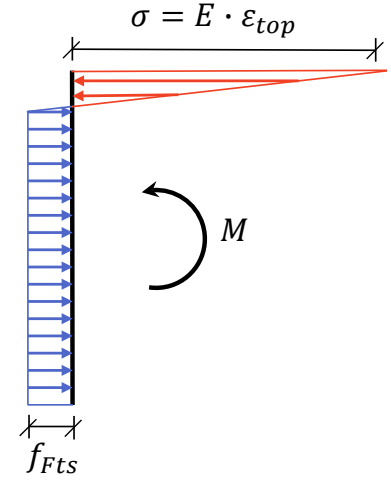

(b)

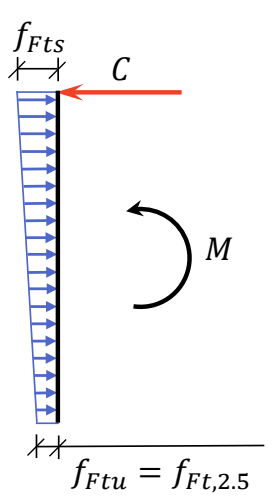

(c)

Figure A.2.: Linear model approximation: (a) strain diagram and stress distribution for (b) SLS and (c) ULS. (adapted from fib Model Code 2010 (2013)).

At SLS, the proposed linear model considers an elastoplastic behavior in uniaxial tension and an elastic behavior in uniaxial compression as depicted in Figure A.2(b). 
Regarding the uniaxial compression, the stress $\sigma$ is calculate as $\sigma=E \cdot \varepsilon_{\text {top }}$ and the strain compatibility is given by: $\varepsilon_{t o p} / x=\varepsilon / y$ (see Figure A.2(a)), where $E$ is the Young's modulus of concrete, $x$ is the depth of compression zone, $y$ is the distance between the neutral axis and the tensile side of the cross section, $\varepsilon_{t o p}$ is the maximum compressive strain and $\varepsilon$ is the maximum tensile strain. For the bottom part of the section, corresponding to the uniaxial tension, the following assumptions are made: crack width $w=\mathrm{CMOD}_{1}=0.5 \mathrm{~mm}, y=h_{s p}-x$, structural characteristic length $l_{c s}=h_{s p}$ and maximum tensile strain $\varepsilon=w / l_{c s}$. Finally, the compressive stress $\sigma$ can be rewrite as:

$$
\sigma=E \cdot \frac{w}{y l_{c s}} \cdot x
$$

From horizontal equilibrium the following equation can be deduced:

$$
\sigma \cdot b \cdot \frac{x}{2}-f_{F t s} \cdot b \cdot \frac{\left(\frac{f_{F t s} \cdot x}{\sigma}\right)}{2}-f_{F t s} \cdot b \cdot\left(y-\frac{f_{F t s} \cdot x}{\sigma}\right)=0
$$

In addition, the rotational equilibrium is calculated by assuming an applied moment $M_{u, e x t}$ determined as:

$$
M_{u, e x t}=f_{F t s} \cdot b \cdot y \cdot\left(\frac{1}{2} \cdot y+\frac{2}{3} \cdot x\right)-\frac{f_{F t s}^{2} \cdot x \cdot b}{2 \cdot \sigma} \cdot\left(\frac{1}{3} \cdot \frac{f_{F t s} \cdot x}{\sigma}+\frac{2}{3} \cdot x\right)
$$

and an internal moment $M_{u, i n t}$ corresponding to $\mathrm{CMOD}_{1}$ is expressed as follows:

$$
M_{u, i n t}=\frac{f_{R 1} \cdot b \cdot h_{s p}^{2}}{6}
$$

By matching the moments $M_{u, i n t}$ and $M_{u, e x t}$ results in:

$$
f_{F t s} \cdot b \cdot y \cdot\left(\frac{1}{2} \cdot y+\frac{2}{3} \cdot x\right)-\frac{f_{F t s}^{2} \cdot x \cdot b}{2 \cdot \sigma} \cdot\left(\frac{1}{3} \cdot \frac{f_{F t s} \cdot x}{\sigma}+\frac{2}{3} \cdot x\right)=\frac{f_{R 1} \cdot b \cdot h_{s p}^{2}}{6}
$$

From the solution of the nonlinear system of Eq. A.3 and Eq. A.4, a relationship between $f_{F t s}$ and $f_{R 1}$ can be established:

$$
f_{F t s}=k_{a}\left(E, l_{c s}\right) \cdot f_{R 1}
$$

where $k_{a}$ is a function of the elastic modulus $E$ and the structural characteristic length $l_{c s}$. By assuming $l_{c s}=h_{s p}, k_{a}$ becomes a function of $E$ and changes over the 
interval $0.361 \leq k_{a} \leq 0.378$, then an average value of $k_{a}=0.37$ is adopted di Prisco et al. (2013a).

At ULS, a compression force acting on upper part of the section and a linear distribution over the whole section in tension are assumed as shown in Figure A.2 (c). Furthermore, a ultimate crack opening of $w_{u}=2.5 \mathrm{~mm}$ for residual strength $f_{F t, 2.5}$ and a linear relation for a softening behavior, as depicted in Figure A.3, are considered, where the value $k_{b} f_{R 1}$ corresponds to $w=0$ and $k_{a} f_{R 1}$ to $w=0.5 \mathrm{~mm}$.

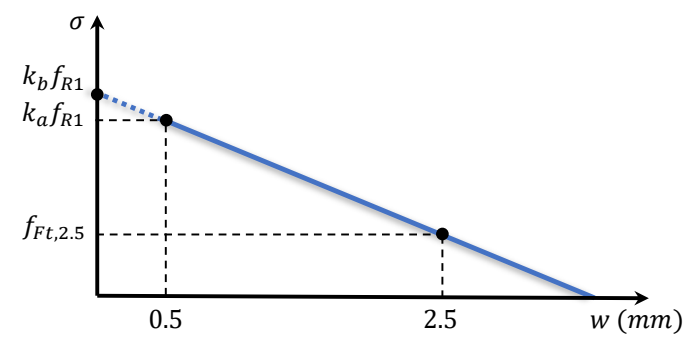

Figure A.3.: $k_{a}$ and $k_{b}$ coefficients (adapted from fib Model Code 2010 (2013)).

The rotational equilibrium $\left(M_{u, e x t}=M_{u, i n t}\right)$ at ULS can be written as:

$$
f_{F t, 2.5} \cdot \frac{b \cdot h_{s p}^{2}}{6}+\left(k_{b} \cdot f_{R 1}-f_{F t, 2.5}\right) \frac{b \cdot h_{s p}^{2}}{6}=\frac{f_{R 3} \cdot b \cdot h_{s p}^{2}}{6}
$$

Solving Eq. A.6 it gives the following relation:

$$
f_{F t, 2.5}=\frac{f_{R 3}}{2}-\frac{k_{b} f_{R 1}}{2}
$$

In addition, the proposed model have to fit the point where $\sigma=k_{a} f_{R 1}$ and $w=$ $0.5 \mathrm{~mm}$ with $k_{a}=0.37$, as consequence, $k_{b}$ can be expressed as:

$$
k_{b}=0.529-0.143 \frac{f_{R 3}}{f_{R 1}}
$$

The value of $f_{R 3}$ is taken equal to $0.5 f_{R 1}$, this approximation its an assumption to consider FRC composites as a structural composite di Prisco et al. (2013a); consequently, $k_{b}$ becomes equal to 0.45 and the Eq. A.7 can be rewritten with approximated coefficients as

$$
f_{F t, 2.5}=0.5 f_{R 3}-0.2 f_{R 1}
$$

Finally, to obtain the value of residual strength for serviceability $f_{F t s}, \sigma=f_{F t s}$ is 
considered, where $\sigma=k_{b} f_{R 1}=0.45 f_{R 1}$ and $w=0 \mathrm{~mm}$, then

$$
f_{F t s}=0.45 f_{R 1}
$$

The ultimate residual strength $f_{F t u}$ is calculated by considering $\sigma=f_{F t u}$ e $w_{u} \neq$ $\mathrm{CMOD}_{3}$ :

$$
f_{F t u}=f_{F t s}-\frac{w_{u}}{\mathrm{CMOD}_{3}}\left(f_{F t s}-0.5 f_{R 3}+0.2 f_{R 1}\right) \geq 0
$$

where $w_{u}$ is the maximum crack opening and depends on the the ductility required. 


\section{B. Appendix}

\section{B.1. Design recommendation of $\mathrm{RC}$ beam according to fib Model Code 2010}

\section{B.1.1. Material properties of concrete and conventional reinforcement}

The partial safety factors and material properties for concrete an,d conventional reinforcement are summarized in Table B.1 and Table B.2, respectively, according to fib Model Code 2010 (2013).

Table B.1.: Partial safety factors for concrete and conventional reinforcement.

\begin{tabular}{ccccc}
\hline & Design strengths & \multicolumn{3}{c}{ Partial safety factors $(\gamma)$} \\
\cline { 3 - 4 } & & \multicolumn{3}{c}{ ULS } \\
\cline { 3 - 4 } & $f_{c d}=f_{c k} / \gamma_{c}$ & $\begin{array}{c}\text { persistent and } \\
\text { transient } \\
\text { situations }\end{array}$ & $\begin{array}{c}\text { accidental } \\
\text { situations }\end{array}$ & SLS \\
\hline Plain concrete & $f_{y d}=f_{y k} / \gamma_{s}$ & 1.5 & 1.2 & 1.0 \\
\hline $\begin{array}{c}\text { Conventional } \\
\text { reinforcement }\end{array}$ & & 1.15 & 1.0 & 1.0 \\
\hline
\end{tabular}


Table B.2.: Main material parameter for concrete and conventional reinforcement.

\section{Concrete}

Stress-strain diagram (parabola-rectangle) for NSC $\left(f_{c k} \leq 50 \mathrm{MPa}\right)$

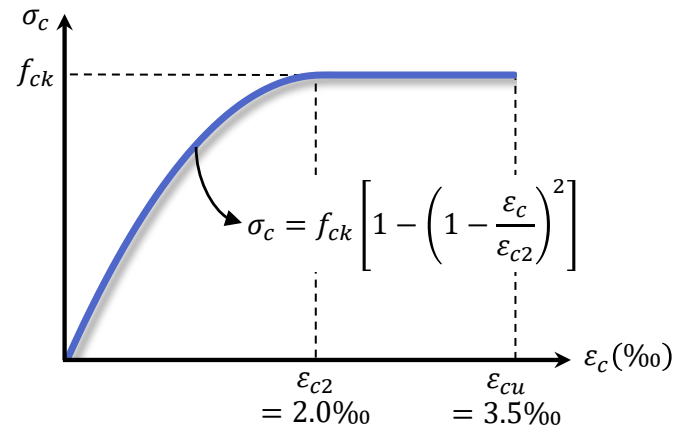

\begin{tabular}{|c|c|}
\hline characteristic compressive strength & $f_{c k}$ \\
\hline mean value of compressive strength & $f_{c m}=f_{c k}+8 \mathrm{MPa}$ \\
\hline mean value of tensile strength & $f_{c t m}=0.3 \cdot\left(f_{c k}\right)^{2 / 3}$ \\
\hline modulus of elasticity & $\begin{array}{c}E_{c i}=21.5 \cdot 10^{3} \cdot \alpha_{E} \cdot\left(\frac{f_{c m}}{10}\right)^{1 / 3}(\mathrm{MPa}) \\
\alpha_{E}=1.0 \text { (quartzite aggregates) }\end{array}$ \\
\hline \multicolumn{2}{|c|}{ Steel } \\
\hline \multicolumn{2}{|c|}{ Stress-strain } \\
\hline 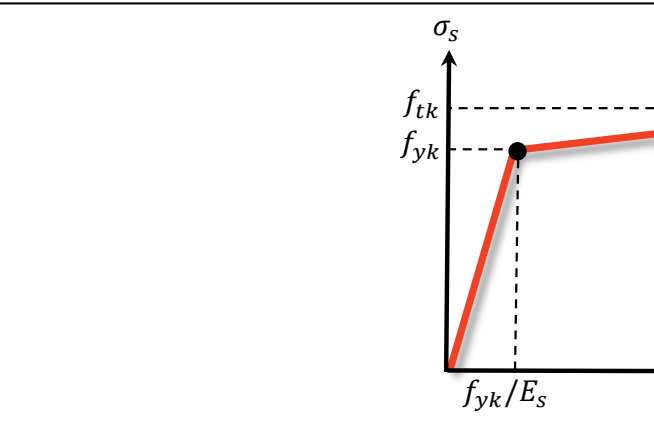 & $\underset{\varepsilon_{u k}}{\stackrel{2}{\longrightarrow}} \varepsilon_{S}$ \\
\hline characteristic yield strength & $f_{y k}$ \\
\hline modulus of elasticity & $E_{s}=200 \mathrm{GPa}$ \\
\hline
\end{tabular}

\section{B.1.2. Design of RC structures under bending}

On design of RC structures under bending is assumed the simplification presented in Figure B.1. 


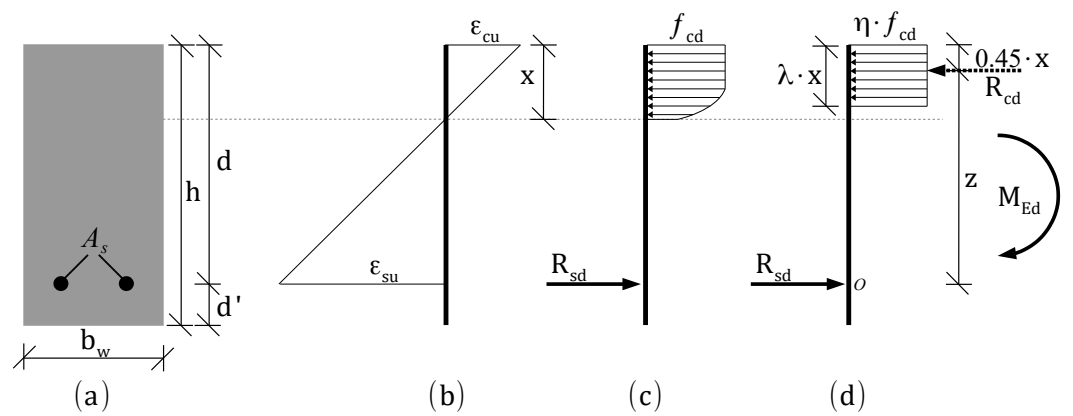

Figure B.1.: Conventional reinforced rectangular section at ULS: (a) cross-section (b) strain diagram (c) parabolic rectangle stress distribution (d) equivalent stress block.

The rotational equilibrium of the design moment $M_{E d}$ and the moment resistance of the cross-section $M_{R d}$ is given by:

$$
M_{E d}=M_{R d} \Rightarrow M_{E d}=R_{c d} \cdot z=R_{s d} \cdot z
$$

where $z$ is the level arm between between $R_{c d}$ and $R_{s d}$ can be calculated as

$$
z=d-0.45 \cdot x
$$

and $R_{c d}$ is the volume of the equivalent stress block:

$$
R_{c d}=\eta \cdot f_{c d} \cdot \lambda \cdot x \cdot b_{w}
$$

so that substituting Eq. B.3 in Eq. B.1 gives:

$$
M_{E d}=\eta \cdot f_{c d} \cdot \lambda \cdot x \cdot b_{w} \cdot(d-0.45 \cdot x)
$$

where the values of the coefficients are $\lambda=0.8$ and $\eta=1.0$ for $f_{c k} \leq 50 \mathrm{MPa}$. Solving the Eq. B.4 it gives the depth of the section neutral axis $x$. The resultant force $R_{s d}$ is the area of the reinforcing multiplied by the assumption of steel yielding stress:

$$
R_{s d}=f_{y d} \cdot A_{s}
$$

Then, the area of the conventional reinforcing is obtained by substituting Eq. B.2 and Eq. B.5 in Eq. B.1:

$$
A_{s}=\frac{M_{E d}}{f_{y d} \cdot(d-0.45 \cdot x)}
$$




\section{Appendix}

C.1. Design calculation report for RC-SFRC beams according to fib Model Code 2010 (2013) 
University of São Paulo

Department of Structural and Geotechnical Engineering

Author: Yasmin T. Trindade

Date: July 24th, 2018

SFRC DESIGN ACCORDING TO fib MODEL CODE 2010 (2013)

Comments:

This program aim to design SFRC structures according to fib Model Code 2010 (2013).

Version 1.0:

Design of bems with fiber reinforcement and conventional reinforcement.

\section{GEOMETRIC PROPRETIES}

$b_{w}:=125 \mathrm{~mm}$

$h:=250 \mathrm{~mm}$

$c:=2.5 \mathrm{~cm}$

$l:=1800 \mathrm{~mm}$

$d^{\prime}:=39 \mathrm{~mm}$

$d:=h-d^{\prime}=211 \mathrm{~mm}$

$d^{\prime \prime}:=d^{\prime}$

$I:=\frac{b_{w} \cdot h^{3}}{12}=\left(1.63 \cdot 10^{8}\right) \mathrm{mm}^{4}$

Environmental class: XC2 width of beam

depth of beam

concrete cover

effective span

effective depth

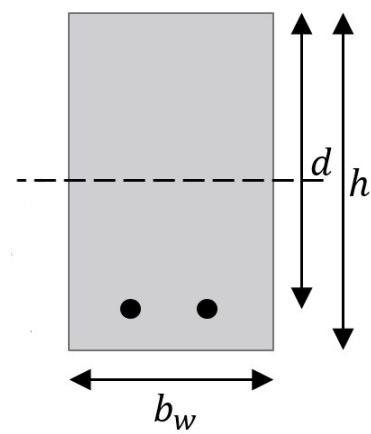

moment of inertia

$P_{k}:=82 k N \quad$ total point load

simply supported beam • ULS

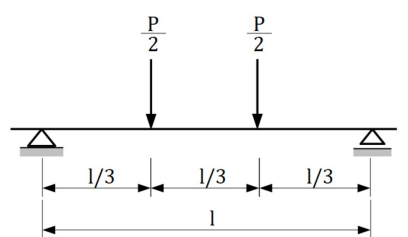

$P_{d}:=P_{k} \cdot 1.5=123 \mathrm{kN}$

$P_{S L S}:=P_{k}=82 \mathrm{kN}$

$M_{\max }:=\frac{P_{d}}{2} \cdot \frac{l}{3}=36.9 \mathrm{kN} \cdot \mathrm{m}$

$M_{S L S}:=\frac{P_{S L S}}{2} \cdot \frac{l}{3}=24.6 \mathrm{kN} \cdot \mathrm{m}$
- SLS

$V_{\text {max }}:=\frac{P_{d}}{2}=61.5 \mathrm{kN}$ 


$$
\begin{aligned}
& f_{c k}:=35 \cdot M P a \\
& \text { characteristic compressive strength } \\
& f_{c m}:=f_{c k}+8 M P a \\
& \text { mean value of concrete compressive strength } \\
& \alpha_{E}:=1.0 \\
& \text { parameter for quartize aggregates } \\
& f_{c t m}:=0.3 \cdot \sqrt[3]{f_{c k}^{2}} \\
& f_{c t m}:=2.35 \mathrm{MPa} \\
& \text { mean value of concrete tensile strength } \\
& \text { value adopted in the numerical analysis of the EN } \\
& \text { test } \\
& E_{c i}:=21.5 \cdot 10^{3} \cdot \alpha_{E} \cdot \sqrt[3]{\frac{f_{c m}}{10}} \\
& E_{c i}=35 \mathrm{GPa} \\
& \alpha_{i}:=0.8+0.2 \cdot \frac{f_{c m}}{88}
\end{aligned}
$$

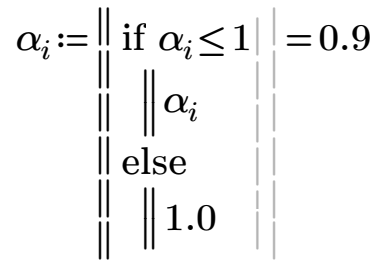

$$
\begin{aligned}
& E_{c}:=\alpha_{i} \cdot E_{c i}=31.39 \mathrm{GPa} \\
& \gamma_{c}:=1.0 \\
& \text { plain concrete partial safety factor } \\
& f_{c d}:=\frac{f_{c k}}{\gamma_{c}}=35 \mathrm{MPa} \\
& \text { modulus of elasticity at the concrete age of } 28 \text { days } \\
& \text { parameter to reduce the modulus of elasticity }
\end{aligned}
$$

\section{CONVENTIONAL REINFORCEMENT PARAMETERS}

$\begin{array}{ll}E_{s}:=200 \mathrm{GPa} & \text { steel modulus of elasticity } \\ f_{y k}:=500 \mathrm{MPa} & \text { characteristic yield strength } \\ \gamma_{s}:=1.0 & \text { conventional reinforcement partial safety factor } \\ \alpha_{e}:=\frac{E_{s}}{E_{c}}=6.37 & \text { modular ratio }\end{array}$




$\mathrm{Vf}=15 \mathrm{~kg} / \mathrm{m}^{3} \quad \mathrm{Vf}=30 \mathrm{~kg} / \mathrm{m}^{3} \quad \mathrm{Vf}^{3} \quad 45 \mathrm{~kg} / \mathrm{m}^{3}$
$f_{L k .15}:=4.96 \mathrm{MPa} \quad f_{L k .30}:=4.84 \mathrm{MPa} \quad f_{L k .45}:=4.85 \mathrm{MPa}$

Experimental

results of EN14651 $f_{R 1 k .15}:=1.88 M P a \quad f_{R 1 k .30}:=3.34 M P a \quad f_{R 1 k .45}:=6.04 M P a$

(characterization

test of SFRC)

$$
f_{R 3 k .15}:=1.67 \mathrm{MPa} \quad f_{R 3 k .30}:=3.07 \mathrm{MPa} \quad f_{R 3 k .45}:=5.17 \mathrm{MPa}
$$

Classification

$1.5 b$

$3.0 c$

$6.0 b$

\section{SFRC CONSTITUTIVE MODELS}

- RIGID-PLASTIC MODEL:

ultimate residual strength

$$
\left(f_{\text {Ftuk }}\right)
$$

serviciability residual strength

$$
\left(f_{F t s k}\right)
$$

$\mathrm{Vf}_{\mathrm{f}}=15 \mathrm{~kg} / \mathrm{m}^{3} \quad f_{\text {Ftuk.15.rp }}:=\frac{f_{R 3 k .15}}{3}=0.56 \mathrm{MPa} \quad f_{\text {Ftsk.15.rp }}:=f_{\text {Ftuk.15.rp }}=0.56 \mathrm{MPa}$

$\mathrm{Vf}=30 \mathrm{~kg} / \mathrm{m}^{3} \quad f_{\text {Ftuk.30.rp }}:=\frac{f_{R 3 k .30}}{3}=1.02 \mathrm{MPa} \quad f_{\text {Ftsk.30.rp }}:=f_{\text {Ftuk.30.rp }}=1.02 \mathrm{MPa}$

$\mathrm{Vf}=45 \mathrm{~kg} / \mathrm{m}^{3} \quad f_{\text {Ftuk.45.rp }}:=\frac{f_{\text {R3k.45 }}}{3}=1.72 \mathrm{MPa} \quad f_{\text {Ftsk.45.rp }}:=f_{\text {Ftuk.45.rp }}=1.72 \mathrm{MPa}$

- LINEAR MODEL:

$C M O D_{3}:=2.5 \mathrm{~mm} \quad$ Assuming: $w_{u}:=2.5 \mathrm{~mm}$ 


\section{$\mathrm{Vf}=15 \mathrm{~kg} / \mathrm{m}^{3}$}

$f_{F t s k .15 . l i n}:=0.45 \cdot f_{R 1 k .15}=0.85 \mathrm{MPa}$

$f_{\text {Ftuk.15.lin }}:=f_{\text {Ftsk.15.lin }}-\frac{w_{u}}{C M O D_{3}}\left(f_{F t s k .15 . l i n}-0.5 f_{R 3 k .15}+0.2 \cdot f_{R 1 k .15}\right)=0.46 \mathrm{MPa}$

\section{$\mathrm{Vf}=30 \mathrm{~kg} / \mathrm{m}^{3}$}

$f_{\text {Ftsk.30.lin }}:=0.45 \cdot f_{R 1 k .30}=1.5 \mathrm{MPa}$

$f_{\text {Ftuk.30.lin }}:=f_{F t s k .30 . l i n}-\frac{w_{u}}{C M O D_{3}}\left(f_{F t s k .30 . l i n}-0.5 f_{R 3 k .30}+0.2 \cdot f_{R 1 k .30}\right)=0.87 M P a$

\section{$\mathrm{Vf}=45 \mathrm{~kg} / \mathrm{m}^{3}$}

$f_{F t s k .45 . l i n}:=0.45 \cdot f_{R 1 k .45}=2.72 M P a$

$f_{F t u k .45 . l i n}:=f_{F t s k .45 . l i n}-\frac{w_{u}}{C M O D_{3}}\left(f_{F t s k .45 . l i n}-0.5 f_{R 3 k .45}+0.2 \cdot f_{R 1 k .45}\right)=1.38 M P a$

\section{SUMMARY OF THE SFRC CONSTITUTIVE MODELS}

$\begin{array}{ll}\text { RIGID-PLASTIC } & \text { LINEAR } \\ \text { MODEL } & \text { MODEL }\end{array}$

$\mathrm{Vf}=15 \mathrm{~kg} / \mathrm{m}^{3} \quad f_{\text {Ftsk.15.rp }}=0.56 \mathrm{MPa} \quad f_{\text {Ftsk.15.lin }}=0.85 \mathrm{MPa}$

$f_{\text {Ftuk.15.rp }}=0.56 \mathrm{MPa} \quad f_{\text {Ftuk.15.lin }}=0.46 \mathrm{MPa}$

$\mathrm{Vf}=30 \mathrm{~kg} / \mathrm{m}^{3} \quad f_{\text {Ftsk.30.rp }}=1.02 \mathrm{MPa} \quad f_{\text {Ftsk.30.lin }}=1.5 \mathrm{MPa}$

$f_{\text {Ftuk.30.rp }}=1.02 \mathrm{MPa} \quad f_{\text {Ftuk.30.lin }}=0.87 \mathrm{MPa}$

$\mathrm{V}_{\mathrm{f}}=45 \mathrm{~kg} / \mathrm{m}^{3} \quad f_{\text {Ftsk.45.rp }}=1.72 \mathrm{MPa} \quad f_{\text {Ftsk.45.lin }}=2.72 \mathrm{MPa}$

$$
f_{\text {Ftuk.45.rp }}=1.72 \mathrm{MPa} \quad f_{\text {Ftuk.45.lin }}=1.38 \mathrm{MPa}
$$




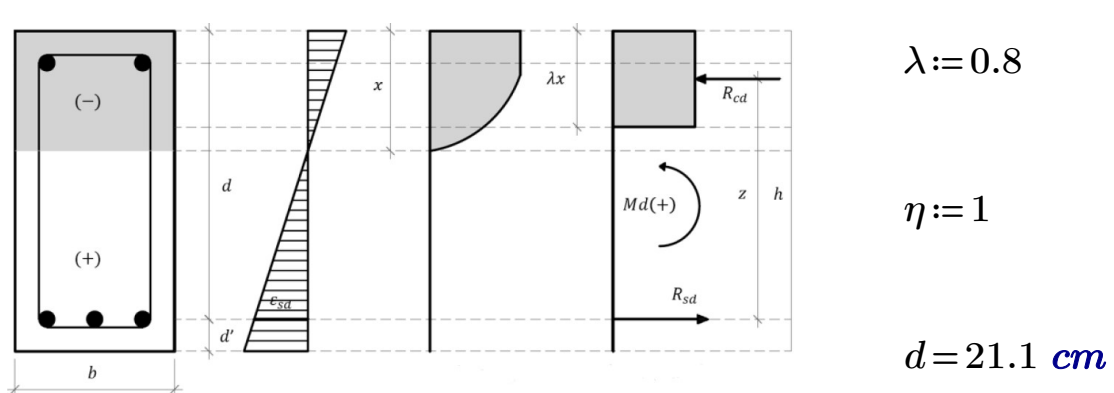

Assuming: $\quad \sigma_{s d}:=\frac{f_{y k}}{\gamma_{s}}=500 \mathrm{MPa} \quad \gamma_{s}=1 \quad f_{c d}:=\frac{f_{c k}}{\gamma_{c}}=35 \mathrm{MPa} \quad \gamma_{c}=1$

Rotational equilibrium at ULS $\quad M_{u . e x t}:=M_{\max }$

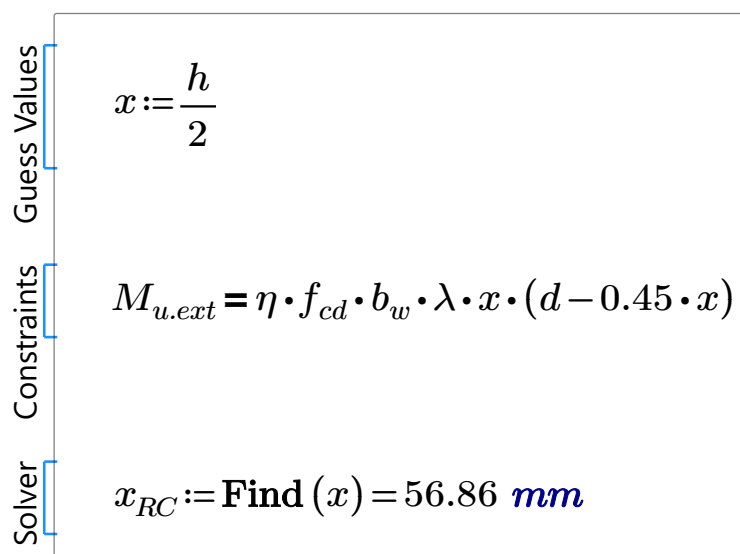

$$
\begin{gathered}
x:=x_{R C}=56.86 \mathrm{~mm} \\
\frac{x}{d}=0.27<\frac{x_{u}}{d}=0.45 \quad \text { ok }
\end{gathered}
$$

$A_{s . R C}:=\frac{M_{u . e x t}}{(d-0.45 \cdot x) \cdot \sigma_{s d}}=4.0 \mathrm{~cm}^{2} \quad>\quad A_{s . \min }:=0.26 \cdot \frac{f_{c t m}}{f_{y k}} \cdot b_{w} \cdot d=0.32 \mathrm{~cm}^{2} \quad o k$

$$
\phi_{s}:=16 \mathrm{~mm} \quad A \phi_{16}:=2.0 \mathrm{~cm}^{2}
$$

$$
A_{\text {s.adop }}:=2 \cdot A \phi_{16}=4 \mathrm{~cm}^{2} \quad A_{s}:=A_{\text {s.adop }}
$$


Assuming

$M O D E L:=$ "rigid-plastic"

("rigid-plastic" or "linear")

\section{$V f=15 \mathrm{~kg} / \mathrm{m}^{3}$}

FRC can replace

conventional

reinforcement partially

or totally?

$$
\begin{aligned}
& \text { if } \frac{f_{R 1 k .15}}{f_{L k .15}}>0.4 \mid=\text { "No" } \\
& \| \text { if } \frac{f_{R 3 k .15}}{f_{R 1 k .15}}>0.5 \mid \\
& \|\| \text { "Yes" } \\
& \| \text { else } \\
& \| \text { "No" }
\end{aligned}
$$

\section{$\mathrm{Vf}=30 \mathrm{~kg} / \mathrm{m}^{3}$}

FRC can replace conventional

reinforcement partially or totally?

$$
\begin{aligned}
& \text { if } \frac{f_{R 1 k .30}}{f_{L k .30}}>0.4 \mid=\text { "Yes" }
\end{aligned}
$$

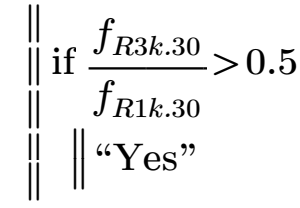

$$
\begin{aligned}
& \text { else } \\
& \text { " "No" } \\
& f_{\text {Ftud. } 30}:=\frac{f_{F t u k .30}}{\gamma_{F}}=1.02 M P a
\end{aligned}
$$

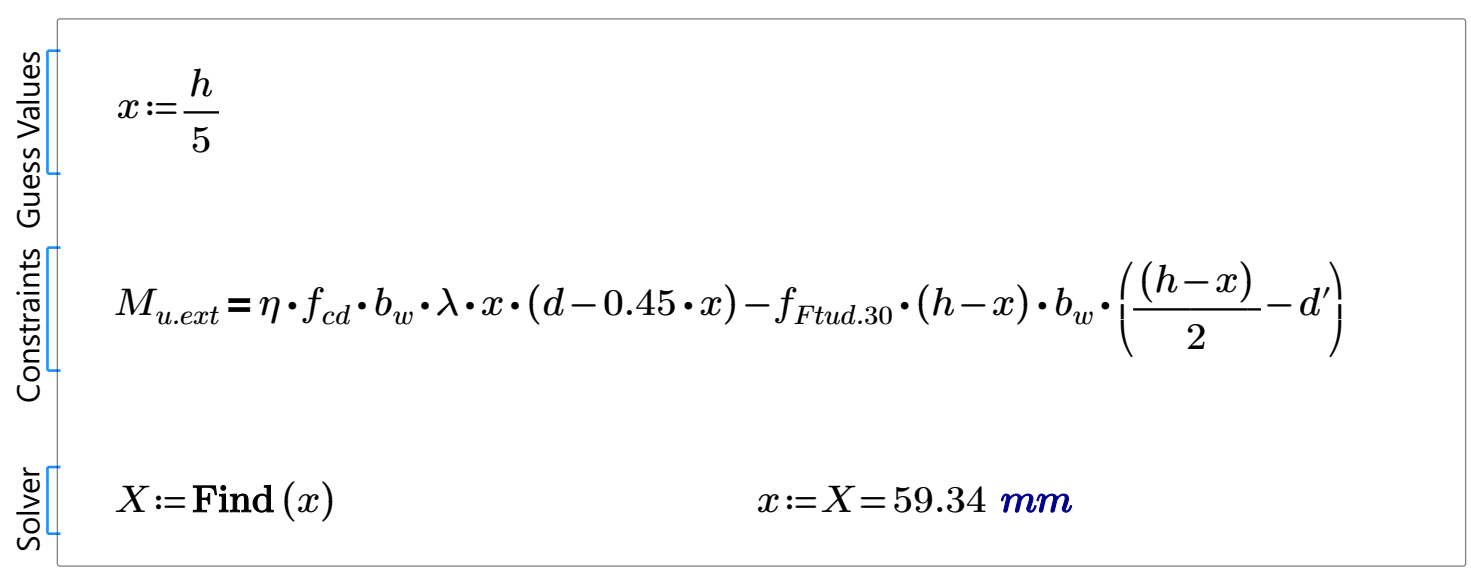




$$
A_{s .30}:=\frac{M_{u . e x t}-f_{F t u d .30} \cdot b_{w} \cdot(h-x) \cdot\left(\frac{(h-x)}{2}+(x-0.45 \cdot x)\right)}{(d-0.45 \cdot x) \cdot \sigma_{s d}}=3.67 \mathrm{~cm}^{2}
$$

\section{$\mathrm{Vf}=45 \mathrm{~kg} / \mathrm{m}^{3}$}

FRC can replace

conventional

reinforcement partially or totally?

$$
\begin{aligned}
& \text { if } \frac{f_{R 1 k .45}}{f_{L k .45}}>0.4 \mid=\text { "Yes" } \\
& \begin{array}{l}
\| \text { if } \frac{f_{R 3 k .45}}{f_{R 1 k .45}}>0.5 \\
\|\| \text { "Yes" }
\end{array} \\
& \text { else } \\
& \text { || "No" } \\
& f_{\text {Ftud. } 45}:=\frac{f_{\text {Ftuk.45 }}}{\gamma_{F}}=1.72 \mathrm{MPa}
\end{aligned}
$$

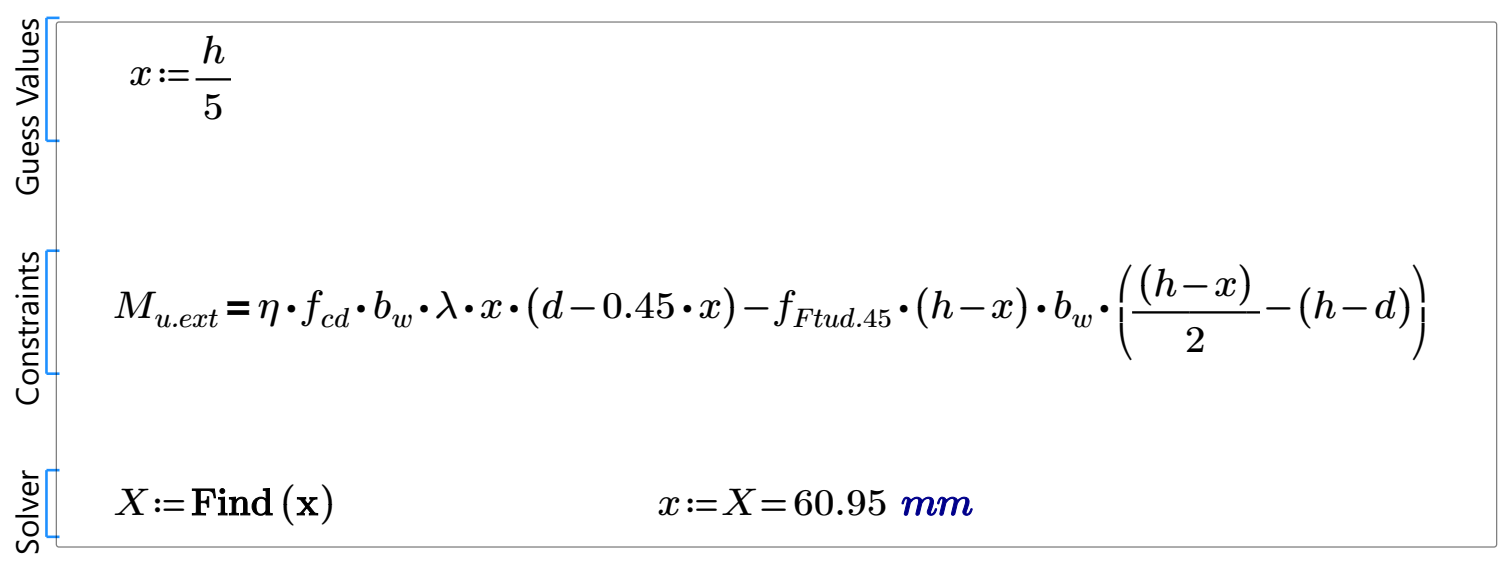

$$
A_{s .45}:=\frac{M_{u . e x t}-f_{F t u d .45} \cdot b_{w} \cdot(h-x) \cdot\left(\frac{(h-x)}{2}+(x-0.45 \cdot x)\right)}{(d-0.45 \cdot x) \cdot \sigma_{s d}}=3.45 \mathrm{~cm}^{2}
$$

\section{SUMMARY OF THE RESULTS (BENDING)}

$\mathrm{RC}$ :

$$
\text { RC }
$$$$
A_{s . R C}=4.0 \mathrm{~cm}^{2}
$$$$
A_{\text {s.adop }}=4.0 \mathrm{~cm}^{2}
$$

$\mathrm{Vf}=15 \mathrm{~kg} / \mathrm{m}^{3} \quad$ Can not replace conventional reinforcement

$$
\begin{aligned}
& \text { RC } \\
& + \\
& A_{s .30}=3.67 \mathrm{~cm}^{2} \\
& \frac{\left(A_{s . R C}-A_{s .30}\right)}{A_{s . R C}}=8 \% \\
& \frac{\left(A_{s . R C}-A_{s .45}\right)}{A_{s . R C}}=13 \%
\end{aligned}
$$




$$
\begin{gathered}
\rho_{l}:=\frac{A_{\text {s.adop }}}{b_{w} \cdot d}=1.52 \% \quad \sigma_{C P}:=0 \\
V_{R d . c t}:=\left(\frac{0.18}{\gamma_{c}} \cdot\left(1+\sqrt{\frac{200}{d}}\right) \cdot\left(100 \cdot \rho_{l} \cdot f_{c k}\right)^{\frac{1}{3}}+0.15 \cdot \sigma_{C P}\right) \cdot b_{w} \cdot d \\
V_{R d . c t}=35.21 \mathrm{kN} \\
V_{R d . \text { max }}:=V_{\text {max }}=61.5 \mathrm{kN}
\end{gathered}
$$

Minimum shear reinforcement

$$
f_{y k}:=600 M P a
$$

$s:=0.75 \cdot d=16 \mathrm{~cm}$

spacing "s" must not exceed $0.75 \mathrm{~d}$ or $50 \mathrm{~cm}$

$\rho_{w . \min }:=0.08 \cdot \frac{\sqrt{f_{c k}}}{f_{y k}}=0.08 \%$

$A_{\text {sw.s.min }}:=\rho_{w . \min } \cdot b_{w}=0.99 \frac{\mathrm{cm}^{2}}{\mathrm{~m}}$

Adopting $\quad \phi_{5} \quad n:=\frac{A_{\text {sw.s.min }}}{2 \cdot A \phi_{5}}=2.47 \frac{1}{m}$

$s:=\frac{100}{n}=40.6 \mathrm{~m}$

Design Shear Reinforcement

$\rho_{w . \min }:=0.08 \cdot \frac{\sqrt{f_{c k}}}{f_{y k}}=0.0009$

$V_{R . d s}:=V_{R d . \max }-V_{R d . c t}=26.29 \mathrm{kN}$

$A_{s w . s . R C}:=\frac{V_{R . d s}}{z \cdot \frac{f_{y k}}{\gamma_{s}}}=3.06 \frac{\mathrm{cm}^{2}}{\mathrm{~m}}$

Adopting $\quad \phi_{5.0} \quad n:=\frac{A_{\text {sw.s.RC }}}{2 \cdot A \phi_{6.3}}=4.85 \frac{1}{m}$

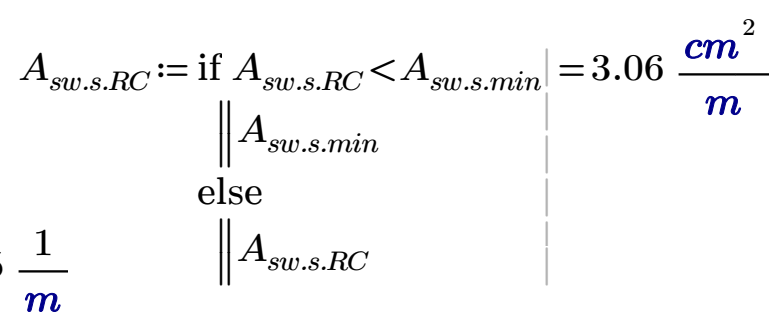

$s:=\frac{1}{n}=20.6 \mathrm{~cm}$ 
FRC cannot replace conventional reinforcement partially or totally

$V_{f}=30 \mathrm{~kg} / \mathrm{m}^{3}$

$$
\begin{gathered}
f_{\text {Ftsk.30.lin }}-\frac{1.5 \mathrm{~mm}}{C M O D_{3}}\left(f_{F t s k .30 . l i n}-0.5 f_{R 3 k .30}+0.2 \cdot f_{R 1 k .30}\right) \\
V_{R d . F}:=\left(\frac{0.18}{\gamma_{c}} \cdot\left(1+\sqrt{\frac{200}{d}}\right) \cdot\left(100 \cdot \rho_{l} \cdot\left(1+7.5 \frac{f_{F t u k .30}}{f_{c t m}}\right) \cdot f_{c k}\right)^{\frac{1}{3}}+0.15 \cdot \sigma_{C P}\right) \cdot b_{w} \cdot d \\
V_{R d . F}=57.11 \mathrm{kN}
\end{gathered}
$$

Minimum shear reinforcement

$f_{\text {Ftuk.30 }}=1.02 \mathrm{MPa}>\left(0.08 \sqrt{f_{c k}}\right)=0.47 \quad$ ok $\quad$ conventional shear reinforcement Minimum shear resistence for SFRC

$V_{R d . F \min }:=\left(0.035 \cdot\left(1+\sqrt{\frac{200}{d}}\right)^{\frac{3}{2}} \cdot \sqrt{f_{c k}}+0.15 \cdot \sigma_{C P}\right) \cdot b_{w} \cdot d$

$V_{R d . F}=57.11 \mathrm{kN} \quad>\quad V_{R d . F m i n}=15.14 \mathrm{kN} \quad \mathrm{ok}$

Design shear reinforcement

$\rho_{w . \min }:=0.08 \cdot \frac{\sqrt{f_{c k}}}{f_{y k}}=0.08 \%$

$V_{R . d s}:=V_{R d . \max }-V_{R d . F}=4.39 k N$

$$
f_{y k}:=600 \mathrm{MPa}
$$

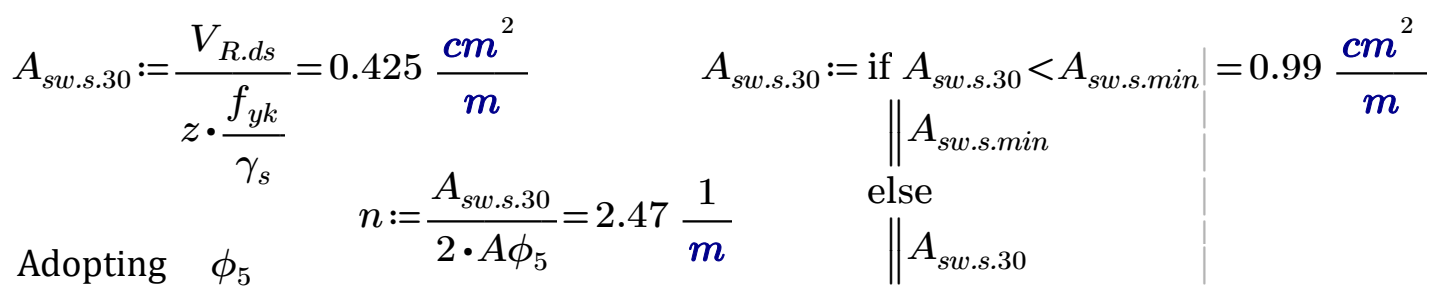

$s:=\frac{1}{n}=40.57 \mathrm{~cm}$ 


$$
\begin{gathered}
f_{F t s k .45 . l i n}-\frac{1.5 \mathrm{~mm}}{C M O D_{3}}\left(f_{F t s k .45 . l i n}-0.5 f_{R 3 k .45}+0.2 \cdot f_{R 1 k .45}\right) \\
f_{F t u k .45}=1.72 \mathrm{MPa} \\
V_{R d . F}:=\left(\frac{0.18}{\gamma_{c}} \cdot\left(1+\sqrt{\frac{200}{d}}\right) \cdot\left(100 \cdot \rho_{l} \cdot\left(1+7.5 \cdot \frac{f_{F t u k .45}}{f_{c t m}}\right) \cdot f_{c k}\right)^{\frac{1}{3}}+0.15 \cdot \sigma_{C P}\right) \cdot b_{w} \cdot d \\
V_{R d . F}=65.72 \mathrm{kN}
\end{gathered}
$$

$\underline{\text { Minimum shear reinforcement }}$

$f_{\text {Ftuk.45 }}=1.72 \mathrm{MPa}>\left(0.08 \sqrt{f_{c k}}\right)=0.47 \mathrm{ok} \quad \begin{aligned} & \text { conventional shear } \\ & \text { reinforcement are not required }\end{aligned}$

Minimum shear resistence for SFRC

$V_{R d . F}=65.72 \mathrm{kN} \quad>\quad V_{R d . F m i n}=15.14 \mathrm{kN} \quad \mathrm{ok}$

OBS.: $A_{s w . s}=\frac{A_{s w}}{s}$

Design shear reinforcement

$$
f_{y k}:=600 M P a
$$

$V_{R . d s}:=V_{R d . \max }-V_{R d . F}=-4.22 k N$

$$
V_{R d . \max }=61.5 \mathrm{kN}
$$


RC:

$$
\begin{aligned}
& A_{\text {sw.s.min }}=0.99 \frac{\mathrm{cm}^{2}}{\mathrm{~m}} \quad \text { min } \quad \begin{array}{c}
\text { adopted } \\
\phi 5.0 / 150
\end{array} \\
& A_{\text {sw.s.RC }}=3.06 \frac{\mathrm{cm}^{2}}{\mathrm{~m}} \quad \begin{array}{cc}
\text { adopted } \\
\max & \phi 6.3 / 150
\end{array}
\end{aligned}
$$

$\begin{array}{cll}\mathrm{RC} & \mathrm{Vf}=15 \mathrm{~kg} / \mathrm{m}^{3} & \text { cannot replace conventional reinforcement } \\ + & & \text { partially or totally }\end{array}$

SFRC:

\section{$\mathrm{Vf}=30 \mathrm{~kg} / \mathrm{m}^{3}$}

$$
\begin{array}{lcc}
f_{\text {Ftuk.30 }}=1.02 \mathrm{MPa} & \min & \text { steel fiber } \\
A_{\text {sw.s.30 }}=0.99 \frac{\mathrm{cm}^{2}}{\mathrm{~m}} & \max & \text { adopted } \\
& & \\
& \text { percentage reduction }
\end{array}
$$

$$
R_{\text {adopt } .30}=47 \%
$$

\section{$V_{f}=45 \mathrm{~kg} / \mathrm{m}^{3}$}

$$
\begin{aligned}
& f_{\text {Ftuk.45 }}=1.72 \mathrm{MPa} \quad \min \text { steel fiber } \\
& \begin{array}{l}
A_{\text {sw.s.45 }}=0.99 \frac{\mathrm{cm}^{2}}{\mathrm{~m}} \quad \max \quad \text { steel fiber } \\
\text { percentage reduction }
\end{array}
\end{aligned}
$$

$$
R_{\text {adopt. } 45}=100 \%
$$




\section{- CRACK WIDTH}

\section{RC}

Adopting state II analysis of the beam in cracked state - triangular stress block

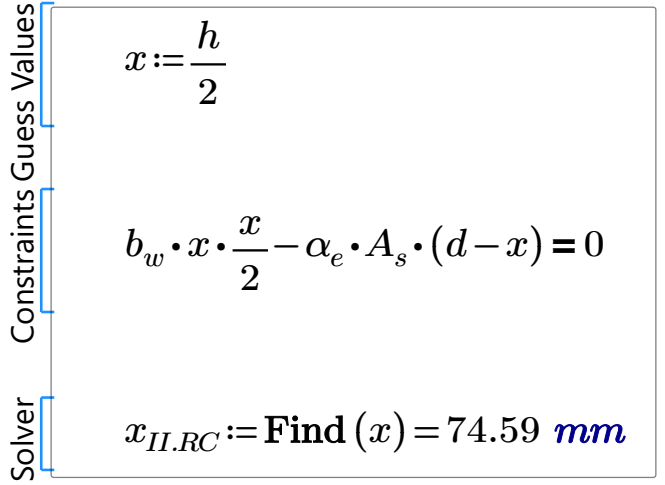

$$
\begin{aligned}
& M_{S L S}=\frac{b_{w} \cdot x \cdot \sigma_{s}}{2} \cdot\left(d-\frac{x}{3}\right) \quad \sigma_{s} \cdot A_{s}=\frac{1}{2} \cdot b_{w} \cdot x \cdot \sigma_{c} \\
& \sigma_{c . R C}:=\frac{2 \cdot M_{S L S}}{b_{w} \cdot x \cdot\left(d-\frac{x}{3}\right)}=28.35 \mathrm{MPa} \quad \sigma_{s . R C}:=\frac{b_{w} \cdot x \cdot \sigma_{c . R C}}{2 \cdot A_{s}}=330.4 \mathrm{MPa}
\end{aligned}
$$

$\mathrm{A}_{\text {c.ef }}:=b_{w} \cdot\left(\min \left(\frac{(h-x)}{3}, 2.5 \cdot(h-d)\right)\right)=73.09 \mathrm{~cm}^{2} \quad \begin{aligned} & \text { effective area of concrete in } \\ & \text { tension }\end{aligned}$ $\rho_{\text {s.ef }}:=\frac{A_{s}}{\mathrm{~A}_{\text {c.ef }}}=5.47 \%$

$\rho_{s}:=\rho_{l}=1.52 \%$

$\sigma_{s r . R C}:=f_{c t m} \cdot\left(\frac{1+\alpha_{e} \cdot \rho_{s}}{\rho_{s . e f}}\right)=47.09 M P a$

maximum steel stress in a crack in the crack formation stage

$$
k:=1.0 \quad c=2.5 \mathrm{~cm} \quad \phi_{s}=16 \mathrm{~mm}
$$

$$
\begin{array}{lll}
\tau_{b m}:=1.8 \cdot f_{c t m}=4.23 \mathrm{MPa} \quad \beta:=0.6 & \begin{array}{l}
\eta_{r}:=0 \\
\varepsilon_{s h}:=0
\end{array} & \begin{array}{l}
\text { short term loading } \\
\text { the length over which } \\
\text { between concrete and } \\
\text { occurs. }
\end{array} \\
l_{\text {s.max.RC }}:=\left(k \cdot c+\frac{1}{4} \frac{\phi_{s}}{\rho_{\text {s.ef }}} \frac{f_{c t m}}{\tau_{b m}}\right)=65.6 \mathrm{~mm} & &
\end{array}
$$

the length over which slip between concrete and steel occurs. 
$w_{d}:=2\left(k \cdot c+\frac{1}{4} \frac{\phi_{s}}{\rho_{s . e f}} \frac{f_{c t m}}{\tau_{b m}}\right)\left(\frac{\sigma_{s . R C}-\beta \cdot \sigma_{s r . R C}}{E_{s}}+\eta_{r} \cdot \varepsilon_{s h}\right) \quad$ crack width in RC members

$$
w_{d}=0.2 \mathrm{~mm}
$$

$w_{d . t e n . R C}:=w_{d} \cdot \frac{(h-x)}{(d-x)}=0.25 \mathrm{~mm} \quad<w_{\text {lim }}:=0.30 \mathrm{~mm} \begin{aligned} & \text { crack width at the extreme } \\ & \text { tensile fibre }\end{aligned}$

\section{$\mathrm{Vf}=15 \mathrm{~kg} / \mathrm{m}^{3}$}

$f_{\text {Ftsm.15 }}:=f_{\text {Ftsk.15.lin }}=0.85 \mathrm{MPa}$

Adopting state II analysis of the beam in cracked state and solving by an iterative procedure:

$$
\begin{aligned}
& \varepsilon_{s}(x):=\left(\frac{d-x}{x}\right) \cdot\left(\frac{M_{S L S}}{0.5 E_{c} \cdot b_{w} \cdot x \cdot\left(\frac{2}{3} x+\frac{(h-x)}{2}\right)+E_{s} \cdot\left(\frac{d-x}{x}\right) \cdot A_{s} \cdot\left(d-x-\frac{(h-x)}{2}\right)}\right) \\
& \varepsilon_{c}(x):=\left(\frac{x}{d-x}\right) \cdot \varepsilon_{s}(x) \\
& \varepsilon_{s .15}:=\varepsilon_{s}\left(x_{I I .15}\right)=0.15 \% \quad<\quad \varepsilon_{s y}:=\frac{f_{y k}}{E_{s}}=0.3 \% \quad o k !
\end{aligned}
$$

The value of depth of compression zone taking the effect of the fibers into account

$$
x:=x_{I I .15}=78.79 \mathrm{~mm}
$$

$$
\begin{array}{ll}
\mathrm{A}_{\text {c.ef }}:=b_{w} \cdot\left(\min \left(\frac{(h-x)}{3}, 2.5 \cdot(h-d)\right)\right)=71.34 \mathrm{~cm}^{2} & \begin{array}{l}
\text { effective area of concrete in } \\
\text { tension }
\end{array} \\
\rho_{\text {s.ef }}:=\frac{A_{s}}{\mathrm{~A}_{\text {c.ef }}}=5.61 \% & \\
\sigma_{\text {sr. } 15}:=\left(f_{c t m}-f_{F t s m .15}\right) \cdot\left(\frac{1+\alpha_{e} \cdot \rho_{s}}{\rho_{\text {s.ef }}}\right)=29.42 \mathrm{MPa} & \begin{array}{l}
\text { maximum steel stress in a } \\
\text { crack in the crack formation } \\
\text { stage }
\end{array}
\end{array}
$$




$$
\begin{gathered}
\sigma_{c}:=\frac{M_{S L S}+f_{F t s m .15} \cdot b_{w} \cdot(h-x) \cdot\left(\frac{(h-x)}{2}-d^{\prime}\right)}{\frac{b_{w} \cdot x}{2} \cdot\left(d-\frac{x}{3}\right)}=27.97 \mathrm{MPa} \\
\sigma_{s .15}:=\frac{M_{S L S}-f_{F t s m .15} \cdot b_{w} \cdot(h-x) \cdot\left(\frac{(h-x)}{2}+\frac{2}{3} x\right)}{\left(d-\frac{x}{3}\right) \cdot A_{s}}=299.06 \mathrm{MPa} \\
w_{d .15}:=2\left(k \cdot c+\frac{1}{4} \frac{\phi_{s}}{\rho_{s . e f}} \frac{\left(f_{c t m}-f_{F t s m .15}\right)}{\tau_{b m}}\right)\left(\frac{\sigma_{s .15}-\beta \cdot \sigma_{s r .15}}{E_{s}}+\eta_{r} \cdot \varepsilon_{s h}\right) \\
w_{d .15}=0.14 \mathrm{~mm} \quad \text { crack width in RC members }
\end{gathered}
$$

$w_{d . t e n .15}:=w_{d .15} \cdot \frac{(h-x)}{(d-x)}=0.18 \mathrm{~mm} \quad \begin{aligned} & \text { crack width at the extreme } \\ & \text { tensile fibre }\end{aligned}$

$l_{s . m a x .15}:=k \cdot c+\frac{1}{4} \frac{\phi_{s}}{\rho_{s . e f}} \frac{\left(f_{c t m}-f_{F t s m .15}\right)}{\tau_{b m}}=50.36 \mathrm{~mm} \quad \begin{aligned} & \text { length over which slip } \\ & \text { between concrete and steel } \\ & \text { occours }\end{aligned}$

$s_{r m .15}:=1.17 \cdot l_{s . \max .15}=58.93 \mathrm{~mm}$

mean distance between cracks

$k_{c}:=1.0 \quad$ for rectangular cross-sections

$k:=1.0 \quad$ for webs with $h \leq 300 \mathrm{~mm} \quad$ or $\quad b_{w} \leq 300 \mathrm{~mm} \quad \phi_{s}=16 \mathrm{~mm}$

$A_{c t}:=x \cdot b_{w}=98.49 \mathrm{~cm}^{2}$

$A_{s . m i n .15}:=k_{c} \cdot k \cdot\left(f_{c t m}-f_{F t s m .15}\right) \frac{A_{c t}}{f_{y k}} \quad \begin{aligned} & \text { minimum reinforcement for } \\ & \text { crack control }\end{aligned}$

$A_{\text {s.min. } 15}=0.25 \mathrm{~cm}^{2} \quad A_{\text {s.min. } 15}<A_{s} \quad$ ok

\section{$\mathrm{Vf}=30 \mathrm{~kg} / \mathrm{m}^{3}$}

$f_{\text {Ftsm.30 }}:=f_{\text {Ftsk.30.lin }}=1.50 \mathrm{MPa}$

Adopting state II analysis of the beam in cracked state and solving by an iterative procedure: 
$\left.\varepsilon_{s}(x):=\left(\frac{d-x}{x}\right) \cdot\left(\frac{M_{S L S}}{0.5 E_{c} \cdot b_{w} \cdot x \cdot\left(\frac{2}{3} x+\frac{(h-x)}{2}\right)+E_{s} \cdot\left(\frac{d-x}{x}\right) \cdot A_{s} \cdot\left(d-x-\frac{(h-x)}{2}\right)}\right)\right)$

$\varepsilon_{c}(x):=\left(\frac{x}{d-x}\right) \cdot \varepsilon_{s}(x)$

$\varepsilon_{s .30}:=\varepsilon_{s}\left(x_{I I .30}\right)=0.14 \%<\varepsilon_{s y}:=\frac{f_{y k}}{E_{s}}=0.3 \% \quad o k !$

The value of depth of compression zone taking the effect of the fibers into account:

$x:=x_{I I .30}=82.2 \mathrm{~mm}$

$\begin{array}{ll}\mathrm{A}_{\text {c.ef }}:=b_{w} \cdot\left(\min \left(\frac{(h-x)}{3}, 2.5 \cdot(h-d)\right)\right)=69.92 \mathrm{~cm}^{2} \quad \begin{array}{l}\text { effective area of concrete in } \\ \text { tension }\end{array} \\ \rho_{\text {s.ef }}:=\frac{A_{s}}{\mathrm{~A}_{\text {c.ef }}}=5.72 \% & \\ \sigma_{\text {sr.30 }}:=\left(f_{c t m}-f_{\text {Ftsm.30 }}\right) \cdot\left(\frac{1+\alpha_{e} \cdot \rho_{s}}{\rho_{\text {s.ef }}}\right)=16.24 \mathrm{MPa} & \begin{array}{l}\text { maximum steel stress in a } \\ \text { crack in the crack formation } \\ \text { stage }\end{array}\end{array}$

$\sigma_{c}:=\frac{M_{S L S}+f_{F t s m .30} \cdot b_{w} \cdot(h-x) \cdot\left(\frac{(h-x)}{2}-d^{\prime}\right)}{\frac{b_{w} \cdot x}{2} \cdot\left(d-\frac{x}{3}\right)}=27.58 \mathrm{MPa}$

$\sigma_{s .30}:=\frac{M_{S L S}-f_{F t s m .30} \cdot b_{w} \cdot(h-x) \cdot\left(\frac{(h-x)}{2}+\frac{2}{3} x\right)}{\left(d-\frac{x}{3}\right) \cdot A_{s}}=275.42 \mathrm{MPa}$

$w_{d .30}:=2\left(k \cdot c+\frac{1}{4} \frac{\phi_{s}}{\rho_{s . e f}} \frac{\left(f_{c t m}-f_{F t s m .30}\right)}{\tau_{b m}}\right)\left(\frac{\sigma_{s .30}-\beta \cdot \sigma_{s r .30}}{E_{s}}+\eta_{r} \cdot \varepsilon_{s h}\right)$

$w_{d .30}=0.10 \mathrm{~mm}$
$w_{d . t e n .30}:=w_{d .30} \cdot \frac{(h-x)}{(d-x)}=0.13 \mathrm{~mm}$

$l_{s . \max .30}:=k \cdot c+\frac{1}{4} \frac{\phi_{s}}{\rho_{\text {s.ef }}} \frac{\left(f_{c t m}-f_{F t s m .30}\right)}{\tau_{b m}}=39 \mathrm{~mm}$ crack width in RC members

crack width at the extreme tensile fibre

length over which slip between concrete and steel occours 
$s_{r m .30}:=1.17 \cdot l_{s . \max .30}=45.63 \mathrm{~mm}$

$A_{s . m i n .30}:=k_{c} \cdot k \cdot\left(f_{c t m}-f_{F t s m .30}\right) \frac{A_{c t}}{f_{y k}}$

$A_{\text {s.min. } 30}=0.14 \mathrm{~cm}^{2} \quad A_{\text {s.min }}<A_{s} \quad A_{s}=4 \mathrm{~cm}^{2}$ mean distance between cracks

minimum reinforcement for crack control

\section{$\mathrm{Vf}=45 \mathrm{~kg} / \mathrm{m}^{3}$}

$f_{\text {Ftsm.45 }}:=f_{\text {Ftsk.45.lin }}=2.72 \mathrm{MPa}$

Adopting state II analysis of the beam in cracked state and solving by an iterative procedure:

$$
\begin{aligned}
& \left.\varepsilon_{s}(x):=\left(\frac{d-x}{x}\right) \cdot\left(\frac{M_{S L S}}{0.5 E_{c} \cdot b_{w} \cdot x \cdot\left(\frac{2}{3} x+\frac{(h-x)}{2}\right)+E_{s} \cdot\left(\frac{d-x}{x}\right) \cdot A_{s} \cdot\left(d-x-\frac{(h-x)}{2}\right)}\right)\right) \\
& \varepsilon_{c}(x):=\left(\frac{x}{d-x}\right) \cdot \varepsilon_{s}(x) \\
& \varepsilon_{s .45}:=\varepsilon_{s}\left(x_{I I .45}\right)=0.12 \%<\quad<\quad \varepsilon_{s y}:=\frac{f_{y k}}{E_{s}}=0.3 \% \quad \text { ok! }
\end{aligned}
$$

The value of depth of compression zone taking the effect of the fibers into account:

$$
x:=x_{I I .45}=88.87 \mathrm{~mm}
$$

$$
\begin{array}{ll}
\mathrm{A}_{\text {c.ef }}:=b_{w} \cdot\left(\min \left(\frac{(h-x)}{3}, 2.5 \cdot(h-d)\right)\right)=67.14 \mathrm{~cm}^{2} \quad \begin{array}{l}
\text { effective area of concrete in } \\
\text { tension }
\end{array} \\
\rho_{\text {s.ef }}:=\frac{A_{s}}{\mathrm{~A}_{\text {c.ef }}}=5.96 \% & \\
\sigma_{\text {sr. } 45}:=\left(f_{c t m}-f_{F t s m .45}\right) \cdot\left(\frac{1+\alpha_{e} \cdot \rho_{s}}{\rho_{\text {s.ef }}}\right)=-6.77 \mathrm{MPa} & \begin{array}{l}
\text { maximum steel stress in a } \\
\text { crack in the crack formation } \\
\text { stage }
\end{array}
\end{array}
$$

$$
\sigma_{c}:=\frac{M_{S L S}+f_{F t s m .45} \cdot b_{w} \cdot(h-x) \cdot\left(\frac{(h-x)}{2}-d^{\prime}\right)}{\frac{b_{w} \cdot x}{2} \cdot\left(d-\frac{x}{3}\right)}=26.68 \mathrm{MPa}
$$




$$
\begin{aligned}
& \sigma_{s .45}:=\frac{M_{S L S}-f_{F t s m .45} \cdot b_{w} \cdot(h-x) \cdot\left(\frac{(h-x)}{2}+\frac{2}{3} x\right)}{A_{s} \cdot\left(d-\frac{x}{3}\right)}=233.58 \mathrm{MPa} \\
& w_{d .45}:=2\left(k \cdot c+\frac{1}{4} \frac{\phi_{s}}{\rho_{s . e f}} \frac{\left(f_{c t m}-f_{F t s m .45}\right)}{\tau_{b m}}\right)\left(\frac{\sigma_{s .45}-\beta \cdot \sigma_{s r .45}}{E_{s}}+\eta_{r} \cdot \varepsilon_{s h}\right) \\
& w_{d .45}:=\text { if }\left(f_{c t m}-f_{F t s m .45}\right)>0 \\
& \| w_{d .45} \\
& \text { else } \\
& \|_{\|} 2\left(k \cdot c+\frac{1}{4} \frac{\phi_{s}}{\rho_{s . e f}} \frac{0 M P a}{\tau_{b m}}\right)\left(\frac{\sigma_{s .45}-\beta \cdot 0 M P a}{E_{s}}+\eta_{r} \cdot \varepsilon_{s h}\right) \\
& \text { crack width in } \\
& \text { FRC members } \\
& w_{d . t e n .45}:=w_{d .45} \cdot \frac{(h-x)}{(d-x)}=0.08 \mathrm{~mm} \\
& l_{s . \max .45}:=\left(k \cdot c+\frac{1}{4} \frac{\phi_{s}}{\rho_{\text {s.ef }}} \frac{\left(f_{c t m}-f_{F t s m .45}\right)}{\tau_{b m}}\right) \\
& l_{\text {s.max. } 45}:=\text { if }\left(f_{\text {ctm }}-f_{\text {Ftsm. } 45}\right)>0 \quad \mid=25 \mathrm{~mm} \\
& \| l_{s . \max .45} \\
& \text { else } \\
& \|_{\| i}\left(k \cdot c+\frac{1}{4} \frac{\phi_{s}}{\rho_{s . e f}} \frac{0 M P a}{\tau_{b m}}\right) \\
& \text { crack width at the extreme } \\
& \text { tensile fibre } \\
& \text { length over which slip }
\end{aligned}
$$$$
s_{r m .45}:=1.17 \cdot l_{s . \max .45}=29.25 \mathrm{~mm}
$$

mean distance between cracks

$$
\begin{array}{cl}
A_{\text {s.min. } 45}:=k_{c} \cdot k \cdot\left(f_{c t m}-f_{F t s m .45}\right) \frac{A_{c t}}{f_{y k}} & \\
A_{\text {s.min.45 }}=-0.06 \mathrm{~cm}^{2} \quad A_{\text {s.min }}<0 & \begin{array}{l}
\text { minimum reinforcement can } \\
\text { be due only to the fibre } \\
\text { reinforcement }
\end{array}
\end{array}
$$

\section{SUMMARY OF THE RESULTS ( CRACK WIDTH)}

\section{RC}

$$
w_{d . t e n . R C}=0.25 \mathrm{~mm}
$$

$V_{f}=15 \mathrm{~kg} / \mathrm{m}^{3}$

\section{$V_{f}=30 \mathrm{~kg} / \mathrm{m}^{3}$}

$V_{f}=45 \mathrm{~kg} / \mathrm{m}^{3}$

$$
w_{d . t e n .15}=0.18 \mathrm{~mm}
$$$$
w_{d . t e n .30}=0.13 \mathrm{~mm}
$$$$
<w_{\text {lim }}=0.3 \mathrm{~mm}
$$$$
w_{\text {d.ten.45 }}=0.08 \mathrm{~mm}
$$

$$
s_{r m . R C}=77 \mathrm{~mm}
$$$$
s_{r m .15}=59 \mathrm{~mm}
$$

$s_{r m .30}=46 \mathrm{~mm}$

$s_{r m .45}=29 \mathrm{~mm}$ 


\section{- DEFLECTION}

Simplified method for calculating deflection:

$$
I_{c}:=\frac{b_{w} \cdot h^{3}}{12}=\left(162.76 \cdot 10^{-6}\right) m^{4}
$$

moment of inertia of uncracked section - state I

$$
\mathrm{RC} \quad x_{I I . R C}=74.59 \mathrm{~mm}
$$

$$
\begin{array}{ll}
I_{I I}:=\frac{b_{w} \cdot x_{I I . R C}{ }^{3}}{3}+\alpha_{e} \cdot A_{s} \cdot\left(d-x_{I I . R C}\right)^{2} & \begin{array}{l}
\text { moment of inertia of } \\
\text { cracked section - state II }
\end{array} \\
I_{I I}=\left(6.47 \cdot 10^{-5}\right) m^{4} & \\
\delta_{\text {max.I }}:=\frac{\left(\frac{P_{S L S}}{2}\right) \cdot \frac{l}{3}}{24 \cdot E_{c} \cdot I_{c}} \cdot\left(3 \cdot l^{2}-4 \cdot\left(\frac{l}{3}\right)^{2}\right)=1.66 \mathrm{~mm} & \begin{array}{l}
\text { deflection of a four-point } \\
\text { bending beam }
\end{array} \\
\delta_{\text {max.II }}:=\frac{\left(\frac{P_{S L S}}{2}\right) \cdot \frac{l}{3}}{24 \cdot E_{c} \cdot I_{I I}} \cdot\left(3 \cdot l^{2}-4 \cdot\left(\frac{l}{3}\right)^{2}\right)=4.18 \mathrm{~mm} & \quad \text { for a single short term loading } \\
\zeta:=1+\beta \cdot\left(\frac{\sigma_{\text {sr.RC }}}{\sigma_{\text {s.RC }}}\right)^{2}=1.01 & \\
\delta_{\text {max.inst.RC }}:=\zeta \cdot \delta_{\text {max.II }}+(1-\zeta) \cdot \delta_{\text {max.I }}=4.21 \mathrm{~mm} \quad< & \delta_{\text {lim }}:=\frac{l}{250}=7.2 \mathrm{~mm}
\end{array}
$$

$\mathrm{Vf}=15 \mathrm{~kg} / \mathrm{m}^{3} \quad x_{I I .15}=78.79 \mathrm{~mm}$ moment of inertia of cracked section - state II

$$
\begin{aligned}
& I_{I I .15}:=\frac{b_{w} \cdot x_{I I .15}{ }^{3}}{3}+\alpha_{e} \cdot A_{s} \cdot\left(d-x_{I I .15}\right)^{2}+\frac{f_{F t s m .15} \cdot b_{w}}{2} \cdot\left(h-x_{I I .15}\right)^{2} \cdot \frac{x_{I I .15}}{\varepsilon_{c .15}} \cdot \frac{1}{E_{c}} \\
& I_{I I .15}=\left(6.93 \cdot 10^{-5}\right) m^{4} \\
& \delta_{\text {max.II.15 }}:=\frac{\left(\frac{P_{S L S}}{2}\right) \cdot \frac{l}{3}}{24 \cdot E_{c} \cdot I_{I I .15}} \cdot\left(3 \cdot l^{2}-4 \cdot\left(\frac{l}{3}\right)^{2}\right)=3.9 \mathrm{~mm} \\
& \zeta:=1+\beta \cdot\left(\frac{\sigma_{\text {sr. } 15}}{\sigma_{s .15}}\right)^{2}=1.01 \quad \beta:=1.0 \quad \text { for a single short term loading } \\
& \delta_{\text {max.inst. } 15}:=\zeta \cdot \delta_{\text {max.II.15 }}+(1-\zeta) \cdot \delta_{\text {max.I }}=3.92 \mathrm{~mm}<\quad \delta_{\text {lim }}:=\frac{l}{250}=7.2 \mathrm{~mm} \quad \mathrm{ok} !
\end{aligned}
$$




$$
\begin{aligned}
& I_{I I .30}:=\frac{b_{w} \cdot x_{I I .30}{ }^{3}}{3}+\alpha_{e} \cdot A_{s} \cdot\left(d-x_{I I .30}\right)^{2}+\frac{f_{F t s m .30} \cdot b_{w}}{2} \cdot\left(h-x_{I I .30}\right)^{2} \cdot \frac{x_{I I .30}}{\varepsilon_{c .30}} \cdot \frac{1}{E_{c}} \\
& I_{I I .30}=\left(7.33 \cdot 10^{-5}\right) m^{4} \\
& \delta_{\text {max.II.30 }}:=\frac{\left(\frac{P_{S L S}}{2}\right) \cdot \frac{l}{3}}{24 \cdot E_{c} \cdot I_{I I .30}} \cdot\left(3 \cdot l^{2}-4 \cdot\left(\frac{l}{3}\right)^{2}\right)=3.69 \mathrm{~mm} \\
& \zeta:=1+\beta \cdot\left(\frac{\sigma_{\text {sr.30 }}}{\sigma_{\text {s.30 }}}\right)^{2}=1 \\
& \delta_{\text {max.inst.30 }}:=\zeta \cdot \delta_{\text {max.II.30 }}+(1-\zeta) \cdot \delta_{\text {max.I }}=3.7 \mathrm{~mm} \quad<\quad \delta_{\text {lim }}:=\frac{l}{250}=7.2 \mathrm{~mm} \quad \text { for a single short term loading }
\end{aligned}
$$

$\mathrm{Vf}=45 \mathrm{~kg} / \mathrm{m}^{3} \quad x_{I I .45}=8.89 \mathrm{~cm} \quad$ moment of inertia of cracked section - state II

$$
\begin{aligned}
& I_{I I .45}:=\frac{b_{w} \cdot x_{I I .45}{ }^{3}}{3}+\alpha_{e} \cdot A_{s} \cdot\left(d-x_{I I .45}\right)^{2}+\frac{f_{F t s m .45} \cdot b_{w}}{2} \cdot\left(h-x_{I I .45}\right)^{2} \cdot \frac{x_{I I .45}}{\varepsilon_{c .45}} \cdot \frac{1}{E_{c}} \\
& I_{I I .45}=\left(8.2 \cdot 10^{-5}\right) m^{4} \\
& \delta_{\text {max.II.45 }}:=\frac{\left(\frac{P_{S L S}}{2}\right) \cdot \frac{l}{3}}{24 \cdot E_{c} \cdot I_{I I .45}} \cdot\left(3 \cdot l^{2}-4 \cdot\left(\frac{l}{3}\right)^{2}\right)=3.3 \mathrm{~mm} \\
& \zeta:=1+\beta \cdot\left(\frac{\sigma_{\text {sr. } 45}}{\left.\sigma_{s .45}\right)^{2}=1} \quad \beta:=1.0 \quad\right. \text { for a single short term loading } \\
& \delta_{\text {max.inst.45 }}:=\zeta \cdot \delta_{\text {max.II.45 }}+(1-\zeta) \cdot \delta_{\text {max.I }}=3.3 \mathrm{~mm} \quad<\quad \delta_{\text {lim }}:=\frac{l}{250}=7.2 \mathrm{~mm} \quad \mathrm{ok} !
\end{aligned}
$$

\section{SUMMARY OF THE RESULTS (DEFLECTION )}

RC $\quad \delta_{\text {max.inst. } R C}=4.21 \mathrm{~mm}$

$\mathrm{V}_{\mathrm{f}}=15 \mathrm{~kg} / \mathrm{m}^{3} \quad \delta_{\text {max.inst. } 15}=3.92 \mathrm{~mm}$

$\mathrm{Vf}_{\mathrm{f}}=30 \mathrm{~kg} / \mathrm{m}^{3} \quad \delta_{\max . i n s t .30}=3.7 \mathrm{~mm}$

$$
<\quad \delta_{\text {lim }}=7.2 \mathrm{~mm}
$$

$\mathrm{Vf}_{\mathrm{f}}=45 \mathrm{~kg} / \mathrm{m}^{3} \quad \delta_{\max . i n s t .45}=3.3 \mathrm{~mm}$ 